\title{
INTERCULTURAL ADAPTURGY:
}

\section{TWENTY-FIRST CENTURY WOMEN ADAPTING SPANISH GOLDEN AGE PLAYS}

\author{
A dissertation \\ Submitted to the department of Theatre and Performance Studies \\ By Mary Elaine Vansant \\ University of Missouri: Columbia \\ Dr. David Crespy and Dr. Cheryl Black
}

July, 2021 
The undersigned, appointed by the dean of the Graduate School, have examined the dissertation entitled

\section{INTERCULTURAL ADAPTURGY:}

TWENTY-FIRST CENTURY WOMEN ADAPTING SPANISH GOLDEN AGE PLAYS

presented by Mary Elaine Vansant, a candidate for the degree of doctor of philosophy, and hereby certify that, in their opinion, it is worthy of acceptance.

Dr. David Crespy

Dr. Cheryl Black

Dr. Kevin Brown

Dr. Mar Soria Lopez 


\section{DEDICATION}

While writing a dissertation is a solitary project, it is impossible to produce in a vacuum. I could not have finished this work without the invaluable support of my family and friends. My parents, Tom and Suzy Vansant, supported me through my seemingly unending graduate school career. My partner, Cody Proctor, made sure I was fed and entertained and occasionally laid down the law to make sure I was working. My siblings, Robbie, Daniel, Nellie, Stella, and Judy made me smile, kept me from going stir-crazy during the pandemic, and let me talk them into playing board games. Finally, I could not have finished this project without the unconditional love and reminders to pause and take a walk from my pets, Ann Perkins, Sherman, Kiltie, and Tiga.

I am also grateful to my peers and mentors, who provided engaging brainstorming conversations over post-show drinks, who collaborated on projects, and who inspired me to keep going. A thousand thanks to Cat Gleason, Xiomara Cornejo, Taylor Sklenar, Andy Black, Aaron Scully, Kate Busselle, Simona Simkins, and the graduate student community at the University of Missouri - Columbia for your friendship, engagement, and support. 


\section{ACKNOWLEDGEMENTS}

Theatre is a collaborative art, and our research works best when we bring those collaborative skills to our research as well. As such, I would like to thank my co-chairs for this dissertation for their kind feedback and complementary styles - Dr. David Crespy, thank you for being my 'Jewish Mother,' for your kind feedback, and for reminding me that a good dissertation is a done dissertation. Dr. Cheryl Black, thank you for your detailed feedback, for the big dreams you have for this work, and for your excitement about all the connections this work can make. A thousand thanks to my other two committee members, Dr. Kevin Brown and Dr. Mar Soria Lopez, as well. I have heard others say that graduate students can expect to be the only ones to read their dissertations, but your detailed feedback proves that, for this dissertation, that is not the case. Your feedback and help have been invaluable.

My Fever/Dream collaborators also played a significant role in the creation of this dissertation, whether they were fully aware of it or not. I owe a second thank you to my dramaturg, Taylor Sklenar, whose work is featured prominently in this dissertation. My designers, Kate Busselle, Brad Carlson, Marc Vital, Vincente Williams, and Gabby Velasquez, brought the play to life in ways that I never could have imagined on my own. Finally, a big thank you to the entire brilliant cast.

For their help with new play readings and development, a thousand thanks to the organizational teams, actors, and audiences at the Missouri Playwrights' Workshop, Mizzou New Play Series, MU Comedies in Concert, and Scene One Rough Writers. It is so important to hear plays read out loud, and your talents were the first to bring these scripts to life. Finally, thank you so much to Caridad Svich for being willing to speak to me about her adapturgy process and the Spanish Golden Age in general. 


\section{TABLE OF CONTENTS}

Acknowledgements

Page ii

Abstract

Page iv

Chapter 1: Introduction: Defining My Place

Page 1

Chapter 2: Preserving the Unusual in $A$

Little Betrayal Among Friends

Page 60

Chapter 3: Transferring Intention in

Fever/Dream

Page 95

Chapter 4: Applying Intercultural

Page 129

Adapturgy

Chapter 5: How to Build a Noble House

Page 168

Chapter 6: With the Temptation, a Way of

Escape

Page 234

Chapter 7: Conclusion

Page 291

Works Cited

Page 306

Vita

Page 317 


\begin{abstract}
Transferring work from one culture to another through translation or adaptation is a delicate process which requires careful consideration of both the positionality of the adapter and the intertextual reaction of the adapted work's target audience. In addition to traditional adaptation theories like intertextuality, the theatrical field of dramaturgy offers helpful insight into the adaptation process, especially as it relates to plays. This dissertation examines the ways that the combination of adaptation studies and dramaturgy, which Jane Barnette calls adapturgy, can inform intercultural adaptaitons of dramatic literature to create performable and effective theatre experiences for twenty-first century audiences. I achieve this goal by first examining two adapted plays: A Little Betrayal Among Friends by Caridad Svich, adapted from La traición en la amistad by Maria de Zayas y Sotomayor, and Fever/Dream by Sheila Callaghan, adapted from La vida es sueño by Pedro Calderón de la Barca. I look at how dramaturgical and adapation theories can be applied to these plays via script analysis and contextual questioning. Then, using the skills gleaned from those two examples, I create my own translation and adaptation of Los empeños de una casa by Sor Juana Ines de la Cruz, and I reflect on my adapturgical process of doing so. In creating both a translation, titled How to Build a Noble House, and an adaptation, titled With the Temptation, a Way of Escape, I both preserve the unique traits of the Spanish Golden Age for performance in the twenty-first century and amplify Sor Juana's comedic and social intentions for a contemporary society. I believe that both of these considerations, alongside a reflection on the adapter's positionality and the intentions of the producing organization and production team for a live production, are invaluable to both the field of adaptaiton studies and of dramaturgy.
\end{abstract}





\title{
Chapter One
}

\author{
Introduction: Defining My Place
}


The practice of adaptation is booming today - the Internet makes it possible for more people than ever to parody, cover, sample, revise, and rewrite their favorite literary, musical, and performative works for a global audience. However, the urge to adapt is hardly a recent phenomenon. Retellings of Greek myths permeate European and postcolonial cultures (influenced by Europe) around the world, especially in the theatre where they were born. From Sophocles' re-telling the stories of Oedipus to the 2019 Tony award winner for Best Musical, Hadestown, people have returned to these stories over and over again through adaptation, a process that Linda Hutcheon defines in A Theory of Adaptation as creating "openly acknowledged and extended reworkings of particular other texts" (16). However, these hegemonic cultures have also used adaptation to white-wash stories, stripping them of their more unique attributes. Adaptations both remind those who know the original stories of their plot and themes and emphasize the importance of these stories for those who do not yet know them. Because of these powerful associations, adaptors often choose to validate and amplify stories and voices that are already well-known parts of the hegemonic culture. As a result, traditionally oppressed groups may find that their oppression is refracted and repeated through the adaptation of old stories.

Often, adaptation culture in the United States tends to exclude works that are outside of the traditional literary canon, including plays from the Spanish Golden Age which, though some plays are often anthologized, is not adapted as often as Shakespeare or the ancient Greeks, for example. While William Shakespeare is consistently the mostproduced playwright in the US theatre according to Diep Tran's analysis of American Theatre Magazine's member theaters' calendars (2016), playwrights from the Spanish Golden Age, situated quite close to the Bard in both space and time, have not had enough 
productions to appear on American Theatre Magazine's list of "Most Produced Playwrights" since its inauguration in 2014. Despite the large number of plays produced during this era, if these works are included in class curricula or theatrical seasons, they are generally limited to two or three works that North American culture has deemed iconic: Pedro Calderón de la Barca's La vida es sueño, Lope de Vega's Fuenteovejuna and works featuring the character of Don Juan, created by Tirso de Molina in his play El burlador de Sevilla. Though these plays were all written by Spanish men, there are plays from the sixteenth and seventeenth centuries written by other playwrights. Adapters could support the diversification of the canon by using their work to illuminate and legitimize underrepresented perspectives, such as the female or indigenous perspective, while still creating new versions of old texts that engage modern audiences' interests and sensibilities. While many of these texts are somewhat unusual and still relatively unknown, their age and recognizable themes make them ripe for adaptation, much like their more familiar sixteenth-eighteenth century counterparts.

In her book Adapturgy: The Dramaturg's Art and Theatrical Adaptation, Jane Barnette points out the intersection between adaptation studies and the theatrical art of dramaturgy. Both fields give researchers the tools to investigate adaptations from both the creative artist's and the audience's point of view. According to the website for the Literary Managers and Dramaturgs of the Americas (LMDA), "Working in theatres and playwrights' organizations, in colleges and universities, and on a project-by-project basis, dramaturgs contextualize the world of a play; establish connections among the text, actors, and audience; offer opportunities for playwrights; generate projects and programs; and create conversations about plays in their communities." Similarly, Michael Chemers 
identifies the dual nature of the art of dramaturgy, pointing out that dramaturgs work with the aesthetic architecture of a play through script analysis and new play development and the practical philosophy of a production, which involves giving production teams and audiences background information which will help them fulfill their role in the theatre for that production. Additionally, many dramaturgs are adapters and vice versa. Adapter or not, every dramaturg forms a bridge between the dramatic text and the people interacting with it, offering research to the actors and the design team which helps to contextualize the script and later offering similar context to the play's audiences through lobby displays and program notes. Dramaturgs are also trained to ask probing questions of new plays and of traditional work to help production teams and playwrights understand the world of the play. In this way both dramaturgs and those studying adaptation examine and enhance the intertextual aspects of a piece of literature and go beyond the study of intertextuality to develop and ask questions that connect that piece to the audience's experience of literature, which is often centered around the literary canon.

Thomas Leitch also unintentionally underlines the connections between Adaptation Studies and dramaturgy in his introduction to The Oxford Handbook of Adaptation Studies. He sees the most recent wave of Adaptation Studies as a movement away from the traditional litearary canon and toward a canon of questions - a set of questions that can be applied to various literary pieces, especially adaptations, in classrooms across academia. Asking questions is one of the central tenets of dramaturgy, and one of the goals of this project is to create and apply a 'canon of questions' that reveals both the dramaturgical/theatrical possibilities of an adaptation for the stage and the literary/historical significance of that adaptation. 
This dissertation, therefore, will follow Barnette's example in combining the lenses of adaptation studies and dramaturgy to illustrate the process of adaptation as it applies to three Spanish Golden Age plays adapted for stages in the United States. These plays are $A$ Little Betrayal Among Friends by Caridad Svich, adapted from La traición en la amistad by María de Zayas y Sotomayor; Fever/Dream by Sheila Callaghan, adapted from Pedro Calderón de la Barca's La vida es sueño, and which I directed at the University of Missouri in 2018; and my own abridged translation of Los empeños de una casa by Sor Juana Inés de la Cruz titled How to Build a Noble House, followed by a freer adaptation called With the Temptation, a Way of Escape. I will explore the adapturgical process involved in writing, contextualizing, and producing each of these plays, which brings up ethical issues related to the canon of dramatic literature as a whole. The adapters of these works have considered the implications of LGBTQ+ erasure on their audience, the importance of maintaining a sense of the uniqueness of Spanish Golden Age style, and the expectations of twenty-first-century audiences in their work to varying degrees. Each play brings unique considerations, but the ethical questions involved in writing all of them contribute to the canon of adapturgical questions and more general areas of inquiry which should be applied in any adaptation project.

\section{Defining Terms}

\section{Canon}

In order to more effectively discuss the items listed in this exploration, I must first clarify some key terms that are relevant to this study. First, in my discussion of the canon, I refer to the literature that is most often taught in schools and produced onstage. J.D. 
Porter's article for the Stanford Literary Lab includes works in the canon when they have both popularity and prestige, meaning that a critical mass of people in educated society have heard of, read, or seen the piece and that piece has also garnered critical attention in academic circles. Nancy LaGreca echoes the importance of both realms when she refers to the "canonization of texts by the standards of both male and female scholars, students, and reading publics" (387). Since this dissertation is in the field of theatre and performance studies, the canon I refer to is usually the canon of dramatic literature, meaning productions on all levels (professional, amateur, and academic, among others) affect both a work's popularity and its prestige. Another contributor to and signal of both axes is the postgraduate reading list, which is often required for Masters' comprehensive exams or $\mathrm{PhD}$ qualifying exams. These lists are becoming more diverse as the canon is examined and reexamined, but authors included on these lists have traditionally been predominantly cisgender, heterosexual, white, and male. For example, Stuart Spencer includes a similar list of "required reading" at the end of his book The Playwright's Guidebook (2002) which includes seven plays, all of which are written by (presumably) cis-gendered white men and only includes one openly homosexual man - Tennessee Williams. This list is followed by a more general "recommended reading" list which includes 103 playwrights, only six of whom are women ${ }^{1}$ and only two of whom are people of color ${ }^{2}$ (Spencer, 323-330). Other examples at the time of writing include UCLA's graduate reading list for dramatic literature (which has not been updated since 2012), and the suggested reading list for the department of theatre at the same institution, which makes better attempts at inclusivity but still skews

\footnotetext{
${ }^{1}$ Caryl Churchill, Lorraine Hansberry, Lillian Hellman, Carson McCullers, Marsha Norman, and Sophie Treadwell

${ }^{2}$ Lorraine Hansberry and John Leguizamo
} 
toward the 'traditional' canon. However, for the most part, it does not appear that these lists have been archived or compared extensively. Such a project is outside the purview of this study but would be a fascinating area for further research.

\section{Adaptation vs. Translation}

Adapters accept and acknowledge that they are creating a distinct and unique text - that they are changing the source text in some way, shape, or form. While translation seeks to recreate a text as accurately as possible, adaptation creates differences between the two texts in areas including medium, genre, tone, and time period. An adaptation inevitably comments on the original text in that transition, perhaps parodying or satirizing the source text, applying a conceptual lens to help the audience see new meaning in the story, as directors do when applying a concept to a script, or modernizing the text to make it more accessible to a contemporary audience. To borrow an adage from anthropology, adaptations often 'make the strange familiar,' with the unfortunate side-effect of sanding down unique aspects of the source culture within the text. André Lefevere suggests a further distinction in adaptations which are written under constraints to appeal to new audiences. He calls these "refractions," but for the sake of clarity and to position myself more clearly within adaptation studies, I will not use this distinction throughout this dissertation.

The shifts that adapters choose to make create a commentary and conversation with the original text, either intentionally or unintentionally. Margarita Laera points out that "the process of adaptation implies negotiations of numerous kinds, such as interlingual, intercultural, intersemiotic, intermedial, but also ideological, ethical, aesthetic, and 
political" (5), giving a label to several of the kinds of adaptation that I have discussed here. She also points out that all theatrical productions are intermedial adaptations, adaptations that translate a source from one medium to another, like a film version of a novel, since they take a written play text and turn it into a performance (Laera). I accept that these are all varieties of adaptation but choose to focus in this dissertation on intramedial and intertemporal adaptations which adapt a play text into another play text (intramedial) but move the story to a different point in time (intertemporal), moving the mise-en-scène to the United States in the twentieth and twenty-first centuries. These are also interlingual adaptations, also known as translations, and intercultural adaptations. The shift to the twenty-first-century United States allows me to apply dramaturgical questions developed and often implemented in the United States and the intertextual content of a culture that I know well.

\section{Production Teams}

The roles in the theatre seem clear to practitioners but may be less obvious to those outside the field. In this case, when I discuss the production team for a piece, I refer to the director and all of the designers involved in the process, which typically includes designers for the set, lights, costumes, props, sound, and sometimes projections. In my definition, the production team does not include the actors or construction teams (though some members may overlap), nor does it include the theatre's front of house or marketing personnel. Dramaturgs are sometimes considered part of the production team and at other times are more connected to marketing and venue management teams. I have already discussed the mercurial nature of the role of the dramaturg to a small extent, but this liminal space 
between the production team and the producing organization is a good illustration of the variety of roles that a dramaturg can play.

\section{Hispanic and Latinx}

Finally, the language that I will use surrounding the Americas and the presence of Spanish-speakers in the area requires further specification. According to Shereen Marisol Meraji's interpretation of a 2020 Pew Research poll, most Latinx people in the United States prefer to be identified by their country of origin, so I will try to do so with individuals mentioned here. However, groups of people are often more difficult to identify. Meraji also points out that, while most individuals do not self-identify as Latinx, the word has been used in Universities to describe groups of people for some time, and the genderless construction shows solidarity with the LGBTQ+ community, so I will continue to use Latinx to refer to groups or art forms coming from Latin America, which primarily consists of Mexico, Central and South America, and the Caribbean, and Latin American communities in the United States. I will use the gendered Latino or Latina if the subject's gender is defined and Latinx for words with no gender in English and genders which do not conform to the binary. I will use Hispanic, on the other hand, to refer to any person or work coming from Spain and in generalizations that include Spain with other Spanishspeaking Latinx countries, in accordance with Hispanic Lifestyle's definition, "Hispanic refers to people who speak Spanish and/or are descended from Spanish-speaking populations, while Latino refers to people who are from or descended from people from Latin America" (“The Difference Between Hispanic and Latino"). In this way, María de Zayas y Sotomayor and Pedro Calderón de la Barca, who were born and wrote their plays 
in Spain, are Hispanic but not Latinx, but Sor Juana, who lived and worked in Mexico but came from Spanish heritage is both Latina and Hispanic. Similarly, I will aim to incorporate a more complete use of the word American to include all of the Americas, including North, Central, and South America as well as the Caribbean. However, the term is sometimes useful to refer to the narrative of the United States and its culture specifically - in these cases, I will use the term "American" in quotation marks to signal that I am referring to the rhetoric of "Americanness" and not simply the culture of the United States. Since "Western" has been seen to be Orientalizing and demeaning to Middle Eastern, African, and Asian cultures, I will use Euro-American to refer to the culture shared between Europe and the Americas through the process of colonization and colonialism.

\section{Justification}

As a twenty-first-century dramaturg and academic, I feel that it is my job to make a wider variety of classical plays available to contemporary audiences while considering the implications and impacts this work might have on contemporary romantic narratives and historically excluded groups, including Spanish-speakers and the LGBTQ+ community. The field of Adaptation Studies has never been stronger, and the intersections between classical European works and twenty-first-century stages are also influenced by global studies, transatlantic performance studies, and more. My personal experience as a theatre practitioner, and specifically as a playwright and new play dramaturg, puts me in a unique position to adapt plays for modern audiences, which I am excited to do with this project. I also believe that it is important to highlight women's work from both the Spanish Golden Age and from the twenty-first century -- it is my firm belief that the current literary 
and performance canon is woefully undersupplied with work from woman authors and playwrights. A Little Betrayal Among Friends, Caridad Svich's adaptation of María de Zayas's Traición en la amistad, Fever/Dream, Sheila Callaghan's response to Pedro Calderón de la Barca's La vida es sueño, and With the Temptation, a Way of Escape, my own adaptation of Los empeños de una casa by Sor Juana de la Cruz, all offer engaging, funny, and energetic alternatives to the currently quite male-centered canonical offerings.

The diversification of the canon has been a hot topic in recent years as the Internet provides opportunities to learn more about a variety of global texts, and academics and artists in the United States grapple with the ways that white privilege has formed the current literary canon. A 2018 article in the Harvard Political Review by Devon Black points out that "some teachers are fighting back against ethnically and racially homogenous literature" and highlights high school teachers seeking to diversify their classroom reading lists. Similarly, Sadie Berlin and Ted Witzel write in a HowlRound article titled "Beyond the Western Canon" that "Amid this catastrophe, we have an opportunity to rebuild: what stories will tell us who we are and how we got here, and how will we gather to tell them?" The "catastrophe" they refer to seems to be the Covid-19 pandemic of 2020 but may also refer to the numerous deaths of Black individuals like Breonna Taylor and George Floyd at the hands of police which led to the Black Lives Matter protests that same year. The combination of these two ongoing events led individuals to create crowdsourced Google documents such as the "\#BIPOCSwap List," which offers alternatives to over-emphasized traditional scripts suggesting, for example, that classes read Pass Over by Antoinette Nwandu instead of Waiting for Godot by Samuel Beckett. This list does not include any Spanish Golden Age plays, and most suggested alternatives to Shakespearean plays are 
adaptations of those same plays. To be fair, however, the playwrights discussed in this dissertation are not BIPOC (Black or Indigenous People of Color). On another list, a group called Preying Womantis initiated a crowdsourced list of "Non-Western plays, plays by Black, Indigenous, people of color, by women and by queer writers from before 1945" called “Alternative Canon to 1945." This list does include several Spanish Golden Age plays but inaccurately lists all of them as having "no English translation" at this time. While academia has continually circled back to the idea of what should and should not be in the canon, the fact that many of these articles come from popular sources and grassroots efforts shows the importance of this issue beyond the academy in the twenty-first century.

This lack of diversity is not only due to the United States' history of forgetting, ignoring, and suppressing minority work; it appears in contemporary trends as well. The easiest place to show this is through the US theatre's lack of work by women, who form a large portion of the global population but whose work is still pushed aside. A 2018 report by Martha Wade Steketee and Judith Binus shows that the 2010-2017 off-Broadway seasons, despite consisting primarily of new work, only included $29 \%-37 \%$ female playwrights and all roles in Off-Broadway theatres are similarly gendered. Another collaboration between The Guardian and Elizabeth Freestone looked closely at the 20112012 seasons of top publicly funded theatres in the UK and found that, though audiences are predominantly female, only $35 \%$ of new plays being produced were written by women. Charlotte Higgins, writer of the article describing this project, says "This failure to represent women, argued the actor, writer and director Stella Duffy, was deeply entwined with society's wider failure to put women's voices on an equal footing with men's" (Higgins). These two reports show a disheartening lack of change in the works which are 
most likely to eventually become part of the canon due to their current popularity and prestige. The most important producing institutions in the theatre, like educational programs reevaluating their reading lists, must work harder to diversify their work so that their audiences can see their own stories onstage.

Just as women comprise nearly half of the world's population, the prevalence of Spanish speakers in the United States makes the dearth of traditional plays based in Spanish-language traditions in classrooms and on US stages shocking and unacceptable. According to the Pew Research Center, Hispanic and Latinx people are “the nation's second-fastest-growing racial or ethnic group, with a $2.0 \%$ growth rate between 2015 and 2016" (people of Asian origin or descent are the fastest growing group, which should also be considered canonically, but such research is beyond the scope of this study). According to the United States Census Bureau estimates as of July $201918 \%$ of the U.S. population self-identifies as Hispanic, and a 2012 Pew Research article reports that almost $65 \%$ of the United States' Hispanic population has Mexican heritage (Motel \& Patten). The first Mexican playwright who is widely recognized and celebrated is Sor Juana Inés de la Cruz (1648-1695), but her heritage is entirely Spanish. Unfortunately, very little pre-colonial theatre from Latin America is ever produced in the United States and, according to E.J. Westlake, many of the pieces that we might consider to be theatrical were part of ancient religious practices. While this evaluation is almost certainly overly simplistic, research into pre-colonial theatrical traditions is not within the scope of this study. Further research is needed to investigate ways to honor indigenous Latinx traditions and new work in American Theatre both North and South of the Rio Grande. 
While much is being done to promote and encourage contemporary Latinx writers in the United States, that goal is not within the scope of this project. However, I do hope that this dissertation will provide a canon of important practical and ethical questions which can be used by scholars who choose to adapt Spanish-language work. Current trends in new work are included in this dissertation through the inclusion of Caridad Svich, a prolific contributor to Latinx theatre in the United States. According to the Instituto Cervantes' 2016 study, "El Español: Una lengua viva" the United States has 42,561,531 native Spanish speakers and 14,954,051 students of the language, meaning there are more Spanish speakers in the United States than there are in Spain itself (Spain's population is just under 47 million people according to Eurostat). Therefore, the study of Hispanic cultural pieces and pieces exploring the intersection between Hispanic traditions and US culture are more and more relevant to US culture as the US's Hispanic population increases and the hegemonic white culture makes space for other voices. This study will serve as an example of ways to help audiences connect with Spain's rich literary tradition without sacrificing either Spain's unique literary traits or contemporary US concerns about the fair treatment of women, LGBTQ+ folx and other groups. The plays presented in this study, should they be produced, may encourage emerging Hispanic playwrights, allowing them to see part of their own heritage (albeit the colonizer's heritage, in some cases ${ }^{3}$ ) in traditional work that has both the complexity and the flexibility revered in English-language authors like Shakespeare, who currently dominates the canon. I hope that this effect will be especially strong for young women, another underrepresented group in the traditional canon of

${ }^{3}$ Sor Juana, as I have mentioned, was born in Mexico, though her parents were both Spanish, and was sympathetic to indigenous philosophy and culture. She provides a unique bridge between the two cultures. 
dramatic literature, which is why I have chosen to focus my study on female adapters and mostly female playwrights specifically.

Adaptation studies, like dramaturgy, is a growing field which, as Thomas Leitch pointed out in his introduction to the Oxford Handbook of Adaptation Studies, is entering a new, more nuanced era of study. While the first waves of adaptation studies focused primarily on similarities and differences between original and adapted works and later researchers connected adaptation more closely to intertextuality, the current wave of adaptation studies scholars seems to be finding yet another path to understanding adaptations. This parallels a new wave of dramaturgical study. As LMDA points out, "Over the past three decades, the role of the dramaturg and literary manager has expanded in the United States and Canada alongside the increasing importance of contemporary playwriting." Dramaturgy's growth offers opportunities to educate and engage audiences in new and innovative ways. Similarly, adaptation studies scholars like Margherita Laera and Linda Hutcheon have chosen to expand their scope beyond the adaptation of novels into films and to consider the many other, more interactive, ways that adaptation happens in our world today. Even long-established adaptation theories encourage change and growth, which is why this dissertation integrates older adaptation techniques, like those described by Hutcheon and McFarlane, with newer methods of questioning which run parallel to both the theoretical basis and practical art of dramaturgy.

\section{Positionality}

The concept of positionality is more at home in the field of ethnography than in the field of adaptation studies, but I believe that it is an important consideration for adapturgs 
of all stripes, including myself in this study and in my own adaptation. The primary difference between this study and an ethnographic one is that ethnographers work with living subjects and the playwrights of the original works that I am investigating are dead and their work is old enough to have entered the public domain ${ }^{4}$. Therefore, some ethical questions, such as asking who benefits monetarily from this study, are moot because the source playwrights in question simply cannot benefit in that way. I will certainly keep in mind the benefits and effort provided by the living writers discussed in this study, but I believe that the academic attention will be nothing if not beneficial for them as well, and I myself do not expect to benefit monetarily directly from this dissertation.

Most importantly, establishing my positionality in this case involves recognizing where my identity connects with and overlaps the identities of the source and studied texts and where those identities differ. This is a counterintuitive turn in translation studies, the parent of adaptation studies, in which the translator tries to metaphorically 'get out of the way' of the source text. Often translators are not listed on the front pages of books and sometimes their credits can be downright difficult to find. There is also a shift in the field of ethnography from an outsider/insider dichotomy to a more nuanced view of the ways that researchers connect with their subjects. Hangyan Lu and Warren A. Hodge point this out in "Toward Multi-Dimensional and Developmental Notion of Researcher Positionality," arguing that "The purpose of this paper is to argue for a multi-dimensional and developmental notion of researcher positionality in conducting qualitative research, in lieu of the dichotomous notion of outsider and insider" (225). They point out that a variety of research has been produced in recent years encouraging other researchers to consider

\footnotetext{
${ }^{4}$ The authors of the other two adapted works are both living.
} 
their positionality based on a "wide range of issues such as gender, geopolitical locale, race, ethnicity, cultural background, educational status, linguistic competence and professional status" (225) and how those issues may affect the researcher's power dynamic with their subjects.

I will consider these various issues as they relate to myself and my literary subjects in this work so that I may more ethically and effectively discuss their work, and I will suggest guidelines for future adapturgs attempting to do the same. Like Sor Juana, Zayas, Svich, and Callaghan, I am an educated woman and a writer. It appears to me that our gender informs all our work significantly and that we prioritize the effort of telling women's stories and creating theatrical roles for femme actors. However, women's roles in the twenty-first century are very different from their roles in the seventeenth century, which offers me a great deal more freedom to conduct this research and stage these plays than Zayas or Sor Juana enjoyed. It was nearly impossible for women to get their plays produced in the seventeenth century, and those difficulties were frustrating to both women, a challenge that Calderón did not have to face, which allows him higher canonical status to this day. Similarly, all these playwrights and I share educational privilege and relative racial privilege as people of European descent, though the issue of race is complicated in this context. Callaghan and I enjoy relatively uncomplicated whiteness while the Spanish women in this study are involved in a more complicated racial identity that José G. SotoMárquez calls "bifurcated ethnicity." With this bifurcated ethnicity, Spaniards in the United States must navigate a liminal space between their European whiteness and the perception of many in the United States that they are people of color. Svich is Latina and thus she is more certainly othered in US culture. Though I hope to be able to create work 
that would inspire Latinx and Hispanic audiences, it is important that I treat that outreach with care as I am not from that racial group. Geopolitically, all six playwrights again come from a place of privilege as members of colonizing cultures, though the United States in the twenty-first century experiences that colonization in a more complex way. In general, I share several points of privilege with these playwrights as well as some social struggles born from our gender, albeit much more pointedly for the seventeenth-century women than for myself.

The differences in positionality between the playwrights for this project and myself are not, as I have mentioned, as significant as the differences between my intended audience and myself. Though Sor Juana, Zayas, Calderón, and Svich are all Hispanic, I am not, and my Spanish language skills come from formal education and not from natural acquisition. I do not know if Sheila Callaghan speaks Spanish at all, but she presents as a white American playwright with relatively little connection to Hispanic culture, which makes her work a relevant comparison to my own. As Callaghan and Svich are currently alive and writing in the United States, we are connected in time and geographic area. However, Callaghan lives and works primarily in New York, which is culturally quite distinct from Missouri, where I live and work. Svich, on the other hand, has produced a world premiere production at the University of Missouri - Columbia and recently had a Rolling World Premier through the National New Play Network which graced the Unicorn Theatre in Kansas City, MO. She has also worked extensively on the coasts and outside of the US, so her cultural considerations are more nuanced and flexible than, perhaps, Callaghan or myself. 
As a white academic, translating Spanish-language work for a Hispanic and Latinx audience is a delicate process which I hope to mediate by focusing on the process of adaptation and the universality of Spanish Golden Age work. Though I primarily focus on Adaptation Studies and dramaturgical theory, I also include intersectional considerations of my positionality throughout this dissertation. To do so, I rely heavily on theories outlined in Nancy LaGreca's survey of Latin American feminist research, "Feminist Literary Criticism of Latin American Women's Writing: Context, Approaches, and Analysis of the 1990s and Early 2000s." Though many of these theorists prefer to analyze their work through the lens of theorists indigenous to the country of origin for the artistic work as well, LaGreca points out that "because social struggles transcend national, cultural, racial, and linguistic borders, foreign theory [theory written in a country other than the country of origin of the artistic work] can yield nuanced and multivalent readings" (387). Since researchers around the world regularly use foreign theory, and foreign theory has the most clout in academia, I feel justified in using it in this dissertation. This dissertation is also transcontinental, meaning some aspect of the theories I apply will always be foreign to either the source texts or the adapted works. I will also integrate intersectional feminist theories by Debra Castillo, whose research on Spanish-speaking early women writers provides invaluable insight based specifically in Hispanic studies and Comparative Literature $^{5}$. I will also integrate decolonial theory by focusing not only on white hegemonic theories (though admittedly those are sometimes included), but by acknowledging the practical American origins of the adaptations I have chosen to study and researchertheorists based in these traditions like Svich and Castillo.

\footnotetext{
5 The subjects that Castillo teaches at Cornell University, according to her website.
} 


\section{Theatre Practice}

The fields surrounding this research are growing and changing every day, making this research difficult at times, but increasingly relevant. New translations of Spanish Golden Age plays, especially Spanish Golden Age plays by women, have been released consistently over the past several years, though they still do not manage to get many productions. However, academic and community theatre groups like UCLA's Diversifying the Classics program, are seeking to remedy this issue by finding plays that speak to a more diverse US culture and communicating to Hispanic audiences that their history also matters. Perhaps these adaptations can inspire and encourage new generations of Latinx theatre artists -- a strong and growing group which can bring untold richness and depth to the current US theatre.

My experiences in all areas of theatre practice and playwriting, including my dramaturgical skills, give me a practical perspective on this work, and my passion for language and for this project make me well-suited to undertake this investigation. I have contributed to all areas of the theatre in some way, shape, or form, including direction, stage management, acting, and playwriting; I am in-tune with the tools that make a play engaging to an audience. I have studied audience engagement as a dramaturg primarily focusing on new play development, a skill and set of connections which is invaluable to my research and to the application of literary and practical theories and techniques in this dissertation. My Master's degree is in Spanish language teaching, and I have taken the time and made the effort to understand Spanish Golden Age culture quite thoroughly. I also have a $\mathrm{PhD}$ minor in linguistics, which is an anthropological field intent on preserving the voices 
of many diverse people and making those voices and languages accessible to a wider audience, more academically valued, and preserved for posterity. I believe that all these skills are valuable in translation and adaptation.

In the interest of sharing Spanish Golden Age stories in all corners of the United States, I hope to create roles that could be performed by casts that are as diverse as the cities in which they are performed and are as flexible as those found in Shakespeare. ${ }^{6}$ I believe that the European context in which Los empeños de una casa was written lends itself to this kind of casting while still contributing to the valorization of one or more Spanish-speaking women with Mexican heritage, though I intend to make the casting and identity of the characters more specific in my adaptation to ensure the presence of Latinx voices in all productions.

These adaptations' potential to reach a Hispanic and Latinx audience in the United States is valuable and exciting and lends particular relevance to this study in the current moment. However, my primary goal in this dissertation is curating and implementing my own canon of dramaturgical questions and considerations which can be applied to dramatic adaptations by integrating my work in new play development with adaptation theory. Additionally, the writers that I will study in this dissertation have challenged the canon by working with both well-known and lesser-known pieces and adapting them to celebrate underrepresented identities, pushing back against current and traditional notions about gender, culture, ethnicity, and class. These issues interplay in complex ways in the psyche of the United States, where people of all races, ethnicities, genders, and classes come

${ }^{6}$ Similar to Shakespeare's writing, many Spanish Golden Age plays, including those represented in this dissertation, feature vague character descriptions which do not specify the race or even the age of their characters. 
together to create theatre. I believe that increased understanding of the considerations adapters must make and the strategies that they use to exploit and inform audiences' intertextual webs of knowledge will aid the work of emerging adapters and dramaturgs like myself. I also hope to inspire teachers, students, and autodidacts to broaden their concept of the canon and the United States' artistic and cultural legacy to represent more diversely “American" writers and works.

The diversity of cultures present in the United States has traditionally been underrepresented in her theatre seasons, casts, and company leadership, but the combination of the 2020 coronavirus pandemic and the Black Lives Matter Movement have called for a reckoning in these areas. Theatres were forced to close and given time to reconsider what they should be when they returned to live stages. Many of these stages opted to return to more inclusive, diverse identities. The American Theatre editors reported in August of 2020 that the "Penumbra Theatre [was] to Become Penumbra Center for Racial Healing," and Ciara Diane, also writing for American Theatre Magazine, pointed out that "Black students also note a tendency toward Eurocentric and white-authored programming and standards, a scarcity of teachers of color, and tokenization." While these issues are centered around promoting more African American and non-European programming, theatres and academic programs are rightfully searching for more ways to produce unique, underrepresented work which I hope may include seventeenth-century plays by women and plays originally written in Spanish alongside plays featuring African American stories, African stories, indigenous stories, new Latinx stories, and more. All in all, the United States is clamoring for a new canon now more than ever before, which may 
lead to both an increased interest in adaptation and increased curiosity about the Spanish Golden Age.

\section{The Adapters}

The adapters I have chosen to study are both mainstays of the American new play community. According to her website, Sheila Callaghan has had work "produced and developed with Soho Rep, Playwright's Horizons, Yale Rep, South Coast Repertory, Clubbed Thumb, The LARK, Actor's Theatre of Louisville, New Georges, The Flea, Woolly Mammoth, Boston Court, and Rattlestick Playwright's Theatre, among others" an impressive list of venues in the United States' regional theatre circuit. She also writes for television and was nominated for a Golden Globe in 2016 and a Writers Guild of America (WGA) Award in 2017. Since twenty-first-century theatrical tastes are strongly influenced by television, Callaghan's success in TV positions her uniquely to make an impact on new audiences with old stories and, as I have mentioned, she is a white writer from the United States who adapted a Spanish Golden Age play, emphasizing the universality of Spanish Golden Age theatre. Despite her impact on twenty-first-century theatre, little has been written about Callaghan -- she has two anthologies, one of short plays called The Transit Plays, (2013) and Lascivious Something/ Roadkill Confidential/ That Pretty Pretty; Or, The Rape Play: Three Plays (2011), which include thoughtful forwards from the playwright herself. In addition, Kate Busselle's 2018 dissertation, Killing "Woman": Gender and Violence in Selected Plays by Sheila Callaghan and Marisa Wegrzyn, began to explore the theoretical side of Callaghan's work by investigating her use of women's violence. Catherine Larson also published an article about Fever/Dream 
in Comedia Performance in 2013 titled “Calderón’s La vida es sueño Meets Callaghan's Fever/Dream: Adaptation and Performance." While this article discusses adaptation theory quite well, Callaghan is not known for adaptations, and Fever/Dream is unique in her oeuvre, but the creativity that typically springs into her original work is a prominent and attractive feature of her adaptation style. As a woman who is drawn to comedy, I also wanted to highlight women who are writing and adapting comedies; I believe that adapting comedy brings its own unique challenges, which I illuminate throughout this research. Callaghan aggressively breaks the stigma associated with women in comedy and the old assumption that women aren't funny, as she incorporates other narrative traits that are not traditionally feminine such as violence, drug use, and general grit. Despite the many things that make her unique, theoretical writing about her writing process and work has been rare -- so far. I am confident that this will change with time.

Caridad Svich, on the other hand, is a practiced adapter and translator, as well as a creative and prolific writer of original work. Like Callaghan, she embraces twenty-firstcentury trends in dramatic literature and engages her audience through her impactful, experimental style. Her play Red Bike received a National New Play Network Rolling World Premiere in which it was performed with a different number of actors at each venue. She also earned the 2012 OBIE for Lifetime Achievement, the 2018 Association for Theatre in Higher Education's Ellen Stewart Career Achievement in Professional Theatre Award, and the 2018 Tanne Foundation Award, among others. Svich is a Latinx and Hispanic playwright and translator, and her translations and adaptations span important work across the Spanish-speaking world. Her adapted works range from plays like A Little Betrayal among Friends and Federico García Lorca's Blood Wedding to novels like Isabel 
Allende's House of the Spirits and Julia Álvarez's In the Time of the Butterflies. She is also a prolific theoretical writer, writing for HowlRound Theatre Commons and Theatre Communications Group. Most of her theoretical work is included in anthologies (which she often edits) about Latinx theatre, playwriting, audience engagement, or her mentor, Cuban American playwright María Irene Fornés. Svich has also been the subject of academic discourse and analysis. A chapter of Anne García-Romero's book The Fornés Frame is dedicated to Svich, as is an article by Kevin Brown titled "Oceanic Geographies: The Fluid Dramaturgy of Caridad Svich.” There are also eloquent introductions preceding her anthologized work, such as Brown's introduction to JARMAN (all this maddening beauty) and other plays titled "Beautiful Strangeness: The Plays of Caridad Svich" and an introduction to Lorca: Six Major Plays by James Leverett and Amy Rogoway. However, these introductions are reserved for those who have already sought out Svich's work and on a wider level, relatively little has been written about her even though she herself has contributed profoundly to theatrical knowledge in her lifetime.

\section{The Playwrights of the Spanish Golden Age}

Both Callaghan and Svich promote women's voices and women's roles through their work, which I deeply admire. Svich shows this specifically in A Little Betrayal among Friends through her choice to adapt the work of a Spanish Golden Age woman, Maria de Zayas y Sotomayor (1590-1661), an underrepresented playwright whose work will be amplified and supported by this research. Zayas's work is woman-authored and focused on women supporting women; it would make an excellent addition to the literary canon. Zayas came from a wealthy family, which allowed her the opportunity to write in a time when 
female writers were rare. She is known primarily for her novels, and La traición en la amistad is her only extant play. Much of her writing is about women and women's issues, and her opinions about the relationships between men and women are clear in La traición en la amistad, which centers on the relationship between the women in the play more than it depends on those women's relationships with the play's men. Svich's adaptation offers a light, producible version of Zayas's play and, since Svich is such a prolific adapter, research into her adaptation style will certainly further adaptation studies in general.

There is no doubt that Pedro Calderón de la Barca (1600-1681) is a significant playwright in the realm of academic inquiry. La vida es sueño has been translated and adapted many times, but I chose to focus on this particular adaptation not only because Callaghan is an exciting and refreshing twenty-first-century playwright but also because her adaptation both centers the female characters and gender-swaps one character to create more roles for women. Though Calderón, arguably, empowers his female characters (they even occasionally wield swords), Callaghan's re-writing gives the women in the play a greater variety of motivations and personality traits, and her choice to gender-swap the character of Clarín ensures that the play features women helping women and that it passes the Bechdel-Wallace test, a metric that was created as a joke but now wields significant influence in twenty-first-century feminist culture. Callaghan is known for creating strong, gender-subverting female characters -- sometimes disturbingly so -- and centering them in her work, which I believe is an important part of intertextual conversations with the canon. The fact that La vida es sueño is more typically part of the US canon of dramatic literature means that the intertextual connections made by audiences watching this piece will be more varied and sometimes much richer. Because this connection is so strong, the adapturgical 
line of questioning and consideration is different for Fever/Dream and subversions of seventeenth-century traits are more obvious to audience members in general.

Finally, I have chosen to adapt a play by Sor Juana Ines de la Cruz (1648-1695), the most well-known female writer of Spain's Golden Age. Her heritage is Spanish, but she was born in and wrote from Mexico, so her place in Golden Age culture is somewhat disputed. She was known for pushing back against the social mores of her time and allegedly cut her hair so as not to be distracted from her learning with beauty. She included indigenous themes in her work, demonstrating a scandalous early leaning toward intersectionality, and her most famous poem, Hombres necios que acusáis, is an excellent example of her regular complaints about men's double standards for women. As a nun, she was chastised for pointing out men's flawed logic, but it makes her work fascinating and timely to this day. She primarily wrote short religious plays called autos sacramentales, many of which, including her most famous Loa del divino Narciso, are uniquely sympathetic toward indigenous issues and religion, even though they were supposedly written to promote Catholic ideals. Contemporary scholars only have two full-length plays which are indisputably attributed to her as the only playwright, El gran Narciso, (which the aforementioned loa is meant to precede) a religious allegory of the myth of Narcissus showing that Sor Juana herself was an adapter, and Los empeños de una casa, a secular cloak-and-dagger farce which centers several female characters. The agency and humor found in these female characters is what draws me to this script and is, I think, what will make this script successful in US theatre. Sor Juana incorporates low-brow humor and virtuosic wordplay, both of which show the entertainment and literary potential of Spanish Golden Age women. Adapting this play will not only provide an excellent opportunity for 
entertaining productions but will also point readers back to this worthy original script for study and analysis.

\section{Method}

I believe that both adaptation theory and practical dramaturgical insight are important to understanding how the choices made by adapters impact their audiences and artistic environments. I will look at both kinds of theory throughout this dissertation to determine what I believe are the best practices for adapurgs working on classical plays and to glean meaning from their choices in the adaptation process for these three specific Spanish Golden Age plays. Barnette similarly talks about both "Theorizing Adaptation" and "Adapting Theory" in Adapturgy. This pair of practices is useful for me in this context, in that I, like Barnette, have practical experience with Fever/Dream as a director and with With the Temptation, a Way of Escape as a playwright and adapter. These experiences allow me to use my dramaturgical and artistic skills to approach this work with theoretical expertise backed up by real-world experience. I will begin with the theoretical groundwork and incorporate more practical dramaturgy as I progress through the dissertation. Throughout my work, I will keep the tenets of intersectional feminism and decolonialism in mind to help balance my scholarly privilege. The first source of this scholarly background comes from adaptation studies.

\section{Leitch's Periods of Adaptation Studies}

Adaptation studies is, itself, a relatively young field which often focuses on film. Because the field focuses so much on elements of popular and low brow culture, it has had 
a strained relationship with theory. In fact, Kamilla Elliott says that "adaptation and theorization are similar and yet inimical, overlapping and yet irreconcilable processes: they vie to rework whatever they touch in their own images" (682). Partly because of this tension and partly because of the relative youth of the field, adaptation studies has yet to define itself by specific theories, though several have been suggested and used in adaptation studies reflections throughout time. In his introduction to The Oxford Handbook of Adaptation Studies, Thomas Leitch describes three phases of Adaptation Studies. In this study, I will use concepts from two of these phases: Adaptation Studies 2.0, which focuses on intertextuality and is exemplified by Hutcheon and McFarlane, and Adaptation Studies 3.0, which focuses on questions and questioning. I will add to this most recent wave of adaptation studies by connecting it to theories from Barnette, Chemers, and others.

The terms Adaptation Studies 2.0 and Adaptation Studies 3.0 are Leitch's invention - attempts to categorize different eras of popular theory in adaptation studies. Leitch cites the beginning of Adaptation Studies 1.0 as George Bluestone's 1957 book Novels to Film, which inspired a wave of adaptation research primarily based on case studies that focused on fidelity between the source text and the adapted text. As this was the first iteration of theories in adaptation studies, it is not surprising that its popularity and relevance has fallen by the wayside in favor of more nuanced analysis. However, this shift did not happen until the turn of the twenty-first century. In fact, Elliott points out that into the 1990s, "scholars such as Brian McFarlane and Patrick Cattrysse condemned adaptation scholarship for its impressionistic, subjective value judgements, advocating their replacement with empirical, descriptive, systematic theories" (680). This more nuanced approach was much more effective, though Leitch believes that its popularity was short-lived. 
Leitch sees many of the adaptation researchers that I will use for this dissertation as members of Adaptation Studies 2.0, in which researchers rejected the limitations of fidelity criticism and focused instead on investigating the effects of intertextuality on adapted texts. This organizational distinction effectively clarifies the central theories in this dissertation, but does not add to the theories presented in Adaptation Studies 2.0. Instead, Leitch reserves his own ideas for Adaptation Studies 3.0. Brian McFarlane's 1996 book Novel to Film: An Introduction to the Theory of Adaptation and Linda Hutcheon's $2006^{7}$ book A Theory of Adaptation both fall into Adaptation Studies 2.0 in that they both define themselves by the rejection of fidelity criticism and suggest that adaptations be analyzed through the lens of intertextuality. Since every person's experiences of the various literatures of life is different, each audience member or reader will experience a text differently as well. Adaptations are, therefore, burdened with the weight of the intertextual connections with the source text as well as the same cultural intertextual connections that occur in the consumption of any other text. McFarlane and Hutcheon also offer tools for practical analysis, which are helpful for this dissertation and will be discussed shortly.

Adaptation Studies 3.0 explores the limits of intertextuality and attempts to distinguish itself from intertextuality as a theory. Leitch characterizes this period as an emerging one which has yet to be defined by clear or specific theories. However, he does see Adaptation Studies 3.0 as characterized by conversations about what does and does not belong in the canon. He points out that "adaptation studies abandons the possibility of a canon of the sort that has held literary studies, and to a surprising extent cinema studies, together for so long" and that "adaptation studies' stance, more anti-canonical than non-

\footnotetext{
${ }^{7}$ The most recent edition was published in 2012 , but this is the original publication date.
} 
canonical, looks downright prophetic" (6). Certainly, the evidence presented thus far in this dissertation shows that a reconstruction of the canon is imminent, but Leitch takes this idea one step further and proposes a canon made up of questions and not of specific texts. Some of these questions in the field of adaptation studies, in his opinion, include the question of what makes a work an adaptation, what responsibilities the adapter has to the original text, and whether adaptation studies itself should be "fundamentally analytical or fundamentally evaluative" (8). This focus on questions is reminiscent of dramaturgical work, and I will demonstrate throughout this dissertation the benefits of incorporating dramaturgical theory into new waves of adaptation studies more directly. While Leitch's questions provide a helpful foundation for his work, the canonical questions that I will explore in this dissertation are more closely related to dramaturgy and adapturgy and focus more on the product and process of adaptation rather than evaluation or categorization. However, the idea of canonical questions, originating from Leitch, is central to my work.

\section{Adapturgy and Adaptation Studies 3.0}

As I mentioned, Adaptation Studies 3.0 focuses on questioning - both questioning the canon and asking analytical questions of adaptations, a line of thinking that is clearly connected to the theatrical practice of dramaturgy, though the two seem to have evolved independently. I will lean into the connections between the two by creating and applying my own canon of questions culled from both dramaturgical study and Adaptation Studies, illustrating the direct relationship between dramaturgy and Adaptation Studies 3.0.

As an experienced theatre practitioner, new play dramaturg, and literature teacher, I have taken these dramaturgical questions into account many times, and they have always 
proven useful. I therefore integrate some dramaturgical questions into this dissertation, first using the ones suggested by Michael Chemers in his book Ghost Light: An Introductory Handbook for Dramaturgy. The most important of these questions is why this play now? which is like some of Hutcheon's inquiries but focuses more specifically on the environment in which a play might be produced. This question might also be expanded to reflect some of the changes revealed from the intertextual comparison between the adaptations and their antecedents. In fact, Barnette suggests an alternative to this question, why this text as theatre now? The difference between the answers to these questions can reveal practical and artistic shifts that cater to twenty-first-century audiences and sometimes significantly change the meaning of these stories. The practical changes also contribute to the success of a performance on its audience, which is reflected in Chemers, who borrows questions from Johann Wolfgang von Goethe, a seventeenth-eighteenthcentury German philosopher, and adapts them to playwriting, asking what was the playwright trying to do? were they successful? and was it worth doing? Answering these questions requires the asker to define terms like 'success' and the value of the playwright's effort, which is part of what makes answering said questions a valuable academic exercise. In this case, the subjectivity of these questions is their strength.

In Adapturgy, Barnette describes the two major wings of dramaturgy - new play dramaturgy which is, in this case, adapting scripts and helping playwrights work on their adapted scripts, and production dramaturgy, which focuses on offering context to a production's audience and community. Both wings may use lines of inquiry reminiscent of script analysis, though they occur more often in production dramaturgy and are often more interpretive. In this document, I will combine David Ball's script analysis method with 
Brian McFarlane's analysis of adapted works, as these two theories are conveniently quite similar. This process reflects a new play dramaturg's potential perspective on these scripts. Production dramaturgs, on the other hand, communicate with the audience via a lobby display, website, talkback, or other contextualizing experience which involves both creating an intertextual web for the play and helping the audience see and understand the production team's vision. Barnette refers to the double-sided nature of this task as being 'Janus-faced,' referring to Roman god of doorways and transitions. An adaptation dramaturg must hold both the original text and its new iteration equally in hand.

The new play development section of Adapturgy sheds light on my own adaptation process, as does the research within this dissertation. To describe my own Janus-faced journey, I will start with the primary work of listing the cardinal functions (as McFarlane calls them) or triggers and heaps (as Ball calls them) of the original play and considering intertextual palimpsests and problems that contemporary audiences are likely to deal with, including social issues that are thankfully very different now than they were in the seventeenth century. I will also discuss my development process for this play, which includes readings and feedback from twenty-first-century audiences. The University of Missouri - Columbia has excellent resources in terms of reading opportunities, including the Missouri Playwrights Workshop and their summer Comedies in Concert. Readings at these venues helped me understand how audiences react to my translation and adaptation and to ensure that they are understandable, entertaining, and suitable for production.

\section{Practical Considerations}


The most practical book used in this dissertation is McFarlane's Novel to Film, even though this dissertation deals with neither novels nor films. However, after the requisite rejection of fidelity criticism, McFarlane outlines a very practical adaptation methodology. First, he separates plot-based story elements which would significantly alter the story from the ways that more ephemeral concepts like character and mood are portrayed in different works and suggests that the former is more transferrable than the latter. He calls these storybased, transferrable elements narrative elements and the other elements of enunciation, which he claims cannot be transferred "involving as it does quite separate systems of signification" (23). He then focuses on the difference between story and plot, discusses the choice of primary narrative elements, saying that the most important plot points that any piece highlights are its cardinal functions, identifying the roles of various characters and what he calls "fields of action," and finding the patterns within a text that create its message (pp. 23-25). McFarlane applies these ideas to several films that were adapted from novels and I will use a similar approach to analyze the choices made by Callaghan and Svich, and later myself, in transferring plays from seventeenth-century drama to performable twentyfirst-century work.

In each chapter, therefore, I will outline the cardinal functions of both the Spanish Golden Age play in question and the twenty-first-century adaptation of that play. To do this, I will look at McFarlane's methodology alongside David Ball's book Backwards and Forwards, as I find the two approaches to be similar, but prefer Ball's design, as it was created specifically to analyze plays. I will then describe and analyze the differences between the two sets of cardinal functions, followed by the specific enunciation choices made in each work. This will illuminate authorial choices made to appeal to audiences in 
two very different times and spaces and may also illuminate important changes in the messages delivered by the plays or the ways that audiences understand them through their unique intertextual webs.

Hutcheon also presents practical questions for consideration in $A$ Theory of Adaptation. She breaks down her questioning about adaptation into several categories named after the five Ws: who, what, when, where, why, and how ${ }^{8}$."What" refers to medium specificity and the kind of storytelling that applies best in novels vs. films. Though this dissertation looks at intramedial adaptations, the prevalence of television in recent years has changed the theatrical form and elements of this "what" shift can therefore still be seen in these adaptations. "Who" and "Why" are grouped together in a discussion of adapters and their motivations, which ties back to the idea of positionality and benefits discussed in the justification portion of this chapter. "How" discusses how adapters communicate with audiences and the differences between audiences who are and are not aware of the original text. As such, this chapter and the following chapter, which covers "where" and "when," rely the most on intertextuality. The chapter titled "Where? When?" deals specifically with transcultural ${ }^{9}$ adaptation, a discussion which clearly applies to this dissertation.

In this dissertation, I will investigate, in varying degrees of specificity, how these practical applications apply to each of these three adaptations, including how I apply them actively in my own. Hutcheon's five Ws provide a helpful structure and theoretical grounding for working with intertextuality, and I use that structure to analyze and investigate the intertextual world in which each of these plays was created. Gender plays a

\footnotetext{
${ }^{8}$ Yes, the five Ws include a sixth word that begins with an $h$.

${ }^{9}$ Or intercultural, to use Laera's term
} 
prominent role in each of these playwrights' work, even Calderón. The characters of Ana in Los empeños de una casa, Fenisa in La traición en la amistad, and Rosaura in La vida es sueño are each strong and interesting, but clearly feminine, women who are likely to be interpreted by seventeenth- and twenty-first-century audiences in very different ways. I will look at ways that these characters and others are in conversation with Spanish Golden Age concerns about gender and propriety, some of which I believe are satirized in both the original plays and their adaptations, and I will discuss how my adaptation continues those themes of satirization in order to effectively use the audience's intertextual understanding.

I will use Hutcheon and McFarlane's techniques, along with other intertextual and dramaturgical theories, to illustrate the effectiveness of dramaturgy and adaptation studies working in collaboration to investigate and analyze these theatrical adapted works and the cultural considerations involved in creating them. I will look at Svich's work as a new play dramaturg and Callaghan's work as a director using production dramaturgy to show the nuance that these approaches bring to adaptation theory. I will then apply those theories in an adaptation of my own. Adaptation studies, for its part, highlights the intertextual context that led to the creation of A Little Betrayal Among Friends and Fever/Dream. These intentions may also be inflected by gynocriticism, especially since most of the playwrights discussed in this dissertation are women who are also writing about female characters part of what makes these plays so attractive for contemporary productions. Knowing how other playwrights and audiences have responded to adaptations of Spanish Golden Age plays will shed light on the choices made by Svich and Callaghan and can help me make more effective choices as an adapter myself. 


\section{Intersectional Feminism}

Since all these texts are adapted by women, and two of the three original works are written by women as well, I will also incorporate aspects of a feminist branch of intertextual semiotics: gynocriticism. Elaine Showalter coined this term and elaborates on it in “Towards a Feminist Poetics," saying "gynocritics begins at the point when we free ourselves from the linear absolutes of male literary history, stop trying to fit women between the lines of the male tradition, and focus instead on the newly visible world of female culture." While the gender binary is proving to be a concept that lacks nuance and excludes many, I do feel that there is strength in individuals of underrepresented genders bringing their predecessors' work to light. Consideration should also be made to represent women and people of other underrepresented genders in a way that does not perpetuate harm in contemporary society, even if this means changing the original text. With that work, gynocriticism also encourages a questioning of the literary canon and has led to comparisons of femme characters across the barriers of space and time, a concept which bridges the gap between Adaptation Studies 2.0 and Adaptation Studies 3.0 in this context. This dissertation seeks to add to that conversation and to encourage a practical application of gynocritical ideas through these refracted adaptations of work by people of underrepresented genders in the theatre.

Showalter's work focuses not on women's work in relation to men's work, but on women's work in relation to itself throughout time. In "Towards a Feminist Poetics" (again, published in 1979) she divides women's writing up into three main eras: the Feminine (1820-1840), the Feminist (1880-1920), and the Female (1920 and later) eras. Though the Feminine era begins later than the Spanish Golden Age, the playwrights in this dissertation 
clearly associate more closely with it than with the other two eras, as they write characters who conform to traditionally feminine traits and try to write in styles and themes that are similar to the ways that men were writing at the time. However, the female adapters studied in this dissertation certainly are not hindered by loyalty to masculine formulas or characters, though these adaptations may not be the best examples of the dramatic ingenuity of the source texts. They can, instead, be looked at through a much more intersectional lens, as both the original playwrights and their adapters have been influenced by their own unique cultures and identities. In the case of these adaptations, the playwrights' relationship to Spanish culture is especially relevant and is, I would argue, more relevant than their relationship to patriarchal expectations.

Debra Castillo's organization of women's work illuminates some patterns that appear when, as Showalter suggests, women's work is compared with other women's work. Castillo calls these "literary strategies," and they apply well to early women writers like Sor Juana and Zayas. These strategies are silence, appropriation, cultivation of superficiality, negation, writing from a position of marginality; and the subjunctive mood (LaGreca, 383). Several of these patterns can be seen in the seventeenth-century pieces I include in this dissertation, and the rejection of these patterns is both clear and meaningful in their adaptations. As such, I will look for shifts in these moods and themes when I compare the plot points of the original plays and their adaptations. The integration of the Latinx lens with feminist study through Castillo's theory offers insight into the complex intersectionality negotiated by these plays.

\section{Postcolonial Translation Studies and Decoloniality}


While I enjoy the work of adapting seventeenth-century Spanish plays to speak to a twenty-first-century US audience, my position as a White, non-Hispanic woman requires me to carefully consider the harm that my work may be doing to the very communities that I hope to inspire with this project. As such, I will consider theories coming from postcolonial translation studies and decoloniality as counterarguments to my work throughout this dissertation.

While this dissertation deals with adaptation and not translation, all these adaptations are inter-lingual, which makes them translations as well as adaptations. A typical problem arising in postcolonial translation again reflects the conversation about positionality discussed earlier in this prospectus. Jeremy Munday writes that "the central intersection of translation studies and postcolonial theory is that of power relations" (210). Translation into English reinforces the idea that English is the standard global language and that other languages are inferior. Often things that make a global work unique are stripped away in translation and all translations end up conforming to what Munday calls a poetics of translation rather than reflecting the poetics of the document's source country. One of the primary theorists focusing on postcolonial translation is Tejaswini Niranjana who, according to Munday, believes that "translation into English has generally been used by the colonial power to construct a rewritten image of the 'East' that has come to stand for the truth" (210). In this colonized version of the 'East,' many religious beliefs were translated into Christian/Catholic beliefs, the concept of the author shifted to a more European perspective, and many of the supernatural or poetic aspects of the text were sanded over in favor of safer images and language. Decolonial theory has noticed the same trends in knowledge production in general and has pushed back against them. 
Researchers like Aníbal Quijano, Sonia Therborn, and Walter D. Mignolo, among others, have suggested that the production and semiotics of knowledge become decolonialized in the twenty-first century, a time that should be well past the issues of colonialization. As Mignolo points out in "The Geopolitics of Knowledge and the Colonial Difference," "It is no longer possible, or at least it is not unproblematic, to 'think' from the canon of Western philosophy, even when part of the canon is critical of modernity. To do so means to reproduce the blind epistemic ethnocentrism that makes difficult, if not impossible, any political philosophy of inclusion" (66). With this criticism, Mignolo suggests that the theories of knowledge that are taken for granted as staples of Euro-centric philosophy, including Aristotle's Poetics and the traditional literary canon, be supplemented by theorists and knowledge-producers from colonized places. Society has moved forward under the assumption that the knowledge created by colonizers is the only correct knowledge, leading to a colonization that is not only physical and economic but becomes intellectual and spiritual as well. Aníbal Quijano explains the basic premise of decolonialism in "Coloniality And Modernity/ Rationality" thus: "The cultural repression and the massive genocide together turned the previous high cultures of America into illiterate, peasant subcultures condemned to orality; that is, deprived of their own patterns of formalized, objectivized, intellectual, and plastic or visual expression" (170). Decoloniality, therefore, encourages the use of previously buried knowledge, expanding both the literary canon and the theoretical canon.

Though these plays come from Spanish culture, a colonizing power, they are adapted to American culture and influenced by work that comes from the Americas. Sor Juana specifically validated indigenous religions in her Loa al divino Narciso and includes 
references to indigenous culture in Los empeños de una casa. Svich's theories also reflect this decolonial view. Svich actively criticizes the phrase "Magical Realism" in an interview with Quiara Alegría Hudes, pointing out that what European colonizers called "magic" was simply reality for people from Latin American indigenous cultures ${ }^{10}$ (ironically, Callaghan's Fever/Dream fits more cleanly under the generally acknowledged aesthetic style of Magical Realism than Svich's A Little Betrayal Among Friends). I interviewed Svich about her adaptation process in order to center and valorize her thoughts over colonial theorists. I will also address articles that are critical of the production of these plays in English such as "Who's Afraid of Sor Juana Inés de La Cruz? Transatlantic Performances of Los empeños de una casa (The House of Desires)" by Esther Fernández and "Translation as Erasure: Thoughts on Modernity's Epistemic Violence," by Rolando Vázquez. In this way, I hope to apply decolonial theory and maintain awareness of my own power and privilege in this dissertation.

\section{Overall Justification}

Through my investigation of these three adapted plays, I will illuminate the practical and theoretical considerations necessary to successfully negotiate intercultural and intertemporal adaptation. In order to effectively look at each aspect of adapturgy in this context, I will build on the theories in each one but use slightly different approaches throughout. I will begin with a more traditional adaptation studies and intertextuality-based approach paired with script analysis techniques typical of new play dramaturgy. These techniques will be applied to La traición en la amistad and A Little Betrayal Among Friends

\footnotetext{
${ }^{10}$ This criticism is also echoed in The Fornés Frame.
} 
to illuminate the different choices made by two dramatists. I will then build on those intertextual techniques and discuss how a dramaturg would bring that intertextual context to an audience through production dramaturgy. I will show this through a reflection of my experience directing Fever/Dream and the excellent dramaturgical work of my own production dramaturg, Taylor Sklenar. Finally, I will reflect on my own adaptation process in the creation of both How to Build a Noble House and With the Temptation, A Way of Escape, demonstrating a practical application of all of these theories. I will use the standard dramaturgical questions why this play now? and what were the artists trying to do? were they successful? was it worth doing? to offer context and structure to the beginning of each chapter.

\section{Literature Review}

The fact that this particular combination of artistic application and theoretical context comes out of the University of Missouri (MU) is no accident, as students and faculty at this institution are encouraged to embrace the title of artist/scholar, a combination which allows for more thorough, engaged, and well-informed approaches to scholarship. These plays have been studied, translated, and even adapted in other versions, but these adaptations are the only inter-temporal adaptations I was able to find that brought Spanish Golden Age stories forward into the twenty-first century. Additionally, all three adapters in this dissertation are women and two of the three Spanish Golden Age playwrights are as well. Research on women's work has been underrepresented in the academy and on stages in general. I hope that this dissertation will add some representation to both of those spaces as well. In order to do so, this project will take advantage of my overlapping skills in theatre 
and performance studies, and romance languages and will allow me to apply them alongside theories from adaptation studies.

\section{Dramaturgy and Performance Practice}

The dramaturg's role in US theatre is both new and ill-defined. Dramaturgs serve many roles in theatre companies and as independent artists, as is shown by the variety of essays collected in The Routledge Companion to Dramaturgy, edited by Magda Romanska. This book includes Elinor Fuchs" "Visit to a Small Planet," a source of many questions that I will use to interrogate these adaptations. This dissertation's research is situated alongside sections in this tome which include "Dramaturgy in the Age of Globalization" and, significantly, "Dramaturg as Mediator and Context Manager: Transculturalism, Translation, Adaptation, and Contextualization," as both the dissertation and these articles deal with global theatrical influences and communicating texts from one culture to another. These articles offer practical descriptions of the processes dramaturgs go through to work with said translations and adaptations and the challenges that go along with them, especially Jane Barnette's “Literary Adaptation for the Stage: A Primer for Adaptation Dramaturgs." Barnette also wrote an extended work detailing the relationship between dramaturgy and adaptation entitled Adapturgy: The Dramaturg's Art and Theatrical Adaptation, which details a specifically dramaturgical approach to adaptation and supports my theory that dramaturgical questioning should be incorporated into Adaptation Studies 3.0. Barnette's strategies may prove useful as supplementary tools and contexts for this dissertation as well. 
Other playwriting books have informed my dramaturgical practice and will likewise inform my approach to this project. Specifically, David Ball's book Backwards and Forwards: A Technical Manual for Reading Plays suggests an approach to play structure that is similar to McFarlane's methods outlined in Novel to Film, so my approach to identifying McFarlane's cardinal functions is influenced by Ball's strategy of backward reading. As I have mentioned, Chemers uses the term Major Dramatic Question to refer to the primary through line that defines the plot of a play. I will actively use these theories in my analysis of the modern adaptations in this dissertation, but I have also been influenced by play analysis theories from The Playwright's Guidebook by Stuart Spencer, The Art and Craft of Playwriting by Jeffrey Hatcher, and Playwriting in Process: Thinking and Working Theatrically by Michael Wright. The methods that I applied in readings of my own adaptation focus on asking open-ended questions of the audience and actors and on approaching the process of new play development with an eye to revisions that make the play more accessible and engaging based on the reading and reactions from these groups. These come primarily from my own practice but also come from David Kahn and Donna Breed's book Scriptwork: A Director's Approach to New Play Development and New Play Development: Facilitating Creativity for Dramaturgs, Playwrights, and Everyone Else by Lenora Inez Brown. All of these are practical texts designed for playwrights, however, and none of them apply their theories to the adaptation of Spanish Golden Age plays. This dissertation will seek to apply these theories to Spanish Golden Age plays, which have received more and more scholarly and popular interest in recent years.

\section{Spanish Golden Age Translations}


Despite the lack of representation for the Spanish Golden Age in books and articles about theatrical adaptation, the plethora of recently published play anthologies suggests that the world is clamoring for more pieces to fill previously unnoticed exclusions from the canon. Dramas of Distinction: A Study of Plays by Golden Age Women (1997) by Teresa Scott Soufas collects several plays by women in Spanish with classroom-friendly informative introductions to each one and is accompanied by another analytical book, making scholarly engagement even easier. Newer books, like Feliciana Enríquez de Guzmán, Ana Caro Mallén, and Sor Marcela de San Félix: Women Playwrights of Early Modern Spain (2016) translated and annotated by Harley Erdman, and The Golden Age of Spanish Drama: New Translations, Backgrounds and Contexts, Criticism (2018) translated by G. J. Racz and edited by Barbara Fuchs provide translations of plays by women, though The Golden Age of Spanish Drama focuses less on the gender of its playwrights than it does on simply presenting diverse works for its audience. Again, brief introductions are included in both books, providing context for classrooms and scholars seeking to expand their literary contexts. While these books include some plays that have already been translated, many of the plays by women specifically find only their first or second translations in these volumes.

These plays specifically have each had at least one prior translation, though only La vida es sueño has another well-known adaptation that is easily accessible. David Pasto claims the first translation of Los empeños de una casa, The House of Trials, in 1997. It was also translated as Pawns of a House in 2005 by Michael McGaha in an edition edited by Susana Hernandez Araico and in that same year the Royal Shakespeare Company published the script used for their production, which was translated by Catherine Boyle as 
The House of Desires. The most recent published translation is by R.C. Racz in a book edited by Barbara Fuchs and is titled The Trials of a Noble House. The only available translation of La traición en la amistad that I was able to find is a 1999 translation by Catherine Larson titled Friendship Betrayed, a disappointing oversight which Svich luckily supplements. La vida es sueño, on the other hand, has been translated often, the first of which was a partial translation in 1856 by Richard Chevenix Trench. Pulitzer Prizewinning playwright Nilo Cruz also created a translation in 2007 that is quite poetic and performable - it is published through Dramatists Play Service, one of the leading publishers of theatrical performance scripts. Obie award-winning Latino playwright José Rivera created the most popular adaptation of Calderón's play, which is simply titled Sueño, in 1999. The popularity of La vida es sueño's translations and productions suggests that there is a market for translations and adaptations of Spanish Golden Age plays, but there is still a dearth of scholarship and artistic work devoted to the other two adaptations featured in this dissertation. While the genre of the three plays is different (possibly because Calderón had more flexibility of genre due to his gender), I believe that comedic cloak-and-dagger plays like La traición en la amistad and Los empeños de una casa have a place on US stages and in US scholarship alongside more dramatic and surreal works like La vida es sueño.

As I have mentioned, there is some interest in the performance of Spanish Golden Age plays in English as well. Catherine Boyle, David Johnston, and Janet Morris have also written essays describing the experiences of those working with the Royal Shakespeare Company to produce Spanish Golden Age plays in their book, The Spanish Golden Age in English: Perspectives on Performance. While this book offers theoretical insight, that 
insight is based on practical application and is clearly created by other scholar/artists. Similarly, the stated goal of UCLA's "Diversifying the Classics," program supports the goals of this dissertation as well:

"Diversifying the Classics" promotes the vibrant, Spanish-language theatrical tradition developed on both sides of the Atlantic by playwrights such as Spaniards Lope de Vega and Calderón de la Barca, or Mexicans Ruiz de Alarcón and Sor Juana Inés de la Cruz. The project seeks to foster awareness and appreciation of Hispanic classical theater in Los Angeles and beyond, expanding the canon to include the heritage of US Latino communities. While our work is based in Los Angeles, we hope to reach theater professionals and audiences across the US, offering them the materials and tools to explore the rich tradition of the comedia. (http://diversifyingtheclassics.humanities.ucla.edu/home-2-2-2/home-2-2/)

Both programs focused primarily on translations of Spanish Golden Age plays as opposed to the adaptations discussed in this dissertation, which move the piece in space and time. However, as I have mentioned, performance can be considered adaptation in and of itself, and these performances are examples of intermedial script-to-stage adaptations.

In addition to dramaturgy and dramatic analysis, research on the Spanish Golden Age sometimes overlaps with performance studies. For example, Harley Erdman and Susan Paun de García’s book Remaking the Comedia: Spanish Classical Theatre in Adaptation pays fresh attention to Spanish Golden Age plays through the eyes of comedia scholars who, as Catherine Larson points out in her introduction, "have also developed everincreasing interest and expertise in discussing the performance of classical texts" (3). Similarly, Performance Reconstruction and Spanish Golden Age Drama: Reviving and 
Revising the Comedia by Laura L. Vidler encourages theorists in performance studies to continue pursuing research on the Spanish Golden Age, and on the performance of this era today. These texts explore the idea of performance through a historical lens, which is fascinating, but as a dramaturg and theatre practitioner, my work will investigate Golden Age adaptations from the contemporary performance perspective that begins to take shape in Boyle et. al. I will take Boyle's justification of adapted plays for the twenty-first century one step further by investigating intercultural and intertemporal adaptations which have made both cultural and temporal changes to become more engaging to their audiences.

\section{Dramatic Adaptation}

The theatre has a long history of using adaptations both to share important cultural stories and to "get butts in seats" as it were, since audiences are more likely to come see a production for which they recognize the title. As such, there is plenty of research on theatrical adaptation and its various forms. However, Spanish Golden Age plays have, for the most part, not been included in this adaptation analysis, as books and articles focusing on theatrical adaptations are typically practical guides focused on adaptation in both theatre and film, discussions of intermedial adaptations of literature outside of theatre, or collections of articles about adapted productions which rarely ${ }^{11}$ feature Spanish Golden Age plays.

There is no doubt that staging adaptations is lucrative -- an article by Emma Halpern in American Theatre magazine refers to 'the tyranny of the title' in Theatre for Young Audiences, stating that plays with well-known titles sometimes seem to be the only ones

\footnotetext{
${ }^{11}$ With the notable exception of Boyle and Johnston's The Spanish Golden Age in English, which I have already discussed briefly
} 
getting produced - which may be what leads to the publication of several textbooks about theatrical adaptation geared toward practical, descriptive explanations of how it should be done. For example, Theatrical Translation and Film Adaptation: A Practitioner's View by Phyllis Zatlin offers a variety of practical applications for playwriting and screenwriting students working on their own adaptations, including pieces that are obviously directly related to adaptation such as "Practical Approaches to Translating Theatre" and other, more general suggestions, including "Networking: Collaborative Ventures." The line between translation and adaptation is thin in this book, as it is in many places, so the theories here include those from both adaptation and translation theory. Similarly, but on a more academic note, Mary Ellen Wright's dissertation, Adrian Hall's Dramatic Adaptations: A Playwriting Process And Model describes a pedagogical approach to adaptation. There is certainly theoretical support, but the primary goal of these theories is still adaptation pedagogy. Another playwriting book, Page to Stage: The Craft of Adaptation by Vincent Murphy, shows even in its title that it is both focused on teaching play adaptation and that it assumes that those adaptations will be intermedial, coming from novels, poetry, or other sources.

Like Page to Stage, many books and articles focus on intermedial adaptations rather than intramedial ones, like the three studied in this dissertation. Linda Hutcheon's A Theory of Adaptation is one of these books, though it focuses on adaptations in general and approaches theatrical adaptations specifically in something of a roundabout way. The adapted script she focuses most on is His Dark Materials by Nicholas Wright which is adapted from a trilogy of complex fantasy novels by Philip Pullman, an incredibly difficult source to adapt for the stage. Hutcheon is convinced of its merit, but the script does not 
seem to have had notable productions beyond the original at the Olivier Theater in London, which I would argue makes it a less-than-ideal example ${ }^{12}$. While Hutcheon's theories about adaptation in general are insightful and well-respected in the field, her take on theatre specifically seems to lack familiarity with the field. The other theoretical book that this dissertation depends on, Novel to Film: An Introduction to the Theory of Adaptation by Brian McFarlane, makes no attempt to include the theatre in its theories, though those theories can be applied to theatrical works as well as films. Other works that have analyzed intermedial adaptations include Janice Balodis's 2012 dissertation, The Practice Of Adaptation: Turning Fact And Fiction Into Theatre, which includes helpful examples of theoretical lenses but ultimately focuses on Balodis's own adaptation of a novel (Perfect Skin by Nick Earls), and ethnographic research and not on adaptations of other plays. Translation and Adaptation in Theatre and Film, edited by Katja Krebs, combines media not only in the source material for the adaptations it studies but also in the result of those studies, and it includes several case studies in its final section that choose to focus on adapted works outside of the Spanish Golden Age. Similarly, Contemporary Approaches to Adaptation in Theatre, edited by Kara Reilly, includes a variety of chapters about different adaptations, but many of these focus on intermedial adaptations as well, including an entire section titled "Re-mediating the Book to the Stage."

Like most books on intramedial adaptation, Contemporary Approaches to Adaptation in Theatre focuses primarily on adapting plays that fit securely into the canon, but it does also include a couple of chapters on intramedial adaptations. In Contemporary Approaches, this means a section titled "Reinscribing the Other in Contemporary

\footnotetext{
${ }^{12}$ In my opinion, it is also too complex and focused on spectacle, lacking in the complex dialogue, focus on character, and suspension of disbelief that make theatre unique.
} 
Adaptations of Greek Tragedy" and specific chapters about the work of Eugene O'Neill and, of course, Shakespeare. A thorough investigation of adaptations of Shakespeare's work is also available in Interlinguicity, Internationality, and Shakespeare, edited by Michael Saenger, and the Bard's work permeates Laera's Theatre and Adaptation as well, though it is supplemented by chapters about newer work like War Horse and The Curious Incident of the Dog in the Nighttime. Volume $66^{13}$ of the Theatre Journal was dedicated to "Theatre and Adaptation" as well, but, given the nature of the journal, it was split up into articles and reviews about various scripts as well, though some, like Katja Krebs' article "Ghosts We Have Seen Before: Trends in Adaptation in Contemporary Performance," merged this review of other plays with theory, and Bethany Wood's article in this issue, "Gentlemen Prefer Adaptations: Addressing Industry and Gender in Adaptation Studies," offers valuable insight into the field of adaptation studies.

Production dramaturgy also sheds light on how other theatre makers have interacted with adaptations of Spanish Golden Age plays in the past to inform my own adaptation work. Several helpful books exist on this subject, including Margherita Laera's Theatre and Adaptation: Return, Rewrite, Repeat, which outlines various adaptation projects from around the world, many of which deal with Shakespeare, providing a classical theatre perspective, and with world drama, providing a perspective which moves beyond the traditional canon and challenges audiences' intertextual expectations. Catherine Boyle and David Johnston also published The Spanish Golden Age in English: Perspectives on Performance, which is a set of essays from theatre-makers staging Spanish Golden Age plays in England, inspired by the Royal Shakespeare Company's staging process. This

\footnotetext{
${ }^{13}$ December 2014
} 
process was thoughtfully conceived and implemented, and insight into the inner workings of their festival will illuminate my research as well. Similarly, the University of California, Los Angeles (UCLA) has an ongoing program called Diversifying the Classics, spearheaded by Barbara Fuchs, which encourages the production of Spanish Golden Age plays in English.

\section{Intertextuality}

Since theorists have, for the most part, moved past the comparative structure of Adaptation Studies 1.0, the first focus in this dissertation will be on Adaptation Studies 2.0 with its focus on both intertextuality and practical suggestions and the future of Adaptation Studies 3.0, especially where it overlaps with and could learn from dramaturgical practice. As I have mentioned, Linda Hutcheon's theories on intertextuality and genre shaped Adaptation Studies 2.0 in many ways. A Theory of Adaptation has a focus on genre and the mediums through which stories are told, which is particularly illuminating in today's age of television and technology. Film and TV structures have greatly influenced the way that playwrights think and write, and theatre has ways to be interactive that novels and film do not. Hutcheon considers this interactivity to be a strength primarily of video games, but in doing so I think that she discounts one of theatre's greatest strengths. Hutcheon also outlines the influence of intertextuality, invoking the image of a palimpsest, or an erased but still visible image on a piece of paper, to help readers understand an audience's experience of seeing an adapted text when they are aware of the original piece. By drawing on specific contemporary settings, Callaghan and Svich create palimpsests that not only connect with the original texts but also draw in specific audiences. 
Hutcheon also draws deeply on Mikhail Bakhtin and Julia Kristeva's theory of intertextuality. Both of these theorists worked in semiotics and therefore analyzed literary work on the level of individual words/signifiers and their relationship to their signified objects. In theatrical adaptations, this relationship becomes quite complicated, as in an example that Kristeva herself points out, using theatre as an example of carnivalesque structure in which the signifier is separated from the thing it signifies by multiple authorial perspectives which may, in this case, include the original playwright, the adapter, and the creative team and actors involved in each individual production. Kristeva's 'subject of utterance' and 'subject of enunciation' become complicated in this context as well. The 'subject of utterance' is the person creating meaning through an utterance in the presence of their hearer, but in a theatrical context, an actor may embody this 'subject of utterance' even though they are not, themselves, the person who wrote those words. That person - the 'subject of enunciation' -- is removed from the production in time and location. In this dissertation, I will investigate the various layers of meaning added, lost, or maintained at each of these levels to disentangle the possible web of intertextual connections surrounding these texts.

Several books were helpful in understanding the context in which the Spanish Golden Age plays were written. Gender, Identity, and Representation in Spain's Golden Age edited by Anita K. Stoll and Dawn L. Smith offers a variety of perspectives on the titular topic. The introduction to this book offers a clear overview of the topic, as do W.B. Worthen's ever-consistent entries in general theatre history textbooks. Robert Bayliss offers context for the ways the hierarchy of the Spanish courts is portrayed in The Discourse of Courtly Love in Seventeenth-Century Spanish Theater. This courtly love is 
also clearly portrayed in the plays of this era themselves, several of which are catalogued and analyzed in Teresa Scott Soufas's books, Women's Acts, which anthologizes a number of Spanish Golden Age plays specifically by women. The introductions in this book and the accompanying analysis in Scott Soufas's book Dramas of Distinction illustrate many of the challenges specific to Spanish Golden Age women, including a description of the specific privileges women needed access to in order to become a playwright at that time.

Much has been written, both historically and through some fictionalization, about Sor Juana's life specifically. For this dissertation, I relied primarily on Octavio Paz's 1983 biography, Sor Juana Inés de la Cruz, o, Las trampas de la fe. Paz gives Sor Juana more agency than many other writers, including making a case for her co-authorship of two other seventeenth-century plays, La segunda Celestina, which is normally attributed to Agustín de Salazar y Torres, and Amor es más laberinto, which she co-authored with Fray Juan de Guevara. While Paz includes useful digging into Sor Juana's biography, Stephanie Merrim offers insight into her work from a solely literary perspective in Early Modern Women's Writing and Sor Juana Inés de la Cruz, which offered helpful context surrounding the other women's work of the era and the restrictions placed on women writers' roles in polite society. Sor Juana has also become something more than herself in the time since her tragic death in 1695. Popular culture has picked up her narrative as a scholar before women were allowed to be scholars who fought back against the double standards of her time and was eventually punished for it. There are also theories that Sor Juana may have had same-sex lovers, or at least attractions, though there is very little concrete evidence for these theories. While this fictionalized version of Sor Juana may or may not have much to do with the actual woman, it is relevant to contemporary audiences' view of her work. Thus, popular 
films and series about Sor Juana's life like Yo, peor de todas directed by María Luisa Bemberg and Juana Inés, directed by Patricia Arriaga-Jordán offer insight into this popularized version of the iconic playwright and poet.

\section{The Literature as a Whole}

Though there is clear interest in each of these realms of study, the fact remains that the adaptations highlighted in this study have not yet been the focus of scholarly research, despite their value, as established in the justification section of this document. There is clear interest in additional research on the Spanish Golden Age, based on the many recent publications from that era and the renewed interest in diversifying the literary canon and the performances on US stages. Likewise, both adaptation studies and dramaturgy are relatively new fields in which new research is continually developed, and both suggest creating a canon of questions rather than a canon of works. Continuing to bring these two fields together, as Barnette does in Adapturgy, will benefit both areas of study. Further, their application to Spanish Golden Age adaptations will prove their efficacy as it validates the plays themselves.

\section{Organization}

Through the combination of these varied theories, I will create a new approach to classical literature based on Barnette's example. As I have mentioned, the adaptations that I chose to focus on in this dissertation are written by women who I believe deserve wider recognition in the field of dramatic literature, just as I believe that these original plays also deserve more recognition. Through the following chapters, I will apply knowledge and 
theories gleaned from Adaptation Studies 2.0, Adaptation Studies 3.0, and dramaturgical analysis in order to illuminate the process and product of Callaghan's Fever/Dream and Svich's A Little Betrayal Among Friends and effectively and reflexively create my own intercultural and intertemporal adaptation of Sor Juana's exciting comedy, Los empeños de una casa.

Chapter One includes an outline of the methods I use throughout the dissertation and also discusses the state of the literature in both adaptation studies and dramaturgy as of 2021. This chapter establishes a basis and background for the work applied throughout the paper and most importantly, from an ethical point of view, allows me to establish and discuss my own positionality in relation to the source materials and adapted works I discuss throughout the dissertation. I also discuss ways in which I tried to mediate my biases through traditional research routes along with intersectional feminist and decolonial research strategies. This kind of acknowledgement of privilege is important for researchers working outside of their own cultures, as it can inform the decisions made throughout the dissertation with the tools to do more good than harm through intercultural adaptation.

Chapter Two focuses on the dissertation's most experienced adaptor, Caridad Svich. In this chapter, I analyze her process of adaptation in creating A Little Betrayal Among Friends from María de Zayas y Sotomayor's play La traición en la amistad. I look at these two texts primarily through the tools of adaptation studies and dramaturgical tools which run parallel. As I have already mentioned, McFarlane's cardinal functions and Ball's action units work together quite nicely here. After breaking down the two scripts through these methods, I am able to look at the intertextual implications of each and highlight the changes that Svich made in her adaptation. I use an interview with Svich to talk about the 
methodology and justification behind her choices and find that women's voices, while they were stronger in Zayas's work than in many other Spanish Golden Age plays, are allowed to be more nuanced in Svich's adaptation.

In Chapter Three, I look at the role of production dramaturgy on the production of Fever/Dream that I directed for the University of Missouri in 2018. This is an adaptation of La vida es sueño by Pedro Calderón de la Barca, one of the most produced Spanish Golden Age plays. I first look at the choice to produce the play through the lens of core dramaturgical questions, which I believe might serve well as canonical questions for adaptation studies as well. I then describe the adapturgical choices and actions that went into contextualizing Fever/Dream for a mid-Missouri audience, many of whom were not familiar with La vida es sueño. I was able to make intersectional feminist choices in the casting and production of this play, and I believe that the result was a piece that interacted with the Spanish Golden Age while simultaneously offering visibility for marginalized people in the twenty-first century.

In Chapter Four, discuss my own adaptation of Sor Juana's Los empeños de una casa, using my chosen canon of questions. I begin with the dramaturgical questions I explored in Chapter Three and then move on to use the adaptation studies methodology used in Chapter Two to complete my adaptation, thus tying together all of the aspects of adapturgy in one project. To complete this project, I ended up producing both an adaptation and an abridged translation of Los empeños de una casa. This way, I was able to maintain the unique aspects of the original work and avoid some colonization in one version while also exploring themes and social issues that are important to twenty-first-century audience in the other. I hope that having both available will allow people seeing one piece to learn 
about the other and will demonstrate that I have taken the time to thoroughly understand the source text before adapting it. Chapters Five and Six contain the text of How to Build a Noble House, my translation, and With the Temptation, a Way of Escape, my adaptation, respectively. Each has a short introduction outlining my translation and adaptation process and the special considerations I had to make for each one specifically. This reflection demonstrates the level of thought that must go into the process of adapting a piece from another culture.

Finally, in Chapter Seven I reflect on the adaptation process overall and the different ethical considerations that Svich, Callaghan, and I each took into account when creating and presenting these intercultural scripts for a twenty-first century US audience. While the more practical parts of each process are described throughout the dissertation, this chapter looks at the adapter's attempt to do no harm in the creation of their adaptation, which may mean preserving parts of the original text that make it unique or it may mean changing relationships or representations which could be harmful to perpetuate in the twenty-first century. I borrow some considerations from comedy writing as well as adaptation studies and dramaturgy, of course.

\section{Conclusion}

This example of adapturgical investigation will, I hope, encourage the reader to consider the ideal canon of questions for adaptation scholars of the future. Insofar as a literary canon is still necessary and entrenched, this will also, I hope, create interest in expanding what is included in that canon and how Barnette's Adapturgy offers a useful expansion of Leitch's Adaptation Studies 3.0. The questions gleaned from this 
dramaturgical study will support the theories from adaptation studies admirably, and the practical applications of dramaturgy can also supplement adaptation studies and offer a wider variety of methodology to a new generation of adaptation studies scholars. The adaptations within this dissertation may create many more opportunities for people of all genders and origins to find their place in classrooms and onstage, giving the world a more diverse set of stories and a more nuanced understanding of the world, we live in. With this lofty goal in mind, let us investigate its application in the world of the specific, starting with A Little Betrayal Among Friends. 


\section{Chapter 2}

\section{Preserving the Unusual in A Little Betrayal Among Friends}


Caridad Svich is one of the most prolific translator/adaptors of Spanish-language plays who is still working and writing today. According to her website and New Play Exchange page, she has translated eleven plays by Federico Garcia Lorca, as well as at least one by Alberto Pedro, Abilio Estevez, Pedro Calderón de la Barca, Silvia Pelaez, Antonio Buero Vallejo, Rene Marquez, Lope de Vega, and, of course, María de Zayas. Similarly, she has adapted at least six novels into plays, including Isabel Allende's famous House of the Spirits and Julia Álvarez's In the Time of the Butterflies, and her New Play Exchange page includes one Shakespeare adaptation - King Henry VIII. She has also published six anthologies of adapted plays: Blasted Heavens: Five Contemporary Plays Inspired by the Greeks; Federico Garcia Lorca: Impossible Theater - Five Plays and Thirteen Poems; Lorca: Six Major Plays; Lorca: Major Plays Volumes I \& II; and Caridad Svich: The Spanish Golden Age Plays, which contains the play that I will be investigating here, A Little Betrayal Among Friends. She has also seen many of these adaptations produced and has become so well-known for adapting Spanish-language work that she was commissioned for at least five of these adaptations by educational and regional theatres alike. This makes her a staple of Spanish-language adaptations, and an excellent beginning for my investigation into the adapturgy of plays adapting the Spanish Golden Age.

A Little Betrayal Among Friends is also an example of a play that was originally written by a woman which has also been adapted for twenty-first century audience by a woman. It contains several excellent roles for women, and in both adaptations, women drive the action of the story. This serves as a direct contrast to many canonical plays by men, which center on men's experiences and concerns. Zayas is careful to center the story on female friendship rather than only on heterosexual coupling (though that is certainly 
present), and the way the characters are written seems almost disdainful of men and certainly highlights the double standards to which women are held. Its plot and subplots interact in complex and sometimes confusing ways, and the action spans over three acts, which is typical of the Spanish Golden Age, but hardly normal in US theatre today. Like many sixteenth and seventeenth century plays, it revolves around strict gender and sexual roles, letter-writing, servants who provide comedic relief, and it ends in the requisite quadruple engagement. While many of these things do not transfer well to twenty-first century society, with its cell phones and more relaxed societal norms, Svich handles the challenge of adapting this story for a contemporary audience with finesse, including making significant cuts to make it conform to a more typical twenty-first century run time.

My first task in studying the relationship between Svich's adaptation and Zayas's original script is to investigate the core structure of each play individually in order to understand the meaning behind things that were preserved or changes in the adaptation of Zayas's story. As I mentioned in Chapter 1, comparison studies lacks nuance and has long been dismissed in adaptation studies circles in favor of theories centered around intertextuality and the audience and author's experience of the text. However, in this case the comparison will, I believe, be valuable on both an adaptation studies level and on a dramaturgical level. Understanding Svich's adaptive choices is important in understanding the intertextual connections that will be made by contemporary audiences, and script analysis falls well within the role of a dramaturg, especially one working with new plays and adaptations. As such, I will use a combined analysis based on Brian McFarlane's adaptation work described in Novel to Film and David Ball's script analysis strategies 
described in Backwards and Forwards. This combined approach will offer an adapturgical approach to my analysis of A Little Betrayal Among Friends.

\section{Cardinal Functions}

McFarlane serves as one of the core members of what Thomas Leitch calls "Adaptation Studies 2.0," the generation of adaptation scholars who rejected comparison theory in adaptation studies, however, he also describes and uses a very comparative methodology in Novel to Film. In doing so, McFarlane shows that comparative analysis can be used as a jumping-off point for deeper analysis. This theory is based in Roland Barthes' description of narrative functions, which are the core ideas that make up a story. As McFarlane puts it, "they are 'horizontal' in nature, and they are strung together linearly throughout the text; they have to do with 'operations'; they refer to a functionality of doing” (13). These events make up the story in a piece, and McFarlane suggests that they are the only elements that are transferrable to other mediums (though I am discussing an intramedial adaptation in this case). In addition, cardinal functions occur at turning points in the narrative - when characters' choices change the path of the story and where it could end up.

These cardinal functions are echoed in David Ball's play analysis methods, as described in Backwards and Forwards. As the title demonstrates, Ball suggests that the dramaturg (or other play analyst) read a play 'backwards' by reading it two times and then asking themselves, "what happens that makes something else happen?" (10). He calls these two related events 'triggers' - the first part of an action, which causes a reaction -- and 'heaps' - the second part of the action, which happens because of the trigger (10). Like 
McFarlane's cardinal functions, triggers and heaps are turning points in the story, places where characters' choices move the overall action of the story forward, forging yet another connection between adaptation theory and dramaturgical practice - in this case, script analysis.

\section{A Little Betrayal Among Friends}

My first task is, therefore, to identify the triggers and heaps forming the cardinal functions of A Little Betrayal Among Friends. The following chart shows my own analysis of these triggers and heaps:

\begin{tabular}{|l|l|l|}
\hline $\begin{array}{c}\text { Action } \\
\text { Unit }\end{array}$ & \multicolumn{1}{|c|}{ Trigger } & \multicolumn{1}{|c|}{ Heap } \\
\hline 1 & Marcia falls for Lysander; it is 'love at & Marcia shows Felicia a picture of \\
first sight.' Felicia tries to discourage & Lysander to convince her that she \\
her (19). & (Marcia) is right (20). \\
\hline 2 & $\begin{array}{l}\text { Marcia shows Felicia a picture of } \\
\text { Lysander to convince her that she }\end{array}$ & $\begin{array}{l}\text { Felicia decides to steal Lysander from } \\
\text { (Marcia) is right (20). }\end{array}$ \\
\hline 3 & $\begin{array}{l}\text { Felicia decides to steal Lysander from } \\
\text { Marcia, and she asks don Juan about } \\
\text { him. He refuses to answer. (24-31) }\end{array}$ & $\begin{array}{l}\text { Felicia declares to don Juan that she is } \\
\text { going to fall in love with Lysander }\end{array}$ \\
\hline 4 & $\begin{array}{l}\text { Felicia decides to publicly pursue } \\
\text { Lysander }\end{array}$ & Felicia finds a way to meet Lysander \\
and give him a letter asking him to \\
meet "Marcia" late at night (37-40)
\end{tabular}




\begin{tabular}{|c|c|c|}
\hline 5 & $\begin{array}{l}\text { Gerry and Marcia used to date, and } \\
\text { Gerry still likes her (new sub-plot). }\end{array}$ & $\begin{array}{l}\text { Gerry hangs around Marcia's } \\
\text { window, proclaiming his love (43-44). }\end{array}$ \\
\hline 6 & $\begin{array}{l}\text { Laura and Lysander used to be } \\
\text { engaged, but Lysander ran away (new } \\
\text { sub-plot) }\end{array}$ & $\begin{array}{l}\text { Laura complains to her friend, Felix, } \\
\text { about how Lysander has mistreated } \\
\text { her (47). }\end{array}$ \\
\hline 7 & $\begin{array}{l}\text { Laura complains to her friend, Felix, } \\
\text { about how Lysander has mistreated } \\
\text { her (47). }\end{array}$ & $\begin{array}{l}\text { Felix goes off to find Lysander for } \\
\text { Laura (49). }\end{array}$ \\
\hline 8 & $\begin{array}{l}\text { Felicia has found a way to meet with } \\
\text { Lysander after hours }\end{array}$ & $\begin{array}{l}\text { She flaunts this meeting with don } \\
\text { Juan. He kisses her (53-55) }\end{array}$ \\
\hline 9 & $\begin{array}{l}\text { Felix goes off to find Lysander for } \\
\text { Laura (49). }\end{array}$ & $\begin{array}{l}\text { Felix leads Laura to Marcia, and Laura } \\
\text { tells Marcia everything that has } \\
\text { happened to her (56-58). }\end{array}$ \\
\hline 10 & $\begin{array}{l}\text { Laura and Marcia meet, and Laura } \\
\text { tells Marcia everything that has } \\
\text { happened to her (56-58). }\end{array}$ & $\begin{array}{l}\text { Marcia and Laura come up with a plan } \\
\text { to get revenge (60-61) }\end{array}$ \\
\hline 11 & $\begin{array}{l}\text { Marcia and Laura come up with a plan } \\
\text { to get revenge }(60-61)\end{array}$ & $\begin{array}{l}\text { Laura texts Lysander and tells him } \\
\text { that she is joining a convent (62) }\end{array}$ \\
\hline 12 & $\begin{array}{l}\text { Laura texts Lysander and tells him } \\
\text { that she is joining a convent (62) }\end{array}$ & $\begin{array}{l}\text { Felicia finds out about Laura and } \\
\text { confronts Lysander, telling him to } \\
\text { meet her in the park (66-68). }\end{array}$ \\
\hline
\end{tabular}




\begin{tabular}{|c|c|c|}
\hline 13 & $\begin{array}{l}\text { Felicia flaunts her meeting with } \\
\text { Lysander to don Juan. Don Juan kisses } \\
\text { her }(53-55) \text {. }\end{array}$ & $\begin{array}{l}\text { Don Juan circles back to tell Felicia } \\
\text { that he is over her, but also jealously } \\
\text { swears to keep her from getting what } \\
\text { she wants (70-74) }\end{array}$ \\
\hline 14 & $\begin{array}{l}\text { Marcia and Laura come up with a plan } \\
\text { to get revenge }(60-61) \text {. }\end{array}$ & $\begin{array}{l}\text { Lysander has been talking to Laura } \\
\text { thinking that she is Marcia (75). }\end{array}$ \\
\hline 15 & $\begin{array}{l}\text { Gerry and Marcia used to date, and } \\
\text { Gerry still likes her. }\end{array}$ & $\begin{array}{l}\text { Marcia decides that she actually likes } \\
\text { Gerry (75) }\end{array}$ \\
\hline 16 & $\begin{array}{l}\text { Don Juan circles back to tell Felicia } \\
\text { that he is over her, but also jealously } \\
\text { swears to keep her from getting what } \\
\text { she wants (70-74). }\end{array}$ & $\begin{array}{l}\text { Don Juan breaks up Felicia's meeting } \\
\text { with Lysander in the park and slaps } \\
\text { her (78). }\end{array}$ \\
\hline 17 & $\begin{array}{l}\text { Marcia decides that she actually likes } \\
\text { Gerry (75). }\end{array}$ & $\begin{array}{l}\text { Marcia offers to marry Gerry. He is } \\
\text { happy }(80) \text {. }\end{array}$ \\
\hline 18 & $\begin{array}{l}\text { Lysander has been talking to Laura } \\
\text { thinking that she is Marcia ( } 75) \text {. }\end{array}$ & $\begin{array}{l}\text { Lysander talks about how much he } \\
\text { loved Laura in the past and how much } \\
\text { he loves Marcia (who is really Laura) } \\
(80-81) \text {. }\end{array}$ \\
\hline 19 & $\begin{array}{l}\text { Lysander talks about how much he } \\
\text { loved Laura in the past and how much } \\
\text { he loves Marcia (who is really Laura) } \\
(80-81) \text {. }\end{array}$ & $\begin{array}{l}\text { Marcia in disguise gets him to put this } \\
\text { declaration in writing (83). }\end{array}$ \\
\hline
\end{tabular}




\begin{tabular}{|c|c|c|}
\hline 20 & $\begin{array}{l}\text { Don Juan breaks up Felicia's meeting } \\
\text { with Lysander in the park and slaps } \\
\text { her (78). }\end{array}$ & $\begin{array}{l}\text { Leon (Lysander's friend) hears a } \\
\text { rumor (supposedly from Felicia) that } \\
\text { Felicia married don Juan (84). }\end{array}$ \\
\hline 21 & $\begin{array}{l}\text { Leon hears a rumor (supposedly from } \\
\text { Felicia) that Felicia married don Juan } \\
\text { (84). }\end{array}$ & $\begin{array}{l}\text { Lysander decides that he is in love } \\
\text { with Felicia after all (84). }\end{array}$ \\
\hline 22 & $\begin{array}{l}\text { Don Juan breaks up Felicia's meeting } \\
\text { with Lysander in the park and slaps } \\
\text { her (78). }\end{array}$ & $\begin{array}{l}\text { Don Juan appears to tease Felicia } \\
\text { again and they fight }(88-89) \text {. }\end{array}$ \\
\hline 23 & $\begin{array}{l}\text { Marcia in disguise gets him to put this } \\
\text { declaration in writing (83). }\end{array}$ & $\begin{array}{l}\text { Laura and Marcia reveal that } \\
\text { Lysander has actually been talking to } \\
\text { Laura and Marcia gets out the letter } \\
\text { declaring his love (90). }\end{array}$ \\
\hline 24 & $\begin{array}{l}\text { Laura and Marcia reveal that Lysander } \\
\text { has actually been talking to Laura and } \\
\text { Marcia gets out the letter declaring his } \\
\text { love (90). }\end{array}$ & $\begin{array}{l}\text { Felicia tries to stop Lysander from } \\
\text { marrying Laura. }\end{array}$ \\
\hline 25 & $\begin{array}{l}\text { Marcia offers to marry Gerry. He is } \\
\text { happy ( } 80) \text {. }\end{array}$ & $\begin{array}{l}\text { Marcia and Gerry leave to get married } \\
\text { (92) }\end{array}$ \\
\hline 26 & $\begin{array}{l}\text { Laura and Marcia reveal that Lysander } \\
\text { has actually been talking to Laura and } \\
\text { Marcia gets out the letter declaring his } \\
\text { love (90). }\end{array}$ & Lysander apologizes to Laura (92-93). \\
\hline
\end{tabular}




\begin{tabular}{|l|l|l|}
\hline 27 & $\begin{array}{l}\text { Lysander apologizes to Laura, } \\
\text { finishing out her and Marcia's plan for } \\
\text { revenge (92-93). }\end{array}$ & Laura turns him down and goes away \\
& $\begin{array}{l}\text { Don Juan appears to tease Felicia instead (93). } \\
\text { again and they fight (88-89). }\end{array}$ & Don Juan and Felicia fight but also \\
\hline 28 & kiss (95). \\
\hline
\end{tabular}

Because there are multiple intermingled subplots, it is impossible to draw a straight line from the beginning of the script to the end, but the cardinal functions and action units remain intact, nonetheless. In this case, Svich has focused primarily on Felicia's story, which we can see because she both begins and ends the play. The primary love triangle is, therefore, between Felicia, don Juan, and Lysander, and this seems to be the most important relationships in the play overall. Felicia and Lysander share ten separate action points ${ }^{14}$, and Felicia and don Juan share $\operatorname{six}^{15}$. Some of these overlap with one another, but the love triangle takes up, in total, twelve out of the twenty-eight, almost half, of the action units. Conversely, the relationship between Marcia and Felicia is only present in three of these action units ${ }^{16}$, at the very beginning and the very end of the play. For a play that is supposedly about their friendship and its betrayal, the titular relationship does not get much stage time at all. I will analyze the possible reasons for this focus after seeing how engaged Zayas is with these same relationships.

On the other hand, Felicia is not part of the plot at all in thirteen of these action units $^{17}$, more than half the plot of A Little Betrayal Among Friends. Most of these scenes

\footnotetext{
$141,2,3,4,8,12,16,20,21$, and 24

$153,8,16,20,22$, and 28

161,2 , and 24

$175,6,7,9,10,11,14,15,17,18,19,23,25,26$, and 27
} 
involve Laura, who is not onstage with Felicia until the very end of the play, and who represents her foil - the good friend to set off Felicia's bad friendship. This highlights the ensemble nature of the piece, though it makes it difficult to use some other script analysis tools. There are eight named characters, and all but one (Leon) of these named characters appears in at least two action units. For a seventeenth-century play, this is a small number, but a twenty-first-century play rarely incorporates so many characters, primarily for budgetary reasons, and to have a plot which depends on so many characters is also unusual.

A significant amount of this plot also occurs offstage, which leads to quite a bit of 'telling, not showing,' for a play written in the television era. There are nine action units ${ }^{18}$ that include action that happens offstage, including the very first one, leading the audience to start the play by hearing about Marcia's offstage encounter with Lysander, not with an actual encounter with any character. Other important plot points that occur offstage include quite a bit of the trick that Laura and Marcia play on Lysander, including all of Laura's conversations with Lysander while she is disguised as Marcia and the misleading messages that she sends him about becoming a nun. We also do not see either of Felicia's trysts with Lysander or don Juan slapping her, though we do see several scenes with don Juan and Felicia and some physical altercations between the two of them. Perhaps this, again, helps the audience focus on the more important relationships in the play, like those between don Juan and Felicia and between Marcia and Laura, who share significant stage time together. This may also have helped cut down on the run time of the play, which surely struggled to fit the plot of the original into the typical runtime of twenty-first century plays.

$181,6,12,14,16,18,20,21$, and 22 


\section{La traición en la amistad}

To get more insight into the possibilities of an adaptation of Zayas's La traición en la amistad, it is helpful to see what the action units of the original are in order to understand the impact of changes made by the adapter, Svich, to make the play more meaningful and engaging to her audience. Following the same script analysis method, these are the action units I identified in La traición en la amistad:

\begin{tabular}{|l|l|l|}
\hline $\begin{array}{c}\text { Action } \\
\text { Unit }\end{array}$ & \multicolumn{1}{|c|}{ Trigger } & \multicolumn{1}{|c|}{ Heap } \\
\hline 1 & $\begin{array}{l}\text { Marcia sees Liseo in el Prado, it is } \\
\text { love at first sight. She tells Fenisa } \\
\text { about it (277) }\end{array}$ & $\begin{array}{l}\text { Marcia shows Fenisa a picture of Liseo } \\
\text { and Fenisa also falls in love with him } \\
\text { (278) }\end{array}$ \\
\hline 2 & $\begin{array}{l}\text { Marcia shows Fenisa a picture of } \\
\text { with him (278) }\end{array}$ & $\begin{array}{l}\text { Fenisa and don Juan fight, Fenisa } \\
\text { decides to punish him by going after }\end{array}$ \\
\hline 3 & $\begin{array}{l}\text { Marcia sees Liseo in el Prado, it is } \\
\text { love at first sight. She tells Fenisa } \\
\text { about it (277) }\end{array}$ & $\begin{array}{l}\text { Marcia tells Liseo, he shows up (with } \\
\text { don Juan (281-2) }\end{array}$ \\
\hline 5 & $\begin{array}{l}\text { Fenisa decides to pursue Liseo (279) } \\
\text { Fenisa tells Liseo that Marcia is with }\end{array}$ & $\begin{array}{l}\text { Fenisa tells Liseo that Marcia is with } \\
\text { don Juan (281-2) }\end{array}$ \\
\hline
\end{tabular}




\begin{tabular}{|c|c|c|}
\hline 6 & $\begin{array}{l}\text { Gerardo appears and asks musicians } \\
\text { to sing about his love (284) (new sub- } \\
\text { plot) }\end{array}$ & $\begin{array}{l}\text { Marcia and Belisa come to the window } \\
\text { and hear Gerardo's love song (284) }\end{array}$ \\
\hline 7 & Liseo comes to Marcia's house (281) & $\begin{array}{l}\text { Laura (and Felix) also come to } \\
\text { Marcia's house (285) }\end{array}$ \\
\hline 8 & $\begin{array}{l}\text { Laura (and Felix) also come to } \\
\text { Marcia's house (285) }\end{array}$ & $\begin{array}{l}\text { Laura meets Marcia and tells her that } \\
\text { Liseo took her honor (287) }\end{array}$ \\
\hline 9 & $\begin{array}{l}\text { Laura meets Marcia and tells her that } \\
\text { Liseo took her honor ( } 287 \text { ) }\end{array}$ & $\begin{array}{l}\text { Marcia agrees to give Liseo up } \\
\text { immediately and agrees to help Laura } \\
\text { get revenge (288) }\end{array}$ \\
\hline 10 & $\begin{array}{l}\text { Marcia agrees to give Liseo up } \\
\text { immediately and agrees to help Laura } \\
\text { get revenge (288) }\end{array}$ & $\begin{array}{l}\text { Belisa mentions that she has also been } \\
\text { wronged by don Juan, who once } \\
\text { promised to marry her (288-9) }\end{array}$ \\
\hline 11 & $\begin{array}{l}\text { Belisa has also been wronged by don } \\
\text { Juan, who once promised to marry } \\
\text { her (288-9) }\end{array}$ & $\begin{array}{l}\text { Belisa threatens to leave don Juan } \\
\text { because he has been flirting with } \\
\text { Fenisa (290) }\end{array}$ \\
\hline 12 & $\begin{array}{l}\text { Belisa threatens to leave don Juan } \\
\text { because he has been flirting with } \\
\text { Fenisa (290) }\end{array}$ & Don Juan wins her over again (290-1) \\
\hline 13 & $\begin{array}{l}\text { Marcia and Laura agree to get } \\
\text { revenge on Liseo (288) }\end{array}$ & $\begin{array}{l}\text { Liseo gets a letter from Laura saying } \\
\text { that she is going to a convent ( } 291)\end{array}$ \\
\hline 14 & $\begin{array}{l}\text { Liseo gets a letter from Laura saying } \\
\text { that she is going to a convent ( } 291)\end{array}$ & $\begin{array}{l}\text { Fenisa gets jealous when she sees Liseo } \\
\text { tearing up the letter (292) }\end{array}$ \\
\hline
\end{tabular}




\begin{tabular}{|c|c|c|}
\hline 15 & $\begin{array}{l}\text { Fenisa gets jealous when she sees } \\
\text { Liseo tearing up the letter (292) }\end{array}$ & $\begin{array}{l}\text { Liseo swears that he is loyal to Fenisa } \\
\text { and promises to meet her later in the } \\
\text { park (292-3) }\end{array}$ \\
\hline 16 & $\begin{array}{l}\text { Fenisa and don Juan fight, Fenisa } \\
\text { decides to punish him by going after } \\
\text { Liseo (279). }\end{array}$ & $\begin{array}{l}\text { Gerardo and Lauro show up, Fenisa } \\
\text { tries to flirt with both and brags about } \\
\text { having ten lovers, asks about don Juan } \\
\text { (293). }\end{array}$ \\
\hline 17 & Gerardo and Lauro show up (293). & $\begin{array}{l}\text { Fenisa hits on Gerardo, but he turns her } \\
\text { down because he is loyal to Marcia } \\
\text { (294). }\end{array}$ \\
\hline 18 & $\begin{array}{l}\text { Marcia and Laura agree to get } \\
\text { revenge on Liseo (288) }\end{array}$ & $\begin{array}{l}\text { Laura has been talking to Liseo } \\
\text { pretending to be Marcia (295). }\end{array}$ \\
\hline 19 & Gerardo is still loyal to Marcia (294). & $\begin{array}{l}\text { Marcia decides to accept Gerardo's } \\
\text { hand (295). }\end{array}$ \\
\hline 20 & $\begin{array}{l}\text { Liseo swears that he is loyal to Fenisa } \\
\text { and promises to meet her later in the } \\
\text { park (292-3) }\end{array}$ & $\begin{array}{l}\text { Don Juan tells Belisa about finding } \\
\text { them in the park and slapping Fenisa } \\
\text { (296). }\end{array}$ \\
\hline 21 & $\begin{array}{l}\text { Don Juan tells Belisa about finding } \\
\text { them in the park and slapping Fenisa, } \\
\text { proving his loyalty to Belisa (296). }\end{array}$ & $\begin{array}{l}\text { Belisa offers don Juan her hand and } \\
\text { asks him to have Gerardo go see } \\
\text { Marcia (296). }\end{array}$ \\
\hline 22 & $\begin{array}{l}\text { Liseo swears that he is loyal to Fenisa } \\
\text { and promises to meet her later in the }\end{array}$ & $\begin{array}{l}\text { Felix tells Laura that they got married } \\
\text { and Laura faints (297). }\end{array}$ \\
\hline
\end{tabular}




\begin{tabular}{|c|c|c|}
\hline & $\begin{array}{l}\text { park, leading to a rumor that they got } \\
\text { married (292-3) }\end{array}$ & \\
\hline 23 & $\begin{array}{l}\text { Belisa offers don Juan her hand and } \\
\text { asks him to have Gerardo go see } \\
\text { Marcia (296). }\end{array}$ & $\begin{array}{l}\text { Gerardo comes to see Marcia and she } \\
\text { declares her love (298). }\end{array}$ \\
\hline 24 & $\begin{array}{l}\text { Felix tells Laura that Liseo and } \\
\text { Fenisa got married and Laura faints } \\
\text { (297). }\end{array}$ & $\begin{array}{l}\text { Liseo comes to the balcony and admits } \\
\text { that he should have married Laura, but } \\
\text { she cannot stay because she is too upset } \\
(300) \text {. }\end{array}$ \\
\hline 25 & $\begin{array}{l}\text { Liseo comes to the balcony and } \\
\text { admits that he should have married } \\
\text { Laura, but she cannot stay because } \\
\text { she is too upset ( } 300) \text {. }\end{array}$ & $\begin{array}{l}\text { To prove he means it and get legal } \\
\text { proof, Marcia, disguised as Belisa, } \\
\text { convinces Liseo to write down a } \\
\text { marriage proposal to Laura }(300) \text {. }\end{array}$ \\
\hline 26 & $\begin{array}{l}\text { Don Juan has slapped Fenisa in the } \\
\text { park, and Liseo has gone back to } \\
\text { Marcia. }\end{array}$ & $\begin{array}{l}\text { Fenisa talks to Lucía about how she lost } \\
\text { both don Juan and Liseo. Lucía } \\
\text { confirms that "Marcia" and Liseo are } \\
\text { engaged (302). }\end{array}$ \\
\hline 27 & $\begin{array}{l}\text { Fenisa talks to Lucía about how she } \\
\text { lost both don Juan and Liseo. Lucía } \\
\text { confirms that "Marcia" and Liseo are } \\
\text { engaged (302). }\end{array}$ & Fenisa swears to get revenge (302). \\
\hline
\end{tabular}




\begin{tabular}{|c|c|c|}
\hline 28 & $\begin{array}{l}\text { Gerardo and don Juan have both } \\
\text { become engaged to Marcia and } \\
\text { Belisa. }\end{array}$ & $\begin{array}{l}\text { Gerardo and don Juan arrive at the } \\
\text { balcony to see their fiancées (306). }\end{array}$ \\
\hline 29 & Fenisa swears to get revenge (302). & $\begin{array}{l}\text { Fenisa 'catches' don Juan and calls him } \\
\text { out for being with her earlier ( } 307 \text { ) }\end{array}$ \\
\hline 30 & $\begin{array}{l}\text { Fenisa 'catches' don Juan and calls } \\
\text { him out for being with her earlier } \\
\text { (307) }\end{array}$ & $\begin{array}{l}\text { Marcia comes out and tells Fenisa to } \\
\text { stop (307). }\end{array}$ \\
\hline 31 & $\begin{array}{l}\text { Marcia, disguised as Belisa, } \\
\text { convinces Liseo to write down a } \\
\text { marriage proposal to Laura (300). }\end{array}$ & $\begin{array}{l}\text { Laura appears with the letter to claim } \\
\text { Liseo (307). }\end{array}$ \\
\hline 32 & $\begin{array}{l}\text { Laura appears with the letter to claim } \\
\text { Liseo (307). }\end{array}$ & Liseo agrees to marry Laura (308) \\
\hline 33 & $\begin{array}{l}\text { Fenisa 'catches' don Juan and calls } \\
\text { him out for being with her earlier } \\
\text { (307) }\end{array}$ & $\begin{array}{l}\text { Fenisa insists that don Juan marry her } \\
\text { (308) }\end{array}$ \\
\hline 34 & $\begin{array}{l}\text { Fenisa insists that don Juan marry her } \\
(308)\end{array}$ & $\begin{array}{l}\text { Belisa stops Fenisa with her } \\
\text { engagement (308). }\end{array}$ \\
\hline 35 & $\begin{array}{l}\text { Marcia is angry at Fenisa's } \\
\text { unkindness and Belisa has stopped } \\
\text { her by taking her engagement to don } \\
\text { Juan. }\end{array}$ & $\begin{array}{l}\text { Fenisa is punished by being left with no } \\
\text { one, not even her maid, at the end of the } \\
\text { play ( } 308 \text { ) }\end{array}$ \\
\hline
\end{tabular}


Again, Fenisa begins and ends this play, showing that she is the principal character, and the one the audience should be tracking throughout the play. However, don Juan does not seem to share that prominence in La traición en la amistad like he does in A Little Betrayal Among Friends. Instead, the focus is on Fenisa's evil nature and the punishment that she receives because of that evil nature. While most of Fenisa's scenes focusing on the love triangle between her, don Juan, and Liseo exist in this version, they are diluted by other scenes and characters, including other lovers for Fenisa to love and leave. However, Fenisa does haunt other plot points more actively throughout the play. Therefore, though her actions are primarily the same, her influence extends into new action units and ends up holding similar sway throughout. In this case, the Fenisa/Liseo/don Juan love triangle occupies nineteen action units, ten ${ }^{19}$ with Fenisa and Liseo and thirteen ${ }^{20}$ with Fenisa and don Juan. This added emphasis on don Juan may be because of the character of Belisa, who Svich removed in her version, and whose plot also centers on don Juan. Don Juan is, perhaps, a more active character in A Little Betrayal Among Friends because fewer of his actions are motivated by someone else (Belisa) telling him what to do, but he is certainly less present in Betrayal than he is in Traición. However, the overall importance of Fenisa's love triangle, which is, in fact, broader in this version, is similarly important.

More emphasis is put on justification of the title in La traición en la amistad, certainly. It is mentioned verbatim twice in the script in metatheatrical asides, which are relatively few in this script overall. However, the relationships between women in this version are balanced similarly with the rest of the script. There are five action units ${ }^{21}$

\footnotetext{
$191,2,4,5,14,15,20,22,26$, and 27

$202,11,12,16,20,21,26,27,29,30,33,34$, and 35

$211,4,17,30$, and 35
} 
between Fenisa and Marcia, and Marcia has a more active role in Fenisa's punishment at the end, mostly because her punishment is unsuccessful in Svich's adaptation. However, they still clash in the beginning and resolve that clash at the end, though they hardly interact in the middle and their one 'interaction' is indirect. Marcia and Laura share seven action units $^{22}$, which is also similar to Svich's adaptation. Laura remains the foil to Fenisa's bad friendship, and through her the play is able to celebrate and highlight female friendship and women helping women even though there is severe hatred and jealousy between women where Fenisa is concerned.

Though Fenisa is still clearly the primary character for the audience to follow, the ensemble nature of the plot remains, and is highlighted by even more characters and conflicts. Twelve action units ${ }^{23}$ do not involve Fenisa in any way, leaving room for Marcia, Laura, and now Belisa to forge their friendship instead. Every action unit involves at least one of these women in both versions - though there are scenes between men, they do not drive the plot forward to the multi-wedding end goal. La traición en la amistad has a total of thirteen characters, some of whom are in only one or two scenes and have little bearing on the plot. Gerardo uses musicians to sing to Marcia who do not seem to return, and Fenisa's additional lover, Lauro, only has one scene in which he is actually onstage. This draft also adds a servant for Fenisa given that she is a wealthy woman in seventeenth century Spain, but she is used fairly well to further the plot and deepen Fenisa's punishment at the end of the play. The large cast is much more common of Spanish Golden Age plays, but Zayas's thorough use of this large cast led Svich to a cast that is similarly quite large for the time in which she writes.

$228,9,10,13,19,25$, and 31

$23 \mathrm{3}, 6,7,8,9,10,11,13,14,16,18,20,21,22$, and 26 
Though Traición is longer, much of the plot still occurs offstage, probably for practical reasons rather than for time concerns. There are still thirteen action units ${ }^{24}$ that depend on events happening offstage, including the very first action unit of the play. These are the same as the offstage plot points in A Little Betrayal Among Friends - the scene in which Marcia meets and falls for Liseo, Laura's breakup with Liseo and most of her disguised conversations with him, the park scene in which don Juan slaps Fenisa, and several examples of rumor-spreading and letter delivery. In addition, this version adds Belisa's breakup with don Juan, which would be a helpful clarification to have, since Fenisa claims to have been seeing don Juan before Belisa. While telling and not showing is more common in Spanish Golden Age plays, it is still surprising to me that we see, or rather fail to see, so much of it, given that there are multiple tangents celebrating the characters' cleverness but otherwise tangential to the plot, which take up quite a bit of time and space onstage but do not seem to further the plot at all. This is surely a quirk of Spanish Golden Age theatre, which leads me to my analysis of the various cardinal functions/action units in these two plays.

\section{Indices}

While the cardinal functions/action units make up the core plot of a literary work, indices make up the less transferrable characterization, setting, and ambiance that give the plot meaning. McFarlane takes this word, again, from Barthes and splits it into two separate units, indices proper, and informants. Informants consist of aspects of character, setting, genre, and the like which can be transferred easily, such as characters' names and the

$241,8,9,10,11,13,14,16,18,20,21,22$, and 26 
specific setting in which a story takes place. Indices proper (whose name suggests that McFarlane believes them to be the only true indices) "relate to concepts such as character and atmosphere, are more diffuse than the functions proper, and are therefore more broadly open to adaptation rather than to the comparative directness of transfer" (14). The difference between the two can be seen clearly in a typical theatre production which, as I have mentioned, is always an adaptation of the play's script. Many aspects of characterization will be transferred directly, such as the actual lines that the characters say and some of the blocking. In this case, these are the functions of the story. However, other aspects will change drastically from production to production, such as the costuming, set, lighting, line readings, and specific blocking. These are the indices of this particular script/production adaptation pair. Both make meaning, but only functions (cardinal functions or index functions) directly affect the plot.

\section{A Little Betrayal Among Friends}

For the purposes of this dissertation, I consider everything that is not a cardinal function to fall under the umbrella of indices in some way, shape, or form. In modernizing the script, quite a bit of the background indices are changed in Svich's version, though some aspects are kept remarkably similar. A Little Betrayal Among Friends includes, for example, quite a few references to phones and technology when compared to La traición en la amistad (though not much when compared to everyday life in the twenty-first century). Characters show one another pictures on their phones and send text messages asking them to meet one another in various places and threatening to join convents. This eliminates the need for several of the servant characters, like Lucía, whose primary purpose 
in Traición seems to be running these letters and listening to exposition from her mistress, Fenisa. Despite this specificity of time, however, the stage directions in Betrayal are fairly sparse. Before the beginning of the play, Svich identifies the setting as "the present. A cosmopolitan city full of secret alleys and unsuspecting mazes" (17). However, she uses very few stage directions throughout and usually does not clarify where the characters are when they enter most of the time, leaving it open to interpretation from either the director or perhaps even the audience. Most action is left up to the director's and actors' discretion as well, meaning that each production adaptation of this script adaptation is likely to be even further differentiated from one another.

The characterization in A Little Betrayal Among Friends also demonstrates how open-ended indices can be when transferring from one time period to another. The most notable of these is the relationship between don Juan and Fenisa, which is seen as a kind of sexual masochism in that both characters seem to enjoy and get aroused by fighting with the other, making them perfect for one another at the end of the play (and terrible for anyone else). Don Juan's characterization is made particularly complicated by the popularity of Tirso de Molina's infamous womanizer of the same name, who is not necessarily the same character in La traición en la amistad, although some characteristics may be transferred through the power of tropes and archetypes. However, due to the name and the fact that Fenisa takes on a very donjuanesque role in this play, Svich chooses to characterize don Juan as the "legendary bachelor and playboy," making him an appropriate match for her. Finally, many of the servants in Traición become friends in Betrayal or simply disappear, as I mentioned previously. Felix becomes a man stuck in the friendzone to Laura, and Leon becomes Lysander's assistant, making him still an employee, but one who can fight back 
against Lysander's punches, which read as friendly in this draft and not comedic servant abuse.

This is, perhaps, because servant abuse reads as horrific rather than funny to a twenty-first-century audience. The perspective on both humor and romance is in A Little Betrayal Among Friends, and both are much more friendly to the individuals with less power in the adaptation. The treatment of the marriages at the end of the play, for example, shows Svich's shift in perspective regarding romance. In a change to the cardinal functions, Svich chooses not to have Fenisa end the play in lonely punishment nor to have Laura end up marrying Lysander. The play seems to suggest that don Juan and Felicia deserve one another. Don Juan illustrates this idea at the end of the play "will you point your dagger at me forever, Felicia? If you kill me, you kill yourself, for we are one and the same" (94). This challenge is followed by a threat of violence and then a passionate kiss from Felicia, which does not suggest a marriage, but certainly seems to be a happy ending for the two of them. There is, in fact, much less blame laid on Felicia throughout the play, which deemphasizes the titular betrayal, but also serves to make the audience more sympathetic toward the play's hero (or anti-hero, depending on who you ask). On the other hand, Lysander's actions, which are essentially the same as Felicia's in that he is trying to juggle multiple women at once, some of whom he is trying to 'steal' from male friends, are punished through Laura's refusal of his advances at the end of the play. Instead, Laura chooses to get with friend zoned Felix, who has been consistent, sweet, and supportive throughout. Unlike Fenisa, Laura is not a promiscuous or overly sexual character, and as such, pairing her with a womanizer like Lysander seems inappropriate and unfair. However, the audience does get the satisfaction of seeing her best him in cleverness and 
make him, not Felicia, suffer for what he did wrong. Laura sends him off with the quip "pay someone in misery, they'll pay you in kind," before exiting with Felix (93). The comedy was also updated to include slightly less slapstick and fewer tangential jokes, though there are still moments of humorous play fighting, mostly between Felicia and don Juan, though there are exceptions. Similarly, Svich includes humorous linguistic banter between the characters, especially Leon and Felix, though Marcia has her funny moments as well. This scene between Leon and Lysander is an excellent example of both the linguistic and the physical humor in Betrayal:

LEON: ... Why do you hit me?

LYSANDER: Huh?

LEON: You hit me all the time.

LYSANDER: I do not.

LEON: You just did.

LYSANDER: Love tap.

LEON: That was not a love tap (65).

Here, Leon calls out Lysander's physical abuse, but does so in a friendly and comedic way, which gives him some power in the relationship and keeps the audience from being distracted by feeling sorry for him.

\section{La traición en la amistad}

The setting in La traición en la amistad is also fairly vague, which is common in Spanish Golden Age plays, though some set pieces are suggested by the dialogue. Like Shakespearean plays, playwrights during the Spanish Golden Age did not typically include a lot of stage directions in their plays and, instead, worked actions into the dialogue of the script itself. For example, instead of giving a stage direction that Marcia takes Liseo's portrait away from Fenisa, Fenisa asks her in Act I Scene 1 “¿por qué el retrato me quitas?” 
(why do you take the portrait away from me?) (278). The overall setting is, like that of $A$ Little Betrayal Among Friends, fairly vague, and though the characters seem to be interacting in various different spaces, the script does not define characters' locations very clearly at any point in time. We do know that there is a window and/or a balcony in Marcia's house, through which she, Laura, and Belisa talk to Liseo to carry out their scheme. However, the other spaces are up to interpretation. Costume descriptions are also fairly vague, though the women appear to be covered enough that Liseo cannot tell them apart even though he has met and claimed to love both Marcia and Laura.

The characterization is much more gendered in La traición en la amistad, though this does not always end up being positive for the male characters, as it often does in seventeenth-century literature. As I mentioned briefly, Fenisa is villainized in Traición from the beginning of the play. Even Fenisa herself seems to question her own motives, saying “¿soy amiga? Sí. Pues, ¿cómo/ pretendo contra mi amiga/ tan alevosa traición?” (“am I a friend? Then, how do I plot such a treacherous plot against my friend?") (279). This judgement continues throughout the play from other characters, primarily Marcia, but also the men in Fenisa's life, until she is finally thoroughly punished in the end of the play with loneliness and a warning to the audience that they, too, should shun Fenisa for her sins. This punishment is handed down from Marcia herself, who, when Fenisa finds herself alone says "de tu mal nadie tiene/ la culpa, sino tú mesma./Las amigas desleales/ y que hacen estas tretas,/ pocos son estos castigos;/ consuélate y ten paciencia" ("Your bad end is no one's fault but your own. For disloyal (female) friends who play these tricks on one another, this is a small punishment, so console yourself and be patient”) (308). Fenisa also seems to be much prouder of her conquests, and she brags about having ten or more lovers 
at a time, while don Juan is easily tamed by Belisa and seems to give up all womanizing without much of a fight. Liseo, on the other hand, still blatantly lies to both Marcia and Fenisa and abuses León, but he is not held accountable for this behavior in this version and ends up married to Laura in the end, which is what he claims to want. The servants are also much more typical of servant archetypes, as they are driven by hunger for both food and sex, but they are also able to fill the role of the wise fool, pointing out illogical things about noble behavior. León shows both of these tendencies in the first act when he asks Liseo why he would want a chaste woman at all, when experienced women seem like so much more fun. León and the other servants also fill in most of the comedic space in Traición in a way that is difficult to transfer into the English adaptation.

Again, comedy and romance are difficult to transfer between adaptations, and this example is no exception. As León's comment shows, romance in this play seems to be much more about honor and preserving one's status for the women in this play. While they think that the men are attractive, and Fenisa swears that she loves all of her conquests, Marcia, Laura, and Belisa spend much more time with one another than they spend with any men, and their motivations for marrying these men seem to be primarily based on preserving their honor. While Belisa greets Laura with "No hay más bien/ que ver cuando viendo estoy/ tal belleza; el cielo os dél la ventura cual la cara;/ si hombre fuera, yo empleara/ en vuestra afición mi fe." (“There is no better thing than seeing as much beauty as I see now; Heaven gave you a fortunate face; if I were a man, I would put all my faith in your attentions") (287). While she does say similarly romantic things to don Juan, her love interest in this script, they are framed as manipulative and dishonest, whereas her affection for Laura and Marcia seems to be honest. The comedy in Traición also comes 
from an unexpected place, primarily in long asides from León and other characters talking to León who tell humorous stories with linguistic deftness that entertain the audience but do not further the plot. This inclusion of set character-related bits is reminiscent of commedia dell'arte, but the linguistic focus in this case also showcases Zayas's intelligence and ability to craft these clever anecdotes. Overall, like characterization and setting, the romantic and comedic genres in La traición en la amistad and A Little Betrayal Among Friends contribute indices which are difficult to transfer to different times and locations because of the cultural implications of each and the intertextual connections of the audiences in each time and space.

\section{Analysis}

While comparison studies is the hallmark of Adaptation Studies 1.0 and is widely criticized by later adaptation scholars, this criticism focuses on the idea that comparison leads to a value judgement of the adaptation based on how well it conforms to the original story. Adaptation Studies 2.0, on the other hand, focuses on intertextuality, which looks at each piece within the context of its production. I will use a comparison of the original text and the adapted text, in this case, as a starting point to discuss the interaction of intertextuality with these pieces, since comparison is likely to highlight those things that had to be changed in different intertextual contexts. As Hutcheon points out, "this means not only that change is inevitable but that there will also be multiple possible causes of change in the process of adapting made by the demands of the form, the individual adapter, the particular audience, and now the contexts of reception and creation" (142). In the case of Traición and Betrayal, most of these possible venues for change are very different. Even 
the demands of the form are unique, despite the fact that both are stage plays because the stage play of the Spanish Golden Age is quite different from the stage play of the twentyfirst century.

\section{Demands of the Form}

La traición en la amistad was written for a seventeenth-century audience whose goal was to be entertained for an evening, and whose examples of such entertainment were typically longer, three-act plays, whereas A Little Betrayal Among Friends was written in the context of twenty-first century United States theatre, which runs the gamut of runtimes and complexity but tends toward shorter pieces. On top of the three acts that were written into many Spanish Golden Age plays, there would also be entremeses and other musical acts included in an evening of entertainment (Worthen, The Spanish Golden Age). This play is typical of comedies at the time in that it combines low-brow and high-brow humor, focuses primarily on the upper class and their ideas of honor and propriety, and ends in multiple engagements. It is typical of such comedies of manners at this time to tumble into multiple engagements in the last few pages of the play, whether these engagements have been justified by the rest of the play or not. Many examples of this can be seen in the anthology Women's Acts by Teresa Scott Soufas. These plays are also influenced by tropes from Italian commedia dell'arte, which leads to plots and characters that Spanish Golden Age audiences would be familiar with, but which may seem strange to audiences in the twenty-first century.

On the other hand, twenty-first century plays are often much shorter and much more conservative about the number of actors and characters involved, leading to many of the 
changes that Svich chose to make in her adaptation of this story. The 90-minute play is something of a trope in twenty-first-century theatre; it is long enough to tell a good story but short enough that it does not require an intermission and audiences can leave the theatre with plenty of evening left to enjoy. Audiences enjoy this condensed entertainment, perhaps because there are many more options for evening entertainment than there were in the Spanish Golden Age, or perhaps because the average theatregoer's attentions span is shorter than it was in the seventeenth century. Similarly, playwrights are expected to write for a limited number of actors and to use those actors effectively in order to get the most out of an actor's paid time. Both of these expectations are clearly tied to capitalism - the importance of getting audiences out to purchase and consume more elsewhere and the importance of getting the most for one's dollar when it comes to actor time. Cutting a script to make it an acceptable length is a typical dramaturgical role as well, especially when it comes to Shakespearean dramaturgy. For all of these reasons, Svich has clearly tried to condense the plot points and overall length of the story to create a version that still appeals to twenty-first-century audiences but also communicates the theme of Traición and leaves room for both Zayas's and Svich's humorous imaginations to flourish.

To achieve this condensed storyline, Svich cuts several characters and quite a few comedic lazzi that did not contribute to the plot of the story but merely provided entertainment and showed Zayas' linguistic prowess. Since humor is so culturally dependent, these indices were more effectively translated and adjusted to a twenty-firstcentury audience, which is more focused on the primary plot and may be frustrated with unrelated sidetracking, which was an essential part of Spanish Golden Age performance, which included extra, mostly unrelated, performances between acts of most plays. Svich 
also eliminates Fenisa's wise servant, Lucía, who passes notes for Fenisa amongst her various lovers but advises her against the whole multi-lover plot in general. Fenisa ignoring her servant's advice seems reasonable and perhaps provides commentary on the pride of the upper classes in La traición en la amistad, but to ignore an employee or friend in $A$ Little Betrayal Among Friends would require more time to establish Felicia's pride and/or wealth or would seem excessively rude. To save time catching contemporary audiences up on this background, Svich cut this character and moved her actions to cell phones - the ultimate personal assistants. Svich also cut unnecessary characters like the musicians and Lauro, Fenisa's third lover, and condensed the two nice guy roles, Gerardo and Felix, so they could be performed by one actor. In doing so, she addresses the practical expectations of twenty-first-century theatre style, making Betrayal more attractive to producing organizations and their audiences.

\section{Adaptation Style}

Caridad Svich's individual adaptation style also influences both the cardinal functions that are transferred to her adaptation and how she communicates the less direct indices throughout the piece. This directly relates to the intertextual context in which she writes, which is very different from the intertextual context in which Zayas created Traición. Svich is a student of Maria Irene Fornés, a staple of both experimental theatre in New York and Latinx theatre of the 60s, 70s, and 80s (García-Romero). Fornés's influence often makes Svich's work more inclined toward open-ended stage directions, musical interludes, dreamlike experiences, and overt sexuality. She is also unafraid to portray fierce women but does not have an axe to grind with well-meaning men either. Conversely, Zayas 
wrote in a culture that was unlikely to produce her work because of the ubiquity of male work and the stigma leveraged against women who were educated enough to write. Neither woman is identified by her relationship to a man through marriage, but Zayas's portrayal of men in Traición seems especially vicious.

The romantic double standard between men and women is clearly present in Traición, which seems to be a direct reaction to Zayas's environment which is not echoed in Betrayal with nearly so much edge. As I have mentioned, both Fenisa and Liseo lie to their romantic partners in order to see others, but Liseo goes so far as to lie to the men around him as well and never claims any more noble reason for his actions, whereas Fenisa justifies her various romances in Act III, saying "A todos cuantos quiero yo me inclino,/ los quiero, los estimo, y los adoro ... Tengo la condición del mismo cielo,/ que como él tiene asiento para todos/ a todos doy lugar dentro en mi pecho" (I go towards everyone that I like, I love, respect, and adore them ... I have the same heart as Heaven itself; just like the Lord has a seat for everyone, I give every man a place in my heart") (303). Fenisa's love seems genuine, whereas Liseo's only seems manipulative. Similarly, don Juan strikes Fenisa, which is so looked down upon that Zayas chooses not to show it onstage, and he is never punished for it. This behavior from men perhaps reflects how Zayas perceived the men's behavior in her life among privileged, wealthy Spanish Golden Age gentlemen.

Svich, on the other hand, gives the men in Betrayal more fleshed out motivations for their actions and chooses to change the ending of the play to punish bad behavior from these gentlemen. Because of the context in which she writes, Svich also chooses not to put every character in the play in a marriage at the end of the script, a shift from Zayas's original. While this was an expected structural choice in Golden Age Spain, it would have 
been an odd coincidence for a twenty-first-century story. However, part of Svich's punishment for Liseo's lies is to leave him without a partner at the end of the play and to send him off lonely with his assistant Leon. Instead of romanticizing his lies and bad behavior, a problematic pattern that was particularly prevalent at the end of the twentieth century and the beginning of the twenty-first, Svich pushes back against that trope by giving kinder, gentler characters success with the women they love at the end of the play. Don Juan is not one of these kinder, gentler characters. He lies and strikes Felicia, is punished with a toxic relationship with her, an even punishment with Felicia, as she has to deal with the other side of that relationship. In general, Svich's treatment of both male and female characters seems much more equal and focused on positive relationships, which is reflective of the dramatic shift in gender roles between Golden Age Spain and contemporary US culture.

Both Svich's and Zayas's intertextual context and personal styles led them to incorporate music into their scripts. In A Little Betrayal Among Friends, Svich writes a song for Laura called "Wreck Love," which is our first introduction to her character in Act I, Scene 5. This is close to the same point where there is music in La traición en la amistad, which is also in Act I. In Traición, Gerardo recruits some musicians to sing to Marcia outside her window and help him win her over, which happens immediately before Laura's introduction. The reason for this shift may be related to cardinal functions since Laura is a more central character and perhaps needs more time for development in Svich's relatively shorter script. However, Svich's choice to include music was probably not solely motivated by the song in the original script. Many of Svich's plays incorporate music, as do many of the plays of her mentor, Irene Fornés. This incorporation of music when emotions are too 
strong for simple words is one characteristic of Latinx realism a style explored by Anne García-Romero in relation to Fornés and her legacy, and it is also a staple characteristic of Spanish Golden Age theatre, which had musicians on hand for entremeses, as well as entertainment before and after the show. As such, both Svich and Zayas were influenced by their surroundings to include music in the body of their work.

\section{Audience Reception}

Audience expectations and reception of each of these plays is interrelated with all of the issues I have discussed up to this point, but they also bring their own issues and concerns, which are directly related to the role of dramaturgy in connection with these two plays. A dramaturg's job is to ensure that an audience is well-prepared to understand the piece onstage and create meaning alongside the actors onstage. Similarly, the theory of intertextuality also looks at a piece from a receptive perspective, meaning the audience is also implicated in intertextual meaning-making. Hutcheon, from an adaptation studies standpoint, refers to "the form of the adaptation and therefore the expectations created by it" as "different implied "pacts" between the creator and their audience regarding what a piece will be made up of (123). While the form of both works is theatrical, the pacts between a playwright and a seventeenth-century audience and between a playwright and her twenty-first-century audience are different, especially when one considers the power dynamics involved in each of these pacts.

Zayas' pact with her audience begins with a pact with the producing organizations

in seventeenth-century Spain which was, primarily, the Catholic church (Worthen, The Spanish Golden Age). As such, her play about a promiscuous woman and female 
friendship, both themes which were uncommon in comedies at the time, surely ran across some pushback from literary authorities. Wealthy women in most plays at the time were relatively passive and restricted to their own homes. Men in the theatre, and in life, negotiated weddings amongst themselves while the women were supposed to wait patiently in their houses for relationships to be worked out for them (Couderc). Naturally, many plays focused on the dramatic potential that happened when these norms were broken, but Traición still includes some bold, and probably controversial, choices. For one, Fenisa arranges herself to meet with men outside in the park in several different instances in the play. Her choice to pursue men in general was well outside the norms for a well-bred woman of the time, which may be why Zayas felt she had to be explicitly punished at the end of the play - to please the censors in her audience. However, Fenisa's punishment also breaks the audience pact because it leaves an odd woman out at the end of the play, breaking the pattern of marriages across the board. It is also note-worthy that there are no fathers at all in this play to negotiate the weddings between these upper-class young men and women and many of the women seem to be initiating their own marriage proposals. Belisa certainly makes don Juan come around to a proposal, though she does so in such a manipulative way that he may technically be the one to propose, and likewise, Marcia asks Gerardo to come to her when she is ready to get married. Though he has already expressed his interest, the strength of this summons is significant. For Zayas's audience, this surely would have been a scandal.

Zayas did not have a dramaturg to contextualize her play for the audience or to discuss the plays' significance at the time. However, Svich is, herself, a great contributor to audience outreach and dramaturgical literature. As such, she seems to abide by her 
intended audience's pact more cleanly in many ways that I have already discussed in this chapter. The length of A Little Betrayal Among Friends is expected in twenty-first-century plays, and contemporary audiences would, I think, be pleased that Lysander's toxic behaviors are not rewarded with marriage at the end of the piece. Svich has also chosen to keep things that fit into her experience of an audience pact, like the song incorporated into the action and the slapstick action typical of Spanish Golden Age drama, which she contextualizes with complaints back from Leon (and excuses from Lysander about "love pats") and with a sexually masochistic relationship between Fenisa and don Juan. These small adjustments help Svich thread the needle of 'making the strange familiar' and 'making the familiar strange' that is so often cited as the goal in anthropological study.

The space created by Svich in her lack of stage directions and other context also helps with collaborative meaning-makers in the theatrical production process like directors and dramaturgs. As Jane Barnette points out in Adapturgy, this open space helps directors and even audiences participate in the process of meaning-making in an adaptation where so much must be left out. While Svich did not have to cut many action units in this adaptation, the culture of Golden Age Spain is not present to support the plot of the adaptation, leaving a vacuum which will be filled by either the director's vision or the audience's lived experience, making the piece more authentic and applicable to each individual viewer. Svich provides space for this suggestion from Barnette: "adapters, directors, and dramaturgs must ask themselves what kind of theatricality this adaptation brings to the stage at this moment in time?" (129). While Svich provides the theatricality of modernized language and engaging, farcical, complex love triangles, she also leaves room for interpretation from other artists by keeping away from heavy-handed stage 
directions. Sheila Callaghan creates similar space with stage directions in her play, Fever/Dream, through creative but very thorough stage directions. With my experience as director of this piece, I will approach it with an analytical strategy more closely related to my version of Adaptation Studies 3.0 in the next chapter.

\section{Svich's Intercultural Adapturgy}

My conversation with Svich about A Little Betrayal Among Friends confirmed many of my assumptions about this work based on my own analysis and also brought about a fascinating conversation about the process of adapturgy and what an adapturg must do to move a text from one time and culture to another ethically. Svich was concerned, for example, about keeping some parts of the original text's style and voice consistent. This may be the only chance many of her audience members have to see a Spanish Golden Age play, so maintaining open-ended technical notes, including stage directions, and quirky plot points typical of the Spanish Golden Age, like all of the characters marrying one another at the end of the play, helped Svich maintain some of the spirit of the Spanish Golden Age for her audience. This could help an audience be aware that they are watching something old from a Spanish-speaking place and may help Hispanic audiences identify the cultural capital that La traición en la amistad has earned with age. Maintaining some of these unique aspects of the original script while also updating it to speak to a contemporary audience is difficult, but it is work that Svich prioritizes in this adaptation specifically.

On the other hand, seventeenth-century plays run the risk of perpetuating heterosexism, misogyny, classism, and other issues, a consideration Svich is well aware of. In other adaptations, Svich has changed the gender of characters in order to include 
LGBTQ+ relationships in the play, but she did not choose to go that route with this particular script. However, she does center the female characters in the story, giving them more agency that Zayas was able to at the time. Felicia's importance to the plot is certainly highlighted in A Little Betrayal Among Friends, and Svich celebrates Felicia's bad girl behavior in a way that Zayas had to apologize for in the seventeenth century. While Zayas had to be sure and issue a punishment to Fenisa at the end of the play for being such a bad woman, Svich is able to have her couple up with don Juan at the end of the play instead. While Felicia/Fenisa may have more freedom in Zayas's version, her ending in Svich's story gives her a traditionally happy end on par with the fates of the other characters.

Svich also applied practical adapturgical tools to A Little Betrayal Among Friends to keep it short, active, and interesting for a twenty-first century US audience. The play is efficient and should run about ninety minutes, which is what a contemporary audience expects. Svich also shifted technological references in the play so that characters use cell phones instead of photographs or letters, and the language is casual and unconstrained by set rhythms or rhyme schemes, except in the case of the song. There are no long, expositional monologues and more romantic action, in the form of kissing and making out, happens onstage, though most of the violence involving women as either aggressors or victims still happens offstage. These practical changes, alongside the ethical and cultural ones, serve as useful guides for future adapturgs like myself. 


\section{Chapter Three}

Transferring Intention in Fever/Dream 
Though Adaptation Studies has, in the past, relied on comparison between original and adaptation, and, later, intertextuality, its present focuses more on advocating for a more diverse literary canon and focusing their own research on creating a collection of best practices for academic inquiry into adapted works. With this concept, Thomas Leitch suggests that adaptation studies may lead the charge from a canon of literary pieces to a canon of questions which are regularly applied to adaptation in academic inquiry. Presumably, other fields could then be inspired to create their own canon of questions appropriate to their own areas. The field of dramaturgy in the United States is already firmly rooted in the practice of intentional and consistent questioning of literary work. However, the practical work of production dramaturgs presents a challenge to the comparison between the dramaturg's and the adaptor's work. In defense of this comparison, dramaturgy is, like adaptation, a multifaceted art form. Michael Chemers defines it as "a term that refers to both the aesthetic architecture of a piece of dramatic literature (its structure, themes, goals, and conventions) and the practical philosophy of theatre practice employed to create a full performance. Together, dramaturgy is the very blood coursing through the veins of any theatrical production" (3). Through script analysis and investigation of Caridad Svich's writing process, the previous chapter discussed the aesthetic architecture of $A$ Little Betrayal Among Friends, which required an understanding of María de Zayas y Sotomayor's La traición en la amistad. This chapter will look at the practical philosophy side of dramaturgical practice, including the big -- perhaps even canonical -- questions that dramaturgs ask of a play or plays. It will also explore the question of whether and how the practical aspects of production dramaturgy align with 
adaptation studies. Finally, I will reflect on my own dramaturgical work as a director ${ }^{25}$ on a woman's adaptation of a Spanish Golden Age play: Fever/Dream, adapted by Sheila Callaghan from Pedro Calderón de la Barca's La vida es sueño.

Production dramaturgy seems at first glance not to relate as strongly to adaptation studies, since production dramaturgs are not involved directly with the creation of adapted texts. However, the overlap between adapturgy and production dramaturgy is both strong and justified, which Jane Barnette illustrates clearly in her book Adapturgy. Barnette reflects on her role both as an adapter of other work, which builds on the skills developed by the new play dramaturg, and as a production dramaturg working with adaptations written by other people. She clarifies the overlapping areas of these roles as well. For the context of this chapter, it is significant that tasks she suggests overlap between production dramaturgs and adapturgy include "audience conversations/critics' reviews/ designer communication/ [and the] adapter and director's vision" (38). All of these activities involve both academic inquiry and practical application, a quality that is familiar for theatre scholar/artists, but which may prove to be more revolutionary for the field of adaptation studies. Barnette calls this process "Practicing Theory," putting into words the value of theatrical art which artists in the academy must constantly advocate for, including work done by production dramaturgs which were not included in the limited list above but were included in later chapters of the book, work including lobby displays, embodied experiences (or field trips), and websites, wikis, and study guides for the cast and creative team. Barnette also discusses some of the philosophical work which must be done collaboratively to ground these practical creations, like conscientious casting, a practice

\footnotetext{
25 Though this production had a designated dramaturg, other members of the production team often do
} dramaturgical work as well. 
replacing colorblind casting with active engagement from the director to consider the implications of their casting decisions on the audience's perception of the story, especially when it comes to issues like race, gender, ability, age, and other visible manifestations of privilege or lack thereof.

Questioning is one of the primary tasks of any dramaturg. This includes other big picture questions of framing and analysis, which I believe are also important parts of the production dramaturg's work. In her article “EF's Visit to a Small Planet: Some Questions to Ask a Play," Elinor Fuchs outlines a myriad of questions that a dramaturg might ask about a play they are working on, adaptation or not, which will help them communicate with the director about the philosophy and priorities of the production and later bring the cast and creative team along on that philosophical journey. Similarly, Chemers outlines several important questions in Ghost Light. This line of questioning is similar to the questions that a scholar in an English or adaptation studies department may ask of any adapted work, and I believe a recognition and adoption of these concepts will help develop what Thomas Leitch has described as Adaptation Studies 3.0. In this chapter, I will expand upon two lines of questioning specifically: why this play now? and what were they trying to do? were they successful? was it worth doing? to more thoroughly understand Fever/Dream and its relationship with La vida es sueño.

\section{Why this play now?}

This question delves into the intertextual relationships created by the play with its current audience. Though this question only explores the relationships of the audience to the piece - just one side of the questioning developed through the theory of intertextuality 
- the answer is an invaluable tool for the entire literary and creative team, from literary managers and artistic directors who make the choice to produce a play to directors and designers who must choose how to present the play to their present audience. If a director's answer to why this play now? is, in part, that undergraduate students at an academic institution should have the opportunity to perform, design, and watch classical theatre, the production may look very different from one in which the director strives to accent the similarities between socio-political issues presented in the play and in present-day politics. Such a production may choose to modernize the production's designs and acting style to highlight those similarities and help the audience make the connection.

Directors are not the only people engaged with this dramaturgical question, though. A literary manager or producer must answer this question for each piece they choose to work with or produce to assure that the chosen script will have a meaningful impact (and will do no harm) in the time and space where the production is taking place. For example, the Rogers and Hammerstein musical Seven Brides for Seven Brothers romanticizes kidnapping women and holding them hostage along with reinforcing gender stereotypes, which is likely impossible to avoid in most musicals of the 1950s. Asking why this play now? may lead a producer to justify a musical with regressive gender roles on the grounds of escapism or ticket sales, but kidnapping is more difficult to justify on a moral level. This may lead to more extreme adjustments, like the rewriting of another Rogers and Hammerstein musical, Flower Drum Song, by David Henry Hwang to ensure that AsianAmerican voices were included in the story (Hwang xii). In this way, asking why this play now? serves multiple purposes - to help dramaturgs, literary managers, and production teams connect with their audience's intertextual expectations, and to consider the socio- 
political implications and potential harm or good that may come from producing a specific work in a specific place at a specific time.

While I find this question to be useful in many contexts, I will also use Barnette's re-writing of this question for the context of adapturgy specifically. She suggests that adapters ask, "why this source as theatre now?" (36). This version moves the question away from the end product and therefore assists adapturgs, those who practice adapturgy, earlier on in their process. Even if a play does not yet exist, an adapturg or producing company could ask this question to help them decide whether to commission or set to work on an adapted play. In this chapter, I will use this version of the question to apply specifically to the source text in question, La vida es sueño, and I will ask why this play now? about Fever/Dream, the adapted text. With this approach, I can more accurately investigate the differences between adapting La vida es sueño in general and the specific choices that make Fever/Dream relevant in the twenty-first century.

\section{What was the artist trying to do? Were they successful? Was it worth doing?}

These three questions were posed by Johann Wolfgang von Goethe, a Weimar period German philosopher and dramaturg. They are central to the history of theatre criticism and can be applied to playwrights, adapters, directors, and entire productions. These questions are used by more contemporary scholars like Michael Mark Chemers to help budding dramaturgs look at a piece of theatre through a more objective lens. Though they are most often used in theatre criticism, they are also applicable to adapturgy specifically. Is the adapter trying to reinvigorate a text for a new audience? Or perhaps they are trying to comment on a foundational text's flaws and ask an audience to reconsider their cultural heritage. How does an adapter successfully reach those, or other, goals? And 
what works are worth reviving or commenting on and when is such a revival simply not worth doing? These questions have the potential to overhaul academic responses to dramatic literature in much the same way that questions about the process of adaptation may guide the study of those adaptations in Adaptation Studies 3.0.

Often, the goals of the individuals involved in a production are different but work in tandem to create meaningful work. To borrow an example from the previous chapter, Caridad Svich was commissioned to write the script to A Little Betrayal Among Friends by a producer who wanted to share Spanish Golden Age theatre with a traditional Shakespeare in the Park style audience. Her goal, on the other hand, was to work with a script by a woman that she enjoyed and could fully support (Interview with Caridad Svich). The resulting script achieves both goals and seems to have been successful on both ends. Steve Parks, a Long Island theatre critic, describes this first production as "Sex and the City with an ineffectual Mr. Big (Don Juan) makes for a one-sided battle of the genders. Ladies get the first and last laugh" (newsday.com). Another community member named Linda Henninger praises the play on a neighborhood blog site called "Patch," and Svich herself seemed pleased with the production. Therefore, it seems that the joint goal of both Svich and the Arimid Theatre of an entertaining, classically inspired feminist production is achieved.

Both Fever/Dream, which was written for a twenty-first century audience, and twenty-first century productions of La vida es sueño must take Goethe's questions into account from a dramaturgical perspective. While the focus of this chapter is primarily on Fever/Dream, audience and artistic responses to other translations of La vida es sueño may 
offer insight into the various ways that a piece can be adapted and the particular strengths of Sheila Callaghan's choices in the adaptation of Fever/Dream.

\section{Adapturgy}

Adaptation Studies 2.0 offers useful theories and considerations for production dramaturgs. For example, Barnette cites the experience of palimpsestuous pleasures as important to dramaturgs. This is a clear reflection of Linda Hutcheon's A Theory of Adaptation, highlighting the similarities between Adapturgy and Adaptation Studies. The theory, as I mention in Chapter One, is that the person watching, reading, or otherwise experiencing an adaptation is able to see the shadow of the primary text behind the adapted text they are experiencing at the time, making the viewing experience richer and more valuable. This theory's roots in intertextuality are clear in that the audience's reactions to the adapted text are colored by their lived experience and background. However, the idea of palimpsestuous pleasures only considers the audience's experience of the source text, not the other multitudinous experiences which impact their viewing. Barnette narrows Hutcheon's theory and emphasizes the fact that the palimpsestuous experience is pleasurable, meaning that for this section of the theory, the performance's goal is to make the experience of seeing a performance of an adaptation more pleasurable by learning and teaching about the original context and helping audience members activate the knowledge and experiences of the text that they already have.

Palimpsestuous pleasures come from recognizing both similarities to and differences from the source text. The effect of these changes, including any choices which push back against the messages in the source text to make it more socially acceptable to a 
contemporary audience, Barnette calls the "Janus effect," invoking the two-faced Roman god of doorways. She says: "the Janus effect, then, is the transformation that successful dramaturgy makes within the process and product of adaptation for the stage" (72). At times, these differences allow adaptors to make their work more interesting and engaging to audiences in their own space and time, including eliminating damaging gender and racial biases which may be inherent in the original text. These changes may also help the adapted text fit within the unspoken social contract between audience and art in practical terms like length, language, and staging conventions, though those questions overlap with Barnette's last consideration: the geographies of adaptation.

Geographies of adaptation apply more aptly to pieces that are adapted from other kinds of sources like novels and films. Most novels challenge the neoclassical three unities, the traditional 'rules' of theatre which French classicist Lodovico Castelvetro claims to have gleaned from Aristotle's Poetics. The unities suggest that a play should hold to a unity of time, of place, and of action, meaning he observed that successful plays occurred in one place over a believable amount of time (generally events that happen within one day are considered to be within the unity of time), and contained just one plot. Spanish Golden Age plays often flaunted these unities, and novels, which were never confined by such ideas, smash the unities to pieces, making it difficult to fit their plots into a dramatic structure. The geographies of adaptation deals with moving these expansive stories into a stage space through creative and often non-traditional staging. Barnette's discussion also reflects the reality that many adaptations are inter-cultural, which applies to all the adaptations in this dissertation. Moving a story from one culture to another is a delicate process in which it is 
important to connect to the adaptation's audience without betraying the culture the story came from as well.

The more traditional tasks of a typical production dramaturg, which focus on framing the story for the actors, production team, and audience, are less clearly connected to adaptation studies but are still supported in Barnette's theoretical frame. These skills and tools are more directly related to the art of theatre-making and, therefore, their place in adapturgy as Adaptation Studies 3.0 is up for debate. However, the only task that Barnette includes as only belonging to production dramaturgy and not to adapturgy is the compilation of production histories. She does include many details about other production dramaturgy tasks, therefore justifying the exploration of the relationship between adapturgy and production dramaturgy. The question facing adaptation studies scholars then becomes whether and how much production dramaturgy and its related tools should be considered in the formation of this new wave in adaptation studies.

Production dramaturgs and other members of production teams often prepare a variety of resources and engage in various research and literary activities for any given production. The value of these resources is clear in a theatrical context, but it is difficult to present in more traditional academic settings. Barnette discusses conscientious casting, cast and crew wikis, embodied experiences, websites and study guides, lobby displays, program notes, and audience conversations specifically in Adapturgy. Most of these tasks, especially the creation of websites and study guides, embodied experiences ${ }^{26}$, lobby displays, and program notes, involve thorough research and the provision of background information for the cast, production team, and audience. However, the product of that research is not the

26 'Field trips' for the cast, crew, and production team to places or events that help them understand the world of the play and their characters. 
kind of paper or book which would be expected in an academic context, making it difficult to show how these pieces might fit into Adaptation Studies 3.0. However, it is exciting to imagine how the field might be diversified and improved through new kinds of work. On the other hand, audience conversations and conscientious casting (along with lobby displays, program notes, and possibly study guides) directly affect the audience's experience and therefore the performance text -- a creation distinct from the script of the play which includes the living actors, production elements, and even audience reactions each night of the show -- of the play itself. This makes them even more difficult to record and reproduce at conferences and in journals, though the experiences are shared among many in the audience and may therefore be recorded in performance reviews and theatre archives.

I worked with a production dramaturg when I directed Fever/Dream for the University of Missouri in 2018, and most members of any given production team will engage in some form of dramaturgical research, whether they identify it as such or not. Since this play is an adaptation of La vida es sueño, I will look first at the dramaturgical context of that play and then look at both the big-picture dramaturgical questions and the specific production dramaturgy used in our production of Fever/Dream. The work done for this adaptation supports Barnette's inclusion of production dramaturgy in the field of adapturgy. As a theatre artist, I encourage the inclusion of similar work, and I believe dramaturgical work in general could fit well into Leitch calls Adaptation Studies 3.0.

\section{La vida es sueño}


Fever/Dream is an adaptation of one of the most well-known and loved Spanish Golden Age plays, La vida es sueño by Pedro Calderón de la Barca. In order to understand Fever/Dream, it is important to understand La vida es sueño, which I impressed on my actors and production team as well. I will therefore begin my evaluation of the ways production adapturgy contributed to this performance text with a description of the original play and an analysis of dramaturgy's canonical questions in the context of an adaptation of this particular play. For now, I will delve into the impulse to produce an adaptation of $L a$ vida es sueño in general and not Fever/Dream specifically.

Pedro Calderón de la Barca's 1635 play, La vida es sueño has remained one of the most frequently produced of Spanish Golden Age plays throughout the twentieth and twenty-first centuries. In Jonathan Thacker's 2007 summary of English-language productions of Spanish Golden Age plays in Great Britain, he points out that "of the six Golden Age dramatists performed ... Calderón's plays ... have most often been produced, with 28 productions of 10 different works; however, half of these productions (14) are of La vida es sueño" (Boyle and Johnston, 16). Casual observation of plays which are regularly anthologized, reviewed, and advertised suggests that this trend has remained consistent. La vida es sueño has been translated and adapted by award-winning playwrights like José Rivera and Nilo Cruz, and its translations can be licensed from Dramatists Play Service, Concord Theatricals, Dramatic Publishing, and others. Its exciting and imaginative plot, clear philosophical point of view, and poetry are attractive aspects of its story. These aspects combine with the fact that it is already somewhat removed from the specificity of Golden Age Spain - it is set in 'Poland,' which appears to be Calderón's 
stand-in for a far-away fairy tale land -- to appeal to producers and audience and translate with relatively minimal explanation to contemporary stages.

The easily transferrable fairy tale aspects of La vida es sueño's setting begin at the top of the play, when Rosaura stumbles across a mysterious mountain fortress after fleeing from a "hipogrifo violento" (line 1) or "violent hippogriff," which seems to be a metaphor for a storm, but certainly evokes a fantastic image. In this fortress, Rosaura and her assistant Clarín discover Segismundo, a wild man who has no idea at this point that he is the prince of this mythical version of Poland. As the play goes along, we discover that Segismundo was born during a terrible storm and that his mother died in childbirth. On top of that, a prophecy warned his father, King Basilio, that Segismundo would be a terrible and vicious king, so Basilio exiled him from birth, never telling him about his true origins. However, Basilio has no other children and he decides in the play to give Segismundo a chance to try being king before passing the throne along to his niece and nephew. To ensure that Segismundo returns to the mountain without complaint after this experiment, Basilio and his assistant, Clotaldo, plan to tell Segismundo that the whole thing was a dream, should anything go awry. The experiment goes as expected - Segismundo knows nothing about leading and lashes out at the members of the government establishment because they abandoned him on a mountain his entire life. Basilio and Clotaldo remove him from office and send him back to the mountain, where they tell him that the whole thing was a dream. Segismundo has a moment to reflect on the idea that all of life is nothing but a dream before the townspeople arrive at his fortress and offer to help him take his kingdom back from King Basilio and the people he would unfairly put in leadership. Segismundo agrees and there is an epic battle between the two sides ending in Segismundo's victory. Unlike a 
traditional fairy tale, Segismundo defies both fate and the monarchy and promises to be a thoughtful and spiritual king.

As a dramaturg and adapturg, I am curious as to why this production has captured the imagination of twenty-first century audiences and producers more than so many of its counterparts. Though I cannot explain other producers and directors' motivations, I am able to reflect on my own dramaturgical process in this case. This reflection is an important part of the dramaturgical process and is a demonstration of the line of study central to both adapturgy and Adaptation Studies 3.0. The most important dramaturgical question in this case is Barnette's adaptation of dramaturgy's primary canonical question: why this source as theatre now?

\section{Why this source as theatre now?}

The 'as theatre' part of this question is relatively easy to respond to in this context. Since La vida es sueño was written to be performed as theatre, there is no need for a transition from another format. Though it ignores all of the neoclassical unities ${ }^{27}$, this play was intended to entertain and inspire seventeenth century audiences in an afternoon or evening of entertainment, and it still serves that function today. In fact, its popularity as a translated text and not just as an adapted one shows that it can still be performed in more or less its original context today. This part of the question is, perhaps, replaced by the justification to do a highly adapted version of the script and not a more 'authentic' translation.

27 Though I did not mention any subplots for the sake of space and clarity, they do exist, meaning the unity of plot is not present either. 
Adaptations are an important part of global culture in the twenty-first century in which culture is saturated by reimagined ideas from any and everyone around the world. As such, the very nature of Fever/Dream as an adaptation made it appealing to me as an artist. The choices that Callaghan made in doing this adaptation add as much to the story as Calderón's original ideas. Barnette places adaptations on a multi-faceted trio of spectrums consisting of showing vs. telling, here vs. there, and now vs. then. In this case, Callaghan moves Fever/Dream all the way from there and then to here and now, though perhaps slightly removed spatially from the theatre to an office building. She also chooses to move the story further along the scale in the direction of showing vs. telling, though $\mathrm{La}$ vida es sueño already contained a fair amount of showing, since it is a play and not a novel - the more traditional telling medium. La vida es sueño did, however, rely on long monologues to give exposition and sometimes action as it was happening on- or off-stage, while Callaghan translates almost all of this into dialogue and action via stage directions. This shift toward showing is, perhaps, a reflection of the cultural impact of television and film, media which rely more on showing than telling. Audiences respond to television and film, and theatre can learn from these examples of showing to make their pieces more engaging. Callaghan is the perfect person to make this transition, as she went on to a successful screenwriting career following this production (Callaghan, sheilacallaghan.com).

While it is convenient that this story was already a play and therefore somewhat easier to adapt than a novel, there are other reasons to produce an adaptation of La vida es sueño in a twenty-first-century university context. Its popularity and place in the traditional literary canon still carry clout in academic circles, and students, community members, and 
faculty are likely to either recognize the story and be edified by their re-engagement with it or to learn more about La vida es sueño as an important literary text through their engagement with this production. The essential message of the play, that one should take control of their own fate and take collective action against flawed leadership, is one that resonates with twenty-first-century sentiments as well, especially those of college-aged students. This play happened to be produced between the 2015-2016 Concerned Student 1950 protests on MU's campus and the 2020 Black Lives Matter protests around the country, so collective action and taking a stand against tyrants was a theme that resonated with our community ${ }^{28}$.

Many of the reasons for producing this piece as theatre at the University of Missouri in 2018 are reflected in the dramaturgical justification for Fever/Dream itself, which I explore in more detail below. This section will illustrate our application of production dramaturgy and justify its place in adaptation studies.

\section{Fever/Dream}

I directed Fever/Dream at the University of Missouri - Columbia in the fall of 2018. This project allowed me to have first-hand experience with the dramaturgical process of mounting an already-adapted Spanish Golden Age piece for a University audience. As such, my production team, department, and I addressed essential dramaturgical questions such as how to cast the piece most effectively, how to present 'impossible stage directions,' and the best way to offer context about the Spanish Golden Age and La vida es sueño to our production team, actors, and audience. Along with my dramaturg, Taylor Sklenar, I

\footnotetext{
${ }^{28}$ Though, admittedly, the king in La vida es sueño is replaced with another king, so the pairing is not ideal.
} 
synthesized background information for these groups both about La vida es sueño and about the specific world that Fever/Dream occupies. This experience gave me invaluable practical insight into Adapturgy's practical applications and effect on theatre performance. These effects tie a performance text to the broader academic discussion of a text, enriching both the performance and the academic discussion.

Fever/Dream follows the plot of La vida es sueño closely but maintains significant differences, most notably in its genre, which is much more comedic than the original. Like La vida es sueño, Fever/Dream focuses on a powerful father passing on his legacy to his cursed son. In this case the father, Bill Basil, is the CEO of a nondescript Fortune 500 company and his son, Segis, is housed in the basement of that company. Segis fulfills the role of a customer service employee, but his working/living conditions are Hellish and disgusting. Basil read in his son's horoscope that he would take over the company and prove to be a tyrant and to avoid this fate he banished Segis to this fetid dungeon. Shortly after the play begins, Basil's horoscope inspires him to give Segis a chance and he decides to bring Segis back up from customer service, dress him like a CEO, and see what he does as head of the company for a day. Predictably, this does not go well, as Segis relies on clichés and expressions he has culled from magazine articles about how Basil "bulldozes the competition" and "whips his employees into shape." The play realizes these cliches in a literal way using magical realism ${ }^{29}$ and creative expression. Basil determines that this leadership experience was unsuccessful and instructs his assistant (and Segis's guardian) Fred Clotaldo to take Segis back to the basement and tell him that the whole thing was a dream. Segis accepts this and the office's steadfast employees, Stella Strong and Aston

\footnotetext{
${ }^{29}$ Though many, including Caridad Svich and Elaine Romero, have objections to this term, the suggested alternative term is "Latinx Realism," which I do not feel applies to Callaghan and her work.
} 
Martin, become $\mathrm{CEO}$ and $\mathrm{COO}$ of the company in his place. However, the company's interns, dissatisfied with Stella and Aston's leadership, storm Segis's basement hideout and insist that he become the true leader of the company. In another somewhat magical moment, they escape with him to the top floor, where they have an office battle with the pro-establishment staff, which leaves Segis and the interns victorious. Segis has the opportunity to kill his father but chooses instead to merely force him into retirement and take over the reins of the company. The characters couple off predictably, Segis promotes Clotaldo to Vice President of the company, and everyone lives happily ever after.

Though the plot of Fever/Dream is clearly similar to La vida es sueño, the tone, to a twenty-first century US audience, is clearly distinct. Callaghan imbues the text with her dark humor and encourages extravagant theatricality through dense chunks of 'impossible' stage directions. For example, in the scene where Segis is given the reins to the office, the character Claire spends the entirety of the scene setting cups of seltzer water around the stage. The sequence gets more and more surreal and chaotic until Stella enters the scene, puts her foot down, and gets things back on track. Segis is enamored by her power and through the power of his love, the stage directions say that "The room becomes an ocean. /ALL THE SELTZERS IN THE ROOM glow blue and begin to fizz, volcanically" (47). Other stage directions throughout the play are similarly fantastic, encouraging heightened technical theatricality that Calderón could not have imagined, though a certain amount of magic is also present in La vida es sueño.

\section{Why this play now?}


I asked for the chance to direct Fever/Dream primarily because of the personnel and resources available at the University of Missouri (MU) in 2018. I wanted to present the heightened theatricality in the script (shown in the stage directions and integration of magical elements) as faithfully as possible, and the resources available at MU were greater than any I was guaranteed to have after graduation. Brad Carlson and Marc Vital, my set/projections designer and costume designer, respectively, were the highly trained, imaginative, and talented designers that were necessary to make the magic of this production happen onstage. It was also important to me to have the collaboration of my violence and intimacy designer, Kate Busselle, especially for the office supplies battle at the end of the play. Carlson was also the department's technical director, capable of allocating the extensive resources needed for the production. Though the needs of this script made it an extravagant proposal for a graduate student in the department, I was unlikely to find a team as well-suited to this particular script in my near artistic future.

For the theatre department's part, the advantages to producing this script lay mainly in its pedagogical and academic advantages on campus and in the opportunities it offered for theatre students. As an adaptation of a well-known Spanish Golden Age play, Fever/Dream fits well in an academic season because it provides an experience in conversation with the Spanish Golden Age for the university community. Students required to see the play are likely to absorb at least some of the plots and themes of La vida es sueño, and it provides opportunities for interdisciplinary connections with the School of Languages, Literatures, and Cultures. Fever/Dream also has a large cast with several significant roles for both men and women, most of which are age-appropriate for college students. There are also ensemble opportunities in the interns and accountants. I was able 
to cast seventeen students in the production including students who had never acted before, students who had been in the department for a long time but had never enjoyed starring roles, and a Masters student in the role of Segis. There were also opportunities for the aforementioned faculty designers to show their prowess and for student designers, stage managers, and those involved in set construction to work in new mediums such as welding together windows actors could climb on and creating secret doors (the final set had three). The academic criterion that I was most grateful for was that this play was chosen for the season in part because it related directly to this dissertation and indirectly to Busselle's, as she also wrote about Callaghan's work. In this case, Fever/Dream contributed to MU's academic community in a multitude of ways, greatly influencing the faculty's choice to include it in their 2018 season.

Of course, the question of why this play now? is most meaningful when the dramaturg considers the socio-political atmosphere of the world surrounding the production. In this case, Fever/Dream's setting in the somewhat absurd office of a businessman practicing flagrant nepotism found unique meaning in the middle of the Trump presidency. The play was first produced in 2009 , so it was written in the middle of the United States' Great Recession. The lack of faith in Capitalism and the US economy underscores this piece and may have inspired Callaghan to change the King from La vida es sueño to a CEO in Fever/Dream. While kings could both control and destroy seventeenth century Spain, business tycoons could both control and destroy society in 2009, a fact which Callaghan seems to be criticizing in Fever/Dream. While we were ten years past the 2008 housing market-induced financial crisis and two years shy of the 2020 Covid-induced financial crisis in 2018, this play's skeptical view of the capitalist system and power- 
hungry businessmen still spoke to me as a director and gave the play contemporary relevance at the time.

Though these considerations appear to be simply practical questions related to the art of making theatre more than to the academic pursuit of Adaptation Studies, the points that they cover reveal the intertextual context of Fever/Dream as it was received by 2018 MU audiences. On a theoretical level, they also feed into the practice of canonical questioning proposed by Leitch in his proposal for Adaptation Studies 3.0. Because Fever/Dream was produced at a University, more of the audience was likely to have time to reflect on its origins and the story of its adaptation than may have had access to it in community or even regional theatre. The interdisciplinary connection with the University community means that many of the audience members were aware of the original script and perhaps had even engaged with it academically, meaning they would be familiar with the characters and would more readily make the connection between the seventeenth century power of King Basilio and the twenty-first century power of Bill Basil, following Callaghan's connections and forging their own versions of their own connections in the context of Trump's United States.

On the other hand, many audience members were also students in theatre classes who may not have had much experience seeing theatre. Most of these students have the advantage of classroom discussions before and after seeing the show, allowing them to reflect on their own intertextual connections and perhaps on the ones intended by the playwright. Many of these students live in a world shaped by technology, an aspect of the script which was entirely added by Callaghan to connect with her twenty-first-century audience. In this case, the audience's intertextual connections were more likely grounded 
in that understanding of technology and the entertaining references to the history of technology. Not having as much context from La vida es sueño would possibly make it more difficult for these students to focus on the plot but may also help them connect with characters who were less significant in La vida es sueño, like the interns and Claire, who had more distinct voices and important roles in Fever/Dream than they did in La vida es sueño. Since the newest wave of adaptation studies is not focused on comparison studies, each audience member's experience is neither positive nor negative but always noteworthy.

The students and faculty interacting with our production of Fever/Dream as designers, technicians, and directors also had a unique literary experience with it as an adapted text based on the production value available at MU. Given the open-endedness of Callaghan's impossible stage directions, the play could have taken a much more representational, low-tech approach which would have resembled the technology available in the Spanish Golden Age more than the technology of the twenty-first Century. The rapid changes in scene in La vida es sueño suggest that the set was relatively bare, and actors created ambiance and context verbally and through their actions. While Fever/Dream could be interpreted in a similarly streamlined way, MU's production instead leaned fully into the different ages of technology both mentioned in the script and required to visually create Callaghan's creative stage directions. The inclusion of this technology highlights Callaghan's modernizing choices as well as the power that technology has in twenty-firstcentury society as compared with the seventeenth-century text the story originated from. Not only does basil represent the king in this instance, but the metaphor created by comparing the mountain in the wilderness occupied by Segismundo in La vida es sueño to the basement full of old technology where Segis lives and works in Fever/Dream is 
highlighted when technology occupies so much of the design team's minds and efforts. The specific production elements and artistic choices made by my excellent team also help create the particular performance text unique to each night of our production, a further adaptation of Callaghan's written play text in and of itself. The choices making up these performance texts sprang from every answer to why this play now? that the theatre department, designers, myself as a director, and others made along the way.

\section{What were they trying to do? Were they successful? Was it worth doing?}

These classic dramaturgical questions are more typically answered by theatre critics and are somewhat difficult for the person producing the art to answer, but they form an essential part of production dramaturgy and the canonical questions characteristic of Adaptation Studies 3.0, so I will make an attempt to discuss them as objectively as possible. I believe that an audience member would perceive Fever/Dream's most obvious goal to be entertainment. The spectacle incorporated into this particular production backs up this idea - we had musical numbers, people turning into ants and climbing the walls, and an epic office-supply battle. The sets were complex and beautiful, and we had phones onstage which sent video signals to projectors above the stage. On top of that, Callaghan's comedic voice makes Fever/Dream feel like a romp, capturing the United States' post-9/11 penchant for dark comedy (Gournelos and Greene).

On a purely entertainment level, our production was, I believe, at least moderately successful. I had talented actors who presented their characters with engaging charisma and elicited laughs from the audience. Carlson gave me a set and projection design full of surprises and beauty, including a real dot-matrix printer, a painting that swung open during 
Basil's dream to reveal a Segis singing a rock song written for this piece ${ }^{30}$, and the ability for my interns to vlog to the stage's screens. Vital created helmets that helped the accountants turn into account-Ants and scurry around the set, even climbing the walls at times, and the sound designer, Gabby Velasquez, created an ambiance that was in turns both delightful and bizarre. Busselle also created hilarious and exciting fight sequences and intimate moments as well as training the actors to use the climbing grid onstage. The only things that impeded our spectacle were the slow scene changes as a result of very large set pieces which did not have enough castors on them and therefore moved very slowly, a problem which was exacerbated by the length of the play. Some of the technology also glitched out at times, which may have distracted from its overall effect.

Another goal of the production was, of course, to teach the MU community about La vida es sueño and engage them with a reimagined piece of Golden Age Theatre. This goal was probably more obvious to faculty but could also be perceived by undergraduates, though Catherine Larson argues that the significance of the difference between the two texts "raises important questions regarding audience expectations, as we consider whether our knowledge of the play and its characters enriches or interferes negatively with our esthetic experience" (27). Those familiar with the original text would also see the goal of engaging the palimpsestuous pleasures (the term that Barnette borrows from Linda Hutcheon and uses as a foundation of adapturgy), whether those pleasures were successful or not. These pleasures were probably most effective for the actors and design team since both Sklenar and I had the chance to talk to them about the original script and emphasize the connections between our work and the original piece. These students and staff also

\footnotetext{
${ }^{30}$ Though La vida es sueño, unlike La traición en la amistad and Los empeños de una casa does not include any songs.
} 
spent more time engaging with the text in-depth and becoming intimately acquainted with the plot and characters. Even if we had not emphasized the adapted nature of the play, they would likely recognize these story elements were they to encounter La vida es sueño in the future. However, the work put in to establish these intertextual connections was more intentional and time-consuming than the time it took to connect the actors and production team with the theatricality of the piece or their connections with their own culture. While we included information about the Spanish Golden Age and La vida es sueño in the program notes and the lobby display (which patrons had to pass before entering the theatre), there were other important elements of Fever/Dream that we had to touch on as well like the historical moment in which the play was written and the evolution of technology affecting the present moment in which the play was set, as Callaghan intentionally wrote Fever/Dream to be performed in the present moment - whatever that may be for any given production. Some audience members came because they already loved La vida es sueño and wanted to see the connections, though they may have been distracted, as Larson mentioned, by the extreme difference in tone between the two texts. The activation of palimpsestuous pleasures for students who had not encountered La vida es sueño may have been lost in the shuffle and therefore ineffective. However, in less concrete ways, Fever/Dream surely added something to their overall understanding of La vida es sueño, were they to encounter it in the future.

A final goal that the audience may have perceived from our production of Fever/Dream (though there are many possible goals) is a critique of capitalism that is more or less independent from La vida es sueño. This commentary aligns with Barnette's Janus effect, which emphasizes the differences between the original and the adapted text and the 
understanding that can be drawn from holding the two ideas in one place. In this case, the critique of capitalism is a modern complaint which did not apply to La vida es sueño. The overall complaint tracks with Calderón's intended theme, to criticize the divine right of kings and the idea of fate, which is still reflected in the criticisms of capitalism, the king of the twenty-first century, and horoscopes, which are taken much less seriously than bad omens of the seventeenth century. Though horoscopes hold less sway than seventeenth century prophecies if literary themes are to be believed as reflections of society, they still hold significant cultural sway. Popular articles like Hilary George-Parkin's 2021 BBC article "The Anxieties and Apps Fuelling the Astrology Boom" and Christine Smallwood's 2019 New Yorker article "Astrology in the Age of Uncertainty" are confirmed in their validity by statistical and academic inquiries like Y. Wu and Z. Z. Chen's "The attraction of horoscopes: A consensual qualitative research on astrological personality description" and the 2021 article by Kristoffer Romulo B. Lopez et.al. entitled "Social Contagion of Astrology in the Social Media amid COVID-19 Pandemic.” These show that astrology's popularity has only become more significant since Callaghan wrote this plot point in Fever/Dream. Seeing the play again after the 2021 astronomy boom and the rampant spread of fake news over the last few years may be a very different experience than it was in 2018. The powerful women and feminist undertones in Fever/Dream perhaps provide a more Janus-like commentary than the critique of capitalism since Calderón lived in a society in which educated women in power were rarer (with the obvious exception of the queen). Contemporary audiences are more likely to sympathize with the character of Stella, who is demonstrably competent and is overlooked for the boss's feral son. In the end, Segis agrees to share power with her and add her name to the company, a more redemptive arc 
for him in terms of gender parity than the marriage alliance shoehorned into La vida es sueño.

These messages are more in-line with the everyday experiences and background of our audiences and were, therefore likelier to be clearer and easier to comprehend, even without the context of the original script. Some of these social criticisms, like the criticism of fate, were simply less significant to our production because they are less significant to our society. Basil's reliance on his horoscope makes him seem like a foolish old man while Basilio's belief in fate seems relatively reasonable in the context of other seventeenthcentury plays. The criticism of the US's capitalistic system was probably also less surprising because criticizing capitalism today is much more common than criticizing the monarchy in the seventeenth century. Seeing a ridiculous businessman onstage was likely to register as relevant to the time for our more liberal audience members, though those who were inclined to be sympathetic toward Trump, a significant population at our midMissouri school ${ }^{31}$, could have the luxury of ignoring the connection. This is one reason why I chose not to costume Basil in Trumpish clothing or makeup, which would alienate the audience in this specific location.

The feminist reading was probably harder for our twenty-first-century audiences to see without experiencing the Janus effect which would come from knowing La vida es sueño. Stella's frustration with the incompetence of all the men around her is clear either way, but it would be more striking for audiences familiar with her relatively passive role in the original play. Our production also included Black individuals in the roles of Clotaldo and Rose, which supported an intersectional feminist reading of the play. These characters

\footnotetext{
$3141 \%$ of Missouri's population identifies as Republican according to the Pew Research Center. The Mizzou College Republicans Facebook group has 1,567 likes at the time of writing.
} 
are treated poorly by Basil and promoted at the end of the play, though Clotaldo's support role, even as Vice-President, is not the most ideal placement for a BIPOC. The cast also included a variety of genders and sexualities, though the script did not include any nonhetero relationships. The actor playing Segis identifies as non-binary, which somewhat displays a subversion of hetero relationships, as Segis has a romantic relationship with a woman (played by a woman) in the piece. However, since the character of Segis is male and presents as masculine, the subtlety of a non-binary/femme relationship was probably lost on our audience. This particular production did include an interracial relationship, which hardly seems worth noting in 2018 but may have been notable to conservative members of our audience. I was also lucky to be able to cast talented actors with a variety of body types, though I could have gone to further efforts to find actors on the disability spectrum. This casting could have been more diverse but did represent the racial breakdown (if not quite the gender or ability breakdown) of MU. Taking this casting into consideration is an important part of exploring the play's feminist impact. I believe that these choices were integrated seamlessly and would not be actively noted by the audience, but the consideration of these various elements and allowing students to see a variety of people in these roles I hope would subconsciously encourage them to understand the play as more intersectional and representative of them than the original text was likely to be.

The final question is, of course, whether these things -- theatrical entertainment, exposing the community to La vida es sueño, and commenting on our sociopolitical context -- were worth doing. Larson concludes that "Fever/Dream's timeliness, esthetic vision, poetic coherence and ideological, socio-cultural and linguistic re-writing of La vida es sueño signal its emergence as a successful refraction, a new play separate from but indebted 
to its source text" (49). This seems to be an endorsement of any production of this particular piece. Our production also garnered numerous awards in acting, design, and directing from the Kennedy Center American College Theatre Festival. If I had to choose one goal that I believe was the most worthwhile, I would choose the combination of the palimpsestuous effect and the Janus effect on our audiences. This production allowed audiences to see a variety of people onstage engaging with a famous traditional text and encouraged respect for a variety of designers, actors, and technicians within my team. Because of the University context, producing Fever/Dream allowed us to introduce students indirectly to a classical text, and validated a Spanish Golden Age play in a context where Shakespeare is often performed and studied. In addition, one of the benefits of adaptation is that traditional texts can be updated to reflect both the uniqueness of the original story and the society in which it is being performed. This is a controversial topic in the world of adaptation studies - many believe that the strangeness of the original text is important to maintain and understand - however, sources as diverse as Vogue magazine's Radhika Seth and Daniel Banks writing in Theatre Topics agree that diversifying the cast and creating more strong characters of marginalized genders, races, and sexualities is a worthwhile task (From 'The Great' To 'Bridgerton', Are Colour-Blind Period Dramas About To Become The Norm?" and "The Welcome Table : Casting for an Integrated Society"). Though these goals are worthwhile because of their philosophical and academic merit, the theatricality of the piece is likewise worthwhile because it draws the audience into the story and allows them to absorb the first two ideas without the mental blocks and biases they may normally experience. The challenges presented by this theatricality are also engaging for actors and designers, letting them more fully engage in the play as well. 


\section{Production Dramaturgy}

I have already mentioned a few of the informative tasks that my dramaturg, Taylor Sklenar, performed for our 2018 production of Fever/Dream, but here I will describe them in more depth to help determine the place of production dramaturgy in adapturgy and Adaptation Studies 3.0. The questions that I have already discussed also fall into the genre of production dramaturgy, of course, though they are carried out by various people during the production process and not just the production dramaturg. However, the activity in question here is the creative work the production dramaturg does to disseminate background information to the audience, cast, and production team. In the case of Fever/Dream, Sklenar provided an actor's packet and presentation containing background information about the show which he presented at the beginning of the rehearsal process, joined me for informative radio interviews before the production opened, created a lobby display to introduce the audience to the world of the play, and wrote a program note which supplemented my own by providing a segue between the context in which La vida es sueño was written and the societal context of Fever/Dream. He also included a short introduction to magical realism at the end. While the practical manifestations of this research may be more difficult to integrate into Adaptation Studies 3.0, the motivation behind their research is certainly fitting.

The dramaturgy for Fever/Dream shows how production dramaturgy leans into the intersections of disparate themes and topics that come together to create a piece of literature, and the importance of introducing the audience to those themes. Sklenar's lobby display, for example, contained a wall decorated with papers printed from the dot-matrix 
printer we purchased for the show explaining the evolution of technology and giving helpful vocabulary context for some of the outdated pieces that were referenced in the show. This wall had an interactive section asking about old technology that people missed to let the audience engage with these ideas actively, solidifying their own ideas about technology before they even entered the theatre. On the opposite side, televisions flipped through slide shows about La vida es sueño, Calderón, and the Spanish Golden Age in general, biographies of the cast and crew, and context about the 2008 financial crisis. In all, the lobby display tied together history, technology, literature, and specific production choices to equip the audience with enough information to enjoy the palimpsestuous pleasures and even the Janus-faced changes in Fever/Dream.

Theatre's need to communicate with the public inspires the practical side of dramaturgy, which is difficult to apply to adaptation studies, as adaptation studies itself does not center around public-facing events in the same way. However, the creative application of background research may well be something that would benefit adaptation studies and other academic fields of study. Essentially, a dramaturgy display or actor's packet should provide an audience, cast, or production team with the background necessary to enjoy the palimpsestuous pleasures of the performance. This could be in embodied ways involving traveling and embodied experiences, like those that Barnette describes in Adapturgy, or simply through the collection of images, articles, and vocabulary words as is done in actor packets, websites, or wikis. Finding exactly what kind of information is necessary for each particular piece could be one of Adaptation Studies 3.0's canonical questions in the future and presenting that information through creative and embodied ways would simply make the experience more engaging and interesting for all involved. Often 
academic work does not prioritize accessibility or public engagement, but perhaps it should. Lyrical essays or performative paper presentations could add a new level of engagement and understanding to the expectations of Adaptation Studies 3.0. The choices for what to include in such presentations and the recognition of their role in the creation and enjoyment of the piece are intellectual skills that are entirely necessary and valuable for Adaptation Studies 3.0 and its future. In fact, the availability of these explorations offers an alternative to comparative studies and even case studies focused on the text of a work itself, which could make Adaptation Studies 3.0 more nuanced and subtle if it is willing to embrace adapturgy as well.

\section{Callaghan's Intercultural Adapturgy}

Since Callaghan was working with a script with more privilege and intertextual connections, she had more flexibility in her adapturgy than Svich or myself. La vida es sueño has traditionally been part of the canon, and it is reasonable to expect a portion of the audience to be able to understand and appreciate the palimpsestuous pleasures coming from the original text. This flexibility seems to have allowed Callaghan to embrace her own unique voice in writing the script, including allowing her to make her own points that are relevant to the twenty-first century more than they are relevant to the seventeenth. The

points that she makes about capitalism, for example, would never have come up in a seventeenth-century monarchy, but they are quite effective in Fever/Dream, and unfortunately continue to resonate beyond the financial crash Callaghan was writing about and into other issues arising from late-stage capitalism in the twenty-first century. 
Cultural changes that are made in order to comment on the original text and ease stress on underrepresented contemporary groups are also more obvious to the audience, which could make a clearer point about Callaghan's intention as a playwright and my intention as a director. For example, when Callaghan creates a female character out of a male one, audience may notice the change and understand that Callaghan intends to make a statement about the lack of female voices in classical plays. However, with that the inclusion of that female character might feel less authentic and natural than a character the audience has never known as male. In this case, like Catherine Larson points out, the palimpsests in Fever/Dream have the potential to both add to and distract from the audience's viewing experience.

Callaghan's casual and comedic voice, on the other hand, did make space for effective dramaturgical intervention which made the play friendly to contemporary audiences and allowed for more inclusive casting. Several characters, most notably the accountants and associates, were written without specific genders but with very specific characterization through their voices. For example, one associate ended every statement with a question mark, a speech pattern which is typically feminine according to Robin Lakoff, but the gender of the character was not explicitly specified. Race was not specified for any of the characters. Because of this flexibility, I was able to cast a diverse group of actors. The change in setting to an urban office made this diverse group seem normal and natural, which I also appreciated. The practical expectations of a contemporary audience were well-served through this contemporary language and Callaghan's extensive use of theatre technology, though the run-time for this play was over two hours -- closer to a seventeenth-century three-act play than to a typical twenty-first century piece. 
Overall, Fever/Dream serves as an example of how a Spanish Golden Age play, or another classical play like it, can be transferred dramatically to speak to contemporary audiences and issues. Callaghan maintains plot points from the original text but contemporizes them almost beyond recognition, which works in this case because La vida es sueño has a robust life outside of this text and is likely never to be overshadowed by Fever/Dream. Though a lesser-known piece may need to more carefully temper the erasure of Spanish Golden Age trends and voices, in this particular case the contemporization of Calderón's work is effective and sparks interest in the original piece. Callaghan's sense of humor, use of technology, and clever addition of contemporary issues all contribute to her success and the interest that she sparks. 


\section{Chapter 4}

Applying Intercultural Adapturgy 
Both new play adapturgy and production adapturgy come together in the creation of new adaptations for the stage, a task which lives in the liminal space between the work of a dramaturg and the work of a playwright. Investigating this liminal space through the creation of my own adaptations is the final demonstration of adapturgy's place in Adaptation Studies 3.0. Adaptation studies currently seems to focus on adaptations that have already been made, which leads to limitations on researcher approaches to the field. The nature of case studies leads to comparative analyses, which can lead to interesting discoveries and lay the foundation for deeper investigation but has also been the primary method of adaptation studies since the field's inception. Leitch points out that adaptation studies journals and books are often comprised primarily of case studies. This is a natural result of the variety of adaptations to be studied, and they are valid inquiries, as a case study gives the researcher a clear touchpoint for their work. However, the reflective creation of adaptations may also be a methodology that adaptation studies could borrow from dramaturgy to bring variety and added insight to the field.

Theatre and performance studies scholars have often drawn inspiration from their own creative work, and adapturgy is a prime example of this practice. In her book, Barnette talks about the decisions she made in the creation of her adaptation of The Red Badge of Courage specifically. This particular script was produced by multiple companies, giving Barnette ability to discuss both new play dramaturgy and production dramaturgy in action as they relate to her work. I will continue this line of thought in this chapter by critically reflecting on the choices and development process which went into my own adaptations. I will also situate these choices in the intertextual contexts of both adaptation studies and dramaturgy, thus exploring the nexus between the two: adapturgy. I will discuss my 
translation and cutting of Sor Juana Inés de la Cruz's Los empeños de una casa, in a translation which I re-named How to Build a Noble House, and my freer adaptation of the same script, which I titled With the Temptation, a Way of Escape. My experiences as a creator of adapted plays show a clear intersection between the fields of adaptation studies and dramaturgy and provide insight into the adaptor/dramaturg's process. I will begin with the dramaturgical questions describing my choice of play, as seen in Chapter 3.

\section{Why this text as theatre now?}

Los empeños de una casa resonated with me as a piece that filled several gaps in current canonical literature and did not yet have a staged modernization of which I was aware. I wanted to adapt a play by a female playwright, since women are underrepresented in the canon of classical literature. I also wanted to create a script which could compete with adaptations of Shakespeare or Moliere in terms of producibility and literary/historical merit. I also liked that this play is a comedy, which combats the often disproved idea that women aren't funny, which has been remarkably persistent in the twentieth and twentyfirst centuries. Though women were hardly encouraged to be humorists in the seventeenth century, many of the extant plays by women from that era are comedies, probably because this kind of play involves relationship mishaps within the house, which was women's traditional domain at the time. There has been a boom of interest in female playwrights of the Spanish Golden Age in recent years (Baranda \& Cruz; Fuchs; Romero-Díaz, Nieves, \& Vollendorf), but I have not encountered other adapted versions of this particular play, and I encountered relatively few translations, considering the popularity of the playwright. I also personally enjoy writing and working on comedies, so I believed a comedy would fit 
well with my own voice and playwriting style. Overall, a seventeenth-century femaleauthored Spanish Golden Age comedy with lots of good roles for women fills a number of gaps in the current canon of traditional and period plays.

Sor Juana Inés de la Cruz is perhaps the most well-known female playwright and poet of the Spanish Golden Age, and her position within the culture of the Spanish Golden Age is unique. She was born in Mexico to Spanish parents and was raised within the dominant Spanish culture, but she was remarkably sympathetic by seventeenth-century standards toward the indigenous people and cultures she encountered, as is shown in her most famous dramatic work, the Loa, or precursor, to El divino Narciso - she also wrote the play itself, but it is less Americanist and therefore less revolutionary. Los empeños de una casa is the only full-length secular text that is attributed solely to her, but she is believed to have collaborated on -- or been robbed of -- two other plays, La segunda Celestina, which is attributed to Agustín de Salazar y Torres and Amor es más laberinto, which was partially written by Fray Juan de Guevara. These plays would have been performed for Spanish nobilitythi living in Mexico in a relatively intimate and high-budget setting. However, these plays are the exception and not the rule; most of Sor Juana's plays are short religious pieces intended to be performed for the public as education about the church and its beliefs (Paz; Merrim). Sor Juana hoped that they would be produced in Spain as well, though her pro-indigenous sentiments made that achievement unlikely (Merrim).

Los empeños de una casa is also an illustration of the cloak and dagger plays of the Spanish Golden Age, which generally receive less attention than their more political counterparts. While Calderón's dream play, La vida es sueño, and Lope de Vega's proletariat uprising play, Fuenteovejuna, are often translated and anthologized, they are 
both political and philosophical plays written by men. Los empeños de una casa, on the other hand, takes place primarily inside a home and follows comedic antics associated with love and marriage. While these themes seem frivolous when compared with the groundbreaking pro-indigenous themes in Sor Juana's other work or the rejection of fate's power in La vida es sueño, the fact that the action in Los empeños de una casa takes place in a house and centers around relationships allows the seventeenth-century female characters in the play to play more important, central roles. As linguists like Deborah Tannen and Robin Lakoff, among others, have observed, women have been socialized for centuries to confine their speech to private spaces, while men speak more in public spaces. This is clearly true in Los empeños de una casa, as all of the scenes that take place outside of Ana's house are between men, whereas inside her house, Ana holds much more power and is able to exert her agency to drive the plot forward. The seemingly soap opera-esque style of the cloak-and-dagger genre allows for a lot of speech and power to be wielded both inside the home and in traditionally feminine areas of expertise, like love and relationships. Though the genre seems trivial, the fact that it provides female characters with these opportunities means that it should be reevaluated as a potential part of literary study and artistic seasons in the future. I hope that my translation and adaptation of this work make those productions more feasible.

When it comes to doing this adaptation as theatre, this script is delightfully calibrated for the theatre and is difficult to imagine in any other format. It contains age-old slapstick characteristics that still exist in contemporary farce, most notably the contrasting clever and foolish servant characters, and the visual jokes are what make the play so delightful. Sor Juana also employs quite a bit of delightful wordplay which is, 
unfortunately, difficult to translate. Puns and wordplay are naturally difficult to translate and in addition tangents that focus only on wordplay and do not further the plot were easily accepted by Spanish Golden Age audiences but are likely to be confusing and boring for twenty-first-century audiences. The same is true of Sor Juana's occasional rants about the double-standards society puts on women. Unfortunately, many of those double-standards still exist, but the complaints about feminine double-standards in Los empeños de una casa are often off-topic and out of character. However, while some changes inevitably had to be made to help How to Build a Noble House fit the expectations and unspoken audienceperformer contract involved in twenty-first-century productions, the core of the story and most of the jokes fit precisely into the theatrical genre.

\section{Translation or Adaptation?}

The ethical considerations involved in translation and adaptation, as discussed in Chapter 1, are difficult ones. While I believe that it is valuable to expose individuals, especially students, to the art and culture of societies outside of their own, the practice of translation and adaptation is often an imperial one, especially for a white playwright who is not a member of the source culture. In my interview with Caridad Svich, she pointed out that she felt an obligation to maintain some of the relative strangeness of La traición en la amistad in A Little Betrayal Among Friends to remind the audience that they were seeing something from a different time and place. Other translators have not been so cautious and have caused harm with their work. For example, E. J. Westlake makes a compelling argument against Peter Brook's adaptation of the Mahabharata, which I agree overstepped in its translation and ended up making a mockery of the culture it tried to adapt. I sincerely 
hope that my understanding of Spanish Golden Age culture is sufficient and that my translation and adaptation of Los empeños de una casa are more respectful. In my attempt to engage with the text in a way that respects the cultural uniqueness of the Spanish Golden Age while still creating stories which are engaging for twenty-first-century audiences, I have chosen to create a cut translation of Los empeños de una casa as well as an adaptation. Though these two pieces are both adaptations in a broad sense, I will refer to the one which maintains the original time and place (remaining intra-temporal and intra-spacial) of the text as a translation for the sake of clarity and contrast.

I believe that both texts are performable and would be engaging for a twenty-firstcentury audience: both have a runtime of approximately 90 minutes, lots of physical comedy, and engaging and entertaining characters. Both maintain the farcical comedy and the translation includes all of the characters from the original, though Hernando, Rodrigo's manservant, is cut from With the Temptation, a Way of Escape. Similarly, I cut some wordplay and the one song included in the play from both, as they slowed down the plot and would have involved practical challenges for twenty-first-century producers. The texts of the plays are in Chapter 5 and Chapter 6 of this dissertation so the reader may see the differences and similarities and judge the performability of each for themselves. These practical adjustments are a result of the changing expectations of theatre audiences, performers, and producers, especially those working in the field of new play dramaturgy.

\section{Intertextual Expectations}

The context in which Sor Juana was writing led to several seventeenth-century stylistic choices, including long expositional monologues, verbal sparring that is unrelated 
to the plot, and the inclusion of policemen and musicians who barely have any stage time which were typical of her time but are jolting to contemporary audiences and inconvenient for contemporary casting directors and producers. I first considered the practical considerations borne from these varied intertextual expectations. Many Spanish Golden Age plays begin with an interesting scene to hook the audience, followed by several long monologues of exposition. For example, in Ana Caro's Valor, agravio, y mujer, two women begin the play by climbing down a mountain, but their climbing is interrupted by a long explanation of why they are making this trek (Scott-Soufas, Women's Acts, 163). Similarly, Rosaura begins La vida es sueño by talking about her escape from a hippogriff, but this is followed by an explanation of why both she and Segismundo find themselves on the mountain. In contrast, twenty-first century plays often try to integrate exposition into the action of the play. Part of the joy of being an audience member is discovering this exposition as the play goes on, and playwrights will occasionally hide exposition until the end of the play to create a twist for the audience. I incorporated such a twist with the revelation that Ana has tried to suppress homosexual desires for Juana because of her conservative upbringing.

Asides are also common in Spanish Golden Age plays, a practice which serves a very different role in contemporary theatre. A Spanish Golden Age aside often telegraphs the character's motivations. For example, in Act II, when talking to Leonor, Celia says “'Ah penosa/ atención, que me precisas/ a agradar a quien me enoja!” (“Oh, hateful manners, that require me to be polite to the one I'm angry with") (lines 188-190). The audience can have no doubt about her true feelings about Leonor, even though she is hiding them within the scene, because Celia tells them to the audience so clearly. Today's 
playwrights have developed much subtler ways to convey subtext, relying on the audience's intelligence and engagement with the play. In fact, Stages Theatre Company's playwriting guide says that "Subtext spoken by characters as dialogue is like sand tossed into the innards of an engine" (43). In sum, Spanish Golden Age tradition leads to a lot of spoken subtext, or characters telegraphing what they are going to do and why, which is seen as a problem in contemporary playwriting.

In addition, Spanish Golden Age asides have naturally metatheatrical tendencies and sometimes include commentary about the context of the play, asking for forgiveness or permission from the royalty watching the play, or on-the-nose mentions of the title. For example, in Act III of Los empeños de una casa, Castaño, after putting on all of Leonor's clothes, says

Dama habrá en el auditorio que diga a su compañera: «Mariquita, aqueste bobo al tapado representa». Pues atención, mis señoras, que es paso de la comedia; no piensen que son embustes fraguados acá en mi idea, que yo no quiero engañarlas, ni menos a vuexcelencia (lines 377-386)

Now, there's a lady here in the theatre who just said to her friend: "Mariquita, does that fool look like a covered lady?" Pay attention, ladies. This is just a thing that happens in a story like this. Far be it from me to tell them how to write plays. I don't want to try to trick you, and I would never try to try to trick Her Excellency

These metatheatrical asides are fun and not completely outside the realm of contemporary theatre trends. As such, I have included this particular quote in How to Build a Noble House, but adjusted like so: 
Now, real talk for a minute: is this actually fooling anyone in this audience here? No. Not at all, right? Keep that in mind - we know this is fake. This isn't some sort of political statement, it's just how these farces go, y'know? I'm having fun and all, but don't blame me for the way these people write plays. We're being totally above-board here, y'hear that, Your Majesty?

Another issue with these quotes is that they are usually provided by servant characters, who serve as metatheatrical guides to the audience throughout the play. However, these same characters pose a dilemma surrounding social relevance which I will discuss shortly. As for the reference to royalty, contemporary playwrights are much less concerned with the approval or disapproval of specific individuals, though they may make jabs or pleas for approval directed toward theatre critics or other typical audience members from time to time.

Along with providing spoken subtext, characters in Spanish Golden Age plays, like many plays of their era, often have to provide spoken stage directions, as these were not as clearly outlined in plays during this era. For example, toward the end of Act I of Los empeños de una casa, Ana and Celia divvy up their guests into various rooms of the house, saying:

\author{
DOÑA ANA \\ Caballero, en esa cuadra \\ os entrad. \\ DON CARLOS \\ Ya te obedezco. \\ ¡Oh, quiera el cielo que salga \\ de tan grande confusión! \\ (Vase.) \\ DOÑA ANA \\ Leonor, también retirada \\ puedes estar. \\ DOÑA LEONOR
}


Yo señora,

aunque no me lo mandaras

me ocultara mi vergüenza. (Act I, lines 946-953)

DOÑA ANA

Sir, please go into that room.

DON CARLOS

I'll obey you. Oh, sweet Heaven, save me from all this confusion!

(He exits)

DOÑA ANA

Leonor, you should also retire.

DOÑA LEONOR

I, madam? Even if you didn't ask it of me, I would hide in my shame.

(She exits)

Even the stage directions which are included, like these, are less helpful than they might be, because they do not indicate which doors each person exits through or how many doors there are in total. In a typical farce like this one, small details like these become important as characters have to see each other selectively at various important moments. Instead of relying on clear stage directions included for the director in the text, Sor Juana's characters often take a moment to tell the audience where they are going or who they think they are talking to at any given moment, especially when those assumptions are incorrect. They also point out when they are hidden and then, as a group, play the reality of that 'hiding' even if the actor is actually visible. Since there are few stage directions in general, these spoken stage directions are important to a reader or director's understanding of the play. However, twenty-first-century trends include shifting theatrical focus from telling the audience a story through primarily verbal means to showing them what is happening through visual cues like a film or television show would. 
The most obvious structural difference between seventeenth-century theatrical expectations and those of the twenty-first century is the length of plays and their constituent parts. It was typical for a Spanish Golden Age play to have three acts and last an entire afternoon or evening. There were fewer entertainment options vying for places in people's free time, making audiences more amenable to long, repetitive theatre. In contemporary culture, however, plays are expected to have two acts and one intermission. Though contemporary musicals often run for two and a half to three hours, many still only have one intermission, and plays are encouraged to run for closer to 90 minutes with no break at all. Of course, all theatrical rules are meant to be broken, and plays like Suzan-Lori Parks's Father Comes Home from the Wars and Michael Frayn's Noises Off have achieved success with long run-times and two intermissions. However, if the expositional dialogue and wordplay non sequiturs are cut, this particular Spanish Golden Age play fits easily into the 90-minute window.

Twenty-first-century performance expectations may also be influenced by the prevalence of film and television in contemporary culture. Linda Hutcheon believes that theatre does more telling than showing, and only refers to television, film, and video games as narrative structures that focus on showing. However, the influence of film and television has made theatre as a genre focus more and more on showing in recent times. While television has some advantages with regards to showing, including the ability to go to multiple locations quickly and to direct the audience's view to specific details, theatre is able to use movement, sets, projections, audience interaction, and actors' expressions to convey ideas visually as well as conveying them through dialogue. In fact, this is an important tenet of Barnette's adapturgy and she mentions ways that novels are visually and 
representationally recreated onstage in her adaptations of both The Red Badge of Courage and Moby Dick. In The Red Badge of Courage, the production team chose to use a puppet and a portal in the middle of the set to represent the protagonist and to get important set pieces on and off the stage. In Moby Dick, the whale was represented by huge, billowing cloth to impress upon the audience a sense of its size. Both of these choices replaced long swaths of description in their respective novels; similarly, I faced with the task of translating the expositional dialogue text from Los empeños de una casa into visual representations or more engaging interactions in my own translation and adaptation.

\section{Social Issues}

Though Los empeños de una casa expressed views that promoted female agency and other traits that would later be considered feminist -- in fact, the mere existence of a female-authored play was notable for the Spanish Golden Age -- the toxic relationships in the script and lack of female camaraderie seem shocking and unacceptable in today's society, and for good reason. The characters are hyper-focused on marriage, which appears to be an institution more designed to make a good societal match than to celebrate mutual love and respect. Because of this focus, the inciting incident of the play comes from behavior that would be seen as toxic in today's society. It is Pedro's idea to kidnap Leonor and then force her father to let him marry her to protect her honor after being discovered in a single man's house. ${ }^{32}$ Ana not only goes along with this plan, she implements it -Pedro does the talking (to Leonor's father), but the rest of the plan only happens because Ana wants it to. She is fiercely independent and scornful of Leonor, the only other upper-

\footnotetext{
${ }^{32}$ One could argue that Pedro's failure to find a wife at the end of the play is his punishment for this bad behavior, but that argument is outside the purview of this dissertation.
} 
class woman, so there are no female friendships in the play (nor are there male friendships). This lack of feminine support may reflect some sense of isolation on Sor Juana's part, either her own or an isolation that she perceived among the wealthy class ${ }^{33}$, but it certainly does not reflect trends in feminine empowerment today. Similarly, when I moved the setting of the play to today's United States, the dark implications of a father forcing his daughter to marry someone because of honor become quite clear and it is difficult to maintain the lighthearted nature of the text.

Likewise, servant characters are difficult to adapt to contemporary theatre, as servitude and slavery are seen as unilaterally bad in contemporary culture. While I will not argue that servitude and slavery are not unilaterally bad, the servant characters in Los empeños de una casa fill archetypal roles more than they represent a servant's reality in seventeenth-century Spain. Celia clearly inhabits the role of the clever servant, as she understands the comings and goings in the house and judges her masters for their foolishness. Castaño also fills an archetypal servant's role with his constant hunger, quippy remarks, and slapstick comedy. The servant characters also perform most of the asides to the audience as they offer explanations of the convoluted plot and appeal to attendant royalty's good graces. They are the audience's way into the play, especially a lower-class audience, who may have been able to connect better with servant characters than with the nobility. While a contemporary audience may be able to understand these characters as servants in the context of the Spanish Golden Age, a servant character cannot be properly transitioned to the twenty-first century without creating a dark undertone to the play that I did not intend.

${ }^{33}$ Sor Juana herself was a nun, but seemed to be something of an outcast among the other nuns (Paz) 
Most Spanish Golden Age plays end in all of the characters pairing up into malefemale pairs and promising to marry one another. This typically happens in the last five minutes and sometimes results in pairings that are not justified by any other action in the play. These pairings are also always hetero pairings, which does not reflect the multiplicity of romantic relationships that can occur openly in society today. This presents a dilemma for adapturgs dealing with these plays since, on the one hand, this last-minute pairing off is part of the Spanish Golden Age culture reflected in these plays and one could argue that changing that reflection for the sake of contemporary audiences undermines the uniqueness of the piece. On the other hand, the LGBTQ+ community has long been underrepresented in classical and high-brow literature and excluding them from the narrative in favor of arbitrary heterosexual relationships seems unnecessary. Caridad Svich mentioned this group specifically as one which deserves better representation in adapted versions of Early Modern plays (personal communication, 2020). Even the hetero relationships present a clash in intertextual connotations for the original playwrights and contemporary audiences. Spanish Golden Age playwrights would likely be criticized for leaving single high-class female characters at the end of a play, as shown in Zayas's thorough justifications of Fenisa's singleness at the end of La traición en la amistad, which I discussed in Chapter 2 of this dissertation. On the other hand, the female characters who are locked into marriage for marriage's sake may be perceived as losing agency in the choices by a contemporary audience. This makes adapting the ending of Spanish Golden Age plays in the cloak and dagger genre challenging for both ethical and clarity reasons. 


\section{My Process}

Once I had chosen Los empeños de una casa as an adapturgical project, I began by creating a literal translation of the text to work from. Though the original script, like most of Sor Juana's work, is written in verse, my goal was to make a version of the play that would feel like a contemporary comedy, so I chose to focus on the natural voices of the characters and the meaning of the text rather than on the poetic structure. With that in mind, I revised this literal translation several times with the goal of understanding the jokes and linguistic quirks of seventeenth-century Spanish and reviewing which elements would be most effective in a twenty-first-century setting. Sor Juana was well-read and made allusions not only to Greco-Roman and Biblical characters and stories, which a contemporary audience can be reasonably expected to understand for the most part, but also to specific episodes of Don Quixote: "No haré tal,/sino cerraré la puerta,/ e iré a avisar a Marsilio/ que se le va Melisendra." (I'll do no such thing. Instead, I'm going to lock the door and go tell my Marsilio that his Melisendra is trying to leave him.) (Act III, line 142) and to indigenous legends: “QQuién fuera aquí Garatuza,/ de quien en las Indias cuentan/ que hacía muchos prodigios!" ("What if I were Garatuza, who the Indians say did many wonders!") (Act III, line 293). She also made references to sayings and clichés of the time, some of which could be explained in the text and some of which were more difficult to transfer to contemporary US culture. For example, in Act II, Castaño says:

Tú no debes de saber

lo que es un cuñado, un suegro, una madrastra, una tía, un escribano, un ventero, una mula de alquiler, y un albacea, que pienso que del infierno el mejor y más bien cobrado censo 
no llegan a su zapato

you must not know that a brother-in-law, a father-in-law, a stepmother, an aunt, a scrivener, an innkeeper, a rented horse, and a lawyer are so bad that Hell's census don't even come to their shoes (lines 1032-1040).

While scriveners and innkeepers might not be familiar villains to my target audience, many of the people Castaño lists, like stepmothers and lawyers, are still stereotypically perceived as bad for one reason or another. Other sayings are not recognizable in English but can be justified with context. For example, Castaño also says "que quien bueyes ha perdido..." ("[they say] that he who has lost his cows...") (Act II, line 24). He does not finish the saying in the play, but with more context, the metaphor makes sense. In my literal translation, this line turns into "they say that whoever has lost his cattle hears cowbells everywhere," which offers more information to the audience and lets the characters use the cow metaphor, which comes up several more times.

After a couple of editing passes through this draft of the script, a draft of How to Build a Noble House (as Trials of a Noble House) had a reading at the Missouri Playwrights Workshop at the University of Missouri - Columbia. These types of readings are a typical and vital part of the new play development process, as plays are meant to be experienced verbally and visually, not just on the page. It is important for a playwright to see how their play will be interpreted by actors, feel the energy of the audience, and observe which jokes land and which do not seem to make sense in this particular context. Play readings like this are essential to the new play process and they are one of the most integral sites of dramaturg/playwright interactions. ${ }^{34}$ While individual slapstick scenes had read well in

\footnotetext{
${ }^{34}$ Edward M. Cohen's book Working on a New Play describes several different levels of readings which
} might occur in a play's development process 
other contexts, and the group was positive and enthusiastic in general, it felt like parts of the script dragged and the play lasted upwards of two hours, longer than a typical Playwrights Workshop of 60-90 minutes, leading to fatigue from the listeners at the end of the play when their attention was crucial to keeping up with the now quickly moving plot. This result confirmed my desire to trim the script down to a length that was more typical of contemporary work, cutting out exposition monologues and other miscellaneous rants and songs to focus on getting the audience to that entertaining slapstick ending sooner rather than later.

\section{Cutting the Script}

Cutting a classical script to a shorter, more contemporary, length is a skill that is central to a dramaturg's career. The Back Room Shakespeare Project claims on their website that "Everyone is constantly repeating the same work: cutting Shakespeare to about 90 minutes ${ }^{35 \%}$. A. Hartley in The Shakespearean Dramaturg discusses cutting Shakespearean scripts as one of the dramaturg's interactions between the materiality of the text and the performance. He initiates a unique take on the cutting process and the questions about authority that inevitably come from that process, saying that "Central to the project is a notion of authority defined not by text or author, but by the theatre itself." This is a lovely notion for dramaturgs, but my goal in cutting Los empeños de una casa was not to purge the authority and influence of both Sor Juana and -- the neither/nor situation which Hartley describes here -- but was to instead honor Sor Juana's voice and allow my own voice to come through in the text as well. This desire also ties back to gynocritical theory,

\footnotetext{
35 They go on to encourage dramaturgs and directors to share their cut scripts in their online database
} 
which I connected to the broader umbrella of intertextuality studies in Chapter 1, in that I, a woman adapting the work of another woman, approached it with the goal of lifting Sor Juana's work up and amplifying her voice and not with the goal of countering or replacing that voice. Graham Allen observes that male adapters often try to replace the original text with their own ideas while women's adaptations focus instead on extending the legacy of female authors of the past. Personally, I believe that the gender dichotomy reflected in this accusation may be unfair and less than useful in the twenty-first century, which embraces a much broader range of genders. However, my specific adaptation does attempt to explore feminine work through a feminine lens, which Elaine Showalter identifies as central to gynocritical work. Cutting the text also allows me to reflect on aspects of the original play which were exclusionary, toxic, or harmful to people of underrepresented genders. Though Barnette never mentions cutting as part of adapturgy, the choices I outline in this section rely on a dramaturgical skill set and certainly involve adaptation of the original script. As such, I believe that dramturgical cutting does belong under the umbrella of adapturgy as well.

One concern in contemporary playwriting circles is the economy of casting. Organizations producing new plays typically run on low budgets and therefore are often only able to cast a limited number of actors. Though my primary target audience for this script was an educational audience, for which the casting problem is often reversed since more roles mean more opportunities for students, I wanted to consider whether all hypothetical actors involved would feel their time was well-spent working on a production of How to Build a Noble House. However, I found that most characters had a purpose in the story, and that many had the opportunity to manipulate the wheels of the plot at one 
point or another. The only characters that I combined for both my translation and my adaptation were Rodrigo, Leonor's father, and his manservant, Hernando. As I have mentioned, servants occupy a tricky space in adapted seventeenth-century plays to begin with, and Hernando was merely a person for Rodrigo to talk to, sharing exposition and spoken subtext. For example, when Carlos gives Leonor to Rodrigo to watch in the street, believing that she is Ana, Rodrigo says to Hernando:

DON RODRIGO

Hernando, yo he discurrido (pues voy a ver a don Pedro, y Carlos hizo lo mismo que él sacándole a su hermana, que ya por otros indicios sabía yo que la amaba) valerme de este motivo tratando de que la case, porque ya como de hijo debo mirar por su honor; y él quizá más reducido, viendo a peligro su honor, querrá remediar el mío.

HERNANDO

Bien has dicho, y me parece buen modo de constreñirlo el no entregarle a su hermana hasta que él haya cumplido con lo que te prometió. (Act III, lines 774-791)

DON RODRIGO Hernando, I have found out (since I will soon see don Pedro, and Carlos did the same as him when he took her sister, so now, through other clues I can see that he loved her). This resource is valuable to me, when it comes to marriage, because I will now guard his honor like a son's and he, who is perhaps trapped when he sees his honor in danger, would like to put my honor right as well.

HERNANDO: You've spoken well, and this seems to be a good way to tie him down - you won't give him his sister until he has done what he promised. 
In this case, Hernando appears to be present only to hear and affirm Rodrigo's ty. Not only is the spoken subtext itself something contemporary playwrights want to avoid, but Hernando also seems to be there so that Rodrigo can avoid talking to a woman outdoors on the street. Since Rodrigo implements this plan shortly after this discussion, there is no need to explain the whole thing outside. While some other characters, like Rodrigo himself, spend a lot of time offstage, their presence is still important to the plot and their absence would change the end of the play itself. I did not have to eliminate any female characters though, including female servants. Sor Juana's use of most of the characters in the play shows her respect for both the female characters and the servant characters in her own work.

Contemporary sex comedies like the one I intended to create through the process of adaptation typically focus on moving characters around the stage through different doors. They are active and sometimes chaotic, and people are often in the wrong place at the wrong time, which is the core of a farce's comedy. Therefore, my next step after deciding that the full translation of the play needed to be more efficient to be effective as a contemporary comedy was to focus the script on movement and action by cutting excess wordiness. Several of the exposition monologues included repetitive information, which was interesting in that the audience got to hear different sides of the same story but was not something contemporary audiences were likely to appreciate. Some monologues also included commentary on Spanish Golden Age society, which is unfortunately still relevant to today at times, but felt to me more like Sor Juana pushing an agenda than dialogue that fit the character. I noticed this most clearly in Act II when Carlos says 
de jóvenes altiveces;

que en mirándolas corteses

luego las juzgan livianas;

y sus malicias erradas

en su mismo mal contentas,

si no las ven desatentas,

no las tienen por honradas; (Act II, lines 57-64)

But these are the vain fantasies of young, arrogant men who see women treating them courteously and think that those women are frivolous: and their erring malice is their own discontent - they won't respect a woman unless she is rude to them.

Though this complaint is (unfortunately) still relevant, it does not seem like something the character of Carlos is likely to notice or care about. It seems more likely to me that Sor Juana believed people would hear the thought more clearly if a male character articulated it onstage, which I hope was good for society at the time, though it was not as good for Carlos's character development in my adaptation. For a twenty-first-century style, I prefer to have characters keep their monologues shorter and spend more stage time reacting to one another, so I took some of these out-of-character rants out of the play in my cuts and I broke up other long monologues with interjections and interactions from other characters to add variety and conflict to what was otherwise a one-character story.

After I made these cuts and clarifications, another reading of How to Build a Noble House was 'staged' via Zoom as part of the University of Missouri's Comedies in Concert. Readings followed by audience talkbacks like these are a regular part of the dramaturgical process and may also offer interesting intertextual insight to adaptation studies scholars in the future. In this case, the piece had a dedicated director, David Crespy, and was cast intentionally (whereas the previous reading was cast from whatever students, staff, and community members came to the Playwrights Workshop that day). Because casting was intentional, several characters were played by Latinx and Spanish-speaking actors, who 
helped with the flow of the dialogue, especially since I still used the exclamation ay de mi generously throughout the piece - one way that I chose to preserve and call back to the play's Spanish origins. The play was rehearsed for several hours on the day of the performance, and I was able to virtually attend rehearsals as well as the performance. This gave me the chance to see what questions and concerns came up for the director and actors throughout the piece and to make small changes to the script as needed. Even this short amount of time with the characters made the actors' interpretations much more nuanced, clarifying what worked and what did not with more clarity than a cold reading. This reading lasted about 90 minutes, though the script was only 66 pages long, which showed me that there was enough content for an evening-length performance without adding more text.

After the performance, I was able to ask questions of the audience to gauge their experience of the text, which generally showed me that the text was working in the way that I wanted. Almost every character got a shout-out as a favorite in the talkback, and the audience appreciated the sassy and assertive female characters, which are sometimes hard to find in male-authored classical texts. The audience also appreciated the more elevated language contrasted with the more natural language of the servant characters of How to Build a Noble House. This variety in is one of the aspects of Spanish Golden Age theatre which makes it unique and different from contemporary plays and which I was able to preserve in the translation, though it did not make it into With the Temptation, a Way of Escape. One audience member mentioned that they were "confused about don Juan's role in the beginning," which was seconded by other audience members. This showed me that the audience's intertextual understanding of the character of don Juan, who is portrayed as a persistent and faithful lover in Los empeños de una casa contrasting with the infamous 
womanizer from Tirso de Molina's Burlador de Sevilla, confused the audience. As such, I chose to remove the titles from names whenever possible and use them only when characters are intentionally trying to be polite. I hope that the shift from 'don Juan' to just 'Juan' will clarify the characterization for the audience. Another audience member mentioned that they were confused about who Hernando was, which justified my cutting of that character in the adapted version. In general, both the actor and directorial input and the audience response were very helpful in determining which aspects of the script were effective in a 2020 university setting and which were not.

This cutting therefore incorporates concepts from both dramaturgy and adaptation studies and is an excellent example of adapturgy at work. As I mentioned, the dramaturgical task of cutting scripts for production is also part of adapturgy since it considers the intertextual effect of the dramaturg's choices on the piece's audience. Intertextuality becomes more complicated in the context of cutting because many voices affect the text's outcome. As dramaturg Monica Cross pointed out, each cutting depends on both the practical tools available to the production team, including elements ranging from potential cast size to the director and actors' ability to work with verse, and the specific focus that the dramaturg chooses for that particular cut. Because there is so much variety in intention and ability, Shakespearean plays are cut and re-cut regularly to include different parts and pieces of the work and create different effects on their audiences. Not only is there intertextual context for the original playwright but each production's director, production team, and of course dramaturg affect how that text will be cut. In this way, my cutting of Los empeños de una casa is less specific than many Shakespearean cuts because it was produced as an academic endeavor and not for a specific production, but the Writing 
for Performance program at the University of Missouri - Columbia did influence the textual outcome through the developmental process. The audiences at MU's readings gave me some insight into the final realm of intertextual experience -- the audience viewing or listening to the script itself. Dramaturgical talkbacks provide excellent insight into this final level of intertextual interpretation, making these talkbacks yet another useful tool that could be incorporated into adaptation studies in the future. If adapturgy is indeed part of Adaptation Studies 3.0, adaptation studies scholars may feel inclined to use adapturgical strategies like these talkbacks to discover how audiences react to adapted films, plays, or other texts. This experience showed me that barriers to a good intertextual response from twenty-first-century audiences may also include the social issues I mentioned earlier and, as such, I continued my adaptive work with With the Temptation, a Way of Escape, an adaptation which took more liberties with plot and character in order to mediate some of those harmful social expectations.

\section{Adapting the Translation}

To create an intertemporal and intercultural adaptation of Los empeños de una casa, I found that I needed to get away from working with the translated words that I had used thus far in order to find more creative freedom to change characters, settings, and reactions. However, the basic plot of the original play was still important, so I chose to return to the script analysis method I used in Chapter 2, which combines David Ball's triggers and heaps method of script analysis and Brian McFarlane's cardinal functions, to clarify for myself which aspects of the plot were integral, and which could be changed, adjusted, or creatively 
interpreted. Since I had already simplified the script for How to Build a Noble House, I used that as the basis for this analysis, which is as follows:

\begin{tabular}{|c|c|}
\hline Trigger & Heap \\
\hline $\begin{array}{l}\text { Pedro falls in love with Leonor, who } \\
\text { does not love him back. L, on the other } \\
\text { hand, decides to elope with her man, } \\
\text { but P gets wind of this. (off } / 2 \text { ) }\end{array}$ & $\begin{array}{l}\text { Pedro hatches a scheme to break up their } \\
\text { elopement and get Leonor to run to his } \\
\text { house for safety. (off/2) }\end{array}$ \\
\hline $\begin{array}{l}\text { Pedro hatches a scheme to break up } \\
\text { their elopement and get Leonor to run } \\
\text { to his house for safety. (off/2) }\end{array}$ & $\begin{array}{l}\text { Pedro asks Ana to stay up late to receive } \\
\text { Leonor into their home (off } / 3 \text { ) }\end{array}$ \\
\hline $\begin{array}{l}\text { Ana meets don Juan in Madrid and they } \\
\text { start a courtship (off/2) }\end{array}$ & $\begin{array}{l}\text { Don Juan follows Ana to Toledo; Celia lets } \\
\text { him in the house to hide in her room (off/3) }\end{array}$ \\
\hline $\begin{array}{l}\text { Ana sees Carlos in the street and falls } \\
\text { for him, even though she is kind of } \\
\text { seeing don Juan and they have never } \\
\text { met (off/3) }\end{array}$ & $\begin{array}{l}\text { Ana agrees to let him stay at her house, } \\
\text { hoping to win him over (9) }\end{array}$ \\
\hline $\begin{array}{l}\text { Pedro asks Ana to stay up late to } \\
\text { receive Leonor into their home (off/3) }\end{array}$ & $\begin{array}{l}\text { Pedro's friends, disguised as police, bring } \\
\text { Leonor to Ana's door. Ana agrees to let L } \\
\text { stay, sends her to her own room (5). }\end{array}$ \\
\hline $\begin{array}{l}\text { Pedro hatches a scheme to break up } \\
\text { their elopement and get Leonor to run } \\
\text { to his house for safety. (off/2) }\end{array}$ & $\begin{array}{l}\text { Leonor sneaks out of the house with Carlos } \\
\text { but they run into her cousin in the street. } \\
\text { The cousin tries to stop them, but C stabs } \\
\text { him and it looks like he is dead. Pedro's } \\
\text { friends-dressed- as-policemen break up the } \\
\text { fight and take Leonor to Ana's house. } \\
\text { (off/8) }\end{array}$ \\
\hline $\begin{array}{l}\text { Leonor sneaks out of the house with } \\
\text { Carlos but they run into her cousin in } \\
\text { the street. The cousin tries to stop them, } \\
\text { but C stabs him and it looks like he is } \\
\text { dead. Pedro's friends-dressed- as- } \\
\text { policemen break up the fight and take } \\
\text { Leonor to Ana's house. (off/ } 8 \text { ) }\end{array}$ & $\begin{array}{l}\text { Carlos \& Castano come into Ana's house as } \\
\text { he is running from the police. Ana agrees to } \\
\text { let him stay there as well. (9) }\end{array}$ \\
\hline $\begin{array}{l}\text { Carlos \& Castano come into Ana's } \\
\text { house as he is running from the police. }\end{array}$ & $\begin{array}{l}\text { Ana puts Carlos and Castaño in the storage } \\
\text { room to hide them from Pedro (10) }\end{array}$ \\
\hline
\end{tabular}




\begin{tabular}{|c|c|}
\hline $\begin{array}{l}\text { Ana agrees to let him stay there as well. } \\
\text { (9) }\end{array}$ & \\
\hline $\begin{array}{l}\text { Leonor sneaks out of the house with } \\
\text { Carlos (off/8) }\end{array}$ & $\begin{array}{l}\text { Rodrigo, Leonor's father, hears about her } \\
\text { elopement and decides to offer her hand to } \\
\text { Carlos if he will bring her back (12). }\end{array}$ \\
\hline $\begin{array}{l}\text { Pedro's friends, disguised as police, } \\
\text { bring Leonor to Ana's door. Ana agrees } \\
\text { to let L stay, sends her to her own room } \\
\text { (5). }\end{array}$ & $\begin{array}{l}\text { Juan chases Leonor out of Ana's room, } \\
\text { thinking that L is A. A and Carlos run into } \\
\text { them in the dark courtyard (14) }\end{array}$ \\
\hline $\begin{array}{l}\text { Juan chases Leonor out of Ana's room, } \\
\text { thinking that L is A. A and Carlos run } \\
\text { into them in the dark courtyard (14) }\end{array}$ & $\begin{array}{l}\text { Everyone talks to each other, mistaking their } \\
\text { identities, in the dark until Celia brings in a } \\
\text { light, then they all see one another and } \\
\text { assume that their partners are cheating (16) }\end{array}$ \\
\hline Pedro shows up at the door (17) & $\begin{array}{l}\text { Ana begs everyone to stop fighting and hide } \\
\text { to preserve her honor. They do, and Celia } \\
\text { and Ana hide Juan and Carlos in different } \\
\text { rooms. (17). }\end{array}$ \\
\hline $\begin{array}{l}\text { Ana begs everyone to stop fighting and } \\
\text { hide to preserve her honor. They do, } \\
\text { and Celia and Ana hide Juan and } \\
\text { Carlos in different rooms. (17). }\end{array}$ & $\begin{array}{l}\text { Pedro comes in ready for bed and decides to } \\
\text { talk to Leonor in the morning. He still does } \\
\text { not know about Juan or Carlos (19). }\end{array}$ \\
\hline \multicolumn{2}{|l|}{ Act II } \\
\hline $\begin{array}{l}\text { Ana begs everyone to stop fighting and } \\
\text { hide to preserve her honor. They do, } \\
\text { and Celia and Ana hide Juan and } \\
\text { Carlos in different rooms. (17). }\end{array}$ & $\begin{array}{l}\text { In the morning, Celia comes to move the } \\
\text { guys to another room, so they do not see } \\
\text { Leonor in the garden }(22)\end{array}$ \\
\hline $\begin{array}{l}\text { In the morning, Celia comes to move } \\
\text { the guys to another room, so they do } \\
\text { not see Leonor in the garden }(22)\end{array}$ & $\begin{array}{l}\text { Ana and Leonor are free to walk in the } \\
\text { garden and 'accidentally run into' Pedro } \\
(25)\end{array}$ \\
\hline $\begin{array}{l}\text { Ana and Leonor are free to walk in the } \\
\text { garden and 'accidentally run into' } \\
\text { Pedro (25) }\end{array}$ & $\begin{array}{l}\text { Pedro asks Leonor why she is not interested } \\
\text { in him. It is awkward. Ana arranges for } \\
\text { Carlos to see them talking (27) }\end{array}$ \\
\hline $\begin{array}{l}\text { Pedro asks Leonor why she is not } \\
\text { interested in him. It is awkward. Ana } \\
\text { arranges for Carlos to see them talking } \\
(27)\end{array}$ & $\begin{array}{l}\text { Ana, Leonor, and Pedro go for a walk in the } \\
\text { garden. Before Celia lets Carlos and } \\
\text { Castaño out of the closet, she sneaks Juan } \\
\text { out of the house ( } 31 \text { ) }\end{array}$ \\
\hline
\end{tabular}




\begin{tabular}{|c|c|}
\hline $\begin{array}{l}\text { Pedro asks Leonor why she is not } \\
\text { interested in him. It is awkward. Ana } \\
\text { arranges for Carlos to see them talking } \\
\text { (27) }\end{array}$ & $\begin{array}{l}\text { Celia lets Carlos and Castaño out. Carlos } \\
\text { asks her about Pedro and Leonor. She tells } \\
\text { him that P loves L and has been giving her } \\
\text { gifts (32) }\end{array}$ \\
\hline $\begin{array}{l}\text { Celia lets Carlos and Castaño out. } \\
\text { Carlos asks her about Pedro and } \\
\text { Leonor. She tells him that P loves L } \\
\text { and has been giving her gifts ( } 32)\end{array}$ & $\begin{array}{l}\text { Carlos decides to fight to get Leonor } \\
\text { back/freed (33) }\end{array}$ \\
\hline $\begin{array}{l}\text { Rodrigo, Leonor's father, hears about } \\
\text { her elopement and decides to offer her } \\
\text { hand to Carlos if he will bring her back } \\
\text { (12). }\end{array}$ & $\begin{array}{l}\text { Rodrigo hires/asks Juan to negotiate with } \\
\text { Pedro. They come to Pedro's house to talk } \\
\text { to him and run into Carlos and Castaño } \\
\text { trying to sneak out ( } 34 \text { ) }\end{array}$ \\
\hline $\begin{array}{l}\text { Rodrigo hires/asks Juan to negotiate } \\
\text { with Pedro. They come to Pedro's } \\
\text { house to talk to him and run into Carlos } \\
\text { and Castaño trying to sneak out (34) }\end{array}$ & $\begin{array}{l}\text { Juan and Carlos draw their swords to fight, } \\
\text { Juan because he thinks Carlos is trying to } \\
\text { steal Ana and Carlos because he is trying to } \\
\text { get Leonor back (and will just fight anyone } \\
\text { at this point) (34). }\end{array}$ \\
\hline $\begin{array}{l}\text { Juan and Carlos draw their swords to } \\
\text { fight, Juan because he thinks Carlos is } \\
\text { trying to steal Ana and Carlos because } \\
\text { he is trying to get Leonor back (and } \\
\text { will just fight anyone at this point) (34). }\end{array}$ & $\begin{array}{l}\text { Celia reminds Carlos that he needs to hide } \\
\text { from Pedro to preserve Ana's honor. He } \\
\text { excuses himself and she hides them nearby } \\
(35)\end{array}$ \\
\hline $\begin{array}{l}\text { Rodrigo hires/asks Juan to negotiate } \\
\text { with Pedro. They come to Pedro's } \\
\text { house to talk to him (34) }\end{array}$ & $\begin{array}{l}\text { Pedro enters, Rodrigo scolds him for } \\
\text { stealing Leonor but says he is forced to let } \\
\text { him marry her ( } 37) \text {. }\end{array}$ \\
\hline $\begin{array}{l}\text { Pedro enters, Rodrigo scolds him for } \\
\text { stealing Leonor but says he is forced to } \\
\text { let him marry her ( } 37) \text {. }\end{array}$ & $\begin{array}{l}\text { Carlos hears that Rodrigo thinks Pedro is the } \\
\text { one who 'kidnapped' Leonor and freaks out } \\
\text { (37) }\end{array}$ \\
\hline $\begin{array}{l}\text { Pedro enters, Rodrigo scolds him for } \\
\text { stealing Leonor but says he is forced to } \\
\text { let him marry her ( } 37) \text {. }\end{array}$ & $\begin{array}{l}\text { Pedro asks if Ana can be the one to suggest } \\
\text { the marriage to Leonor so she will be more } \\
\text { amenable. Rodrigo says that is fine, as long } \\
\text { as they get married sometime (38) }\end{array}$ \\
\hline $\begin{array}{l}\text { Pedro asks if Ana can be the one to } \\
\text { suggest the marriage to Leonor so she } \\
\text { will be more amenable. Rodrigo says } \\
\text { that is fine, as long as they get married } \\
\text { sometime (38) }\end{array}$ & $\begin{array}{l}\text { Carlos stresses about what to do and } \\
\text { Castaño suggests talking to Leonor about it. } \\
\text { Carlos agrees and they go to look for her } \\
\text { (39) }\end{array}$ \\
\hline & \\
\hline
\end{tabular}




\begin{tabular}{|c|c|}
\hline $\begin{array}{l}\text { Pedro asks if Ana can be the one to } \\
\text { suggest the marriage to Leonor so she } \\
\text { will be more amenable. Rodrigo says } \\
\text { that is fine, as long as they get married } \\
\text { sometime (38) }\end{array}$ & $\begin{array}{l}\text { Celia lies to Leonor and convinces her that } \\
\text { Carlos is chasing Ana. She tries to convince } \\
\text { L to marry Pedro, but L is not having it ( } 40)\end{array}$ \\
\hline $\begin{array}{l}\text { Celia lies to Leonor and convinces her } \\
\text { that Carlos is chasing Ana. She tries to } \\
\text { convince L to marry Pedro, but L is not } \\
\text { having it ( } 40 \text { ) }\end{array}$ & $\begin{array}{l}\text { Celia tells Leonor that she will let her go, } \mathrm{L} \\
\text { just needs to get her coat out of her room. } \\
\text { When L goes in the room, C locks the front } \\
\text { door ( } 42 \text { ) }\end{array}$ \\
\hline $\begin{array}{l}\text { Juan and Carlos cannot fight because } \\
\text { Celia reminds Carlos that he needs to } \\
\text { hide from Pedro to preserve Ana's } \\
\text { honor. He excuses himself and she } \\
\text { hides them nearby ( } 35)\end{array}$ & $\begin{array}{l}\text { Juan enters the garden determined to get } \\
\text { revenge on Carlos and regain his honor. He } \\
\text { hides ( } 42 \text { ) }\end{array}$ \\
\hline $\begin{array}{l}\text { Carlos stresses about what to do and } \\
\text { Castaño suggests talking to Leonor } \\
\text { about it. Carlos agrees and they go to } \\
\text { look for her (39) }\end{array}$ & $\begin{array}{l}\text { Carlos tells Castaño to take a message to } \\
\text { Rodrigo explaining the whole situation, } \\
\text { Castaño is afraid that the police will } \\
\text { recognize and arrest him, but he takes the } \\
\text { note anyway (43) }\end{array}$ \\
\hline $\begin{array}{l}\text { Carlos tells Castaño to take a message } \\
\text { to Rodrigo explaining the whole } \\
\text { situation, Castaño is afraid that the } \\
\text { police will recognize and arrest him, } \\
\text { but he takes the note anyway ( } 43)\end{array}$ & $\begin{array}{l}\text { Castaño puts on Leonor's clothes to take the } \\
\text { note incognito (44) }\end{array}$ \\
\hline $\begin{array}{l}\text { Castaño puts on Leonor's clothes to } \\
\text { take the note incognito ( } 44)\end{array}$ & $\begin{array}{l}\text { Pedro sees Castaño and thinks he is Leonor. } \\
\text { He begs Castaño not to leave, and Castaño } \\
\text { agrees to stay and marry him. C also makes } \\
\text { P promise that he will not harm C at all if he } \\
\text { decides to back out of the marriage (48) }\end{array}$ \\
\hline $\begin{array}{l}\text { Juan enters the garden determined to } \\
\text { get revenge on Carlos and regain his } \\
\text { honor. He hides ( } 42)\end{array}$ & $\begin{array}{l}\text { Juan jumps Carlos from his hiding place and } \\
\text { they come in fighting with swords, followed } \\
\text { by Ana ( } 49 \text { ) }\end{array}$ \\
\hline $\begin{array}{l}\text { Pedro sees Castaño and thinks he is } \\
\text { Leonor. He begs Castaño not to leave, } \\
\text { and Castaño agrees to stay and marry } \\
\text { him. C also makes P promise that he } \\
\text { will not harm C at all if he decides to } \\
\text { back out of the marriage ( } 48)\end{array}$ & $\begin{array}{l}\text { Castaño turns off the lights in order to } \\
\text { escape. Carlos ends up sneaking Leonor } \\
\text { (who he thinks is Ana) out the front door } \\
\text { while Ana takes Juan to another room. } \\
\text { Pedro tells Castaño-as-Leonor to go to her } \\
\text { room and he does (52) }\end{array}$ \\
\hline
\end{tabular}




\begin{tabular}{|c|c|}
\hline $\begin{array}{l}\text { Pedro asks if Ana can be the one to } \\
\text { suggest the marriage to Leonor so she } \\
\text { will be more amenable. Rodrigo says } \\
\text { that is fine, as long as they get married } \\
\text { sometime (38) }\end{array}$ & $\begin{array}{l}\text { Leonor's cousin wakes up and confirms that } \\
\text { Pedro's servants were there to break up the } \\
\text { fight. Rodrigo thinks this means that Pedro } \\
\text { means to dishonor Leonor and put off the } \\
\text { marriage, so he storms in demanding that } \\
\text { the wedding happen immediately (52-3) }\end{array}$ \\
\hline $\begin{array}{l}\text { Carlos ends up sneaking Leonor (who } \\
\text { he thinks is Ana) out the front door ( } 52)\end{array}$ & $\begin{array}{l}\text { Carlos asks Rodrigo to watch Leonor (who } \\
\text { Carlos thinks is Ana) in the street so he can } \\
\text { go back in and look for Leonor without } \\
\text { being seen with "Ana" (54) }\end{array}$ \\
\hline $\begin{array}{l}\text { Carlos asks Rodrigo to watch Leonor } \\
\text { (who Carlos thinks is Ana) in the street } \\
\text { so he can go back in and look for } \\
\text { Leonor without being seen with "Ana" } \\
\text { (54) }\end{array}$ & $\begin{array}{l}\text { Rodrigo comes in and threatens Pedro } \\
\text { saying if he does not marry Leonor, Rodrigo } \\
\text { will tell everyone about Carlos and Ana ( } 54)\end{array}$ \\
\hline $\begin{array}{l}\text { Rodrigo comes in and threatens Pedro } \\
\text { saying if he does not marry Leonor, } \\
\text { Rodrigo will tell everyone about Carlos } \\
\text { and Ana (54) }\end{array}$ & $\begin{array}{l}\text { Pedro admits to Rodrigo that he did not take } \\
\text { Leonor but agrees to marry Ana to Carlos } \\
\text { ASAP (57) }\end{array}$ \\
\hline $\begin{array}{l}\text { Pedro admits to Rodrigo that he did not } \\
\text { take Leonor but agrees to marry Ana to } \\
\text { Carlos ASAP (57) }\end{array}$ & $\begin{array}{l}\text { Ana overhears this and reveals herself and } \\
\text { also points out that she has (who she thinks } \\
\text { is) don Carlos hidden in her room. She goes } \\
\text { to get him (58) }\end{array}$ \\
\hline $\begin{array}{l}\text { Carlos asks Rodrigo to watch Leonor } \\
\text { (who Carlos thinks is Ana) in the street } \\
\text { so he can go back in and look for } \\
\text { Leonor without being seen with "Ana" } \\
\text { (54) }\end{array}$ & $\begin{array}{l}\text { Carlos comes in to confront Pedro as Leonor } \\
\text { sneaks back in as well. Pedro wants to hear } \\
\text { Carlos's proposal from him, but Leonor } \\
\text { speaks up and says that she will not marry } \\
\text { "that traitor." The R\&P explain the 'deal' to } \\
\text { Carlos (60) }\end{array}$ \\
\hline $\begin{array}{l}\text { Carlos comes in to confront Pedro as } \\
\text { Leonor sneaks back in as well. Pedro } \\
\text { wants to hear Carlos's proposal from } \\
\text { him, but Leonor speaks up and says } \\
\text { that she will not marry "that traitor." } \\
\text { The R\&P explain the 'deal' to Carlos } \\
\text { (60) }\end{array}$ & $\begin{array}{l}\text { Leonor, still in disguise, agrees that she is } \\
\text { Carlos's fiancée. He refuses and declares his } \\
\text { love for Leonor }(61)\end{array}$ \\
\hline $\begin{array}{l}\text { Leonor, still in disguise, agrees that she } \\
\text { is Carlos's fiancée. He refuses and } \\
\text { declares his love for Leonor }(61)\end{array}$ & Carlos and Pedro draw swords (61) \\
\hline
\end{tabular}




\begin{tabular}{|l|l|}
\hline $\begin{array}{l}\text { Ana overhears this and reveals herself } \\
\text { and also points out that she has (who } \\
\text { she thinks is) don Carlos hidden in her } \\
\text { room. She goes to get him (58) }\end{array}$ & $\begin{array}{l}\text { Ana re-enters with 'her betrothed' aka Juan- } \\
\text { who-she-thinks-is-Carlos (61) }\end{array}$ \\
\hline $\begin{array}{l}\text { Rodrigo comes in and threatens Pedro } \\
\text { saying if he does not marry Leonor, } \\
\text { Rodrigo will tell everyone about Carlos } \\
\text { and Ana (54) }\end{array}$ & Celia brings Castaño back in \\
\hline $\begin{array}{l}\text { Ana re-enters with 'her betrothed' aka } \\
\text { Juan- who-she-thinks-is-Carlos, Carlos } \\
\text { declares his love for Leonor (61) }\end{array}$ & $\begin{array}{l}\text { Ana claims she was after Juan the whole } \\
\text { time. Pedro accepts this. (62) }\end{array}$ \\
\hline $\begin{array}{l}\text { Carlos and Pedro draw swords (61) } \\
\text { Carlos and Pedro fight over Leonor/ } \\
\text { Castaño (62) }\end{array}$ & $\begin{array}{l}\text { The real Leonor reveals herself and accepts } \\
\text { Carlos as her husband. Castaño has to reveal } \\
\text { himself as well (63) }\end{array}$ \\
\hline $\begin{array}{l}\text { They all pair off (except Pedro) and the } \\
\text { story ends happily (64) }\end{array}$ & \multicolumn{1}{|l|}{ Cant over Leonor/ } \\
\hline
\end{tabular}

I was able to use this chart as a touchpoint to see what needed to happen next in the story, which was especially helpful since the mechanics of who goes behind what door and who is mistaken for whom is carefully calibrated in this farce. This analysis is simple enough to offer me some flexibility but also detailed enough to help me ensure that all of the moving parts function effectively.

These slamming doors also helped me find ways to ground myself in more contemporary themes and culture, since both the original text and contemporary comedies involve a lot of people hiding behind various doors, moving between those doors, mistaken identity, and romance. The first ground that I chose for my adaptation was, therefore, the genre of a twentieth-century sex farce. I imagined a set and tone similar to Boeing Boeing by Marc Camoletti or Lend Me a Tenor by Ken Ludwig. Though it seems surprising that a 
nun would write a sex farce, Octavio Paz points out in his biography of Sor Juana that seventeenth-century Mexico was, perhaps, less prudish than a twenty-first-century reader might assume. Sor Juana's own family seems to have been fairly open about their various affairs, and she does not seem particularly bothered by characters who may or may not be sleeping together. Characters joined socially by marriage, on the other hand, is a completely different issue. The classical sex farce genre is also populated primarily by male playwrights, including Camoletti and Ludwig, along with Neil Simon, Moliere, and many more. As such, I added a feminine perspective to this farce both through my own translation and the celebration of Sor Juana's work. I believe this difference resulted in a play which centers and respects women more than most farces.

Grounding the concept of honor in the play in the contemporary world proved a little more difficult, since the Spanish Golden Age focus on honor and the reasoning that stems from it regarding who has to marry whom and why is difficult to parallel in contemporary culture. The fact that Rodrigo would force Leonor to marry a man just because she found herself in his house ran the risk of being unbelievable even for a farce or so unjust it is no longer funny to contemporary audiences. I considered lowering the stakes and putting the characters in a situation in which their parents had more control by aging all of them down to teenagers, but that presented other problems. Finally, I landed on characters who were just out of high school and living in an Evangelical Christian community. This allows Rodrigo, as a parent, to have some control over Leonor but it is still possible for Ana and Pedro to live alone without their parents. This culture also justified the absurd amount of control that the men in the play have over the women. I am familiar with Evangelical culture, I grew up around it, and I feel comfortable commenting 
on it based on my own experiences. These two grounding concepts helped me move How to Build a Noble House to a contemporary setting. To reflect the new setting and the twist I chose to incorporate, I chose With the Temptation, a Way of Escape as the title based on a verse from the Biblical book of First Corinthians claiming that God "will not allow the temptation to be more than you can stand" (1 Corinthians 10:13). This worked well as a commentary on the way the 'temptations' in the play turn into something that eventually frees Ana and Leonor from the repressive culture that previously controlled their lives.

This escape was another of my additions - I wanted to comment on the aspects of the original play which could be seen as repressive and add more diversity in gender and sexuality. In my conversation with Svich, she pointed out that addressing the erasure of LGBTQ+ folx is an important part of what adapters are able to do when working with a classical script. With that in mind, I chose to focus on justifying all the romantic relationships which end in marriage at the end of the play and giving both female characters who are otherwise jerked around by honor/purity culture a way out of that culture through these romantic relationships. While using a relationship to escape such a culture is not the most independent way for a character to break free, it fits with the original text and is a believable result, since said characters would have to leave their families and everything they know to make such an escape. The play also offers a contemporary commentary about the ways a supportive partner can provide the necessary means to get out of a controlling situation and the impetus to make that escape as well. In choosing partners more or less outside the Evangelical culture that dominates the play, Leonor and Ana are able to make choices that will give them more freedom when the play is done. 
Ana's relationship is further changed by the fact that I replaced the male character of Juan with a female character named Juana in With the Temptation, a Way of Escape. I felt that this justified Ana's willingness to switch from chasing after Carlos to settling for Juan/a at the end of the play. In the original text, this interaction goes like this:

DON CARLOS

Es manifiesto

engaño, que yo a Leonor

solamente es a quien quiero.

DOÑA ANA

(Aparte.)

(Acabe este desengaño

con mi pertinaz intento;

y pues el ser de don Juan

es ya preciso, yo esfuerzo

cuanto puedo, que lo estimo,

que en efecto es ya mi dueño.)

DON CARLOS: That's nothing but a trick, because Leonor is the only one I love.

DOÑA ANA: (Aside) This disappointment will end with my persistent efforts; and since don Juan is right here, I will make the best effort I can to reel him in, since he is, basically, already my lord.

(Act III, lines 1172-1180)

Clearly, Ana's choice to marry Juan is halfhearted at best. If Ana's determination to win over Carlos exists more for the sake of a good match when she knows she will never be satisfied by any matches at all, her willingness to leave the relationship makes more sense. Ana's final relationship ends this way in my adaptation:

\section{ANA}

Pedro, I don't like it here. And I don't like who I am when I'm here. SO it's time I find something else to do anyway.

\section{PEDRO}

Ha! Yeah right. I give it a week. I'll double the locks on the doors while you're out. 
No it won't.

ANA

(Turning toward JUANA)

Because I want to make a life with Juana. She makes me happy and she makes me better.

I love you too. Can I kiss you?

(JUANA nods yes and they kiss. Uproar from PEDRO and RODRIGO)

This relationship also allowed me to allude to Sor Juana herself, who I believe would have advocated for LGBTQ+ inclusion had it been acceptable at the time. There has also been speculation that Sor Juana may have had romantic relationships with women, though there is little to no conclusive evidence showing this is true. However, the popularity of this belief is shown in both María Luisa Bemberg's film Yo, la peor de todas and Patricia Arriaga-Jordán's series, Juana Inés, both of which are fictionalized biographical films about Sor Juana's life. This change presents a stronger conflict for Ana to overcome by the end of the play and allows her to show growth and regret for her manipulative actions against Leonor. She also takes a moment to apologize to Leonor for those actions, undercutting the competition between women that was rampant in the original:

I'm talking.

\section{ANA}

(Surprisingly, this shuts RODRIGO up for a second)

I'm so sorry, Leonor. He couldn't have done that without me, and that was wrong of me to do. I don't know how I'll ever make it up to you. 
I added a couple of scenes between Celia, Juana, and Ana to help flesh out other positive female-female relationships and motivate Ana to embrace her sexuality and leave everything she knows and choose to live instead with Juana at the end of the play.

Making Celia a friend and not a servant not only let me integrate female friendships into the play, it also helped me address the servant issue. To do this, I simply made Castaño and Celia friends of Carlos and Ana who happen to be present. This way, they are still relative outsiders to Evangelical culture who can therefore receive clarifying exposition at times to justify the kinds of explanations and justifications that the audience is likely to need at the beginning of the play. I was also careful to present Castaño, who is called Bruno in my adaptation ${ }^{36}$, as enjoying dressing in Leonor's clothing, not as a joke using femininity as the punchline but rather as a moment celebrating the joy of a man discovering his love for drag:

\section{BRUNO}

Those guys outside won't care if a girl comes out of the house. I just have to make it convincing.

(He pulls a dress on over his head and flails around in it a little.

When he finally emerges, he smooths it down.)

Ooh. Flowy. But it's missing a couple little things...

(He stuffs a couple of socks or tissues down his front to make 'boobs')

That's better. Now, down south. I see there are some tights in here. Let's see.

(He tries to pull on the tights standing up. He hops around on one leg, almost loses his balance, and finally plunks on the couch. Somehow, he still manages to fall over on the couch, legs flailing in the air. He finally gets the tights on, however, and he stands up)

Phew! Lots of work there, but worth it. Look at those babies. Kapow!

(This is accompanied with a leg-forward pose or high kick) Sexy! I wonder if she has makeup in here.

\footnotetext{
36 This is the only name I changed, though I used 'Rodrigo' as a last name and not a first name. It still means 'brown' but is more recognizable to an English-speaking audience.
} 
(He opens the bag to check. She does. He powders his face, inhales it, coughs. Smears on a little rouge using the tiny mirror on the compact, then pulls out the mascara. He stabs himself in the eye a couple of times, knocks things over in his blindness, generally makes a mess, but by the end he manages to look himself over in the tiny compact mirror)

Excuse me for saying this, Oh Conservative House, but damn! I look hott! Yes, girl! You rock this look!

This mood is remarkably similar to the original text and presents a contrast more with contemporary toxic masculinity than with Spanish Golden Age mores.

With the Temptation, a Way of Escape had a reading with Scene One Rough Writers, a community theatre group in Jefferson City, Missouri, in the spring of 2021. The reading lasted just over an hour, but I anticipate that the amount of action taking place onstage, especially given the farcical genre, would fill in a little more time in a full production. However, the extra time available in the play's run-time makes it possible for me to develop the relationship between Juana and Ana more, which was one request from the audience at the post-reading talkback. Since the relationship between Ana and Juan in the original script is similarly underdeveloped, this lack of development is not surprising. However, in With the Temptation, a Way of Escape, Ana's relationship with Juana has to motivate her to leave her home and therefore has to be much stronger. The audience's desire for a more fleshed-out relationship also reflects the twenty-first-century intertextual expectations that I mentioned previously. Marriage for marriage's sake is one aspect of Spanish Golden Age drama that no longer works for theatregoing audiences. Members of this talkback also wanted to see more integration of Evangelical culture in the play. My next experimental attempt at this script will, therefore, merge the Spanish Golden Age story with contemporary culture even more in order to make the adaptation work as its own 
entity. Perhaps successful adapturgy creates, not the most faithful adaptations but the most interesting intersections of cultures, time periods, and genres.

\section{My Own Intercultural Adapturgy}

As I approached my own adapturgical work, I felt that both Svich and Callaghan were incomplete as separate models, which of course is to be expected as each adaptation and its process is unique. I felt that Svich's minimalistic stage directions would be confusing given the number and importance of the doors in Los empeños de una casa. I also liked the idea of letting Sor Juana's voice ring through in the context of a contemporary style like farce. For Callaghan's part, I felt that it might be important to include more touches from the Spanish Golden Age in my work since Los empeños de una casa is not a well-known or widely produced work. As I pointed out before, this inspired me to create two different pieces which metaphorically cover all of my ethical bases (to the best of my ability). The reflection that I took before setting out to actually work out these adaptations is not something that a casual reader can know entirely, but I believe that reflecting on my own positionality and my dramaturgical purpose for adapting this play now were invaluable to creating an appropriate and focused tone for the piece. Though I do not know what kind of previous reflection Svich and Callaghan did before writing A Little Betrayal Among Friends and Fever/Dream, their examples were helpful as I started the more practical creation process.

In the translation, How to Build a Noble House, I used strategies that I already mentioned like leaving stage directions and costuming instructions relatively vague and added some of my own strategies as well. Since this piece is more aesthetically similar to 
A Little Betrayal Among Friends, I took most of my cues from Svich. One of these cues led me to try and keep as many pieces of the Spanish Golden Age as made sense, like the aforementioned stage directions and costuming choices based on Spanish Golden Age clothing. While I would have liked to leave the costuming open-ended, that was not possible with parts of this piece, as it was important to the mistaken identities throughout the piece that characters be dressed up as a specific kind of fully-covered Spanish nun. I also added (or rather, kept) a few Spanish exclamations like ay de mí, which are easily understood by English-speaking audiences and emphasize the characters' Hispanic origins. Like Svich, I made changes and cuts that allowed contemporary audiences to enjoy the play more as the comedy it was meant to be, not to feel like they are slogging through a very old play.

For With the Temptation, a Way of Escape, I took my cues from Callaghan and Fever/Dream in that I tried to make the play more relevant and entertaining to twenty-first century audiences. Like Callaghan, I aimed to make the comedy and commentary relevant for my audience by including references and settings they experienced or might understand more personally. In addition, taking my cue from my conversation with Svich, I included a non-hetero relationship and let the complications from that relationship affect the rest of the story. I am open to the idea of adding scenes and language that certainly was not in the original script to make the story work for contemporary audiences. While this does not include stylistic choices from the Spanish Golden Age, it does, I believe, reflect the comedic tone Sor Juana wanted to get across and share a story of a woman taking control of her life and the people around her - an issue that I believe was very important to Sor Juana and which can end more happily in the twenty-first century than it could in the 
seventeenth. I hope to see both of these works published and produced so I can gauge audience reactions and renewed interest in the original script. 


\section{Chapter 5}

How to Build a Noble House

By Sor Juana Inés de la Cruz Translated by Lainie Vansant 


\section{Introduction}

Any translation will inevitably include the translator's perspective and their interpretation of the original text. Emily Wilson points out that each translation is influenced by the translator's identity and positionality in time and space, and our understanding of classical texts is enriched by seeing a variety of translations and adaptations, which naturally offer varied perspectives of the text. My translation of Los empeños de una casa, printed here, is affected by my work as a dramaturg and my interest in making the script performable and entertaining for twenty-first-century producing organizations and audiences. As such, my script follows in the path of Caridad Svich, who often describes her work as "riffing on" source texts and playwrights. Another excellent example is the work of Anne Carson, whose translation of Antigone, which was commissioned for performance by the Brooklyn Academy of Music, at first seems like more adaptation than translation but appears quite faithful when compared to her earlier adaptation of the script, Antigonick, which was produced as poetry (Ketenjian). In How to Build a Noble House, the changes inspired by my unique position and influences reflect the concept of adapturgy in that the changes I made from my literal translation of the text to the final translation are based in dramaturgical skills and priorities like those Barnette describes. I had to choose which plot points, characters, and jokes to keep and which to cut, give context if it was needed and decide which aspects did not need context, and make sure that the main action was as clear and performable as possible, which sometimes meant trusting my audience's assumptions and making space for physical and timing-based jokes. For example, at the beginning of Los empeños de una casa, Celia finds Ana waiting by the door in the middle of the night. When Ana says she is waiting for her brother, Celia says: 
Pues eso será velar,

porque él juzga que es temprano

la una o las dos; y a mi ver,

aunque es grande ociosidad

viene a decir la verdad,

pues viene al amanecer.

Mas, ¿por qué ahora te dio

esa gana de esperar,

si te entras siempre a acostar

tú, y le espero sola yo?

Oh, my lady - this might as well be a wake - by his judgment, "early" is one or two in the morning. I don't want to speak ill of my master, but the truth is, he won't return until sunrise.

But why are you suddenly in the mood to wait up? You're always the one going to bed and I'm always waiting here alone.

(Act I, lines 3-12)

In How to Build a Noble House, I modernize this somewhat with contemporary language

and awkward pauses:

Oh, my lady - I warn you - no offense to my Master, but when he comes home "early," it's still one or two in the morning.

(Beat. DOÑA ANA doesn't leave.)

So I would understand if you want to go on to bed.

(Another awkward pause)

What makes you want to wait up for him all of the sudden, Miss? (3)

What How to Build a Noble House does not do is attempt to change the setting or social mores of the play from its original Spanish Golden Age setting. The names and places remain unchanged, and the plot still hinges on the seventeenth-century Spanish code of honor. With the inclusion of these aspects, How to Build a Noble House will, I hope, be a highly performable text for companies who want to present period drama with powerful female characters. Please take the time to imagine the physical gags and over-the top characters as you read my translated work below: 


\section{Characters}

CARLOS: A handsome gentleman

JUAN: A lover. Determined.

PEDRO: A schemer

RODRIGO: An honorable father

LEONOR: A lover. Rebellious

ANA: The mastermind

CELIA: The smartest servant

HERNANDO: The most loyal servant

CASTAÑO: The hungriest servant

POLICEMEN: Enough said.

Setting: The home of Pedro and his sister, Ana. Toledo, Spain 


\section{Act I}

(CELIA is sitting patiently in the front parlor of a wealthy and noble house in seventeenth century Spain. Enter ANA)

Good evening, Celia.

ANA

CELIA

Good evening, Miss.

(Awkward silence. Beat.)

Um... Miss - what are you doing?

ANA

Waiting for my brother. Just like you.

CELIA

Oh, my lady - I warn you - no offense to my Master, but when he comes home "early," it's still one or two in the morning .

$$
\text { (Beat. ANA doesn't leave.) }
$$

So I would understand if you want to go on to bed. (Another awkward pause)

What makes you want to wait up for him all of the sudden, Miss?

ANA

Tonight, my dear Celia, my brother has trusted me with an important task. He met a young lady in Toledo, you know, while he was there on "business." And I found a gentleman of my own here at home while he was gone.

\section{CELIA}

I was there, My Lady. I know your Juan.

\section{ANA}

Mmm. Yes. So. instead of coming home, he forced me to join him here. Maybe he was suspicious, there's no telling. But he summoned me here and I had no choice but to come. Anyway, my brother, Pedro, / was rejected by that noble lady he was chasing.

CELIA

/I know who your brother is, my lady. 


\section{ANA \\ (Without missing a beat)}

He found out that she had another lover, and oh, was he angry. You know men and their jealousy. Anyway, he bribed her maid (so barbarous, not even creative) to get the whole story, and it turns out that this lady - doña Leonor is her name - was going to elope with her lover this very night. so, do you know what he did?

CELIA

Well, the other maids said--

\section{ANA}

He bribed some men to dress up like police so they can take her from her lover and deposit her here to me, like money in the bank. Isn't that just so evil of him? I simply can't believe it!

CELIA

(Under her breath)

I can .

What's that, Celia?

ANA

CELIA

Nothing, my Lady! So surprising!

ANA

Mm. Yes. Anyway, the police will kidnap the lady but let her lover escape, then my brother will give her shelter in his home where he will have her trapped without seeming to be the one to blame.

So, you see, I couldn't possibly go to bed with all of this excitement going on!

\section{CELIA}

\section{(Aside)}

It seems like this should surprise me, but nothing shocks me anymore. You'll see - all of this drama is just par for the course around here. Feminine recklessness, lovers' schemes, everyone's an idiot except the maid, blah blah blah. 


\section{(TO ANA)}

CELIA (cont.)

But you aren't forgetting about Juan in all of this, are you? Didn't he follow you here?

ANA

He did. But still...

CELIA

Still what?

ANA

Oh, it was so gallant of him to come running after me, dropping the ladies' man act and giving me all of himself, but it kind of ruins the thrill of the chase, doesn't it?

And Celia, I must confess, there's a handsome young man who walks through the streets of Toledo. So handsome phew! Ay de mi! Oh Celia, I know I should be thinking about Juan, and this might just be a crush, but... oh, but now I just keep jabbering on without hearing what you have to say.

CELIA

Are you crying?

\section{ANA}

Of course I'm crying! Oh poor me! I know that I'm making a mistake but he's just so handsome!

(Aside)

\section{CELIA}

This girl does not stop! Juan knew that she was... sightseeing here in Toledo, so I snuck him into her room so they can just do the nasty and be done with all this drama. But you didn't hear it from me. (to ANA)

So, Madam, who is this beef-cake you're pining over?

ANA

Don Carlos de Olmedo, the gentleman. (A knock at the door)

Oh! Someone is at the door: Go see who it is!

Who is it?

CELIA 
Police!

MAN

ANA

That will be Pedro's lady; open the door, Celia. (CELIA does)

Come in!

(Enter men whose faces are covered except for their eyes, and Leonor)

MAN

Madam, I know that this is a noble house, but could you please take in this woman? We found her wandering the streets with a man.

ANA

At this time of night? Shocking!

MAN

Yes. Please forgive me. I know that this situation is not something an upright house like yours should be dragged into.

(The police exit)

ANA

What is all this? Celia, the things those men said were simply scandalous! My poor, delicate ears!

\section{CELIA}

(Aside)

Well, she's having fun. Laying it on a little thick though, if you ask me.

\section{LEONOR}

Madam, if you can find it in your kind heart to take pity on me I beg of you - please have mercy on me and my reputation. None of this is what it looks like. I'm-- oh, please don't think that I'm an idiot.

ANA

Ah! Your beauty and your disgrace have stirred up pity in my heart. What my brother says is true, Celia. 


\section{(Aside to Ana)}

CELIA

She is surprisingly beautiful. If this is what she looks like coming in out of the rain, imagine how hott she'd be if she was tryin'.

ANA
Rise, madam, and pardon me for my rudeness. Your elegant manner speaks in your favor and I offer all of my soul to serve you.

\section{LEONOR}

Oh, thank you so much! You're an angel! A Goddess! Thank you for your hospitality!

ANA

Rise, and tell me what happened to bring you to such misfortune;

Though, honestly, with your looks, you can't say you're too unfortunate.

\section{CELIA}

\section{(Aside)}

Ooh, she's jealous. This is going to be fun.

\section{LEONOR}

I hate to talk about it -.I'm so ashamed, but it is fair to tell you what's going on, since you've let me stay in your home and I'm dragging you into all of it.

\section{I'm listening.}

ANA

\section{CELIA}

(Aside)

We're spillin' noblewoman tea now! This outta be good. I'll warn you though: don't believe a word they say.

I was born noble:

\section{LEONOR}

CELIA

(Aside)

Oh God, do we have to go back that far? 
LEONOR

I would say that I was born beautiful as well, but do I really need to say it? You can see for yourself, and if I did say it, it would sound like boasting, so I won't. But then, I don't know if you'll be able to understand my story without it. So...

CELIA

We get it. You're gorgeous, my lady.

LEONOR

Oh no. You're so sweet, but no, not really.

CELIA

Ok, sure. Just keep going.

LEONOR

Well, I was also very studious, and I put a lot of effort into learning and books. I was hidden away from men for most of my life which, of course, made them even more curious and determined to get to me. Soon, stories of my wisdom and my beauty flew through the country and became greatly exaggerated until I had a sea of suitors begging for my hand.

CELIA

(Sarcastic)

A sea of suitors. Right. Relatable. Poor you.

Thank you, my dear...

LEONOR

ANA

Her name is Celia, and she needs to be quiet.

CELIA

You're welcome, miss. Go on.

LEONOR

Anyway, I chased all of those suitors off, so my parents trusted me. And I deserved that trust until I met... him. The man of my dreams. He is both strong and sweet, brave and beautiful, muscular and graceful. Ladies, he is the complete package. I just couldn't resist him: my don carlos de Olmedo 


\section{ANA}

(Aside)

Oh God no! That's my Carlos!

\section{LEONOR}

Oh how I love him! And I wanted to marry him so much, but my father wouldn't allow it, so tonight Carlos came to steal me away from my father's house, but the moment we put foot to the pavement, two policemen shouted at us and I cried out to my Carlos, then he drew his sword, and it seemed like he barely touched one of the men in the street when the man fell to the dirt, dead!

Barely touched him is right.

\section{CELIA}

$$
\text { (ANA shoots her a look) }
$$

\section{LEONOR}

Then the police came and shoved me into your lovely house here, and all I can do is wait to hear my death sentence because when they kill my Carlos, I'll surely die too!

ANA
Oh Miss Leonor, your story is so sad. Celia, take this lady to my room while I wait for my brother.

\section{CELIA}

Come, madam.

\section{LEONOR}

Yes, thank you. Oh, my head aches! There's nothing I can do anyway but accept my fate.

\section{(Exit CELIA and LEONOR)}

ANA

How romantic! Oh Carlos, if only you loved me enough to risk your life for my sake.

(There is a banging at the door. ANA looks for CELIA, sees that she isn't there, and opens it, revealing CARLOS, with an unsheathed sword, and his servant, CASTAÑO) 
DON CARLOS

Thank heavens. Madam, I'm so glad to find someone awake. I know it's untoward, but please, would you let me hide out in your house for just a little while? Your hospitality could save my life.

Though my life hardly matters any more now that I've lost my heart and my soul.

CASTAÑO

My life matters! I don't care what he's doing, I'm gonna hide!

$$
\text { (He tries to hide under ANA's skirts) }
$$

Stop that, you idiot!

CARLOS

ANA

$$
\text { (Aside) }
$$

Heaven help me, it's Carlos!

Here's my chance. I'll take care of him, show him some kindness, and soon he'll be confessing his love for me and not that silly Leonor. Oh, I know he "loves" her, but men are easy to win over.

Oh, not like that, you churls! I'll guard my honor, believe me. I don't need cheap tricks to win this game.

$$
\text { (to CARLOS) }
$$

Good sir, you're injured! You must be very good and brave. Come quickly - I'll hide you in the stable. But be quiet my brother will be back soon, and if he sees you alone with me... well... this does look quite scandalous, don't you think?

\section{DON CARLOS}

Oh Miss, the last thing I want to do is to taint your honor, but I do need this help. Thank you so very much.

$$
\text { CASTAÑO }
$$

Eew, no. Come on, guys. Don't make me hide in this nasty stable, oh beautiful lady? Couldn't you find us somewhere to hide in, say, the kitchen?

ANA

I have a better spot if you can be patient for a moment. That room (pointing) is used for storage now. I'll have to 


\section{ANA (cont.)}

move some things so you can fit but rest assured, an improvement is on the way.

CASTAÑO

(Aside to Carlos)

Sir, even the storage room is far from the kitchen. Look at this fancy-pants place! Have you considered falling for this woman instead? Compared to this, doña Leonor's dowry is five pennies and a rumor. Nice girl, but still.

\section{CARLOS}

Castaño. .

\section{CASTAÑO}

Also, here we are asking for shelter and safety, blah blah blah, but you haven't even mentioned dinner!

\section{CARLOS}

Good grief, you're nothing but a stomach.

\section{ANA}

Follow me.

(She turns aside to the audience, crosses the

fingers on both hands, and smiles a hopeful smile.)

(AIl exit, shift to LEONOR's house, enter RODRIGO and HERNANDO)

\section{RODRIGO}

What are you telling me, Hernando?

HERNANDO

I'm telling you what happened: my lady left the house

$$
\text { RODRIGO }
$$

And with whom? Have we figured that out?

\section{HERNANDO}

How could I?!?! Every man in Toledo and then some have been here for a month mooning over her. There are bound to be a couple of bad seeds, but I can't tell which is which, and, with all due respect, sir, you didn't even lock the doors; you practically invited these men to kidnap her: "just take my daughter, have fun!" 


\section{RODRIGO}

Hernando, don't test my patience. Oh, confound it! I thought she had inherited some of my good sense, but as it turns out, she's just a woman - so.... frivolous! And with all of these men here to court her, now everyone knows about this scandal.

I just want to stab something, Hernando, but I don't know who!

\section{HERNANDO}

Not me, sir, please! Now, I won't say I have real evidence about who could have taken my lady Leonor, but she was hanging out with don Pedro de Arellano quite a bit, and... I'm just saying...

\section{RODRIGO}

Why would don Pedro kidnap her!?! He's a wealthy man; she's sure to like him, and I would be happy to give her to him!

\section{HERNANDO}

Well, sir, with all of these suitors, maybe love made him afraid. It certainly looks like he let fear take over - he took her to so that he could secure her hand. So, give him what he wants and everyone will be happy. Right now she is shamefully hidden in his house, but if she was engaged to don Pedro, then she could visit his house without shame and no one will be the wiser.

\section{RODRIGO}

Oh Hernando, you bright and beautiful treasure! You're right - let's look for don Pedro immediately and turn him from enemy into a son!

\section{(They exit)}

(Shift to ANA's house. It is pitch dark. Enter LEONOR, pursued by JUAN.)

\section{JUAN}

Wait, my sweet, lovely death! What's wrong? You're running from your own victory because your beauty, my love, has slain me!

What a drama unfolds: you run away from love and I run toward my doom. 


\section{LEONOR}

Good sir, or whatever you are, I don't know what you're talking about, but I'm sure it's not me that you're looking for! Just listen to me for a moment!

\section{JUAN}

What a scold you are! I know exactly what's going on here. You know my reputation as the one and only don Juan and you're afraid that I'll use you and run but I assure you, my dear, that will not happen. You've seen the waves of my love crashing on the shore of your modesty for so long now, and even when storms arose to endanger the beach, my respect for you was a protective bank holding back the sea of my hopes.

\section{LEONOR}

I told you, sir, I am not the woman you're looking for! Just go away and tell someone else about your "waves" and your "love," if you must.

\section{Listen.}

JUAN

\section{LEONOR}

No thank you.

\section{JUAN}

You have to listen to me, woman, I've tried to be nice, but we can do this the hard way if we have to!

$$
\text { (He grabs her by the arm) }
$$

LEONOR

What are you doing? Heaven help me!

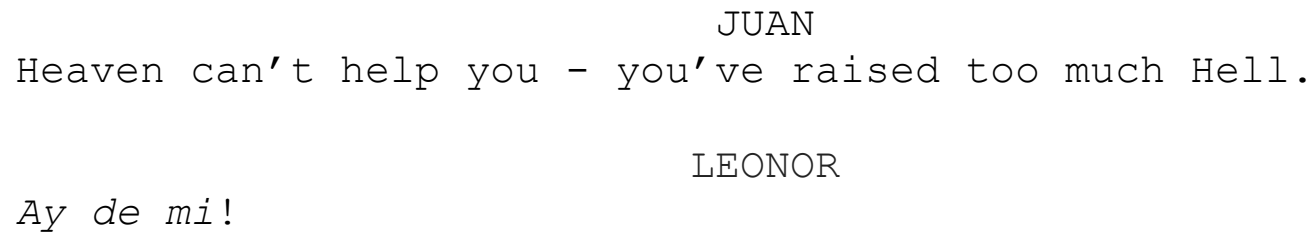$$
\text { JUAN }
$$$$
\text { Heaven can't help you - you've raised too much Hell. }
$$$$
\text { Ay de mi! }
$$$$
\text { LEONOR }
$$

$$
\text { (Enter CARLOS and ANA) }
$$

ANA

(Exiting from the storage room where she has hidden CARLOS and CASTANOO) What's going on out here? 
ANA (cont.)

(to CARLOS)

Stay here - I'll see what's going on, in case that's my brother.

\section{CARLOS}

(Recognizing LEONOR's VOice)

That voice - how could she be here? Miss, I've made a terrible mistake. Forgive me.

\section{ANA}

Who's there?

CARLOS

It's me, my Lady. You were just talking to me.

ANA

Not you.

JUAN

Oh Ana, why do you fight my love? I followed you here like a salamander to the rays of your sun; my face follows yours like a sunflower. To serve you, I left my house, lost my father's respect, and left the safe embrace of my home.

Sure, maybe you had some rough edges. Sometimes you weren't quite as loving, attentive, or polite as I might have wished, but we had an unspoken appreciation, didn't we? Why are you so distant now?

ANA

(Aside)

Good Heavens! It's Juan de Vargas! Listen to him, ugh! But who brought him here?

CARLOS

Please, my love, just listen--

(CARLOS CrOSSES tO LEONOR)

LEONOR

Get away from me! I told you to leave me alone.

CARLOS

Listen, lovely doña Ana - I am don Carlos, your guest. 


\section{LEONOR}

\section{(Aside)}

Don Carlos, he says - good heavens! He sounds just like Carlos. But it can't be. I must just have Carlos in my soul, so everyone seems like a Carlos to me, and he - oh my sweet love! My Carlos is probably already in jail.

Madam?

CARLOS

\section{LEONOR}

Get away from me - I told you to leave me alone! That is enough!

CARLOS

I'm sorry I followed you - I just wanted to be sure you made it to safety.

\section{(Aside) \\ LEONOR}

Heaven help me, he seems so much like Carlos!

JUAN

Why, ungrateful woman, do you despise me with such vigor?

$$
\text { (Enter CELIA, with a light) }
$$

CELIA

What's going on out here?

$$
\begin{gathered}
\text { (Aside) } \\
\text { It is Carlos, isn't it? }
\end{gathered}
$$

(Aside)

\section{CARLOS}

This is Leonor, or my fear is fooling me.

$$
\text { ANA }
$$

\section{(Aside)}

Juan is here? Why, I can't breathe!

(Aside)

$$
\text { JUAN }
$$

Is that don Carlos de Olmedo? He must be here to steal my Ana! I knew something was up! 
(Aside)

\section{LEONOR}

Oh no! If Carlos is here, that means that while I was bawling my eyes out for him he was really safe and sound in the arms of another woman! But how? Is our whole relationship a lie?

\section{(to ANA)}

JUAN

You trollop! You disgust me: to have a man hidden in your house? This is why you turned me away? Well, Heaven lives, traitorous woman,. My honor saves you from my wrath - but I will take revenge on your lover!

Stop, don Juan! Wait!

ANA

\section{CARLOS}

Leonor? Good Heavens, how did you get here?

Stop!

$$
\text { (Restraining JUAN) }
$$

$$
\text { ANA }
$$

\section{JUAN \\ (Straining toward an oblivious CARLOS) \\ Back, tyrant! I must cut down your lover!}

\section{CELIA}

Madam, don Pedro is at the door.

ANA

What are you saying, Celia?

Ay de mi! Gentlemen, stop! Think of my reputation. An upright, frivolous woman like me couldn't have caused any of this havoc. But I do have safe places for all of you to hide and tomorrow we'll sort all of this out. Until then, hide! My brother will be here any moment!

CARLOS

Of course. You saved my life, I owe you a great debt.

$$
\text { JUAN }
$$

I wouldn't do anything to harm you, my love. But I do expect an explanation. 
ANA

I appreciate both of you. Celia, hide these two in different rooms, it won't be possible for them to leave until morning.

CELIA

Well, "morning" will be here in no time. Juan, come with me. Miss, you put this ghost wherever you like.

(Exit CELIA and JUAN)

ANA

Sir, please go into that room.

CARLOS

Of course.

(He exits)

ANA

Leonor, you should get to bed as well.

LEONOR

I'm happy to as long as I find an empty room this time. This whole thing has been so embarrassing!

(She exits)

ANA

What a mess. And normally I'm quite good at these things! (CELIA enters)

CELIA

Madam, he's in my bedroom now. What should I do next?

ANA

(One last check around the courtyard)

All clear. Go open the door for my brother.

\section{CELIA}

(Aside)

Ha! She forgot to ask how Juan got into the house. Score one for Celia!

(She exits) 


\section{ANA}

\section{(Aside)}

Heavens, my life is so hard! I love Carlos, but Juan is... persistent. My rival is sleeping in my room. My maids betray me, and my brother holds me prisoner! Here he comes.

(Enter PEDRO)

\section{PEDRO}

Dearest sister, you're awake and bright as day, which I take it means everything went well! Where do you have Leonor?

\section{ANA}

In my room, asleep. I told her to go to bed - I thought you would be home much earlier. What kept you out so late?

\section{PEDRO}

The plan was messier than we expected. One of her relatives recognized her as they were leaving and Carlos stabbed him and left him nearly dead, which shook me up quite a bit. The plan wasn't ever for people to actually get hurt. So I felt guilty and had my servants take him to his home while the others were carrying out the plan. I didn't want to leave until everything had calmed down.

ANA

I guess that was for the best.

\section{PEDRO}

We got her away from all those other men, that's the important thing. The real romancing can wait until morning. Get some rest, Ana. And thank you for your help.

ANA

What makes you happy makes me happy, Brother.

PEDRO

of course. What a lady you are, Ana.

$$
\text { (Aside) }
$$

ANA

Little does he know...

Let's get some rest. (Aside) 
PEDRO (cont.)

If rest can come for those in love.

ANA

I'm going to unwind a little first. (Aside)

If it's possible for a lover to unwind.

Ah, Love.

$\mathrm{PEDRO} \& \mathrm{ANA}$

(Aside)

(Blackout) 


\section{Act II \\ (Enter CARLOS and CASTAÑO)}

Castaño, I am beside myself.

CARLOS

CASTAÑO

Me too, I guess, since I'm always beside both of you.

CARLOS

What happened last night? Surely all that was a dream.

CASTAÑO

I dunno. I had some crazy dreams too, and then I woke up on this pile of dresses.

CARLOS

Didn't doña Leonor give you her finest clothes to carry last night?

\section{CASTAÑO}

Yes, sir. And I might have wrapped them up to make myself a little sleeping nest...

\section{CARLOS}

Where are they?

$$
\text { CASTAÑO }
$$

There. See that bed? - I carried them first, so the least they could do is carry me off to sleep, amIright?

$$
\text { DON CARLOS }
$$

$$
\text { (Aside) }
$$

This makes no sense!

( to CASTAÑO)

I swear I saw Leonor in this house.

\section{CASTAÑO}

Well, sir, they say that whoever has lost his cattle hears cowbells everywhere, so after that fiasco in the street, maybe you're just imagining Leonores left and right.

What did happen in the street, by the way? It was scary, so I closed my eyes. 


\section{CARLOS}

Nothing happened, you coward. I ran out because I heard a woman's scream. Doña Ana asked me to stay hidden, but my chivalry overcame my good judgement, I'm afraid. A maid also came out with a light, and I thought I saw my sweet Leonor.... maybe it was her presence that drew me out, Castaño! I just knew that she was there!

\section{CASTAÑO}

Leonor? You nutcase - I knew you were going crazy, but good grief. Don't let our hostess hear you talking like that or we'll be back out on our butts in no time.

\section{CARLOS}

You rascal, if we weren't stuck here trying to be sneaky, I would...

$$
\text { (CARLOS raises his hand as if to strike CASTAÑO) }
$$

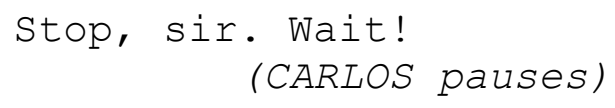

CASTAÑO

Where?

\section{CARLOS}

\section{CASTAÑO}

In your pocket, in that beautiful painting that you have, and it looked to me like she was alive, because I looked at her and I swear she blushed. I know it sounds crazy, but that's what I saw!

What an idiot!

\section{CARLOS}

\section{CASTAÑO}

Granted, I've seen some women who're both alive and painted.

\section{CARLOS}

Leonor is as beautiful as the sun - all other beauty revolves around her. Why would she want to cover it up with makeup? 


\section{CASTAÑO}

Well, if she is the Sun, she must've lost her shine, because I can see it out that window.

Anyway, what would you even do if you saw her in the first place?

\section{CARLOS}

I will wait until I see what brought her here; fate has been on our side so far, I'm sure it will bring her to me, and fate has brought me here, so who am I to leave?

It is better to wait for the chance to whisk her away again.

\section{CASTAÑO}

Gotcha. We're waiting for fate. approach) (Sounds from offstage alert us to CELIA's

Shh - someone's coming. I think it's a maid.

What could she want?

$$
\text { CARLOS }
$$

(Enter CELIA)

\section{CELIA}

Quickly, sir - get to the garden to meet my lady, my Master is coming, and he doesn't know you're here!

\section{(Aside)}

Well, he's coming eventually. And Leonor is sure to be within sight of this room before we know it.

Of course, right away!.

DON CARLOS

(He exits. CELIA and CASTAÑO stare at one another for an awkward beat)

CELIA

Well, this was fun. See ya!

CASTAÑO

Wait! Miss? Could you stay and listen to me first?

\section{Listen to what?}

CELIA

My confession. 


\section{CELIA}

(Sarcastic)

Confession? That's not suspicious at all...

CASTAÑO

Well - isn't confession telling someone my sins?

CELIA

Aha! There it is. I'm not going to "sin" with you, thanks. I'm just here for the plot twists.

\section{CASTAÑO}

While we're all locked up together, and the blue-bloods are all chasing after one another. Don't you want in on the fun?

I already told you. No.

\section{CELIA}

\section{CASTAÑO}

Come on, what more could you want? We're trapped together in this gorgeous house, you're just a maid, and I'm this dapper, handsome, clever...

CELIA

Oh, I'm "just a maid," am I? You worthless lump!?!

$$
\text { CASTAÑO }
$$

And a loud one, at that.

Ha! Goodbye!

CELIA

(She turns to exit)

But if you decide this is more than just a game, I might be convinced to come back.

\section{(She exits)}

CASTAÑO

It is a game. And now it's my turn.

(He exits)

(Enter LEONOR and ANA)

Did you sleep well, Leonor?

ANA 


\section{LEONOR}

Ugh. Don't even ask.

ANA

Why?

(Aside)

This, my friends, is the worst part of polite company - the "polite" part. It's ridiculous, you'll see.

LEONOR

Because if you ask, I would have to tell you if the night was good or bad. I can't say it was bad, because that would be rude to you as my hostess, but if I say it was good, I would be lying to you, and that's not good manners either!

ANA

Leonor, you are both wise and beautiful. It shouldn't be allowed.

LEONOR

Oh no - you're so much more beautiful than me, you're just being polite again. And it comes so naturally to you!

ANA

You're too sweet. But you don't have to lie to me. How are you, really?

\section{LEONOR}

I am like a shipwrecked man in a storm with waves crashing all around, with my keel in the abyss and my stern to the sky.

(Aside:)

I need to ask her why Carlos was here last night, but... I'm afraid of the answer.

ANA

Oh really? And why are you a boat all of the sudden?

Well, you see, I--

\section{LEONOR}

I mean, I do want to know, and I've told you about my love, so of course you know I have to be curious--

It's just I-- I care for Carlos and that I am his

betrothed, so...

(Blurting it out)

Why was he here last night? 
What was that?

ANA
(Opens her mouth to answer, hears something, then
holds up a finger)

\title{
LEONOR
}

What?

ANA

My answer will have to wait, my brother is coming!

Oh! I'll go hide.

\author{
LEONOR
}

ANA

No, no. Stay here. I told him about you, and I have a feeling he might find a solution for you. You know, men are just so good at solving problems!

(She winks at the audience)

\section{LEONOR}

I suppose...

\section{(Enter PEDRO)}

Good heavens! Is this your brother?

$$
\text { PEDRO }
$$

I am, beautiful Leonor; why are you surprised?

\section{LEONOR}

Oh no! Oh, my lucky stars, how could you bring me to don Pedro's house, of all the places?

\section{PEDRO}

Beautiful Leonor, you are safe in my house; even if it costs me a thousand lives, I will free your honor from the things that threaten it.

\footnotetext{
LEONOR

That's very kind of you, don Pedro, but--

PEDRO

Now that the waves of misfortune have washed you up on my shore, you will see that I have always been yours. If anything, your repeated rejections have only made my love
} 
PEDRO (cont.)

stronger! And now my household welcomes you as its true mistress!

Celia!

ANA

(Enter Celia)

CELIA

What can I do for you, madam?

Come here!

ANA

(Aside, to CELIA)

I need you to set Carlos up at that window grate so he can see Leonor talking to my brother.

\section{CELIA}

Yes, Madam. I'll do just what you said.

(She exits)

PEDRO

So, Leonor, why don't you love me?

LEONOR

$\mathrm{Umm}$. .

PEDRO

Was there something wrong with my courtship?

LEONOR

No, it's not that, it's just--

(Interrupting)

PEDRO

Have you treated your other suitors this way? Honestly, it seems to me like I'm doing just the same things as that don Carlos fellow, but when he does it you seem impressed, and I just don't get the same feeling from you when I do the same exact thing. Is it because he's poor? What if I were poorer? Even if we don't get married and have ten children and a strapping heir to my fortune. Of course I want that, but for now, I would settle for just an acknowledgement of my love. Please? 
Oh. Um...

\section{LEONOR}

Your love is certainly a great honor, don Pedro, but please, give me a moment. I'm already in a shameful position, alone with you here in your house and betrothed to another man, and I just can't... um... Is this some sort of revenge for my rejection? Is that it? I think I will be punished enough, you don't need to rub it in any further.

I'm sorry. That was rude, but please, sir. Don't make this worse for me.

\section{(They sit awkwardly together as DON CARLOS, CELIA, and CASTAÑO appear, hidden.)}

CELIA

Stay right here. My master was sure to check that other room eventually, but you'll be snug as bugs in here.

CASTAÑO

Wait, beautiful Celia--

CELIA

Can't! Sorry! Gotta go!

(She exits and re-enters on the other side of the stage. The action continues during her cross)

CASTAÑO

(Castaño tries the door)

It's locked! She locked us in like sinners in a confessional, the crazy old bat!

(He goes to the window and sees PEDRO and LEONOR.)

Dear God! Your insanity must be contagious, sir. I think I'm infected!

CARLOS

(off)

How so?

CASTAÑO

Remember how you heard cowbells from our lost cow last night? I'm hearing 'em now too, and I can even see her horns! 


\section{CARLOS}

What? Oh, my love! It's Leonor, Ana, and Pedro! See, it wasn't just my imagination!

\section{CASTAÑO}

Oooh look - she's awfully close to that other guy, don't you think?

\section{CARLOS}

Let's not worry yet, Castaño. After all, I'm here, and I'm not flirting with don Pedro. Maybe the same stars that brought the two of us here brought her as well.

Huh. How philosophical.

CASTAÑO

But! I think you're giving don Pedro too much credit. If he gets the chance, he's gonna grab our little heifer by the hock.

\section{CARLOS}

Castaño! Don't compare my lady to a-- If she's a cow, then what does that make me? Now shh! Something's happening.

\section{PEDRO}

My dear Leonor, please don't scorn me. Unrequited love is a fate worse than death.

\section{LEONOR}

That's not true.

It is.

$$
\text { PEDRO }
$$

ANA

No, the problem with love is jealousy; it robs a person of logic, causes nothing but problems and it's essentially envy, which is one of the deadly sins!

It does not.

\section{LEONOR}

ANA

Yes, that's how love is. 


\section{LEONOR}

No, the worst part of love is being separated from your beloved. They are there, but just out of reach, and I cannot think of anything more evil than that.

\section{ANA}

It is not so.

Yes, that's how love is. LEONOR

\section{CARLOS}

Oh, Castaño! Jealousy may lead to a deadly sin, but I think that love is even worse! I feel like Love wants more than death from me, it wants my soul. That is more evil than one can bear.

CASTAÑO

It's not so.

CARLOS

Yes, that's how love is.

CASTAÑO

No sir, the worst part of love is seeing a gorgeous maid but not having a dime to your name. I've got the charm alright, but what good is that if I can't pay for a decent date? So poor Castaño always gets kicked to the curb.

You're such a whiner.

\section{CARLOS}

CASTAÑo
(Dramatically, not listening to him)
Yes, that's how love is.

CELIA

(Joining ANA's conversation)

I'd say the most annoying thing about love is when you've got twelve guys hanging on you, but they're all just poor slobs. All the effort and none of the reward. It's enough to make a girl give it all up!

It's not so.

ANA 


\section{CELIA}

Yes, that's how love is.

ANA

Come, Leonor. Let's go to the garden. Maybe the flowers will lift your spirits.

LEONOR

All I can think of to do is cry, but that never helps!

PEDRO

Yes, that is an excellent idea. Come along, my divine impossibility.

(Aside to Celia) ANA

Celia, activate the plan - I'll get you a brand new dress if we can make this scheme work.

(Exit PEDRO, ANA, and LEONOR)

CELIA

(Aside)

Well, that's what I call ordering someone around "with style." Not holding my breath though; I know how masters are. One minute it's "I command you to do this" and the next is "I never said that!" But it's worth a try. Oh! And this...

(She creeps to the door JUAN is hiding behind, opens it, and shoos him out. JUAN rushes to the front door, mouths "thank you" to CELIA, and exits.)

I've fooled my lady into thinking someone else let him in, and now she's put me in charge of this whole scheme because Celia, she's just that good!

(to CARLOS)

Don Carlos?

CARLOS

What do you want, Celia? Oh my!

CELIA

I've come to see how you're getting along. 


\section{CARLOS}

Just fine, thank you. But tell me, Celia, why was that lady talking with doña Ana and don Pedro?

\section{CELIA}

\section{(Aside)}

He took the bait! Now I just have to reel him in. (to CARLOS)

That lady, sir... but no, I can't tell unless you promise me that you'll keep quiet.

\section{CARLOS}

You have my word! Why did she come?

CELIA

It's a sin to gossip, but if I don't technically tell you, well... let's just say that hypothetically there was a beautiful... cat?

Or a cow!

$$
\text { CASTAÑO }
$$

\section{CELIA}

Alright, a cow, sure, that my master adores. Last night, perhaps he went out to the cow's pasture and fell in love with the cow and gave it gifts.

\section{CASTAÑO}

Like grass.

Be quiet, Castaño!

$$
\text { CARLOS }
$$

CELIA

Well, I didn't get any further than that anyway.

Than grass?

$$
\text { CASTAÑO }
$$

$$
\text { CELIA }
$$

Metaphorically, yes.

$$
\text { CASTAÑO }
$$

What other gifts would you give a cow?

She isn't really a cow, Castaño! 
CELIA

Anyway, you didn't hear anything from me. Maybe ask someone else. But you should know that my master is a violent man with a bad temper. I wouldn't cross him if I were you.

$$
\text { (CELIA exits) }
$$

CARLOS

Oh, Castaño! I'm dead for sure!

Because of the cow?

$$
\text { CASTAÑO }
$$

\section{CARLOS}

Who am I? Where am I? Isn't Leonor my fiance? I took such care and asked her so elegantly and I finally beat out all of her other suitors, didn't I? Surely there's some explanation - some way Leonor could have found herself in this house through no intention of her own. And Don Pedro would have taken the opportunity to save her - like fate gave her to him! But Leonor might not return his affection in such a rude circumstance! Yes, that's probably how it is.. But what if she loved him and sought him out? Not this, dear God in Heaven!

No. It can't be. Come, Castaño, we are going to take Leonor back!

\section{CASTAÑO}

With all due respect, Sir, are you possessed? There's an army of servants in this house, and they could do whatever they want with us without thinking twice! And they're all so fancy...

CARLOS

Coward! Even if I had to fight through lightning bolts coming down from the sky, or if I had to swim through the abyss, I would do it to have my Leonor.

CASTAÑO

Ok, let's go. Straight to Hell, it sounds like, if that second part happens.

(They exit. Enter RODRIGO and JUAN) 
RODRIGO

Make him see reason, don Juan. You are his friend, are you not? You saw the damage he caused when he took Leonor - I want you to be the one to represent me in this case, please. You always speak so eloquently. Besides, it always helps to have a third party as a judge.

\section{JUAN}

I promise to share your story, don Rodrigo, but it won't be my words that will win this case - your merit is what will shine through. Let's go.

(They cross into the parlor. On the other side of the stage, CARLOS and CASTAÑO try to sneak across the courtyard after CELIA)

\section{(Aside:)}

What's this? Why is Don Carlos de Olmedo here? I told him off just last night! Ana must have told him! That beautiful basilisk!

CELIA

(Surprised by JUAN and RODRIGO)

Jesus Christ! You scared me! Sir, this is don Juan de Vargas, and ... another old man.

They didn't knock.

\section{CARLOS}

It doesn't matter. I'm not afraid of them.

\section{RODRIGO}

This is Don Carlos, - he could ruin all of our plans!

$$
\text { CASTAÑO }
$$

Sir, you'd better start praying, because these men definitely know that you were the one who took--

\section{CARLOS}

It doesn't matter. I will do what I came to do, come what may.

JUAN

(Drawing his sword)

Then we are well met. Here I am. 


\section{RODRIGO}

Before you do that, sirs, don Juan and I have a certain deal to make with don Pedro. So, young man, please humor an old gentleman and use your young legs to get out of here.

(He doesn't)

Aside)

CARLOS

Good God! Even don Rodrigo is against me!

JUAN

(Aside)

Don Rodrigo is driving me insane! Heaven help me.

CELIA

(Aside to Carlos)

Don Carlos, my lady will get into trouble if her brother sees you. Maybe we should go.

\section{(Aside)}

CARLOS

You're right, God bless it! It would be such bad manners to risk her life when she's been such a good hostess, but what can I do?

Doña Ana's honor is the most important issue here, so yes we will go and hide, but later I will take my revenge!

(Aside to Carlos)

Good! Now hide, for God's sake, before Pedro comes out!

CARLOS

Don Rodrigo, sir, excuse me, this is embarrassing, but I am here in don Pedro's house without his knowledge, so please pardon me while I hide before he comes back.

(RODRIGO seems unconvinced)

A lady's honor is on the line, sir.

\section{(Aside)}

JUAN

That proves it! He obviously means that Ana brought him here. I have the keys to the garden - later I will come back and take my vengeance. 


\section{RODRIGO}

Of course, Don Carlos. Hide yourself if you must. I'm just here to investigate all the shenanigans these young people have dragged me into.

\section{CARLOS}

Thank you sir. Goodbye for now.

May Heaven keep you.

RODRIGO

$$
\text { CELIA }
$$

Let's go! Hurry up!

$$
\text { (Aside) }
$$

Thank God. That was close. (to JUAN)

You, sir, wait while I talk to my master.

(Aside)
My soul is erupting!

(Aside)

JUAN

A volcano is in my chest.

(CARLOS, CELIA, and CASTAÑO go hide. Soon we see CASTAÑO and CARLOS's heads pop up at the window again.)

RODRIGO

It's the never-ending cycle of righteousness: don Pedro has wronged me, don Carlos has wronged him, and down the line there will be a man who wrongs don Carlos. Heaven punishes our sins by sending other people to sin against us in turn.

\section{(Aside)}

$$
\text { JUAN }
$$

There he goes - the cause of all my problems. The last thing I want to deal with right now is Rodrigo's many issues. 


\section{PEDRO}

(Not actually surprised at all)

Don Rodrigo, sir, to what do I owe this surprise? It's such an honor to have you visit my humble home.

\section{RODRIGO}

Thank you, don Pedro. I came by to pick up my lost honor.

\section{PEDRO}

Oh. And you brought don Juan! You and I enjoy one another's company often, don't we, friend. Have a seat, both of you.

\section{(An awkward pause, then RODRIGO looks pointedly at JUAN)}

\section{JUAN}

I can get us started, then. Don Pedro, it was brought to my attention, that you have a disagreement with don Rodrigo.

\section{PEDRO}

With me, don Juan? I had no idea, what is the problem? (Aside)

Good God! What is this?

\section{RODRIGO}

Don Pedro, this is not the time for games. I appreciate the courtesy and the respect, but we can skip the pretense. You could have been my favorite among Leonor's suitors, but now you've stolen her from my household, and that cannot be undone. However, I suppose I must at least give you credit for your bravery. I know that she is in your house and, knowing that, I must demand that you give her your hand in marriage at once.

\section{(Aside)}

\section{PEDRO}

Good God! How do I respond to that? I'm not actually Leonor's kidnapper, but if I confess that I took her from don Carlos, he'll give her to him. If I lose Leonor, I lose my life. But if I agree to marriage on false pretenses, it would be tarnished from the beginning. Maybe I can just put it all off...

\section{JUAN}

Friend, why do you keep us in suspense? Don Rodrigo is offering you the beautiful Leonor's hand - what's the problem? 


\section{PEDRO}

Don Rodrigo, nothing would make me happier than being Leonor's husband, but you should know that my sister was sick last night, and Leonor only came to my house to see her. She was here until late, and she was afraid that you had already come home, so she sent a man to check. He said that you looked for her and you were angry, so she was frightened and didn't want to return. So, you see, I never took Leonor from you and I never could. I intend to make her my wife, and a base kidnapping like that would taint her honor and beauty. But I promise you, I will be her husband as soon as Leonor wants to marry me too.

\section{CARLOS}

Do you hear that, Castaño? I'm either dead or insane!

\section{CASTAÑO}

Your sanity's long gone, but dead would be new.

\section{RODRIGO}

Hmm... Don Pedro, the gossips in town have already had a field day with this whole situation; my honor will never be satisfied until the two of you are married. If Leonor's wishes are what's in the way, call her and I will sort this out in no time.

PEDRO

I don't want to do anything to upset her, sir. Please let my sister suggest this solution first. Of course, I am also eager to get married, but what does it matter if we wait until tomorrow? Then there would be time for me to invite my friends and relatives to my wedding!

\section{RODRIGO}

Fine, if you must, but Leonor will be your wife.

I am a lucky man.

PEDRO

RODRIGO

Well, that's settled. Goodbye, son. I have my own preparations to make.

JUAN

May God keep you, don Pedro. 
PEDRO

Go with God, both of you.

(Exit RODRIGO and JUAN.)

(Aside)

Phew! I'm still so confused, I don't know if I'm happy or sad - if what's happening is great good luck or a terrible mistake. Don Rodrigo begs me to be with Leonor, and I have Leonor here with me. There's going to be a wedding now, no getting out of it: I'm only afraid of what Leonor will do if she isn't given a choice. I suppose she'll have to be mine! Love, please soften her heart!

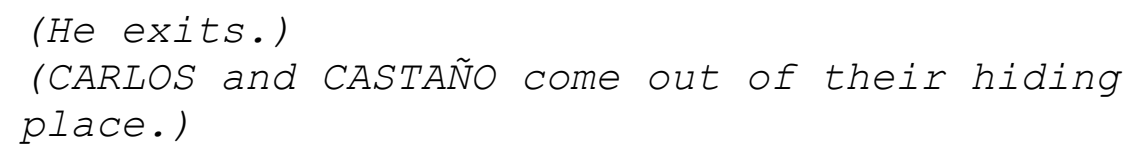

\section{CARLOS}

I shouldn't be standing here like this, Castaño - I'm dead. Don Rodrigo - oh God - don Rodrigo won't even listen to Leonor's side of the story! How could he know that Pedro is lying through his teeth - she didn't choose to run away with Pedro, she chose me!

\section{CASTAÑO}

Yeah, but... look at this place. If you made this much dough, I'd have way more bread. Don Rodrigo's into big game hunting and you, sir, are not big game.

\section{CARLOS}

What do I do, Castaño? This whole situation is out of control!

\section{CASTAÑO}

Hmm... Ok, I've got it. You seduce doña Ana, then you'll have all her money and plenty of revenge - that Pedro will be brother-in-lawed forever!

\section{CARLOS}

(Sarcastically)

Right. What a punishment.

\section{CASTAÑO}

Man, I don't think you know what you're talking about. Brothers-in-law, mothers-in-law, stepmothers, lawyers, 


\section{CASTAÑO (cont.)}

dentists, executioners, and gift horses: Hell has a kinder population.

\section{CARLOS}

But if I lose Leonor, I lose life itself!

\section{CASTAÑO}

You haven't lost a hair on your head that we didn't go looking for. Besides, the lady is the real judge, and I know which way that decision will go.

\section{CARLOS}

And if her father forces her?

\section{CASTAÑO}

Forces her? How's he going to do that? Let's find her and ask - if she says no, she won't be pairing up with Pedro.

\section{CARLOS}

Let's go and stop our complaining. I think we're ready for Act III. 


\section{Act III}

(Enter CELIA and LEONOR)

\section{LEONOR}

Celia, I will kill you if you won't let me leave this house.

CELIA

Take a breath please, Miss. I thought you liked us.

\section{LEONOR}

How am I supposed to like you, Celia? Now my father wants me to be (Oh, God) Pedro's wife. And on top of that, you yourself told me that Carlos (the bastard) Was wooing Ana, and planned to marry her. He is my fiance! His honor trumps everyone else's, but with everything going on, no one has actually thought about me.

\section{CELIA}

\section{(Aside)}

What she says is true. I've been throwing don Carlos off the scent and making Leonor believe he hates her. I was just trying to get a new dress, but these stories are getting ridiculous.

But madam, don't you remember how rude Carlos was? My master idolizes you, and your father approves of him. Besides, if you don't marry him, you'll lose your honor and your home. Why don't you just decide to be happy and go through with this wedding? Then all the little things will fall into place and you can obey your father, make your family happy, reward a man who idolizes you, and get revenge on don Carlos.

\section{LEONOR}

What are you saying, Celia? The stars would all fall out of the sky before I would belong to Pedro! The waves in the sea would stop before they reached the sand. The fiery hearts of the planets would sooner break their orbits. Flakes of fire would sooner freeze into snow, flames would sooner sprout from ice before I would leave Carlos behind, even though he is an ungrateful pig. But I would be my own executioner before I would stop loving him... 
Fine. Do what you will.

CELIA

LEONOR

What I will do?

Friend, please give me a way to escape from here, then I can leave here and curl up in a tiny convent where I can hide, and cry about my tragedy. Then maybe my falling stars will forget about me.

CELIA

Yes, but if you knew about my unluckiness in general ... if I let you go, all that bad luck would fall here with me and my master. When he finds out, I'll be the fallen one, since I would have let his star fly free.

\section{LEONOR}

Friend, do this for me and I will be your eternal slave, for just this one little thing.

CELIA

Nah, I'd have to pay too much for it. After my master, there's my lady's punishment.

LEONOR

You're nothing but my jailer, my enemy! I wish I could kill myself and kill you too!

\section{CELIA}

(Aside)

What do I do? My lady wants me to let Leonor go, but my Master insists that I don't.

I know! If I let her go but tell my master first, maybe I can get the best of both worlds!

Madam, if you're going to do this, I can't stop you. Go put on your cloak and I'll watch the door.

\section{LEONOR}

Oh Celia, you've given me life!.

\section{CELIA}

What can I say, I'm just a softie. I can't stand to see people cry, I just melt like butter. 


\section{LEONOR}

I'll get my cloak.

CELIA

Go on, now. Quickly. I'll be right here.

(EXit LEONOR)

Now we lock the door and go tell Romeo that his Juliet is trying to leave him.

$$
\begin{aligned}
& \text { (She exits) } \\
& \text { (Enter JUAN) }
\end{aligned}
$$

$$
\begin{gathered}
\text { JUAN } \\
\text { (Unlocking a door into the garden) }
\end{gathered}
$$

This jealousy is like a plague! But how could I dare do anything, when my offense goes against my honor? I need true vengeance, since I've truly been wronged, this isn't just talk. If it were only enough to offend me with suggestions - would I still have honor if the situation that caused my dishonor was unsure? When the very evidence of the dishonor comes from nobility, there is no doubt. But honor only offends the suspicious, so there will certainly be dishonor to the one who misunderstands the truth.

Her lover must come at night, so I'll hide here and wait for him. Honor, bring me my vengeance!

(He hides)

(Enter CARLOS and CASTAÑO with a package.)

\section{CARLOS}

We've wandered all over this house, but there's still no sign of her. Castaño, I'm getting desperate.

$$
\text { (Trying the door) }
$$

Bad news, Master - I think they locked us in.

\section{CARLOS}

What? Oh no no no no. Don Rodrigo has to know that I am the one who took his daughter and who promised myself to her. Then he'll forget about Pedro and give her to me. 


\section{CASTAÑO}

That idea would work, but how are you going to leave if doña Ana is keeping guard?

\section{CARLOS}

Easy, Castaño. I can't leave anyway because Leonor is here. But YOU can leave; no one cares if you're here or not. Take this note to don Rodrigo - it tells the whole story.

\section{CASTAÑO}

I have to go? The police are out there in the street looking for me - you're the one with the sword, but I was the distraction - they'll still take me in!

\section{CARLOS}

I need you to do this, Castaño.

\section{CASTAÑO}

Well, it isn't really convenient for me.

\section{CARLOS}

Good God, Castaño, get out of here! You have to go!

$$
\text { CASTAÑO }
$$

How can you swear to a God who lives, when I'm sure to die?!?!

\section{CARLOS}

(Grabbing him)

Are you kidding me, Castaño?

Nope! I'm dead serious.

CASTAÑO

\section{CARLOS}

Get out of here you idiot, or I'm going to kill you right here!

\section{CASTAÑO}

Let go of me, sir! Give me the paper, I'm going.

\section{CARLOS}

Take it, and make sure you come back quickly.

$$
\text { (CASTAÑO takes the paper as CELIA enters) }
$$


CELIA

Don Carlos, sir, my lady wants to see you in the garden right away. She has an important issue to talk over with you.

CARLOS

Of course. Tell her I'm on my way. (To Castaño)

Do it.

(EXit CARLOS and CELIA.)

CASTAÑO

Don Rodrigo won't recognize me, what does it look like if I just show up with this note? I need inspiration or some sort of sign. Maybe Calderon could write me one? Maybe? Huh?

Not this time. But wait a minute! I carried Leonor's bags for her when those imbeciles were trying to run away. If I put her clothes on, I would look like any other covered lady in Toledo. Great! I'm going to get them from over there.

(he takes off his cape, sword, and hat)

First, I need to get my hair under this handkerchief. Ow! Oof! Ee! No pain, no gain, Castaño. Come on. Now, bring on the skirts.

(He runs offstage and grabs them)

Jesus, what fine fabric! I'm gonna look good!

(He returns to the stage halfway into a full-body

gown, flailing with much awkward difficulty)

There we go, all wrapped up.

(And yet, he still tries to make himself

prettier, making a big mess.)

An umbrella would top it all off nicely. And this purse! Ooh, will this blouse fit? And where's the powder? I have to powder my nose.

(He tries it)

Pffft! No! Why do women to this to themselves? Ah, that color doesn't suit me anyway.

What do you think, ladies of this whale's cage? I don't think it could be put on better, even if I had help. Me, I think I'm gorgeous! Everything looks great on me. But it's not perfect just yet... Oh, the gloves.Yes. Don't want to go out with these hairy monsters. And the cloak is really what tops it all off. Throw it over my head. Ooh! Honey! 


\section{CASTAÑO (cont.)}

Now, real talk for a minute: is this actually fooling anyone in this audience here? No. Not at all, right? Keep that in mind - we know this is fake. This isn't some sort of political statement, it's just how these farces go, $y^{\prime}$ know? I'm having fun and all, but don't blame me for the way these people write plays. We're being totally aboveboard here, $y^{\prime}$ hear that, Your Excellency?

Now that's out of the way, here goes nothin.

$$
\text { (He goes to exit, but runs into PEDRO) }
$$

\section{PEDRO}

Beautiful Leonor, why are you all covered up at this hour?

(Aside)

Celia was right - she's going to the convent right now! (TO CASTAÑO)

Where are you going in such a hurry?

\section{CASTAÑO}

(Aside)

Good God! He's taken me for Leonor. Looks like the disguise works, folks.

PEDRO

Where are you going, my lovely Leonor? Why the suspense?

(Aside)

\section{CASTAÑO}

Listen to this Leonor-lover! But will it ruin everything when he hears my voice?

\section{PEDRO}

Why don't you talk to me, madam? I love you, doesn't that mean anything? Why are you trying to escape? Aren't you swayed even a little bit by my honor and my nobility? This whole beautiful house could be yours! You only need to say the word and I would give you anything you asked for. Please, Lady, I throw myself at your feet! Please love me!

\section{CASTAÑO}

(Aside)

He's a little dramatic, but I like it! It's kind of nice to have someone crazy for you!

(TO PEDRO) 


\section{CASTAÑO (cont.)}

Don Pedro, I don't care about your reasons, I'm going! I'm dying of starvation here because everyone's all caught up in their own drama, so I have to head to the bakery myself to get something in my stomach.

\section{(Aside)}

\section{PEDRO}

What is she talking about? Leonor has picked up some strange habits... But they're attractive habits still, right?

(TO CASTANO)

Madam, if you wanted to tarnish my reputation, you could do so in another way, not by insulting my hospitality with words that make you sound uneducated as well.

\section{CASTAÑO}

I'm saying that you're starving me to death! Is that unclear?

PEDRO

It is clear enough, madam, but I still don't understand.

\section{CASTAÑO}

Well, if you don't understand that way, understand me this way

$$
\text { (He tries to exit.) }
$$

\footnotetext{
PEDRO

Wait, you don't have to leave! Your father wants you to be here, and every moment I keep you is a blessing for me. I know that you are resistant to marriage, but I am not. I am already yours.
}

\section{CASTAÑO}

Don Pedro, you are an idiot. And that's enough of a reason to stop a woman of my stature from staying here and starving to death.

\section{(Aside)}

\section{PEDRO}

Is this what she really thinks of me? No, she must be pretending to convince me not to marry her. Not to worry, my blind passion cannot be discouraged!

(TO CASTAÑO) 
PEDRO (cont.)

Dear Leonor, I know that you are a refined lady, why pretend otherwise? However, I am sure you have your reasons for pretending to be idiotic.

CASTAÑO

Oh don Pedro, I see your refinement can last despite my rudeness; just open this door for me, and I will be your wife tonight.

PEDRO

What are you saying, my lady?

\section{CASTAÑO}

That I will be yours like two and two is four.

PEDRO

Do not say that lightly - the pain of losing you again would kill me!

\section{CASTAÑO}

Oh no sir. You won't die, God willing, until I've given you a little boy to pass all of this on to.

\section{PEDRO}

"All of this" as you say, my Lady, is yours!

\section{CASTAÑO}

Believe me, I know! It will be good to have it all locked down.

PEDRO

And lock it we will, my dear. But you promise that you're not teasing me? You really do want to be my wife?

\section{CASTAÑO}

What am I, an actress? I gave you my word that we would be married. If that isn't what you want now, just tell me.

$$
\text { PEDRO }
$$

If it's not what I want?

$$
\text { CASTAÑO }
$$

Let's make a bet, shall we? When the time comes, I bet you'll be the one to back out. 


\section{PEDRO}

I would never! Don't insult me like that!

CASTAÑO

Well then, at least give me your word that, if you want out of this marriage, you won't hurt or harm me in any way.

\section{PEDRO}

Of course. But let me earn your vow - please, wife, give me your lovely hand.

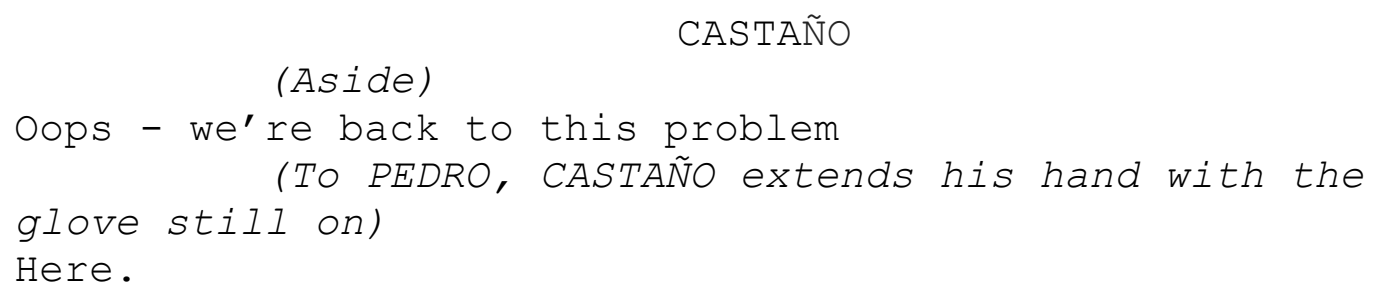

PEDRO

You give it to me with the glove?

CASTAÑO

Yes, because my hand is ... sick.

PEDRO

What illness do you have on your hands?

CASTAÑO

I puked on them one day, and no ice treatments or special soaps could make them smooth again.

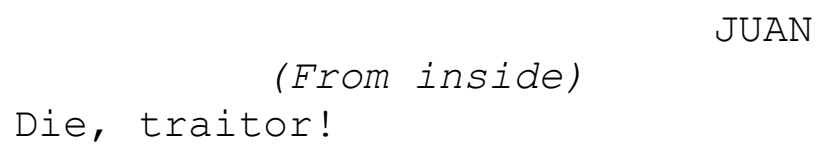

PEDRO

What was that?

\section{CARLOS}

(From inside)

You will die at my hands!

PEDRO

Good God, that's coming from inside my house!

(Enter CARLOS and JUAN, dueling with swords. ANA follows.) 
Gentlemen, stop!

That's my brother! I'm dead!

CASTAÑO

One minute they call you beautiful, the next they're chasing you with a sword. It's so hard to be a woman these days!

PEDRO

What is this? Two men at each other's throats in my house and at this hour, you shame me, sirs!

$$
\text { (Aside) }
$$

I will avenge this insult by dealing death to them myself, especially since one is carlos.

$$
\text { (Aside) }
$$

ANA

Why is Pedro here?

\section{(Aside)}

\section{CARLOS}

I must protect doña Ana!

\section{CASTAÑO}

This is going to be messy. All I have to do is get to the door... And look! I've got the only candle! shouts.)

(CASTAÑO blows out the candle and everyone

PEDRO

Even in the dark, I know how to kill you all!

(He draws his sword and charges across the stage. Each of the men tries to duel one another, but they can't see, so they end up swinging their swords against walls, furniture, etc.)

(Aside)

\section{CARLOS}

Doña Ana put her faith in me, but in trying to protect me, she put her own life at risk. 
(LEONOR enters, covered like a nun.)

(Aside) LEONOR

Oh no! I left Celia here! Oh God, forgive me for putting her in danger!

But it doesn't matter now. I just need to get to that door.

(She bumps into Carlos)

\section{(Aside)}

CARLOS

This must be Ana.

Madam, come quickly, and I'll get you out of this mess.

$$
\text { (Aside) }
$$

\section{LEONOR}

Who does this man think he is?

But, on the other hand, this might be my only chance to get out of here. Maybe when he sees that I'm not who he thinks I am he'll let me go on my way.

\section{(Aside)}

ANA

And this is all about Leonor, isn't it? Pff. Men. I knew they were idiots, and now I've put Carlos in danger!

You soiled my honor! Die!

$$
\text { PEDRO }
$$

$$
\text { CASTAÑO }
$$

(Aside, stumbling into a cabinet full of

$$
\text { glassware) }
$$

Where-- is-- that-- door--? Wait ... here, I think I've found it!

(He opens the door clumsily and all of the glasses fall out, shattering)

Oops!

$$
\text { ( LoudIy) }
$$

These things were all so jealous of my beauty that they threw themselves out of this cabinet... all on their own!

ANA

(Aside)

What's that noise at the door? 
ANA (cont.)

It's probably Juan leaving while my brother won't see him. And wait-- I only hear two swords. Where is Carlos?

(ANA crosses to JUAN)

\section{CARLOS}

This is the door, madam. Let's get out of here.

$$
\text { (Exit CARLOS and LEONOR) }
$$

I will kill you all! GRAHHH!

$$
\text { PEDRO }
$$

\section{ANA}

\section{(Aside)}

That is my brother, this one must be Carlos. (to JUAN)

Go quickly, sir. I will hide you!

\section{(Aside)}

JUAN

Oh! My sweet Ana is trying to hide me from her brother. (to $A N A$ )

Of course. I would follow you anywhere.

$$
\text { (Doña ANA exits with JUAN.) }
$$

\section{PEDRO}

Where are you hiding, traitors? My sword can't find you! Hello? Someone bring a light!

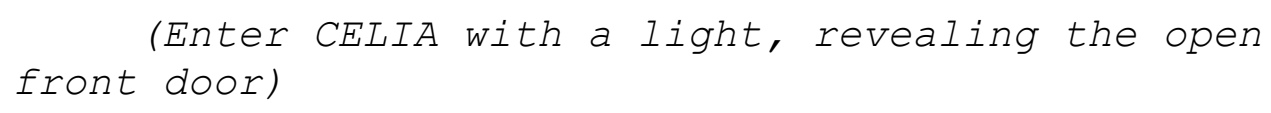

CELIA

What's going on out here?

What do you think?

\section{PEDRO}

\section{(Aside)}

What's this? My door is open and my rival is gone, but if Leonor is in my house, what does it matter? I wonder how they all got in. (to CASTAÑO)

Leonor, please go sit in your room. I will go get your father. I want our wedding ceremony to be tonight. 
(Aside)

\section{CASTAÑO}

I just want to fix my face. I must look like a total mess!

(CASTAÑO exits. PEDRO closes and locks the door behind him.)

\section{PEDRO}

As much as I love Leonor, she still might be the mastermind behind this whole thing. If she tries to escape now, she'll see that the joke is on her. In the meantime, I'm going to figure out what's going on in this blasted house!

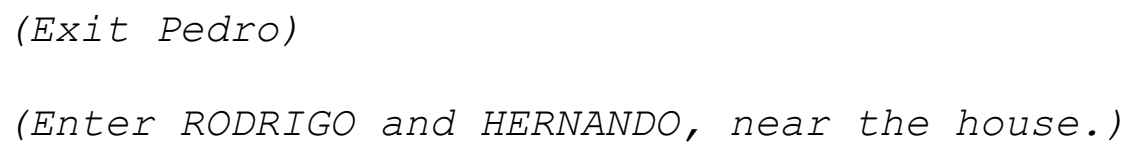

RODRIGO

That confirms my suspicions, Hernando! Now that don Diego has recovered from that brawl in the street, he has confirmed everything that I thought!

\section{HERNANDO}

I thought don Diego was dead, sir.

\section{RODRIGO}

He certainly didn't seem to be doing well, Hernando, but now he's come to, and revealed that Pedro's servants were waiting out there in the street, I think they knew what was going to happen! We have got to keep that Pedro on a short leash, Hernando, just like I said!

HERNANDO

When did you say that, sir?

$$
\begin{aligned}
& \text { RODRIGO } \\
& \text { (ignoring him) }
\end{aligned}
$$

Pedro has gone to great lengths to postpone this wedding, but I am resolved! I have come back to this house to take fate by the horns! I will demand that this wedding happen now and right where I can see it!

HERNANDO

I see. Then we are here to cure the disease of dishonor with diligence. 
(Enter CARLOS with LEONOR, dressed like a nun.)

CARLOS

Don't be afraid, lovely doña Ana. You're safe out here.

LEONOR

(Aside)

Good heavens! Did Carlos take me thinking that I am doña Ana? Oh cruel world! He is in love with her - it's so clear!

\section{CARLOS}

(Aside)

Heavens above - I rescued doña Ana, but left my poor Leonor in danger! If I can just sit her down, I will go back in for my love.

(He notices RODRIGO and calls out to him)

Who is there?

RODRIGO

It is I!

CARLOS

Thank Heaven! It's don Rodrigo.

Don Rodrigo, sir, I have a problem that only you can fix!

RODRIGO

How can I help you, don Carlos?

\section{CARLOS}

This lady that I have with me, sir, is don Pedro's sister. I am in her debt and now her honor is in danger. However, if I were to be seen with her on the street, it would also look rather... uncomfortable, but you, sir, are wellrespected and well-aged. Could you take her with you while I go deal with another problem in don Pedro's house?

RODRIGO

I understand your predicament, don Carlos. Of course I will take her.

CARLOS

You're doing me a great favor. With that, I'll go. (He exits) 
(Aside)

\section{LEONOR}

Oh no, not my father!

RODRIGO

A-ha Hernando! Now I hold the honor of Pedro's household in my hands just like he holds mine!

HERNANDO

This certainly does seem like a good way to tie him down trade his sister for your daughter.

RODRIGO

Come along, madam. And don't be afraid. I am obligated to protect you well.

(They cross back into PEDRO's house.)

LEONOR

(Aside)

Oh no, not here again. It's almost poetic: my father has brought me back to the house of my enemy, and I have no choice but to follow him.

Oh, there's Pedro!

RODRIGO

My lady, stay here with Hernando while I talk to your brother.

LEONOR

(Aside)

Oh God, kill me now! At least that way, my death would be quick!

(She sits on a bench with HERNANDO)

RODRIGO

Here he comes.

(Enter PEDRO)

(Aside)

PEDRO

How could it be? My enemy was right here in my own house it makes me so furious! I haven't even found my sister yet, 


\section{PEDRO (cont.)}

but I am checking for her here in the garden. She may have been frightened by the noise.

Oh look, Rodrigo is here. He's come at a good time, since Leonor has told me that she would like to be my wife. (to RODRIGO)

Welcome, sir! I am glad you are here. I was about to come looking for you.

RODRIGO

Let's sit down. We have a lot to talk about.

(Aside)

PEDRO

That's a good sign!

RODRIGO

Don Pedro, you are right that coming here will bring me honor, but you should be more on your guard - you still are not married, so your house remains open to disgrace. You must be very careful about honor, son. It is an easy thing to lose. Knowing that, you now know that don carlos de Olmedo was born honorably to noble parents...

\section{(Aside)}

PEDRO

Why are we talking about don Carlos? He must know what happened! Today I lose my honor and my life!

\section{RODRIGO}

What's wrong? You've gone as white as a ghost. Is all of this talk about honor hitting a nerve in you, boy?

$$
\text { (Enter ANA, covered like the others) }
$$

ANA

(Aside)

Oh no, Don Rodrigo is here with my brother. I need to hear why he came; my brother saw Carlos here and they might put together that I've been hiding him.

\section{RODRIGO}

It seems to me like don Carlos has had some... interactions with your sister, much as you have with my Leonor. 


\section{PEDRO}

What? Good Heavens! Does don Carlos love my sister?

ANA

How could don Rodrigo have found that out?

\section{RODRIGO}

Don't be humble, I am sure you know all about this. Your sister is now in a similar predicament to the one we find ourselves in; don Carlos took her from your house and came right up to me on the street with her.

What are you saying?

\section{PEDRO}

\section{RODRIGO}

Why, just the same thing you said to me. I have your sister and I know where she has been and who she has been with. Conveniently, you also have my daughter and know where she has been and who she has been with. Look at it this way: Heaven has blessed us with an even deal, so let's take care of this like gentlemen. Now, don Carlos and doña Ana could go ahead without you, but isn't it better, if they're going to do it, that it be with your blessing, doing everything in a sane, reasonable way? Now, if we talk reasonably about your honor, I think you will see that you would be better off to go through with our plan. And for my part, you will know that I come ready to give doña Ana back as long as you are married tonight: so there's no reason to delay. On top of that, I found that you left my nephew, don Diego, mortally wounded last night while you tried to take my Leonor. Clearly, only bad can come from rushing into things dishonorably, but everything will be made right when you and my Leonor are married.

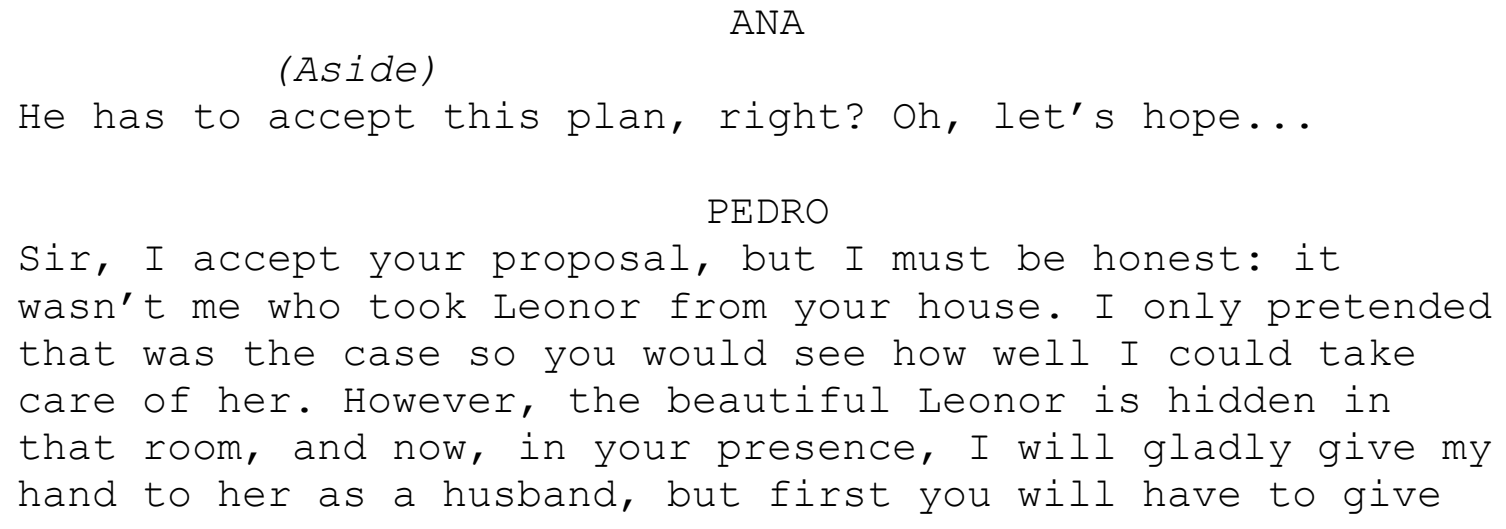


PEDRO (cont.)

me doña Ana, and I will see her married to don Carlos as soon as possible, just as you suggest.

(Aside)

Which works out perfectly for me, one of my rivals will be gone for good!

RODRIGO

Excellent! I knew you were a good man! I will give you your sister now and thank you.

(ANA emerges and crosses to them.)

ANA

There's no need, don Rodrigo, it would be hard to give what you owe when I'm already here. And you, brother, though my actions have caused some chaos tonight, I hope you can find it in your heart to forgive me, since everything seems to have worked out for the best.

PEDRO

Never fear, sister. We will make your wedding as honorable as it can be, even though it will have to be quick and quiet.

\section{RODRIGO}

I don't think there's any need to be as grim as all that. send a page of yours to go find don Carlos.

\section{ANA}

No need to send anyone. I have him hidden in my room.

(The men are scandalized, but PEDRO responds quickly)

PEDRO

Well, go get him, before this gets any worse!

ANA

This is the one time I am incredibly happy to obey. Finally, all my efforts have brought me my heart's desire!

$$
\text { (She exits) }
$$

Celia! 
(CELIA enters)

Yes, sir?

CELIA

PEDRO

Take this key and unlock Leonor's room. Tell her she can come out.

(CELIA takes the key and leaves)

Oh, love, you've made me a winner after all! All of my efforts have been worth the wait!

(Enter LEONOR, still covered up)

LEONOR

While they think that I am doña Ana, maybe I can convince my father to free me. I will have to get away from Pedro later, but there are plenty of other ways to do that.

(enter CARLOS)

(Aside)

CARLOS

The only thing left to do is get Leonor out of this humiliating situation. And if I can't do that, then what is the point of living?

\section{(CARLOS crosses near LEONOR)}

LEONOR

It's Carlos, thank God! Oh, he must be so blind from anguish that he didn't even notice me. Oh, I don't know if my heart can take any more of his inconsistency, but what if he is here to free me as Leonor? I have to know what they're saying.

$$
\text { (She creeps closer to the men's conversation) }
$$

CARLOS

Don Pedro, I apologize. I came into your house knowing you were my rival and took advantage of your hospitality. I am ... but, wait a second, are you don Rodrigo? 
RODRIGO

Calm down, Carlos. This whole mess comes down to the three of us now. Though I'll admit, since you owe don Pedro so much, I do suggest that you give him the gratitude he deserves. After all, I'm making sure you end up happily married and eternally grateful to him.

(Aside)

CARLOS

What is this? Don Rodrigo must know that I am the one who took Leonor, so surely he wants to give her to me, but Pedro will be so disappointed, he will probably sabotage the whole thing. And where is Castaño?

(to RODRIGO)

Sir, I don't know what to say. I have certainly been foolish in my time, but I appreciate all the good things that are coming to me.

RODRIGO

See what I told you: He loves her so much! What a romantic! LEONOR

Oh Heavens, what is my Carlos saying? What "good things" is he so excited about?

\section{PEDRO}

I do owe you respect, but I would appreciate hearing a marriage offer directly from you, though I do want to follow don Rodrigo's wishes.

LEONOR
I can't take it anymore! I will not marry that traitor!

(LEONOR crosses to the men, joining their conversation)

RODRIGO

My lady, you have excellent timing, but why are you covered up again? Here is your new husband now.

Don Carlos, the deals are done now. Give your hand to doña Ana.

CARLOS

Excuse me, to who? Who is this? 
RODRIGO

Doña Ana, your wife. Is there a problem?

CARLOS

By God, this is betrayal and traitorousness! I'm supposed to marry Ana?

\section{LEONOR \\ (Aside)}

Thank you, lucky stars! He didn't want to marry her!

\section{PEDRO}

What is this? Don Carlos, didn't you come to an agreement with my sister?

RODRIGO

Of course you did. Carlos himself handed your sister over to me when he had her, saying that he took her from your house because her life was in danger.

Madam, isn't that so?

LEONOR

Yes, sir. I am Carlos's betrothed.

\section{CARLOS}

With all due respect, no, doña Ana. I see now that you've schemed to expose us to public disgrace and force me to marry you, but the woman I truly love wouldn't make me suffer that kind of dishonor. I will forever belong to Leonor!

RODRIGO

To Leonor? What? What's going on? What Leonor?

CARLOS

I am in love with your daughter.

RODRIGO

With my daughter? How can that be, when she is don Pedro's wife?

CARLOS

I will kill myself before those vows can be taken! 
PEDRO

You will suffer so much more than death - now you've insulted my sister and made advances on my fiancee all in one cruel blow!

(They draw their swords just as ANA and JUAN enter, holding hands. At the other door, CELIA and CASTAÑO enter, both dressed as ladies.)

ANA

Brother, my husband and I lay ourselves at your feet. (Aside)

What's going on here? And Juan is scowling beside me, I don't think he recognizes me yet.

PEDRO

Doña Ana, what is going on?

Here is Leonor, sir.

CELIA

PEDRO

Oh, my love! Beautiful, divine master!

(Aside)

CASTAÑO

He thinks I'm pretty now, but I can't move, I'm so afraid. Oh look! My master is here. Phew! He'll defend me for sure.

RODRIGO

I cannot believe what is before my eyes.

Don Carlos, isn't doña Ana the same woman that you brought to me and who you are marrying?

CARLOS

Not at all. Leonor is the only one I love.

ANA

(Aside)

Well, it was worth a shot. At least I've got Juan here. Maybe there's still time to reel him in.

(Aloud)

Don Rodrigo, what did you say? Don Carlos? I don't understand. I only know that don Juan, from Madrid, is the only man in my heart and in my thoughts. 
JUAN

Don Pedro, I must beg you for forgiveness for trespassing in your home.

PEDRO

I am more than happy to have you here, don Juan. Give your hand to doña Ana, as I offer mine to Leonor.

$$
\text { (CASTAÑO crosses to PEDRO) }
$$

CARLOS

Never! I will kill a thousand men first!

(Aside)

I like being this beautiful - they want to kill each other for me!

PEDRO

You wonderful object of my fractured pride, give me your hand!

\section{CASTAÑO}

I give it to you with a flourish, I'll never wash these gloves again!

You won't get away with this!

\section{CARLOS}

$$
\text { (LEONOR reveals herself) }
$$

LEONOR

Stop, Carlos, I'm right here, and I will be your wife. You have slighted me a little, but I respect you far more than the rest of these... gentlemen.

$$
\text { CARLOS }
$$

Leonor. Is it really you?

\section{PEDRO}

What is this? Is this some kind of dream? Leonor is both here (pointing to LEONOR) and there (pointing to CASTANOO). CASTAÑO

No. I guess the gig is up. I'm not your Leonor. 
PEDRO

Well, who are you then?

$$
\text { (CASTANO takes off his habit.) }
$$

CASTAÑO

Nothing but a dead dog.

$$
\text { (CELIA breaks out in raucous laughter) }
$$

PEDRO

I will kill you, Heaven help me!

$$
\text { CASTAÑO }
$$

Wait! Remember the deal we made when I told you I would marry you? You said that if you called it off, you wouldn't harm me and I'm ready to get hitched today unless you're here calling it off.

$$
\text { RODRIGO }
$$

Why are you in that getup, Castaño?

$$
\text { CASTAÑO }
$$

You see, sir - I was supposed to go get you and tell you what was going on here, and so I dressed up in this finery to avoid having any run-ins with the law, and don Pedro saw me and thought that I was just soooo gorgeous, so he locked me in that little room up there. And the next thing I knew, it was now.

\section{CARLOS}

Don Rodrigo, sir, I would be honored to be doña Leonor's husband.

\section{RODRIGO}

As long as Leonor is married and my honor is intact, the rest doesn't matter anymore. Don Carlos, I would be happy to gain such a son.

\section{PEDRO}

\section{(Aside)}

Another loss for me, but I've made it through - I hope. I can never say for sure. At least this elaborate prank ended in a good marriage for my sister. 
ANA

(to JUAN)

I offer you my hand and with it, my heart.

JUAN

And I, my love, accept it. As long as I live, I will repay your love with my own.

CARLOS

To you, my Leonor, I give my hand.

LEONOR

I always belonged to you, Carlos.

CASTAÑO

So, Celia... love is in the air... say something nice, and you might get a "hand" too.

\title{
CELIA
}

I don't have one of my own to give, I left it in the kitchen. Would a finger be enough for you?

(She flips him off)

\author{
CASTAÑO \\ (Shrugging) \\ Maybe next time. \\ And here, good sirs and madams, refined audience, Los \\ empeños de una casa has come to an end. We hope it has \\ entertained you, and that we haven't said anything worthy \\ of beheading. \\ Thank you, and goodnight!
}




\section{Chapter 6}

With the Temptation, a Way of Escape

By Lainie Vansant

Adapted from Los empeños de una casa by Sor Juana Inés de la Cruz 
Unlike How to Build a Noble House, this adaptation, With the Temptation, a Way of Escape, does change the setting of the play from the Spanish Golden Age to contemporary Evangelical Christian culture - a group within which I thought the plot might still be plausible. In Chapter 4, I discussed the difficulties involved in choosing a contemporary culture in which the idea of honor could drive so much of the plot, but I am pleased with the way Evangelical Christianity leads the characters' choices in this version of the story. In addition to being intertemporal and interspacial, this adaptation does not use any of the language from the original text, except perhaps one or two funny lines that I particularly liked. For example, Celia's opening question asking Ana why she is awake at such an odd hour is not present in any form in With the Temptation, a Way of Escape, and I chose to begin the play instead with Leonor and Carlos's fumbled escape from Leonor's house. I used the beat analysis outlined in Chapter 4 to clarify for myself the triggers and heaps that needed to happen in this story. I then worked from that outline to create a contemporary story. I changed the setting to a feasible and flexible late twentiethor early twenty-first-century time and place, allowing directors to choose whether to make this a period piece from the late 1990s, when purity culture was at its height, or to place it in the ever-changing world of 'today.' I also formed the play with characteristics of sex farces from those eras blended with the characteristics of seventeenth-century cloak and dagger plays. This lens shifted the mood of the text, along with the time, place, social issues, and morality that text explored. Therefore, my adaptation is intertemporal, interspacial, and intercultural but remains in the same literary genre (drama) as the original text. I hope that readers will find this play to be as entertaining as How to Build a Noble House, and that they will appreciate my attempt to update the social issues and relationships 
within it. The comedy is, again, often physical so I encourage readers to try to imagine the words and movement onstage and enjoy the text! 


\section{Characters:}

ANA: 19-year-old in an Evangelical Christian household. Strong, independent, makes things happen.

CELIA: ANA's best friend from a more relaxed background.

LEONOR: 18-year-old from another conservative family. Sheltered but curious.

PEDRO: 20-year-old. ANA's older brother.

CARLOS: 19-year-old boy, free spirit in love with LEONOR.

BRUNO: Carlos's best friend, a drag queen still in his egg. 16 .

JUANA: Female but dresses/presents as more masculine than the other characters. In love with ANA.

RODRIGO: Leonor's father. Traditional. (Also plays ROMAN)

Setting: A small Midwestern town deep-seeded with purity culture. Maybe early aughts, maybe later. Nowhere and anywhere. Maybe a little exaggerated but also maybe not. 
(Lights up on the street outside ANA's house. CARLOS and LEONOR come down the street on a bicycle, slowly and stealthily. Before they can get too far, a voice offstage calls out)

VOICE

Hey! What do you think you're doing?

CARLOS

Shit.

Carlos!

LEONOR

CARLOS

Sorry.

(ROMAN runs on and sees them. Intercepting the bicycle)

VOICE

Hey! That's my cousin, you a-hole. Whaddayou think you're doing?

(ROMAN grabs the handlebars.)

CARLOS

( to LEONOR)

Get out of here.

LEONOR

No, I don't---

CARLOS

Go!

(We notice ANA in her doorway. How long has she been there?)

ANA

Over here!

(beaconing to LEONOR)

(LEONOR makes a quick decision, runs to ANA just as ROMAN hauls back to punch CARLOS. CARLOS ducks and pushes his bike forward, running over ROMAN, who screams and grabs his leg. Blackout. 
Transition to the inside of $A N A^{\prime}$ s house. It is well-lit and cozy, decorated with cloying religious memorabilia. ANA hands LEONOR a cup of cocoa. CELIA is also drinking a cocoa on the couch.)

CELIA

Hi! I'm Celia.

LEONOR

Oh. My name is Leonor. Hello.

(She crosses to the door and tries to peer out the window/peephole)

ANA

Leave it alone. There's nothing you can do about them now.

LEONOR

Do you think he'll be alright?

Who?

ANA

LEONOR

Carlos.

ANA

Carlos Olmedo? That guy on the bike was Carlos Olmedo?

LEONOR

Yes. Did you see what happened?

ANA

(Collecting herself)

No. No, I didn't. Hey, are you feeling ok? Why don't you stay here for tonight?

LEONOR

Oh, yes. I should call-- or no. Oh, what should I do?

CELIA

Whaddayou mean? 


\section{LEONOR}

(sinking into the chair next to her)

I was going to say I should call my father, but I can't call my father because he doesn't even know I'm gone. I was running away tonight with my Carlos. We were going to elope.

Elope!

\section{CELIA}

\section{LEONOR \\ (Showing CELIA the ring) \\ Yes! Here's his promise ring and everything!}

CELIA

That's so romantic!

Shut up, Celia.

ANA

CELIA

What? It is!

LEONOR

$I^{\prime} m$ sorry.

ANA

No, go on. You were running away with Carlos the studmuffin. Then what happened?

\section{LEONOR}

He came to my window, and just as it seemed like we were on the verge of getting out of the neighborhood and on to freedom, my cousins discovered us and stopped us in our tracks!

CELIA

No!

Celia!

ANA

CELIA

What? 
ANA

Why don't you get some rest? You can call in the morning and sort everything out then. How old are you anyways?

LEONOR

Nineteen.

ANA

Then who cares what your Dad thinks, right?

LEONOR

I know the situation seems unusual, but he is a good man and he takes care of me. He only wants to shelter me from evil.

CELIA

Oof.

ANA

I totally get it. I wear the promise ring from my Dad too, see? But he will live if you're gone for one night, and you can explain everything in the morning. Come on, I'll put you up in my room.

(ANA begins to lead LEONOR up the stairs in the direction of her room)

Oh! Uh... Ana?

CELIA

ANA

Not now, Celia. I'll be right back.

CELIA

But, uh... I have something to tell you, and it's kind of important, and...

(ANA takes LEONOR into her room and slams the door. CELIA takes out her phone and texts someone frantically. ANA reopens the door and exits again, making CELIA hide her phone)

What is it, Celia?

ANA

CELIA

Oh, nothing. Should be no big deal now, nevermind. 
Right.

(ANA crosses to the bookshelf, takes down a Bible, pulls out a flask, and takes a sip. She flops down on the couch.)

CELIA

The Bible? What if someone goes to read that?

ANA

Since when do Evangelicals do that?

(CELIA gives her a look -- 'Come on.' ANA rolls her eyes)

Pedro's got his own. It's fine.

CELIA

Yeah, speaking of Pedro, when is he coming back?

ANA

I dunno, probably soon. He can't snitch though, he owes me.

For what?

CELIA

ANA

For hiding that girl in my room. He's got the hots for her bad and he's trying to force her father into some kind of shotgun wedding.

(CELIA snickers)

What?

CELIA

"Got the hots?" Who says that? What, are you some kind of mobster now?

ANA

(throwing a couch pillow at CELIA. Affectionately.)

shut up. Anyway, what do we do now?

CELIA

I don't know. You're gonna have to tell me more about this mobster scheme first. You hid Leonor in your room so Pedro could force her into a shotgun wedding? 
ANA

Yeah. Her dad is really strict, so he's thinking that if everyone knows she spent the night at his house--

\section{CELIA}

Don't you both live here?

\section{ANA}

Yeah, but it's still mostly his house. So Leonor spends the night here, her dad is scandalized, bada-bing bada-boom, shotgun wedding, Pedro gets the girl.

Wow. That sucks.

\section{CELIA}

ANA

I know, but the poor thing is hopeless and he's supposed to be 'keeping an eye on me' so I've gotta help him or he'll tell Mom and Dad that I'm doing drugs or something.

CELIA

And you like feeling like a mobster.

Maybe a little.

ANA

(A knock at the door. ANA gets up to investigate.)

Who is that?

CELIA

It's Carlos! (Looking through the peephole)

CELIA

Oh, cool. Let me get Leonor!

ANA

No! Stop right there!

(Whispering)

Carlos Olmedo is super cute, and his parents own the Christian bookstore. 


\section{CELIA}

So?

ANA

So -- he's a major catch! Marrying him would be just like Beauty and the Beast, you get him, PLUS this massive library and an awesome job forever.

CELIA

How romantic.

ANA

Just back me up, wouldya? Don't tell him that Leonor is here?

CELIA

Ok, fine. I'll go make more cocoa. (ANA touches up her hair and opens the door)

ANA

Oh! Hello. What a surprise!

CARLOS

Hello, Miss. Sorry to bother you, but there are some men after me out here and I don't know what to do. I was wondering if Pedro Calderón was here; if he could help me.

You know Pedro?

ANA

\section{CARLOS}

Not yet, but my friend gave me this address and said he was a good guy. Do you think I could come in? Those guys are going to come back soon and they're pretty mad at me. I think I ran over one of them.

Oh!

ANA

CARLOS

With my bike! Just with my bike.

Of course. Come on in. 


\section{CARLOS}

I actually hope he's ok. He was just laying out here...

BRUNO

(Pushing the door open long enough to follow CARLOS in) Eh, he's fine boss.

Oh! Who are you?

ANA

BRUNO

Bruno. Who are you?

\section{CARLOS}

He's here with me. He was supposed to be driving my getaway car, but we never got that far.

Oh. Hello... Bruno. My name is Ana.

BRUNO

That's cute.

ANA

Thanks?

What did you say the two of you were hiding from?

$$
\text { BRUNO }
$$

Well, lover-boy here was trying to run away with his boo--

CARLOS

My fiancee, Bruno. Have some dignity. We were going to elope, but her cousins must have heard and tried to stop me. I assume they took her back home with that boy I ran over.

$$
\text { BRUNO }
$$

Yeah, he probably died.

Do you think so?

$$
\text { CARLOS }
$$

BRUNO

No... I'm sure he's totally fine (He surreptitiously nods at ANA) 


\section{CARLOS}

It's all a blur. I had her there with me. I could see the light of our love in the glorious future.

\section{BRUNO}

Mmmhmm •

\section{CARLOS}

Then there's a crash and she just disappeared. I had her right there, Bruno!

I know, Domino. It's ok.

$$
\text { BRUNO }
$$

ANA

I thought your name was carlos.

It is.

CARLOS

ANA

Oh.

CARLOS

Now all I have is her backpack.

(He picks it up and inhales its scent.)

\section{BRUNO}

Yeah, that's not weird. Let's pull it together, bud.

\section{CARLOS}

I just wish I knew where she was.

We know, we know.

$$
\text { BRUNO }
$$

Anyway, he's buds with some guy who apparently knows your brother. Do you think we could stay here for the night?

CELIA

$$
\text { (Entering with more cups of cocoa) }
$$

Anyone want cocoa? I just made more.

Thank you, Celia. 


\section{ANA (cont.)}

Of course you can stay, but as you can see, Celia here is spending the night, so the guest bedroom is full, and Pedro would have a fit if he came in and saw two strange men in this house with me... alone.

\section{CARLOS}

Oh no. It does look bad, doesn't it?

ANA

Very bad.

\section{CARLOS}

We wouldn't want to tarnish your honor.

Tarnish your honor?

\section{CELIA}

\section{ANA}

Not to worry. I'll just put you up in this little storage space. We'll sneak you out in the morning and Pedro will never know!

(PEDRO's car pulls into the driveway. ANA hears him and moves quickly.)

That's him! Let's go!

(She opens the closet door. It looks a little tight.)

Hurry!

$$
\begin{aligned}
& \text { (CARLOS and BRUNO cram themselves into the } \\
& \text { closet.) }
\end{aligned}
$$

\section{CARLOS}

(Smelling LEONOR'S coat)

This is her coat! I would recognize that smell anywhere!

$$
\text { Yep, enjoy! }
$$

ANA

(She shuts the closet just as PEDRO comes in the
front door.) 


\section{CELIA}

I'm not sure that's gonna work out for you.

PEDRO

What's going to work out?

ANA

Oh, nothing. How was your night?

PEDRO

Andy got roughed up a little, but it's nothing we can't handle. Other than that, everything seems to be going according to plan. Did you get the bird into the nest?

ANA

I did! And Celia helped me, isn't that right, Celia?

Yep. Super helpful.

\section{CELIA}

\section{PEDRO}

Hmm. Alrighty then. I'd better go take a shower before I talk to her. A man needs to make a good impression, you know.

(PEDRO crosses to the master bedroom. After a moment, we hear water running.)

Is that everyone?

\section{CELIA}

\section{ANA}

I think that's everyone!

(Producing her flask again)

Come on, Celia. Let's go to the kitchen and spice up that cocoa a little.

(They turn off the lights on the way to the kitchen. There is a beat before they open the door.)

CELIA

Holy crap, your house is so dark. I can't see anything. 
ANA

Yeah, Pedro is obsessed with those blackout curtains. Something about security, I don't know. Let's get out of here.

(They exit.

There is a scream from upstairs, and LEONOR comes running out of the bedroom, chased by JUANA, who is holding a dozen roses.)

Get away from me!

LEONOR

JUANA

Shh! Ugh, I knew this was a mistake. I'm really sorry, ok?

My heart! My honor! Again!

$$
\text { LEONOR }
$$

\section{JUANA}

I get that, I totally do. I guess I just read the situation wrong, and Celia said -- Idiot! Idiot!

LEONOR

Who are you? Wait -- are you a woman?

I will save you, Madam!

\section{CARLOS}

(CARLOS and ANA burst out of the closet and kitchen at the same time, the door swinging shut behind ANA. They run across the room and end up smacking into one another and falling on the floor. LEONOR screams again.)

\section{CARLOS \\ (From the floor)}

//Where is he? If I could just-- I'll get you, sir!

ANA

//Ow! Good grief, what is going on out here?

(Maybe they try to stand up and run into one another again. BRUNO and CELIA enter; CELIA turns on the light. Everyone squints around in confusion at the scene around them. ANA and 
CARLOS are in a compromising-looking position, which CARLOS tries to quickly extract himself from without much help from ANA. LEONOR, in her nightgown, squeaks and tries to cover herself up. she finds something or someone to hide behind.)

CELIA

Blackout curtains. Terrible idea.

JUANA

Get off of her!

(to CARLOS)

CARLOS

I'm trying to! Leonor, is that--

Don't look at me!

LEONOR

CARLOS

(Averting his eyes, which does not help him extricate himself)

Oh no! Excuse me!

ANA

(Noticing her for the first time)

Juana?

JUANA

(Smiling in spite of herself)

Ana. But -- if you're out here, who was in your room? (She scans the room)

Don't look at me!

LEONOR

ANA

Leonor needed a place to stay for the night.

JUANA

(Glaring at CELIA)

Oh. I wish I had known that.

(CELIA, confused, pulls out her phone and looks at it. She is interrupted by LEONOR beakoning wildly to her. The room breaks into several 


\title{
conversations, which are 'muted' when the audience is listening to another.)
}

\author{
CARLOS \\ (to BRUNO)
}

Did you see what I saw?

I plead the fifth!

$$
\text { BRUNO }
$$

\section{CARLOS}

What?

$$
\text { BRUNO }
$$

Sorry, this just seemed like a sketchy situation. What did you say?

$$
\begin{gathered}
\text { LEONOR } \\
\text { (CELIA has made it to her by now) }
\end{gathered}
$$

Is that Carlos, Celia?

$$
\text { CELIA }
$$

It is. Yes.

$$
\text { LEONOR }
$$

With Ana?

$$
\text { CELIA }
$$

Um... I guess so.

$$
\text { LEONOR }
$$

A-- person snuck into my bedroom, Celia!

$$
\begin{gathered}
\text { ANA } \\
\text { What are those? (to JUANA, re: the roses) }
\end{gathered}
$$

$$
\text { JUANA }
$$

Nothing. They're nothing.

$$
\text { ANA }
$$

And what are you doing here?

Oh, I-- wanted to borrow something. Do you have any... shampoo? 
ANA

You're here for shampoo?

\author{
CARLOS \\ (to JUANA, shouting)
}

You! You tried to attack my Leonor!

JUANA

I wasn't attacking her, sir. I don't even know her.

CARLOS

(Charges over to attack her, then stops)

Wait-- are you a girl?

Who's asking?

JUANA

(Ready to fight him)

(The water shuts off in the other room. ANA hears it and springs into action)

ANA

Pedro! He'll be out here any minute, you all HAVE to go back to bed. Go! Get out of here!

(CELIA ushers LEONOR back to her room. CARLOS and JUANA are locked on one another)

ANA

(Throws something at CARLOS to break his line of sight)

Carlos! If my brother finds you here, you'll ruin my reputation.

CARLOS

(Reluctant)

Alright, but do we have to go back in that closet? It is not comfortable in there.

ANA

Fine. Go in the kitchen. Juana, can you hide in there?

(They go back into their closet)

JUANA

You're putting me in the closet. 
ANA

Um... yes. To be fair, I did not know you were going to show up, so this isn't great for anyone.

I'm really sorry, ok? It'll just be a few minutes. Just until Pedro goes to bed.

JUANA

Alright. I guess.

ANA

Thank you!

(Just as JUANA closes the closet door and CELIA closes the bedroom door, PEDRO comes out of his room.)

Ah! Refreshing. How do I look?

PEDRO

Ah! Refreshing. How do I look?

ANA

Soggy

PEDRO

You know, you could be nicer to me. I'm the only reason Mom and Dad are letting you live on your own.

ANA

Ha! Like this is 'on my own.' You judge my every move, then you literally kidnap a woman. Come on.

It's not kidnapping.

PEDRO

ANA

Sure. Whatever.

(CELIA opens the door to ANA/LEONOR's room and closes it silently behind her. She puts her finger to her lips and tiptoes to ANA and PEDRO.)

CELIA

She just went to sleep. She's had a tough night, poor thing. 
Ok. I'm gonna go talk to her!

PEDRO

ANA

Hold it! Maybe you should wait. Until she's not, like, asleep.

CELIA

Yeah, someone broke into her room once already tonight.

Carlos! That dirty rat!

PEDRO

ANA

Yeah... him. Sure. I'm just saying, tomorrow would probably be better.

PEDRO

You know, maybe tomorrow would be better, if she is already asleep. I'll talk to her then. That's a good idea.

Goodnight, ladies. Sweet dreams.

(He exits into his room.)

CELIA

That asshole. Where does he think we're going to sleep?

(While she says this, ANA crosses to the closet and lets JUANA out. They cross to the couch and sit awkwardly.)

Oh, hey!

CELIA

JUANA

(Awkwardly)

That was really smart of you. He doesn't know anyone else is in the house at all.

Oh, you heard all that?

ANA

JUANA

Yeah, you can hear and see everything in there through that grate thing on the door. 
Cool.

ANA

(Awkward pause)

What happened there anyway? Why are you here?

JUANA

Oh, I don't know. Celia, why am I here?

CELIA

I swear I texted you!

JUANA

The last text I have from you says "About plan! Do come in the window tonight! Important!"

Really?

CELIA

(She looks it up on her phone)

Ah, that's a typo. It should say 'Abort plan! Do not come in the window tonight!" My bad.

$$
\text { JUANA }
$$

"My bad?" I made that poor girl think I was coming in to murder her!

\section{CELIA}

Yeah...

ANA

So why were you here in the first place?

JUANA

Oh, I... it was nothing. Just a stupid idea.

CELIA

No! It was ro--[mantic]!

Shut UP, Celia!

JUANA

CELIA

Ok, fine. Be a chicken then, whatever.

ANA

Tell me what is going on, you two! Now! 
CELIA

I guess it was "nothing."

\section{ANA}

Juana?

(JUANA is quiet. She shakes her head. ANA takes her hand.)

Come on. You can tell me... You're my Sam and I'm your Frodo, right?

JUANA

I'm sorry, I can't do this.

(She stands up and crosses to the door)

I'll see you guys later.

ANA

Don't be mad! You don't have to tell me if you don't want to. Juana?

(She is out the front door already.)

What was that all about?

CELIA

(gathering blankets)

I'm tired. Are you tired?

ANA

Celia, what are you not telling me?

CELIA

I guess we're sleeping out here, since sleeping Beauty is in your room. You have enough blankets?

ANA

(wanting to yell but not to wake everyone up) What is going on?!?!

Oh, the lights!

CELIA

(Huddled in the blankets, she waddles over to the light switch) 
Goodnight!

\author{
CELIA (cont.)
}

(She flips the lights off. Blackout.

Lights up on the next day. PEDRO, ANA, and CELIA are plotting in the living room.)

PEDRO

Do you think she's ready now? How do I look?

ANA

You look good. Almost too good like you're trying too hard, right Celia?

CELIA

Yeah. You don't want to look desperate.

PEDRO

You're right. I am not desperate.

CELIA

Right, this whole plan is totally level-headed and reasonable.

ANA

Ignore her. I'll tell you what, you go back in your room for five minutes, lay down in bed, ruffle your hair, whatever. I'll go wake Leonor up and bring her down to the living room, and you can just happen to run into her in the living room.

Hmm... maybe.

PEDRO

Or, what if I go in there and make myself look a little less perfect while you go up to her room and make sure she wakes up smoothly, then in about five minutes I'll come out of my room and just happen to run into you here in the living room!

ANA

Brilliant. Why didn't I think of that?

PEDRO

It's a plan! Let's go - I'll head in here. See you in five minutes! 
Unbelievable.

\section{CELIA}

\section{Unbelievable,}

ANA

I know. No time to worry about that now though. I'll go get Leonor like we said, you move Carlos and his friend back to the closet so they can see Leonor and Pedro talking.

CELIA

But won't they hear her turn him down? She's definitely not going for that.

I don't know, Celia. Figure it out.

(Before CELIA can respond, ANA takes off for her bedroom and exits. CELIA sighs and opens the kitchen door.)

CELIA

Good morning, gentlemen.

$$
\text { BRUNO }
$$

Finally! Let's get out of here.

$$
\begin{aligned}
& \text { (BRUNO takes off for the front door but CARLOS } \\
& \text { stops him) }
\end{aligned}
$$

CARLOS

Not yet, Bruno! Celia, who was that young woman we saw last night? The one who was hiding her face?

\section{CELIA}

Oh, I don't know. Just some girl who came by last night looking for help. Ana gave her a place to stay.

\section{CARLOS}

Outside this house -- it must be Leonor!

BRUNO

I don't think so, man. Let's just get out of here, can we?

\section{CARLOS}

No, Bruno. We were attacked just outside of this house and Leonor disappeared right away, I would be willing to bet that she came into this same house. It's fate! 


\section{BRUNO}

Or it's wishful thinking. Can't we get out of here and figure that out later?

I have to know, Bruno!

\section{CARLOS}

\section{CELIA}

Well, you can't go back in the kitchen because Pedro will be up any minute to go eat his breakfast, but you can hide in this closet. You can see out of this little grate here, so maybe you can figure out whether it was this Leonor girl or not from in there.

CARLOS

Great idea! Bruno, to the closet!

Really?

BRUNO

(CARLOS has already wedged himself in there) BRUNO (cont.)

(to CELIA)

I hate him sometimes.

CELIA

I know what you mean.

(LEONOR's door begins to creak open, BRUNO hurriedly gets in the closet and CELIA slams the door. ANA enters, checking the room before she gets out of the doorway and lets LEONOR through. LEONOR is dressed in ANA's clothes and holds a bag with her clothing from the day before.)

ANA

Why don't you sit down? I'll grab you some breakfast. Do you drink coffee?

LEONOR

My father says it's a drug and ladies especially shouldn't partake. 
ANA

(Conspiratorially)

Do you want some coffee?

(LEONOR looks shocked.)

I'll get you some orange juice. Orange juice is ok, isn't it?

(LEONOR nods. ANA exits into the kitchen. LEONOR sits primly on the couch with her back to the closet. PEDRO opens his door and makes a show of being surprised to see LEONOR)

PEDRO

My goodness! What are you doing here, Miss Leonor?

(Whenever LEONOR starts to talk, CELIA, still standing by the closet door, starts to whistle or hum annoyingly. PEDRO and LEONOR ignore it politely.)

LEONOR

Oh! Miss Ana let me in last night. Do I know you?

PEDRO

Of course. I've been talking to your father about courting you. We were both at the Children's Miracle fundraiser, remember? You gave me a water bottle.

LEONOR

Oh. Right. What was your name again?

\section{PEDRO}

Pedro Calderón at your service.

(He takes her hand and kisses it. She is uncomfortable.)

This is my house, and I have a good job. I could take very good care of you.

LEONOR

That is very sweet, but I have a fiance. (She shows him her ring) 


\section{PEDRO}

\section{(Investigating it)}

You can't fool me - every good girl has one of those. A purity ring or a promise ring or something.

\section{LEONOR}

But I'm telling you that I have a fiance. I'm spoken for, no matter what my father says.

PEDRO

Are you saying you don't like me? Why don't you like me?

LEONOR
It's not that I don't like you, I don't know you.

PEDRO

I am willing to save your reputation. Honestly, me offering to marry you is a favor to you. After all, what will people think of a single woman in a single man's home overnight?

CELIA

Oh... kay. Why don't we talk about something else?

PEDRO

What do you know, Celia? And why do you keep whistling?

CELIA

I have a song stuck in my head.

Well, stop.

PEDRO

CELIA

Why don't you two go do something? Get breakfast, maybe?

You said you needed to get to know one another.

PEDRO

You know what, we should get to know each other. Why don't we go do something? We could get breakfast!

$$
\text { (LEONOR looks at CELIA, confused) }
$$

\section{CELIA}

Yeah, he does that.

I mean, he's a real catch! He just has some... quirks. 
PEDRO

What are you talking about?

CELIA

Nothing. Breakfast?

PEDRO

Yes. Is this your bag, Miss Leonor? Let me put it in the closet for you.

CELIA

(Intercepting)

I'll get it! You go have fun, you crazy kids.

Do you know where it goes?

\author{
PEDRO
}

CELIA

Of course!

PEDRO

Oh. Because you don't seem to be putting it in the closet, actually.

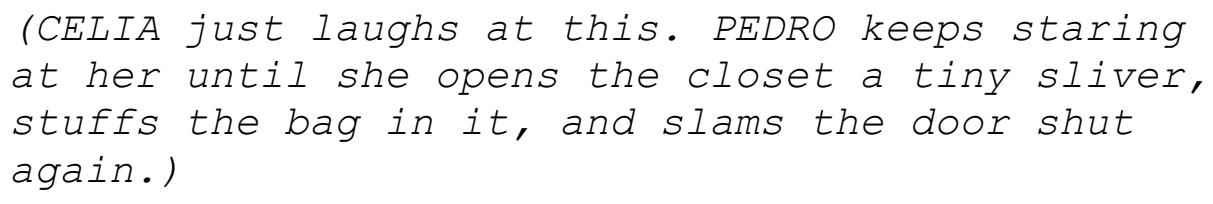

CELIA

Just right there, right? In the closet.

Right.

PEDRO

Come, Leonor!

(He stands and offers his elbow to her. LEONOR is unsure, but she takes it and lets herself be led into the kitchen. As soon as they are gone, CARLOS bursts out of the closet.)

\title{
CARLOS
}

That-- That asshole! How dare he!

BRUNO

I dunno, man. She seemed to be going along with it. 


\section{CARLOS}

(Sinking to the couch in despair)

She did, didn't she. I couldn't hear it very well because there was a strange whistling (or humming) in that closet. What were they saying, Celia?

\section{CELIA}

Oh. Um... lovey-dovey romantic stuff. I didn't really get all of it. Maybe if Ana... Ana!

\section{(ANA comes back out of the kitchen, quickly} shutting the door behind her.)

Oh good, you're here. Would you like to explain to Carlos, here, exactly what is going on with your brother and Leonor?

Oh, of course.

ANA

(She sits next to him on the couch, gently). Have you ever heard of the concept of 'courting?'

CARLOS

Isn't that just an old-fashioned word for dating?

ANA

Our church practices courting today. It's a dating system designed to keep young people from sinning. The man brings gifts to the woman's house and they sit and chat in the presence of her father and family so they can get to know one another personally and intimately before they know each other physically.

\section{CARLOS}

And Leonor and Pedro have been doing this? Courting?

$$
\text { ANA }
$$

Yes.

$$
\text { CARLOS }
$$

Why didn't she tell me?

ANA (rubbing Carlos's back)

I don't know. It's just cruel to lie to someone who loves you. 
CARLOS

Thank you. For all your help.

(Finally escaping whatever is going on in the kitchen, LEONOR opens the door to see Carlos and ANA on the couch. She gasps and shuts the door firmly. ANA notices.)

ANA

Yes, yes. All very sad. Maybe you should go now, though, before my brother finds you here. But if you'd like, we could see each other under more... above-board circumstances soon?

CARLOS

(Still distraught)

No.

ANA

What? But... you have to leave.

\section{CARLOS}

I can't. I have to stay here and get my revenge.

ANA

Revenge?

\section{CARLOS}

Yes, revenge. You should know all about revenge with your obsession with honor and dignity and all that. Pedro has dishonored the woman I love, and I need revenge.

\section{CELIA}

Great .

BRUNO

Are you sure we shouldn't just go?

CARLOS

You can go if you want, Bruno, but I'm staying here.

BRUNO

You know I can't leave you like that, Bro. We probably should hide though. So you can, like, be prepared for your 'revenge.' 


\section{CARLOS}

If you say so.

CELIA

Why don't you stay in Ana's room?

ANA

What? What about the closet?

CELIA

I'm tired of whistling.

Fine. Go to my room.

ANA

(They do. Just as ANA and CELIA return to the middle of the room after settling them in, RODRIGO knocks on the door. ANA goes to answer it.)

(ANA looks through the peephole)

It's Leonor's father - go check on them in the kitchen, see if you can stall them. (CELIA nods and exits into the kitchen. ANA opens the door.)

Oh! Hello, Mr. Rodrigo. How are you?

RODRIGO

I'm looking for my daughter. Have you seen her?

ANA

Do I know your daughter, sir?

\section{RODRIGO}

How should I know? Apparently I know nothing about her friends. She's about your age. Yea high. Seems to have a level head at first but then one day she'll up and run off with a strange man in the middle of the night.

Did my brother call you?

ANA

RODRIGO

No.

ANA

Then I can't say that I've seen her around here, sorry. 
ANA (cont.)

Out of curiosity, what will you do to her when you find her?

RODRIGO

I'll have to track down that boy who stole her and make sure they are properly arranged. A wedding is respectable, children running off in the middle of the night is not.

$$
\text { ANA }
$$

How old did you say she was?

$$
\text { RODRIGO }
$$

She is nineteen, and far too big for her britches if you ask me. Thinks she knows everything.

\section{ANA}

If she's nineteen, is she really a child?

RODRIGO

Sounds like something a nineteen-year-old would say.

If you haven't seen her, I can't sit here yapping. I have to go find her, and she's only getting further away as I stand here talking to you. Go with God, young lady.

ANA

Go with God, sir. I hope you find your daughter.

(RODRIGO mumbles as he takes off. CELIA pokes her head out of the kitchen door. Perhaps she has been doing this throughout the conversation.)

All clear?

\section{CELIA}

\section{ANA}

All clear.

\section{CELIA}

Good. I think she's about to snap.

(She disappears into the kitchen and comes back, behind LEONOR and PEDRO, a moment later) 


\section{LEONOR}

I think I suggested that we put cheese in the eggs, sir, before you did.

No, it was my idea.

PEDRO

LEONOR

With all due respect, sir, if it was your idea, why didn't you say it first?

Aren't you two adorable?

ANA

LEONOR

(shooting her a glare)

I think I would like to go home now please. I've had enough of it here, and I don't care if I'm disgraced, I just want to go home.

ANA

\section{Already?}

LEONOR

I've been here all night.

PEDRO

Leonor, my love! Don't leave me!

LEONOR

Where did you put my things? I want to go.

ANA

I think they're in my room, why don't we... (She starts steering ANA toward her room, but CELIA shakes her head vigorously, reminding her that there are men in there. ANA switches directions and instead steers LEONOR toward PEDRO'S room.)

Or-- in here! They're definitely in here. Yes.

(She steers LEONOR into PEDRO'S room and slips out. PEDRO crosses over and locks the door.)

Did you just lock that?

\section{CELIA}


ANA

All the bedrooms can lock from the outside. My parents don't really care about fire codes.

PEDRO

It is the best way to protect Ana's purity.

CELIA

Wow, Ana. You need to--

PEDRO

What do we do now? She doesn't love me! If I ask her to marry me, she'll definitely say no!

ANA

First, you've got to pull yourself together. Let's -- ugh - let's go get a cup of coffee and wipe that dejected look off your face.

(They exit into the kitchen. Just after they leave, Ana's bedroom door creaks open and CARLOS and BRUNO start to sneak across the living room.)

CELIA

What are you two up to?

\section{CARLOS}

Shh! We're trying to get out of here. See if I can learn anything more about my Leonor from the outside.

From the outside, huh?

CELIA

\section{CARLOS}

Yes. Now, will you just be quiet and let us leave?

(Just as CARLOS puts his hand on the doorknob, RODRIGO bursts back through it, followed by JUANA.)

RODRIGO

This young person says that my Leonor is here, and I demand to see her right away!

\section{CARLOS}

Mr. Rodrigo! Sir. It's... umm... it is a pleasure to see you and I hope you are well today sir. 
RODRIGO

Yes yes. Leonor. Where is she?

JUANA

Wait a second - you're the one from last night!

CARLOS

The one what?

\begin{abstract}
(As he's saying this, JUANA lunges across the room and attacks him. CARLOS, already on edge, attacks back, but JUANA doesn't fight fair.)
\end{abstract}

BRUNO

Woah! Wait! What are you doing?

JUANA

//YOU STOLE HER FROM ME! THAT WAS MY MOMENT!!

CARLOS

//I WILL FIGHT FOR MY LEONOR IF IT'S THE LAST THING I DO!

$$
\text { (CELIA and BRUNO try to pry the fighters apart) }
$$

Carlos! Carlos!

BRUNO

I think that's a woman!

CARLOS

A woman?

JUANA

I'll beat you like a man, you little twerp! You don't deserve her!

\title{
CARLOS
}

Oh God, I'm so sorry Miss!

RODRIGO

You will not take the name of the Lord in vain!

Of course. I'm sorry sir. 
(ANA comes out of the kitchen, followed by PEDRO. Before he can get through the door, she sees the situation, makes an about-face, and pushes him back inside. CELIA springs into action)

\section{CELIA}

They're coming back - can you guys please hide again? Ana will be in so much trouble--

BRUNO

(Already heading toward the closet)

We know, we know. Come on, stud. Let's closet up again.

(CARLOS, still a little confused, follows him into the closet, rubbing the bruises from his scuffle. CELIA crosses to the kitchen and opens the door.)

CELIA

Did you need something, Ana?

ANA

(Entering again, followed by PEDRO)

Oh, no. We were just finishing up in here.

PEDRO

I thought it would be a good idea to top off the coffee before we came ba-- Oh! Mr. Rodrigo. What a pleasure.

Juana!

ANA

JUANA

(Shyly)

Hey •

PEDRO

(Pulling himself together)

Mr. Rodrigo, I was just on my way over to tell you that myself. Leonor is just freshening up as we speak.

RODRIGO

Hmm. Good, good. Let's sit. (They do. RODRIGO looks intentionally at the women)

Ladies? 
ANA

Yes?

RODRIGO

could you excuse us? This is men's business.

(ANA begrudgingly leads the women back into the kitchen.)

That's better. Now, I understand that you came to my house and stole my daughter out from under my nose last night?

PEDRO

Well, I didn't exactly steal her. I just... I wanted...

RODRIGO

Nevermind all that. You took her and now she is here, right?

PEDRO

She is here, yes.

RODRIGO

Fine. Then you should marry her as soon as possible. It's clear that you love her if you took all that effort to sneak her away, and she left this note that says she had gone with her true love, so I suppose this is the best we can do. I don't particularly like it, mind you, but it is what it is. I assume there's no time to waste, so we'll have the wedding tomorrow and be done with it.

PEDRO

Tomorrow?

RODRIGO

Is there a problem?

PEDRO

No sir. I'm sorry, sir. It's just so sudden. I was hoping I could bridge the idea of marriage to Leonor a little more slowly.

RODRIGO

You took her out of my house and you hadn't 'bridged the idea of marriage?' 


\section{PEDRO}

Well... um... I don't... you see...

RODRIGO

Nevermind. Don't hurt your brain. How does next week look? I can wait a little while as long as you do marry her. With all those things she said in that sappy letter, I don't think getting her permission will be an issue.

PEDRO

Next week. Yes. That will-- I can do that, sir. Thank you, sir.

\section{RODRIGO}

\section{(Matter-of-fact)}

Right. Whatever you say. I'm going home now to soak my feet. If you hurt my daughter, I'll come back and kill you. Understood?

Good. Adios!

PEDRO

Yes, sir. Of course, sir.

$$
\text { RODRIGO }
$$

(RODRIGO hobbles out the door and PEDRO sighs, puts his head in his hands. After a moment, he opens the door to his bedroom.)

Leonor? I have great news!

$$
\text { PEDRO }
$$

\section{(CARLOS and BRUNO practically fall out of the closet.)}

\section{CARLOS}

That dirty rat! I'm the one who swept Leonor away out that window and I'm the one she wrote that letter about! It should be me getting to marry her and not that sleeze-ball Pedro!

BRUNO

What are you gonna do about it, Tex? 
CARLOS (cont.)

I don't know. What should I do?

BRUNO

You could go in there and punch him.

\section{CARLOS}

But what if she really does love him? We saw them sitting there on the couch together, all cozied up to each other. What would she think if I just barged in and punched the man she loved?

That it was hot?

$$
\text { BRUNO }
$$

\section{CARLOS}

I don't think so.

Oh.

$$
\text { BRUNO }
$$

\section{CARLOS}

I need to explain things to her father. He at least deserves to know what's going on. Here!

(He grabs a pen and paper from the coffee table/desk and writes intently for a moment.)

Take this to Mr. Rodrigo and tell him that I am here at Pedro's house looking out for Leonor's reputation.

BRUNO

Is that what you call it?

\section{CARLOS}

Just do it. Please?

\section{BRUNO}

But what about those thugs out there? Her cousins or whatever? Those things were ready to take down anything that moved.

CARLOS

Just ignore them or run or something.

BRUNO

I wouldn't be surprised if they had this house staked out, just waiting to pounce on any men who try to sneak out without marrying their precious cousin. 
You're being dramatic.

\section{CARLOS}

BRUNO

Well, you're sending your friend to certain death! Isn't that worse?

\section{CARLOS}

Just GO, will you? I'll stay here and see if I can find Leonor and get a few seconds alone with her. I'm checking Ana's room first. (He walks to the door. BRUNO doesn't move.) Goodbye, Bruno. I'll see you soon.

(He shuts the door, pointedly. The girls open the door from the kitchen and BRUNO dashes into the closet. ANA, JUANA, and CELIA enter, talking casually. ANA's arm is draped around JUANA's neck.)

JUANA

Gandalf would win, I'm telling you. I'm all about girl power and whatever, but he can control the weather and shit. Wonder Woman can't compete with that. Her biggest power is making people tell the truth.

ANA

Plus she's barely clothed. Just, like, slash her bare shoulders and she's done. Pow! Game over.

CELIA

If you two agree, I've got no chance. You make a great team.

ANA

(Enthusiastically)

Yeah we do!

JUANA

(Less enthusiastic)

Yeah.

(She gives a half-hearted high-five and wriggles out from under ANA's arm.)

JUANA

Look, Ana... about last night... 
(PEDRO comes crashing through his bedroom door in frustration. He sees the girls and stops)

PEDRO

I'm going out for a minute. Don't let her leave.

What's--

ANA

PEDRO

I just said don't let her leave. That's all you need to know.

(He storms out. ANA stares after him, shocked, for a moment)

He's such an asshole.

JUANA

(LEONOR, now standing in the doorway, lets out a little gasp of surprise at JUANA's language.)

JUANA (cont.)

Sorry. I'm not good at keeping it in. I'm Juana. We met last night.

LEONOR

Oh. Right. My name is Leonor.

JUANA

That's pretty.

LEONOR

Thank you.

ANA

What got into him?

LEONOR

My father said he would make me marry him, but he can't make me like it. Pedro wants me to like it.

JUANA

Eew .

ANA

What's wrong with Pedro? 


\title{
JUANA
}

(Scoffing)

What isn't wrong with Pedro?

\section{ANA}

Not helping

$$
\text { (JUANA rolls her eyes) }
$$

LEONOR

He doesn't listen. He insists that everything was his idea. He has to have control over every situation he's in...

ANA

ok, ok. But you have to marry someone, right?

I'm promised to Carlos Olmedo.

\section{LEONOR}

ANA

The guy who was hitting on me last night?

Carlos would never!

LEONOR

ANA

You saw it, didn't you? He was all over me there in the dark...

\section{LEONOR}

I--- I don't know what I saw. Carlos loves me, and he-- he wouldn't do that.

You saw it, right? ANA

\author{
CELIA \\ (to JUANA)
}

I can't believe we're still doing this.

Doing what?

\section{LEONOR}

ANA

Nothing. She's just being mouthy. 
LEONOR

Well, whatever it is, I hope you're all happy with it. I may be polite, but I understand more than you think and right now, I just want to go home, if someone would please tell me where all of my things are so I can get out of here.

ANA

I think I saw your coat in the kitchen! Let's all go check.

(Reluctantly, the other women follow ANA into the kitchen. While the living room is empty, CARLOS sneaks across it to PEDRO'S room, opens the door, and slips in. The girls all enter again.)

ANA

Well, shucks. I thought it was in there for sure. Maybe it's in my room with the rest of your clothes.

(ANA herds LEONOR up to her room and nudges her in the door, then slams and locks it)

Ana!

JUANA

ANA

I know where he keeps the extra key.

\section{CELIA}

I think maybe this has gone too far. Isn't this all pretty extreme, Ana? Like, her dad is legitimately going to force her to marry your brother just because she was in your house.

JUANA

And she's right. Your brother sucks.

ANA

This is just how it is. She marries Pedro, I marry Carlos. We all live happily ever after.

CELIA

But, like, you don't have to.

JUANA

Do you really want to marry Carlos, Ana? Do you love him? 
ANA

I-- He-- I will love him, right? I'll grow to love him.

Are you sure?

JUANA

Yes. I'm sure.

$$
\begin{gathered}
\text { ANA } \\
\text { (Looking her in the eye) }
\end{gathered}
$$

$$
\begin{aligned}
& \text { (ANA storms off in the direction of her room, } \\
& \text { remembers that she can't do that.) }
\end{aligned}
$$

I need some fresh air!

ANA

(She storms down to the closet and opens it.)

ANA

(Holding her hand out for it)

Coat!

(CARLOS gives her a coat/cape with a hood. ANA puts it on and storms out the front door.)

JUANA

I hate that guy.

Should we go after her?

CELIA

JUANA

He's stealing her from me.

CELIA

It's not his fault. Do you think she wants to be alone, or...

I'm gonna kill him.

JUANA

CELIA

I'll go check on her.

(JUANA storms off toward the kitchen. CELIA follows ANA out the front door. They exit. BRUNO comes out of the closet.) 


\section{BRUNO}

Finally, some space to breathe. AND I've solved my messenger problem. I'll just put on some of Leonor's things here.

(He holds up the bag of her clothes)

Those guys outside won't care if a girl comes out of the house. I just have to make it convincing.

(He pulls a dress on over his head and flails around in it a little. When he finally emerges, he smooths it down.)

Ooh. Flowy. But it's missing a couple little things... (He stuffs a couple of socks or tissues down his front to make 'boobs')

That's better. Now, down south. I see there are some tights in here. Let's see.

(He tries to pull on the tights standing up. He hops around on one leg, almost loses his balance, and finally plunks on the couch. Somehow he still manages to fall over on the couch, legs flailing in the air. He finally gets the tights on, however, and he stands up)

Phew! Lots of work there, but worth it. Look at those babies. Ka-pow!

(This is accompanied with a leg-forward pose or high kick)

Sexy! I wonder if she has makeup in here.

(He opens the bag to check. She does. He powders his face, inhales it, coughs. Smears on a little rouge using the tiny mirror on the compact, then pulls out the mascara. He stabs himself in the eye a couple of times, knocks things over in his blindness, generally makes a mess, but by the end he manages to look himself over in the tiny compact mirror)

Excuse me for saying this, Oh Conservative House, but damn! I look hott! Yes, girl! You rock this look!

(There is the sound of a key in the front door even though it may not actually be locked - BRUNO panics and throws on LEONOR's coat, flipping the hood over his head.

PEDRO enters the door, somewhat calmed down but still determined. He sees BRUNO and crosses toward him. As he arrives at BRUNO's side, the lights short out.) 
Leonor!

\section{PEDRO}

BRUNO
(Pitching his voice as high as he can)
Aren't you going to fix that?

PEDRO

It doesn't matter. All that matters to me right now is you. I love you, and I want to marry you. To give you this house and everything I have in it. You can stay here and raise our children and you won't ever have to raise a finger or go work for what we have. Just say that you'll marry me. Willingly.

BRUNO

Ooh, that does sound very nice. Just relaxing here all day, doing my own thing.

PEDRO

You could do your own thing anytime I wasn't here. I don't mind!

What the heck, I accept!

$$
\text { BRUNO }
$$

PEDRO

You do?!?

BRUNO

(Jumping up and down with excitement)

I do!

PEDRO

I can't believe it! I'm so happy! Kiss me, Leonor!

BRUNO

Woah! Hang on there, buddy. Hang on. I'm... uh... I'm sick. (Cough cough)

Better save the kissing for later!

Also, would you promise that if you happen to decide against this marriage that you won't. Um. tell anyone about it or punish me in any way, shape or form?

Punish you?

PEDRO 
BRUNO

Yeah. By, like, telling all my friends and making people hate me or anything. Please promise! It'll be romantic!

PEDRO

Leonor, I have decided that I should romantically promise to keep our engagement a secret if I decide to break it off. That way you don't have to worry about any punishment or bullying from me based on my own decisions. Isn't that nice of me?

BRUNO

So nice. You're such a sweetheart!

I know!

PEDRO

$$
\text { (He puts a hand on his stomach) }
$$

All of this wedding talk is making me hungry. Are you hungry?

Always!

BRUNO

PEDRO

Let's get a snack --

(Before BRUNO can protest)

I insist! Come on.

(PEDRO and BRUNO exit into the kitchen, past JUANA, who is peeking out the door. CARLOS sneaks out of the closet wearing a trenchcoat. During the following action, we see LEONOR slowly open the door to ANA's room and hold up a bobby pin triumphantly. She is wearing the same coat/cloak ANA got out of the closet previously. CARLOS goes toward the kitchen to peek in but is interrupted by JUANA throwing herself at him with a meat tenderizer. He grabs the tenderizer hand and flips her onto the couch. He manages to get the tenderizer away from her but she grabs his coat sleeve in the process. ANA opens the front door to see CARLOS spinning around to get out of his coat.)

What is going on here?!?! 


\begin{abstract}
(Before anything else can happen, BRUNO slips out of the kitchen and turns off the lights in order to escape. PEDRO follows him out of the room but lets the door close. In the darkness, none of the characters can see CARLOS, turned around, lunge toward the nearest piece of furniture and starts trying to restrain it. JUANA pulls on the coat, gropes around for her meat tenderizer and starts beating the heck out of the coat/couch. BRUNO stumbles forward and knocks over a bookshelf full of books and knick-knacks, which fall to the floor. ANA hears the sound and runs toward it. The following dialogue overlaps both the action and the other dialogue and may be added to with improvisation to fill time.)
\end{abstract}

JUANA

THIS IS FOR YOUR STUPID HONOR AND YOUR STUPID PURITY AND YOUR STUPID BACKWARDS BELIEFS ABOUT EVERYTHING!

CARLOS

Just calm down, now. Calm down! I wasn't going to do anything.

(Perceiving the piece of furniture as 'restrained')

That's it. Just settle down. Everything will be alright. Shh...'

BRUNO

Oh! That's a-- well. Um. I swear, these chotchkies just saw how fabulous I am and jumped right off the shelf to see me. Not my fault at all, no sir.

ANA

My books! What did you do, you idiot? They're all over the floor and I can't see -- everyone stop moving!

(LEONOR makes her way toward the door while CARLOS slowly leaves his restrained piece of furniture. He runs into her and, groping around her head, comes to the conclusion that she must be ANA.)

CARLOS

Let's get you out of here, Miss Ana. I haven't gone to all this trouble to save your reputation just to ruin it now! 
(CARLOS leads LEONOR/ANA to the door and slips out. Though we can't hear what's happening inside the room, we can see that ANA has found the light switch and taken control of the situation. She sends JUANA, who is hiding her face in CARLOS'S coat, to her ( $A N A^{\prime} S$ ) room, sends BRUNO to PEDRO'S room, and sits CELIA and PEDRO down on the couch. Outside, CARLOS runs into RODRIGO. LEONOR hides her face in the hood).

Mr. Rodrigo! Mr. Rodrigo!

$$
\text { CARLOS (cont.) }
$$

RODRIGO

Yes?

\section{CARLOS}

Sir, this is Ana Calderón -- there's mass chaos in her house right now, and I need to go back and get my Leonor -I mean, your Leonor -- out of there! Can you keep Miss Ana company until I come back for her? It seems like leaving her alone out here isn't right, but also I'm in a hurry, so--

RODRIGO

Not to worry, young man. I'll take good care of Miss Ana. (Taking a brief look at LEONOR and squinting)

Are you sure this is Ana?

(LEONOR nods her head vigorously)

\section{CARLOS}

Yes, of course. Who else would it be?

\section{RODRIGO}

I don't know. She just reminded me of someone. Nevermind, though. You go in and take care of your business.

\section{CARLOS}

Thank you so much sir! I'll be right back!

(CARLOS dashes back into the house to find that ANA has taken control of the situation. She is mid-order) 


\begin{abstract}
ANA
(Hearing him come in but not turning around)

And $\underline{\text { you }}$ - in the closet!!

CARLOS

Yes, Ma'am.

(He goes and hides in the closet. After a beat, RODRIGO comes charging in with LEONOR following him)
\end{abstract}

Mr. Calderón!

RODRIGO

PEDRO

(Standing)

Yes, sir?

RODRIGO

I insist that you marry my daughter right away.

I thought we discussed--

PEDRO

RODRIGO

No good can come of waiting, and now I have an Ace up my sleeve. A dashing young - unmarried - man came up to me on the street of all places and asked me to look after your sister, Ana. I think the only way to avoid shame in this situation is for you to marry my Leonor and your sister to marry this Carlos fellow at once. And since you had the audacity to steal my daughter from my own house, I think you should marry her right away as well. A double-wedding, chop chop!

(PEDRO, confused, looks at ANA. She shrugs but nods enthusiastically.)

Alright, if you insist.

PEDRO

ANA

Carlos is in my bedroom. I'll go get him and be right back. Celia, call the pastor!

I don't have--

CELIA 
Look it up!

ANA

PEDRO

And I will go fetch Leonor from my room.

RODRIGO

She's in your bedroom? Good heavens!

PEDRO

I know. I'm sorry, sir. Just give me one moment...

(He exits into the bedroom, as does ANA. ANA reappears quickly with JUANA trailing behind. JUANA has managed to find a large scarf to wrap around her face)

What?

RODRIGO

Oh, you. Good news, you're engaged.

CARLOS

I am engaged, but not to the woman you think I'm engaged to. The only woman I could ever love is your daughter, Leonor. I was the one who stole her away from your house that night, and I would rather die than marry anyone else!

RODRIGO

Well, that seems a little extreme.

The problem is, Son, I've just promised Leonor to Mr. Calderón here, who I know comes from a nice, upstanding Christian household. He took her from my home and now he has to carry through on that commitment.

\section{CARLOS}

So you're saying that the man who took Leonor from your home has to marry her right away?

RODRIGO

Yes, of course. So stop bothering me. 


\section{CARLOS}

But sir, it was me who took Leonor from your house last night, not Pedro. So by your own logic, I should be the one who gets to marry Leonor!

\section{RODRIGO}

What are you talking about? That's preposterous!

LEONOR

\section{(Revealing herself and running to CARLOS)}

No, Daddy! It's true! Carlos and I were going to elope last night, but Pedro came up with this whole awful scheme to get me to marry him instead. I'm sorry to tell you, Daddy, but you've been tricked.

I hate being tricked!

RODRIGO

(Steaming)

LEONOR

(to CARLOS, smugly)

He hates being tricked.

(PEDRO re-enters with BRUNO, who is still dressed like LEONOR)

PEDRO

Here is your daughter, Mr. Rodrigo!

RODRIGO

HOW DARE YOU!

PEDRO

Me?

RODRIGO

DID YOU THINK I WAS A FOOL!?!

of course not. I--

PEDRO

RODRIGO

Leonor says you tried to trick me!

But-- Leonor is right here.

PEDRO 
(He turns to BRUNO, who takes off his hood.)

Surprise!

BRUNO

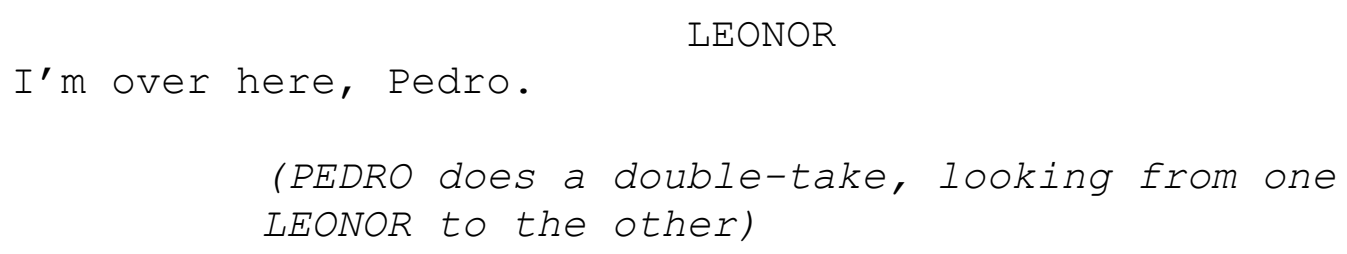

Wait-wait-wait. You promised not to hurt me if you called off this engagement, remember?

I don't think I--

$$
\text { PEDRO }
$$

\section{BRUNO}

You did! I was standing right there and you proposed to me and told me that you would give me a beautiful life. Then you said you would never hurt me for calling it off. It was your own idea!

\section{CARLOS}

Look at you, Pedro - proposing to Bruno like that! How sweet!

$$
\begin{array}{cc}
\text { I-- didn't-- I-- } & \text { PEDRO } \\
\text { (Frustrated, he pouts on the couch.) }
\end{array}
$$

Carlos? 


\section{CARLOS}

I have to call off our engagement, Miss Ana. But since I wasn't in the room when you arranged it, this can't be much of a surprise.

But if you're Carlos, who is--

(She turns and looks at JUANA, who reveals her face)

Surprise!

JUANA

(Weakly)

ANA

Juana? Why are you dressed up like Carlos?

CELIA

Honestly, I think this whole mess is my fault. I should apologize to both of you.

Apology accepted.

PEDRO

CELIA

Not to you.

Ana, I convinced Juana to sneak into your room last night. JUANA

I wanted to tell you that-- that--

I love you, Ana. And if you don't like that or aren't into ... this ... that's ok, but being with you makes me really happy and when I thought that you were going to marry that... guy, I just couldn't take it.

I know this isn't a great time, and you can totally tell me to fu--- shove off, but I think you should know.

ANA

I-- Wow .

I don't know what to say. 


\section{PEDRO}

I do! Get out of here and never come here again! You're disgusting!

No! You know what? No!

ANA

You know what's disgusting, Pedro? Kidnapping someone and then tricking them into marrying you.

I knew it!

RODRIGO

ANA

I'm talking.

(Surprisingly, this shuts RODRIGO up for a second)

I'm so sorry, Leonor. He couldn't have done that without me, and that was wrong of me to do. I don't know how I'll ever make it up to you.

\section{LEONOR}

Don't worry about it. It came out better than I could have hoped.

ANA

Pedro, I don't like it here. And I don't like who I am when I'm here. So it's time I find something else to do anyway.

\section{PEDRO}

Ha! Yeah right. I give it a week. I'll double the locks on the doors while you're out.

No it won't.

ANA

(Turning toward JUANA)

Because I want to make a life with Juana. She makes me happy and she makes me better.

I love you too. Can I kiss you?

(JUANA nods yes and they kiss. Uproar from PEDRO and RODRIGO) 


\section{RODRIGO}

This is disgusting! Come on, Leonor. Take whoever your husband is now and we're going.

(He exits, followed by CARLOS and BRUNO, but LEONOR hangs back and gives JUANA and ANA a silent thumbs-up. They thumbs-up back. She exits.)

PEDRO

Are you done now? Did you get enough attention? Geez. Grow up.

JUANA

Ignore him, Babe. Let's go pack your room.

PEDRO

Good luck fending for yourself out there! You've had it good here and no one out there will take care of you. You'll see!

(The girls exit into ANA's room. PEDRO is left alone on the couch.)

\section{PEDRO}

This was all my idea. I wanted... Leonor to go marry Carlos. She was stupid anyway. Definitely not good enough for me. And I think it is a great idea for me to live on my own. Have the whole house to myself! And Ana-- I think that Ana should--

I think I'm going to miss her.

$$
\text { (Blackout. End of play.) }
$$




\section{Chapter 7}

Conclusion: Ethical Considerations in Intercultural Adapturgy 
The practice of adapturgy as applied to A Little Betrayal Among Friends, Fever/Dream, and With the Temptation, a Way of Escape not only shows the process of adapturgy in all of its forms, it also opens up a conversation about the ethical implications of adaptation. These adaptations all appear to be created out of love and respect for the scripts they were based on, yet each adaptation makes significant changes to the characters, situations, and stories from the original text. While there are ethical concerns around changing the work of a long-dead playwright just to make contemporary audiences more comfortable with their work, dramaturgical practice and intertextuality show us that making these changes is important if the plays are to inspire the same joy and laughter they were originally intended to create. On a practical level and in the context of performance for a community which includes non-academics, I believe that preserving that intention is more valuable than preserving every little detail of the original performances ${ }^{37}$. The social awareness that comes from reimagining seventeenth-century work for the twenty-first century is also important in sustaining theatre's diverse audience and artists.

\section{Choosing to Change}

While it is the anthropologist's job to make the strange familiar and the familiar strange, translations and adaptations, especially those that transpose a piece into a highprivilege language like English, run the risk of betraying the culture of the source material by sanding down aspects of that culture which make it unique. In an increasingly globalized world, translation issues will come up more and more often. Playwrights like Dolores Prida have requested that their work not be translated, and companies like New York's

\footnotetext{
${ }^{37}$ I also believe that preserving all of these details would be impossible.
} 
Repertorio Español unapologetically produce work in Spanish, sometimes with English captions, which is more generous than many theatre companies across the United States which do not accommodate for non-English-speakers (Prida, Repertorio Español).

Both Prida and the Repertorio Español have a point in that works presented in their original language offer something to a Spanish-speaking audience that translation cannot offer. There is linguistic depth and complexity in Sor Juana's work, especially, that cannot be translated and which could edify Spanish-speaking audiences by showing this complexity in their native tongue. This adds prestige and validation to the Spanish language which it so often lacks in the United States and could, perhaps, stem the rapid language loss in second- and third-generation US Hispanics. Pew Research studies show that Spanish language proficiency in the United States is decreasing and Hispanics are less and less likely to speak Spanish to their children at home, especially as they are generationally removed from their immigrant parents (Krogstad et al., Krogstad and Lopez, Lopez et al.). On an anecdotal level, I have personally had multiple Hispanic children of non-Englishspeaking parents tell me that they could not speak or read Spanish, despite the fact that their parents spoke Spanish to them at home. This loss of Spanish ${ }^{38}$ might suggest that the valorization offered through the presentation of non-translated work is important to Hispanic culture in the United States.

Leaving the plays in Spanish would also mean that no valuable details are cut from the work, ensuring that the original context of the play is sustained. This concern is reflected in an essay by Ester Fernández on HowlRound Theatre Commons entitled "Who's Afraid of Sor Juana Ines de la Cruz" in which Fernández critiques European

${ }^{38}$ And Latinx indigenous languages, but that is a tragedy which lies outside the purview of this project. 
productions of Los empeños de una casa which do not explicitly engage with the playwright's Mexican heritage. The discussion surrounding how to present this raunchy play by a seventeenth-century nun is complex and directors have come up with many varied solutions, including showing Sor Juana writing in a nun's habit at the beginning of the play until she gets up to take the role of Leonor (who is cited as the protagonist in this example) and a production which included side-by-side casts of nuns and secular folx presenting the play simultaneously, as described by Jessica Lopez-Barkl in the comments section of this article. While Fernández criticizes directorial choices, there is also a challenge surrounding which translation to use if the play is presented in English, and most of the artists in this case perceive themselves to be working with a translation and not with an adaptation of the script. However, the challenge in this article reaches beyond the level of the text, as one of the European productions in this case was presented in the original Spanish. Fernández focuses less on choices affection the textual adaptation and more on directorial choices, which also reflect adapturgical choices and form part of the ethical dilemma inherent in adapturgy.

\section{In Defense of Adaptation}

This reflection on the ethical implications of adapturgical choices from directors shows us that even productions that don't change a word of the original text face ethical dilemmas when it comes to adapturgy. Fernández distills this challenge at the end of the piece, when she says: "the importance of a transnational critical perspective lies in leading

us to reflect on-not even to answer-why European productions of The House of Desires analyzed divest the play of its cultural origins, while Mexican and North American 
companies tend to restore and privilege an approach grounded in Mexican culture." One possible answer here may be that Spanish society considers Sor Juana and her work to be Spanish. Sor Juana is of solely Spanish heritage biologically and her interactions with indigenous Mexican culture were likely only evangelical in nature. As such, both Mexico and Spain can claim her as their own, and each country's productions of her work seem to reflect that. Which answer, then, can we as twenty-first-century adapturgs claim is right? Which intertextual lens should we apply when producing Sor Juana's work? Further, which intertextual lens did Sor Juana intend to write with when she penned the original work? It is impossible to know her intentions with certainty, so a certain level of adaptation is required to experience Los empeños de una casa in any case. Since it was meant to be performed, reading it on the page is not seeing it as it was intended to be seen, and any production will be forced to make artistic choices which change the way audiences will perceive the overall story.

Since adapturgical choices must be made in order to experience a Spanish Golden Age play like Los empeños de una casa or the other texts in this dissertation, the only courses of action are to either let them waste away in obscurity or to embrace the dilemmas inherent in adapturgical practice, acknowledge the positionality of the adapturg, and press forward with as much academic and spiritual care as possible. One of the lovely things about theatre is that every production of a play will inevitably be unique, this may simply be even truer in the case of adaptations exploring plays across time and space. Like the blind men trying to describe an elephant by telling about its various parts, perhaps the global theatrical community can come to a more complete understanding of, for example, Sor Juana's work if it is presented with adaptations that explore her religious identity, her 
Mexican identity, her Spanish identity, and her comedic identity in varying degrees and intensities. This process is inevitable, and acknowledging the multiplicity of approaches to any work, especially such an old one, I hope will lead to more productions of underproduced work like the plays explored here. Each has offered specific ethical considerations that these future adapturgs may want to keep in mind to ensure that they perform their due diligence while creating meaningful adaptations.

\section{A Little Betrayal Among Friends}

One of Caridad Svich's guiding concerns in creating this adaptation was to maintain aspects of Spanish Golden Age theatre which were sometimes unfamiliar to her twentyfirst-century audience. With this approach, Svich was able to maintain a sense of the original script which feels faithful to María de Zayas's La traición en la amistad because Betrayal maintains the plot of Traición, including most of the cardinal functions, which form the spine of both plots. Svich's low-intervention style, with few and open-ended stage directions and descriptions, also reflects the characterizing indices of La traición en la amistad, giving the audience not only a sense of the original script's plot, but also a clear glimpse into the flexible style of a Spanish Golden Age play. Svich also reflects Zayas's original script and its heightened emotions by including music in Betrayal and allowing her characters to be unapologetically romantic, which is rarely seen in our cynical world. However, the pure romance and friendship of the seventeenth century does not exist without commentary, even in Svich's adaptation.

While many aspects of A Little Betrayal Among Friends reflect the Spanish Golden Age clearly, Svich does make mindful changes, mostly to characterizing and stylistic 
indices, to bring the piece into the twenty-first century. Parts of the script which could send negative messages to audience members, like the condemnation of Fenisa at the end of Traición, are removed, and Svich takes more time to develop the relationships that end in marriage at the end of the play. In this way, she avoids reinforcing positive depictions of men who exert excessive control over the women in their lives as she avoids reinforcing a negative depiction of a woman taking control of her own sexuality. Svich also makes some changes to speak to a contemporary audience's webs of intertextuality, including recognizing don Juan as the name of the stereotypical womanizer and putting the character of don Juan present in Betrayal in conversation with that larger trope. In other modernizations, she shifts letters to text messages and modernizes the language in to the script where necessary, but these touches are light and the modern touches feel incidental, not integral to the plot in any way. Both kinds of changes make the play easier and funnier to watch, as audiences do not have the distraction of dealing with a particular time frame and its elevated diction, and they need not be distracted from the humor by ethical complaints or personal trauma.

The ethical issues involved in adapturgy are met in A Little Betrayal Among Friends in large part because of the context in which this adaptation was made. Dramaturg Monica Cross pointed out that adaptations (in the form of script cuts) are made in the context of the performance for which they are made, be that a commission or a construct of the adapter's imagination. In this case, the fact that Betrayal was commissioned for outdoor theatre made it much easier for Svich to preserve some cultural touchpoints of the Spanish Golden Age. Spanish Golden Age plays were often performed outside with minimal sets and even though Zayas may have had more resources or a grander concept for Traición, 
the style she wrote in was highly influenced by this outdoor theatre. In the twenty-first century, most pre-covid outdoor theatre consisted of Shakespeare festivals, meaning audiences and producing companies were accustomed to an Early Modern style of production as well. This made including those touches in Betrayal even more natural and encouraged Svich to provide a clear example of an adaptation which is primarily focused on communicating the style of that era while still being an intertemporal and intercultural adaptation in many ways.

\section{Fever/Dream}

Sheila Callaghan's adaptation of Fever/Dream was able to take more artistic liberties with the text because the source text - La vida es sueño - is so ubiquitous in the United States literary canon. A significant portion of Callaghan's audiences can be expected to be familiar with the plot of La vida es sueño through reading it in class, seeing a production, or simply through cultural osmosis. Those who are interested in world theatre or surrealism are likely to stumble across Calderón's play at some point in time. With this in mind, Callaghan is more free to play with the intertextual connections of those audience members, making inside jokes or clever connections that people who know the original text are more likely to understand. For example, instead of wielding her father's sword, Rose holds his pen, bringing to mind the adage 'the pen is mightier than the sword,' but never explicitly stating it. As such, Callaghan's references are Easter Eggs but the overall style of the play adheres to Callaghan's personal style without becoming preoccupied with fidelity to Spanish Golden Age production expectations. La vida es sueño was also written by a man, Pedro Calderón de la Barca, so Callaghan had to worry less about taking away 
his voice in her adaptation than one might when adapting a woman's work, especially a Spanish Golden Age woman whose work has been historically excluded in the first place.

Ethically, Callaghan's adaptation suggests that there may be a punching up strategy to keep in mind when performing adapturgy. In comedy, the idea of punching up means that it is more acceptable to make fun of individuals or organizations with more privilege than the comedian, whereas making fun of people with less privilege is uncomfortable and unacceptable. This is why Mindy Kaling and Brenda Withers can play Matt Damon and Ben Affleck in their play Matt and Ben to a humorous effect but minstrel show black face - which clearly exploits a less-privileged group for entertainment - is an atrocity. While it can hardly be said that comedians only ever punch up and never focus their jokes on groups with less privilege, those who are interested in the ethical ramifications of their work begin that consideration by thinking about this simple concept. In adaptaturgy, too, I think it is important to consider what is being cut and changed from the original script and whether those cuts and changes take away power or representation from a marginalized group. In Fever/Dream, for example, the male character of Clarín becomes the female character Claire - this takes away a role for a male actor and creates a role for a female actor, which gives more power and representation to a less privileged group.

While some choices are clear changes from La vida es sueño to Fever/Dream, this play offers interesting examples of lateral changes which preserve the intention and mood through changes in ways that the original may not demonstrate as well in contemporary culture. In this case, the surrealism suggested by king Basilio's interest in astrology and Segismundo's fore into the world of dreams is conveyed in Callaghan's adaptation by technological and artistic conventions that Calderón could not have imagined. In a way, 
both scripts are open-ended as far as staging goes, but while Calderón's script leaves space for interpretation because the stage directions are sparse, leaving the burden of the storytelling on the verbal text, Callaghan offers stage directions that are open to interpretation, like "the room becomes an ocean." Both methods inspire directors and designers to create beautiful work, but Callaghan's directions make the surrealistic nature of the script more clearly present through design choices and not just through the spoken lines of the play. In this way, Callaghan carries on the spirit of La vida es sueño despite the fact that the practical application of her adapturgy, as demonstrated in the number and complexity of stage directions, is quite different.

\section{With the Temptation, a Way of Escape}

I wrestled with the ethical considerations I gleaned from Svich and Callaghan in my own work as well as working through ethical questions that were unique to my own work. Since their two approaches are so different, I chose to create two versions of Los empeños de una casa: a performance translation and cut which maintains the structures and quirks of Spanish Golden Age theatre like Svich's A Little Betrayal Among Friends and a more freely adapted version which preserves the mood of the piece for a more contemporary audience like Callaghan's Fever/Dream. As a white, English-speaking, welleducated woman in the twenty-first century, I hold a little more privilege than the women I translated, since they wrote in a time when women had less privilege overall. I also recognize that my perspective is colored by my European heritage, especially as it connects to Sor Juana, who comes from both Mexican and European heritage. However, I believe that my perspective as a woman, dramaturg, and playwright and my background in Spanish 
Golden Age theatre is still valuable enough to make creating this translation and adaptation worthwhile.

My translation, as I mentioned, maintains the cardinal functions of the source text and many of its character and style indices as well. The Spanish Golden Age concept of honor is the most notable of these indices and serves as the driving force of the play. While this may require a little bit of explanation to read clearly to a twenty-first-century audience, I believe the play has enough internal clarity regarding the unspoken rules of honor culture to allow an audience to follow along. It also maintains open-ended staging options, a tiered social structure which includes servant characters, and I imagine it being produced with period costumes, props, and set pieces. However, I did make some adapturgical choices to make How to Build a Noble House accessible to twenty-first-century audiences. I did not translate the play in verse, for example, which makes it easier to clearly state the meaning of the words Sor Juana was saying but does not show her linguistic prowess. While I do believe that showing her linguistic skills was an important trait of the play for Sor Juana, I think the story is clearer with a less complicated translation. I also cut a lot of expositional monologues, which are a defining aspect of Spanish Golden Age theatre, but which are also likely to lose the audience's attention in the twenty-first century. However, the characters and dialogue are translated more or less directly, and I believe that enough aspects of the style remain intact to give audiences a reliable taste of what Spanish Golden Age theatre is like.

In With the Temptation, a Way of Escape, I chose to change more of the play to ensure more equitable representation and enduring connection with contemporary audiences. This involved changing more indices to affect the characterizations of the 
characters across the board to include more LGBTQ+ characters and more nuanced commentary on the relationships in the play and the code of conduct that serves as the play's inciting incident. I also modernized the language significantly and took steps to ensure that the adaptation was just that - not a translation of another text. Though these changes were significant, I believe they preserved the mood and intention of Sor Juana's original work which is, in my opinion, primarily comedic relief. I believe that Sor Juana wanted to write a highly produceable entertaining comedy with some commentary on gender roles and the role of honor in society. In Sor Juana's world, a play that could be produced, especially if it was written by a woman, could not question the role of honor and gender in Spanish culture and society too much, but Sor Juana's other work, like her Letter to Sor Filotea and the loa to El divino Narciso questioned those roles more directly, showing that she did have interest in undermining traditional gender roles and the role of honor (Paz). While at a first glance Los empeños de una casa seems to uphold honor as an important staple of Spanish Golden Age society, a second look shows that the play's humor centers around the absurdity of the honor code and the characters' happy endings come mostly from honest relationships and not arbitrary ideas about honor and gender. With this in mind, I think Sor Juana would approve of a wider diversity of genders and sexualities being represented in this play. The evangelical Christian culture that I used as a backdrop for With the Temptation, a Way of Escape also parallels Sor Juana's religious background, which I believe was both a liberating tool for her because it allowed her to pursue her academic interests and a cage because that exploration came with the expectation that she would adhere to a strict code of honor. We see Sor Juana fighting back against the church 
in her heated theological debates with "Sor Filotea" ${ }^{39}$," in her secular poetry, and even in Los empeños de una casa, which does not include any religious content at all. Though the religious background returns Escape to a setting that Sor Juana may have intentionally avoided when she wrote Empeños, I believe that the spirit of the play is still a farcical comedy commenting on society's overly rigid social structures. I also believe that the story is conveyed more convincingly to twenty-first-century audiences with more contemporary language and characters.

\section{Adapturgy In Action}

Looking at adapturgy in practice highlights these ethical issues as well as practical ones which give insight into the fields of both adaptation studies and dramaturgy. In adaptation studies, I have demonstrated the importance of positionality, both of the adapter and of the source text and its author. This is a logical extension into Adaptation Studies 3.0, since Adaptation Studies 2.0 also focused on individuals and their relationship with the work through the lens of intertextuality. Considering positionality also leads to questions of what should and should not be adapted, depending on the adapter and their relationship to the source material. Is the goal of this specific adaptation by this adapter at this time to demonstrate the uniqueness of another time or place? Or is this adaptation, perhaps, in conversation with the original text, asking what parts of that text should or should not be re-told in the context of contemporary society. This idea's roots go all the way back to the question of fidelity studies - is an adaptation faithful to the source text or intentionally unfaithful to it and to what end - however, the variety of approaches described

\footnotetext{
39 "Sor Filotea" was actually the Bishop of Puebla writing under a female pseudonym. The argument was about whether women should be allowed to study secular texts.
} 
in this dissertation show that there is nuance in this dichotomy. I have shown how adaptations can be faithful in characterization, mood, and style but also how they can be faithful to the timbre and spirit of a piece and how updates may make that spirit more clearly translated to contemporary audiences. Since these audiences have contemporary webs of intertextual understanding, traditional pieces that are translated directly may actually have a very different effect than the one they intended, whereas an adapter who is aware of those contemporary intertextual webs can better anticipate and hone their audience's reaction.

This intimate connection with the theatre audience is the specialty of the dramaturg, and it makes sense to combine dramaturgical strategies with adaptation strategies and use practical performance observations to see how adaptations affect their audiences. Adapturgy, therefore, provides the perfect overlap between these fields and, I believe, adds an exciting practical element to Adaptation Studies 3.0. The questions a dramaturg typically asks of a play illuminate the adapturg's goals for production even before the actual script is written. This helps adapters, producing organizations, and academics uncover the reason why we do adaptations so much in the first place and what each particular adaptation brings to its new world. Similarly, the work a production dramaturg puts into creating an intertextual web of understanding for the audience raises questions about what should be included in those intertextual webs, both specifically and generally as an audience approaches a familiar or unfamiliar work. Finally, a dramaturg's practical knowledge about script cutting and the unspoken understanding between audiences and producing organizations is invaluable on a practical level and helps the adapter see what 
contemporary audiences may need to feel the impact of a traditional script in a way that reflects and connects with that script's original audience.

I would like to see more adapturgy in action in the coming years, and I believe I will. The impulse to adapt stories into new and more relevant versions is ancient, and the rise of the internet has only made that impulse easier to follow. As adaptation studies scholars look at these inevitable new adaptations, I encourage them to consider practical applications in the form of theatre performance, film, or even the reactions of readers to a novel or short story. Dramaturgy (and adapturgy) offer unique and exciting ways to approach these reactions. Sometimes dramaturgs and adapturgs even help to form them, and the theatre is uniquely equipped to struggle with difficult ethical questions through story and through community. Though it may not be possible to create a single adaptation that fits every ethical consideration perfectly, the strength of that community is in its ability to create adaptation after adaptation, each with its own strengths and flaws, and to create a full, realized picture of the original through its many iterations. 


\section{Works Cited}

Allen, Graham. Intertextuality. Routledge, 2000.

American Theatre Editors. "Penumbra Theatre to Become Penumbra Center for Racial Healing." American Theatre, 10 Aug. 2020, https://www.americantheatre.org/2020/08/10/penumbra-theatre-to-becomepenumbra-center-for-racial-healing/.

Airmid Theatre. “A Little Betrayal Among Friends.” LongIsland.Com, 11 July 2011, https://www.longisland.com/articles/07-11-11/a-little-betrayal-amongfriends.html.

Arriaga-Jordán, Patricia. Juana Inés. Netflix, 2016, https://www.netflix.com/title/80123792.

Babbage, F. H. "Adaptation and Storytelling in the Theatre." Special Topics, no. 12, p. 13.

---, et al. Adaptation in Contemporary Theatre: Performing Literature.

Ball, David. Backwards \& Forwards: A Technical Manual for Reading Plays. Southern Illinois University Press, 1983.

Balodis, Janis Maris. The Practice of Adaptation: Turning Fact and Fiction into Theatre. Queensland University of Technology, 2012. eprints.qut.edu.au, https://eprints.qut.edu.au/60917/.

Banks, Daniel. "The Welcome Table : Casting for an Integrated Society." Theatre Topics, vol. 23, no. 1, Johns Hopkins University Press, 2013, pp. 1-18. Project MUSE, doi:10.1353/tt.2013.0011.

Baranda, Nieves, and Anne Cruz, eds. The Routledge Research Companion to Early Modern Spanish Women Writers. New York: Routledge, 2018.

Barnette, Jane. "Literary Adaptation for the Stage: A Primer for Adaptation Dramaturgs." The Routledge Companion to Dramaturgy, Routledge, 2016, pp. 49-50.

---. Adapturgy: The Dramaturg's Art and Theatrical Adaptation. Southern Illinois University Press, 2017.

Bayliss, Robert. The Discourse of Courtly Love in Seventeenth-Century Spanish Theater. Lewisburg, PA: Bucknell University Press, 2008.

Berlin, Sadie, and Ted Witzel. "Beyond the Western Canon." HowlRound Theatre Commons, https://howlround.com/series/beyond-western-canon. Accessed 28 Aug. 2020. 
Bemberg, María Luisa. Yo, peor de todas. GEA Cinematográfica, 1990.

Bhasin, Christine Scippa. "Prostitutes, Nuns, Actresses: Breaking the Convent Wall in Seventeenth-Century Venice.” Theatre Journal, vol. 66, no. 1, The Johns Hopkins University Press, 2014, pp. 19-35.

Black, Devon. "Reconstructing the Canon." Harvard Political Review, 25 Apr. 2018, https://harvardpolitics.com/culture/thecanon/.

Boyle, Catherine, and David Johnston, editors. The Spanish Golden Age in English: Perspectives on Performance. Oberon Books, 2008.

Brown, Kevin. "Beautiful Strangeness: The Plays of Caridad Svich.” JARMAN (all this maddening beauty) and Other Plays, by Caridad Svich, Intellect Ltd., 2016.

---. “Oceanic Geographies.” Performance Research, vol. 21, no. 2, Routledge, Mar. 2016, pp. 118-24. Taylor and Francis+NEJM, doi:10.1080/13528165.2016.1162506.

Brown, Lenora Inez. New Play Development: Facilitating Creativity for Dramaturgs, Playwrights, and Everyone Else. First Edition, Focus, 2015.

Calderón de la Barca, Pedro. La Vida Es Sueño, n.d.

---. Life Is a Dream. Translated by Nilo Cruz. New York: Dramatists Play Service, 2008.

---. 1856. Life's a Dream, partially trans. Richard Chevenix Trench. In Calderón: His

Life and Genius with Specimens of His Plays, pp. 117-69. New York, Redfield Callaghan, Sheila. Fever/Dream. Samuel French, 2011.

---. "Preface." In Lascivious Something, Roadkill Confidential, That Pretty Pretty; or, the Rape Play: Three Plays, xiii-xv. Berkeley, CA: Soft Skill Press, 2011.

---. "Sheila Callaghan.” Sheila Callaghan., 14 May 2019, www.sheilacallaghan.com/.

Camoletti, Marc. Boeing Boeing. Translated by Beverley Cross and Francis Evans, Concord Theatricals, 2008.

Carroll, Rachel. Adaptation in Contemporary Culture: Textual Infidelities. London: Continuum, 2009.

Castillo, Debra A. "Biographical Information.” Debra A. Castillo, https://www.debracastillo.com/. Accessed 15 Nov. 2020.

---. Talking Back: Toward a Latin American Feminist Literary Criticism. Cornell University Press, 1992.

Chemers, Michael Mark. Ghost Light: An Introductory Handbookfor Dramaturgy. Southern Illinois University Press, 2010.

Cross, Monica. Dramaturgical Cutting of Shakespeare. Interview by Mary Elaine Vansant, 7 Apr. 2021.

Cruz, Juana Ines de la. House of Desires. Translated by Catherine Boyle, Oberon, 2004. 
---. Los empeños de una casa.

---. Los empeños de una casa: Pawns of a House. Edited by Susana Hernández Araico, Translated by Michael McGaha, Bilingual Press, 2007.

Cohen, Edward M. Working on a New Play: A Play Development Handbook for Actors, Directors, Designers, and Playwrights. 2nd edition, Limelight, 2004.

Couderc, Christophe. Galanes y Damas En La Comedia Nueva: Una Lectura Funcionalista Del Teatro Español Del Siglo de Oro. Iboamericana, 2006.

Deaville, James. "The Many Lives of Flower Drum Song (1957-2002): Negotiating Chinese American Identity in Print, on Stage, and on Screen." China and the West: Music, Representation, and Reception, edited by Hon-Lun Yang and Michael Saffle, University of Michigan Press, 2017, pp. 119-36.

Diane, Ciara. "When the Students Have Notes for the Teachers." American Theatre, 5 Aug. 2020, https://www.americantheatre.org/2020/08/05/when-the-students-havenotes-for-the-teachers/.

Elliott, Kamilla. "Adaptation Theory and Adaptation Scholarship.” The Oxford Handbook of Adaptation Studies, edited by Thomas Leitch, Oxford University Press, 2017, pp. 679-643.

Erdman, Harley, and Susan Paun de García. Remaking the Comedia: Spanish Classical Theater in Adaptation. Monografías A 346. Tamesis Books, 2015.

Fernández, Esther. “Who’s Afraid of Sor Juana Inés de La Cruz? Transatlantic Performances of Los empeños de una casa (The House of Desires)." HowlRound Theatre Commons, May 2020. howlround.com, https://howlround.com/whosafraid-sor-juana-ines-de-la-cruz.

Fuchs, Barbara, ed. The Golden Age of Spanish Drama: New Translations, Backgrounds and Contexts, Criticism. Translated by G. J. Racz. New York: W. W. Norton \& Company, 2018.

Fuchs, Elinor. EF's Visit to a Small Planet: Some Questions to Ask a Play. no. 2, Jan. 2004, pp. 5-9. DOI.org (Crossref), doi:10.1215/01610775-34-2-5.

Gamboa, Yolanda, and Bonnie Gasior. Making Sense of the Senses: Current Approaches in Spanish Comedia Criticism. Newark, DE: Juan de la Cuesta, 2017.

Ganelin, Charles. Rewriting Theatre: The Comedia and the Nineteenth-Century Refundición. Lewisburg, PA: Bucknell University Press, 1994.

García-Romero, Anne. The Fornés Frame: Contemporary Latina Playwrights and the Legacy of Maria Irene Fornés. The University of Arizona Press, 2016. 
George-Parkin, Hilary. "The Anxieties and Apps Fuelling the Astrology Boom." BBC.Com, 8 Feb. 2021, https://www.bbc.com/worklife/article/20210205-whyastrology-is-so-popular-now.

Gournelos, Ted, and Viveca Greene. A Decade of Dark Humor: How Comedy, Irony, and Satire Shaped Post-9/11 America. University Press of Mississippi, 2011. JSTOR, https://www.jstor.org/stable/j.ctt2tvmjv.

Halpern, Emma. "The TYA Canon: How Licensing Agencies Build Artists and Audiences.” AMERICAN THEATRE, 22 Mar. 2016, https://www.americantheatre.org/2016/03/22/the-tya-canon-how-licensingagencies-build-artists-and-audiences/.

Hartley, A. The Shakespearean Dramaturg: A Theoretical and Practical Guide. Palgrave Macmillan US, 2005. www.palgrave.com, doi:10.1057/9780230203945.

Hegstrom, Valerie, and Amu Williamsen, eds. Engendering the Early Modern Stage: Women Playwrights in the Spanish Empire. Univ Pr of the South Inc, 1999.

Higgins, Charlotte. "Women in Theatre: Why Do so Few Make It to the Top?" The Guardian, 10 Dec. 2012. www.theguardian.com, https://www.theguardian.com/stage/2012/dec/10/women-in-theatre-glass-ceiling. Henninger, Linda. "Spotlight - A Little Betrayal Among Friends." Patch; Kings Park, NY, 25 July 2011, https://patch.com/new-york/kingspark/spotlight-a-littlebetrayal-among-friends.

Hispanic Lifestyle. "The Difference Between Hispanic and Latino." Hispanic Network Magazine: A Hispanic News Source, Sept. 2017, https://hnmagazine.com/2017/09/difference-hispanic-latino/.

Hormigón, Juan Antonio, Inmaculada Alvear, and Carlos Rodríguez. Autoras En La Historia Del Teatro Español, 1500-1994. Madrid: Publicaciones de la Asociación de Directores de Escena de España, 1996.

Hutcheon, Linda. A Theory of Adaptation. 2nd ed. Routledge, 2012.

Hwang, David Henry. "Introduction.” Flower Drum Song, by David Henry Hwang, Richard Rodgers and Oscar Hammerstein II, Theatre Communications Group, 2003, pp. ix-xiv.

Kahn, David, and Donna Breed. Scriptwork: A Director's Approach to New Play Development. Southern Illinois University Press, 1995.

Ketenjian, Tania. Anne Carson on Translating Antigone for Ivo van Hove's Brooklyn Academy of Music Production. 
https://www.theguardian.com/stage/audio/2015/sep/24/bam-antigone-annecarson-juliette-binoche-podcast. Accessed 5 Apr. 2021.

Krebs, Katja. Translation and Adaptation in Theatre and Film. Routledge, 2013.

---. "Ghosts We Have Seen Before: Trends in Adaptation in Contemporary

Performance.” Theatre Journal, edited by Ellen. McDougall et al., vol. 66, no. 4, The Johns Hopkins University Press, 2014, pp. 581-90.

Kristeva, Julia. Desire in Language: A Semiotic Approach to Literature and Art. Edited by Leon S. Roudiez, Translated by Thomas Gora and Alice Jardine, Columbia University Press, 1980.

Krogstad, Jens Manuel, et al. "English Use on the Rise Among Latinos." Pew Research Center's Hispanic Trends Project, 12 May 2015, https://www.pewresearch.org/hispanic/2015/05/12/english-proficiency-on-therise-among-latinos/.

Krogstad, Jens Manuel, and Mark Hugo Lopez. "Spanish Speaking Declines for Hispanics in U.S. Metro Areas." Pew Research Center, 31 Oct. 2017, https://www.pewresearch.org/fact-tank/2017/10/31/use-of-spanish-declinesamong-latinos-in-major-u-s-metros/.

Laera, Margherita. Theatre and Adaptation: Return, Rewrite, Repeat. Methuen Drama, 2014.

LaGreca, Nancy. "Feminist Literary Criticism of Latin American Women's Writing: Context, Approaches, and Analysis of the 1990s and Early 2000s." Revista de Estudios Hispanicos, vol. 40, no. 2, 2006.

Lakoff, Robin Tolmach. Context Counts: Papers on Language, Gender, and Power. Edited by Laurel Sutton, 1st edition, Oxford University Press, 2017.

Larson, Catherine. “Calderón's La vida es sueño Meets Callaghan's Fever/Dream: Adaptation and Performance." Comedia Performance, vol. 10, no. 1, 2013, pp. $19-58$.

---. 'Found in Translation: María de Zayas's Friendship Betrayed and the EnglishSpeaking Stage." The Comedia in English: Translation and Performance, edited by Susan Paun De García and Donald R. Larson, Tamesis Books, 2008, pp. 8394.

---. "You Can’t Always Get What You Want: Gender, Voice, and Identity in WomenAuthored Comedias." Gender, Identity, and Representation in Spain's Golden Age, edited by Anita K. Stoll and Dawn L. Smith, Associated University Press, 2000, pp. 127-41. 
---. "Zayas's La traición en la amistad in English: Translation and Adaptation in a New Era." Comedia Performance, vol. 11, no. 1, Penn State University Press, 2014, pp. 1-36. JSTOR.

Lefevere, André. "Refraction: Some Observations on the Occasion of Wole Soyinka's Opera Wonyosi." Page to Stage: Theatre as Translation, edited by Ortrun ZuberSkerritt, 1984, pp. 191-98.

Leitch, Thomas. The Oxford Handbook of Adaptation Studies. 1st ed. Oxford Handbooks. Oxford University Press, 2017.

Leverett, James, and Amy Rogoway. "Introduction.” Lorca: Six Major Plays, by Caridad Svich, NoPassport Press, 2009.

LMDA. "The Role of the Dramaturg." Literary Managers and Dramaturgs of the Americas, http://www.lmda.org/dramaturgy. Accessed 15 Nov. 2020.

Lopez, Kristoffer Romulo B., et al. "Social Contagion of Astrology in the Social Media amid COVID-19 Pandemic." International Journal of Multidisciplinary: Applied Business and Education Research, vol. 2, no. 4, 4, Apr. 2021, pp. 349-63.

Lopez, Mark Hugo, et al. "Hispanic Parents' Spanish Use with Children Falls as Generations Pass." Pew Research Center, 2 Apr. 2018, https://www.pewresearch.org/fact-tank/2018/04/02/most-hispanic-parents-speakspanish-to-their-children-but-this-is-less-the-case-in-later-immigrant-generations/.

Lu, Hangyan, and Warren A. Hodge. "Toward Multi-Dimensional and Developmental Notion of Researcher Positionality." Qualitative Research Journal, vol. 19, no. 3, 2019, pp. 225-235. ProQuest

Ludwig, Ken. Ken Ludwig's Lend Me a Tenor. Concord Theatricals, 2010.

Meraji, Shereen Marisol. “'Hispanic,' 'Latino,' Or 'Latinx'? Survey Says ...” NPR.Org, https://www.npr.org/sections/codeswitch/2020/08/11/901398248/hispanic-latinoor-latinx-survey-says. Accessed 8 Nov. 2020.

Merrim, Stephanie. Early Modern Women's Writing and Sor Juana Inés de La Cruz. Vanderbilt University Press, 1999.

Mignolo, W. D. "The Geopolitics of Knowledge and the Colonial Difference." South Atlantic Quarterly, vol. 101, no. 1, Jan. 2002, pp. 57-96. DOI.org (Crossref), doi:10.1215/00382876-101-1-57.

“Mizzou College Republicans.” Facebook.com, 15 July 2021, https://www.facebook.com/mucrs/.

Motel, Seth, and Eileen Patten. "The 10 Largest Hispanic Origin Groups: Characteristics, Rankings, Top Counties.” Pew Research Center's Hispanic Trends Project, 27 
June 2012, https://www.pewresearch.org/hispanic/2012/06/27/the-10-largesthispanic-origin-groups-characteristics-rankings-top-counties/.

Munday, Jeremy. Introducing Translation Studies: Theories and Applications. 4th ed. Routledge, 2016.

Murphy, Vincent. Page to Stage: The Craft of Adaptation. University of Michigan Press, 2013.

New Play Exchange. “Caridad Svich.” Caridad Svich; New Play Exchange, National New Play Network, 2019, newplayexchange.org/users/240/caridad-svich.

O'Thomas, Mark. "Translation, Theatre Practice, and the Jazz Metaphor." Journal of Adaptation in Film \& Performance, vol. 6, no. 1, May 2013, pp. 55-64. IngentaConnect, doi:10.1386/jafp.6.1.55_1.

Pak, Ricky. \#BIPOCSwap List - Google Drive. https://docs.google.com/spreadsheets/u/0/d/1hrNaae60biRBsRTgX3oGPuZ7qMli QrBNgPYdJO40c64/htmlview?fbclid=IwAR1g8RH13rHawCcS_9Yiq2XiXJQ2U CaZzpbm6PHpM87_t-RA15dMHVsmgEg\#gid=0. Accessed 28 Aug. 2020.

Parks, Steve. “"A Little Betrayal Among Friends.” Newsday, 3 Aug. 2011, https://www.newsday.com/entertainment/long-island/theater/a-little-betrayalamong-friends-1.3073031.

Pasto, David. The House of Trials. Peter Lang Inc., International Academic Publishers, 1997.

---. The Trials of Translating and Directing The House of Trials.

Paz, Octavio. Sor Juana Inés de La Cruz, o, Las trampas de la fe. 2a ed, Fondo de Cultura Económica, 1983.

Pew Research Center. "Religion in America: U.S. Religious Data, Demographics and Statistics." Pew Research Center's Religion \& Public Life Project, 2014, https://www.pewforum.org/religious-landscape-study/.

Porter, J. D. "Popularity/Prestige: A New Canon." Stanford Literary Lab, https://litlab.stanford.edu/pop-pres-ny/. Accessed 29 Aug. 2020.

Preying Womantis, and The Alternative Canon Community. "Alternative Canon." Google Docs, https://docs.google.com/document/d/1HwAHAwU83bW_jSzxbMrqWyyuAYms OWtqK-

7HxKA9yek/edit?usp=drive_web\&ouid=116091067580902287193\&usp=embed facebook. Accessed 30 Aug. 2020. 
Prida, Dolores. Beautiful Señoritas \& Other Plays. First Edition, Arte Público Press, 1991.

Quijano, Aníbal, and Sonia Therborn. "Coloniality and Modernity/Rationality.” Cultural Studies, vol. 21, no. 2-3, Routledge, May 2007, pp. 168-78. EBSCOhost, doi: $10.1080 / 09502380601164353$.

Repertorio Español. “Our History.” Repertorio Español, https://repertorio.nyc/\#/repertorio-espanol. Accessed 29 June 2021.

Rivera, José. “Sueño.” In References to Salvador Dali Make Me Hot and Other Plays, 91-167. New York: Theatre Communications Group, 2003.

Romanska, Magda. The Routledge Companion to Dramaturgy. Routledge, 2016.

Romero-Díaz, Nieves, and Lisa Vollendorf, eds. Feliciana Enríquez de Guzmán, Ana Caro Mallén, and Sor Marcela de San Félix: Women Playwrights of Early Modern Spain. Translated by Harley Erdman. Tempe, Arizona: Arizona Center for Medieval and Renaissance Studies, 2016.

Ros, Xon, and Geraldine Hazbun, eds. A Companion to Spanish Women's Studies. Rochester, NY: Tamesis, 2014.

Saenger, Michael. Interlinguicity, Internationality and Shakespeare. McGill-Queen's University Press, 2014.

Seth, Radhika. “From ‘The Great' To 'Bridgerton', Are Colour-Blind Period Dramas About To Become The Norm?" British Vogue, https://www.vogue.co.uk/arts-andlifestyle/article/inclusive-casting. Accessed 21 Apr. 2021.

Scott Soufas, Teresa. Dramas of Distinction : A Study of Plays by Golden Age Women. University Press of Kentucky, 1997.

---, editor. Women's Acts: Plays by Women Dramatists of Spain's Golden Age. The University Press of Kentucky, 1997.

Showalter, Elaine. "Feminist Criticism in the Wilderness." Critical Inquiry, vol. 8, no. 2, The University of Chicago Press, 1981, pp. 179-205.

---. Inventing Herself : Claiming a Feminist Intellectual Heritage. Scribner, 2001.

---. "Towards a Feminist Poetics." Women Writing and Writing about Women, edited by Mary Jacobus, Barnes \& Noble Books, 1979.

Smallwood, Christine. "Astrology in the Age of Uncertainty." The New Yorker, October 28, 2019, Oct. 2019, https://www.newyorker.com/magazine/2019/10/28/astrology-in-the-age-ofuncertainty. 
Smith, Dawn. "Staging Spanish Golden Age Plays for English-Speaking Audiences: An Interview with Laurence Boswell.” Comedia Performance, vol. 6, no. 1, 2009, pp. $161-80$.

Smith, Dawn L. "Cervantes and His Audience: Aspects of Reception Theory in $E l$ retablo de las maravillas." The Golden Age Comedia: Text, Theory, and Performance, edited by Charles Ganelin and Howard Mancing, Purdue University Press, 1994, pp. 249-61.

Soto-Márquez, José G. “'I'm Not Spanish, I’m from Spain’: Spaniards’ Bifurcated Ethnicity and the Boundaries of Whiteness and Hispanic Panethnic Identity." Sociology of Race and Ethnicity, vol. 5, no. 1, SAGE Publications Inc, Jan. 2019, pp. 85-99. SAGE Journals, doi:10.1177/2332649218766388.

Spanish Golden Age, The. Vol. 19, 2018. www.pbs.org, https://www.pbs.org/video/thespanish-golden-age-5na8ao/.

Spencer, Stuart. The Playwright's Guidebook. Farrar, Straus, and Giroux, 2002. Stages Theatre Company, et al. In My Own Voice: Responding to Life and Literature Through Playwriting. Edited by Rachel Brown, stagestheatre.org.

Stam, Robert. "Revisionist Adaptation: Transtextuality, Cross-Cultural Dialogism, and Performative Identities." The Oxford Handbook of Adaptation Studies, edited by Thomas Leitch, Oxford University Press, 2017, pp. 239-50.

Steketee, Martha W., and Judith Binus. Women Count: Women Hired Off-Broadway 2010-2017. League of Professional Theatre Women, 2018.

Stoll, Anita K., and Dawn L. Smith. "Introduction: Gender, Identity, and Representation in Spain's Golden Age." Gender, Identity, and Representation in Spain's Golden Age, Associated University Press, 2000, pp. 9-23.

Svich, Caridad. About Me - Caridad Svich. https://caridadsvich.com/about/. Accessed 23 Feb. 2020.

---. "Caridad Svich.” New Play Exchange, https://newplayexchange.org/users/240/caridad-svich. Accessed 20 Apr. 2021.

---. Caridad Svich: The Spanish Golden Age Plays. Santa Catalina Editions, 2012.

---. Interview with Caridad Svich. 4 Jan. 2021.

---. "Translations/ Adaptations." Caridad Svich, https://caridadsvich.com/translationsadaptations/. Accessed 6 Dec. 2020.

Tannen, Deborah. You Just Don't Understand: Women and Men in Conversation. Morrow, 1990. 
Tran, Diep. The Top 20* Most-Produced Playwrights of the 2016-17 Season. no. Sept. 2016, Sept. 2016, p. 5.

U.S. Census Bureau QuickFacts: United States. https://www.census.gov/quickfacts/fact/table/US/RHI725218. Accessed 19 Apr. $\underline{2020 .}$.

UCLA Department of English, and Megan Smith. Graduate Reading List: Drama. 2012. University of Northern Iowa. "Suggested Reading List." Department of Theatre, https://theatre.uni.edu/department/academic-programs/suggested-reading-list. Accessed 18 Oct. 2020.

Vázquez, Rolando 2011. “Translation as Erasure: Thoughts on Modernity’s Epistemic Violence," Journal of Historical Sociology 24 (1): 27-44

Venuti, Lawrence. The Translation Studies Reader. New York: Routledge, 2012. Versenyi, Adam. "The Dissemination of Theatrical Translation.” The Routledge Companion to Dramaturgy, Routledge, 2016, pp. 288-94.

Vidler, Laura. Performance Reconstruction and Spanish Golden Age Drama: Reviving and Revising the Comedia. Palgrave Studies in Theatre and Performance History. New York: Palgrave Macmillan, 2014.

Voigts, Eckart. "Memes and Recombinant Appropriation: Remix, Mashup, Parody." Oxford Handbook of Adaptation Studies, edited by Thomas Leitch, Oxford University Press, 2017, pp. 285-304.

Weimer, Christopher. "Calderón on the BBC: Radio Translation, Adaptation, and Performance." Religious and Secular Theater in Golden Age Spain: Essays in Honor of Donald T. Dietz, by Susan Paun de García and Donald R. Larson, Peter Lang Inc., International Academic Publishers, 2017, pp. 267-79.

Westlake, E. J. World Theatre: The Basics. Routledge, 2017.

Wilson, Emily. Emily Wilson, Translating the Classics. Anheuser-Busch Natural Resources Building, Conservation Auditorium (Room 111).

Wood, Bethany. "Gentlemen Prefer Adaptations: Addressing Industry and Gender in Adaptation Studies.” Theatre Journal, vol. 66, no. 4, The Johns Hopkins University Press, 2014, pp. 559-79.

Worthen, W. B. "Postcolonial Perspectives." The Wadsworth Anthology of Drama, 6th ed., Wadsworth, 2011, pp. 1510-31.

Worton, Michael, and Judith Still, eds. Intertextuality: Theories and Practices. New York: St. Martin's Press, 1990. 
Wright, Mary Ellen. Adrian Hall's Dramatic Adaptations: A Playwriting Process and Model. Texas Tech University, Dec. 2001. ttu-ir.tdl.org, https://ttuir.tdl.org/handle/2346/17188.

Wu, Y., and Z. Z. Chen. "The Attraction of Horoscopes: A Consensual Qualitative Research on Astrological Personality Description." Computational Social Science, CRC Press, 2021.

Yalom, Marilyn, and Theresa Donovan Brown. The Social Sex: A History of Female Friendship. Harper Perennial, 2015.

Zatlin, Phyllis. Theatrical Translation and Film Adaptation: A Practitioner's View. Multilingual Matters, 2005.

Zayas y Sotomayor, Maria de. La traición en la amistad.

--- et al. La traición en la amistad. Bucknell University Press; Associated University Presses, 1999. 


\section{VITA}

Mary Elaine (Lainie) Vansant (she/her) has worked on productions as an actor, stage manager, playwright, dramaturg, and director and holds a $\mathrm{PhD}$ in theatre and performance studies from the University of Missouri - Columbia. Her plays have been performed in community theatre and summer stock and have received multiple readings at venues like the Midwest Dramatists Conference, the University of Missouri, KCACTF Region V, and Pot Luck Productions. These include "Shiver and Shake" (professional production, Tibbets Opera House, summer 2018), "Overqualified" (reading, Midwest Dramatists Conference), and "Prince Snow" (reading, Comedies in Concert, University of Missouri, summer 2019). She has directed and helped develop short plays for the Mizzou New Play Festival, the Starting Gate New Play Festival, Short Attention Span Theatre, and the Kennedy Center American College Theatre Festival (KCACTF) - Region V. She has also served as a Managing Director for the Mizzou New Play Series and has served on the planning committee for the University of Missouri's production of "The 24 Hour Plays." Her research interests include translation, adaptation, linguistics, and Spanish-language theatre. 